\title{
Biochemische und zellbiologische Charakterisierung des COP Vesikel vermittelten Proteintransports in Pflanzen
}

\author{
Dissertation \\ zur Erlangung des Doktorgrades \\ der Mathematisch-Naturwissenschaftlichen Fakultäten \\ der Georg-August-Universität zu Göttingen
}

vorgelegt von

Peter Pimpl

aus Helmarshausen

Göttingen 2001 
D 7

Referent: Prof. Dr. D. G. Robinson

Korreferent: Prof. Dr. H. W. Heldt

Tag der mündlichen Prüfung: 03.05.2001 


\section{Inhaltsverzeichnis}

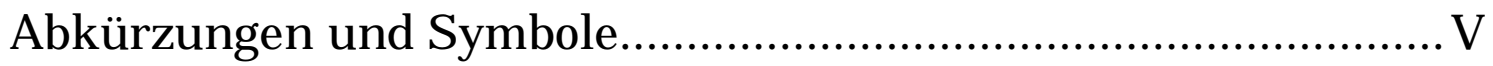

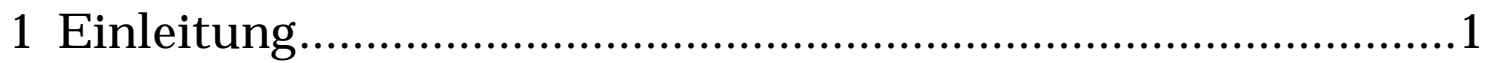

1.1 Der sekretorische Transportweg von Proteinen.....................................1

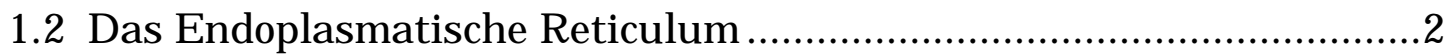

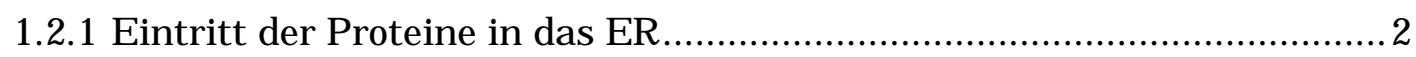

1.2.2 Faltung und Modifikation der Proteine ……………………..................... 3

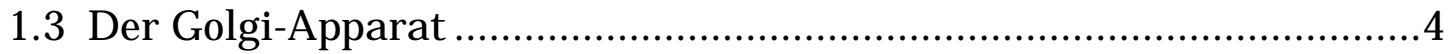

1.3.1 Sortierung lysosomaler Proteine in Säugetierzellen ................................... 6

1.3.2 Sortierung vakuolärer Proteine in Hefen .................................................

1.3.3 Sortierung vakuolärer Proteine in Pflanzen..............................................

1.4 Mechanismen des Vesikel vermittelten Transports ...............................

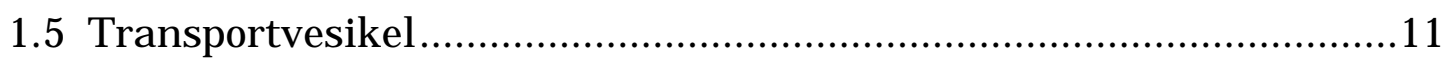

1.5.1 CCVs (,clathrin-coated vesicles“) ..............................................................11

1.5.2 COP Vesikel (,coat protein-coated vesicles“) .............................................13

1.6 Sekretion und Retention von löslichen Proteinen.................................18

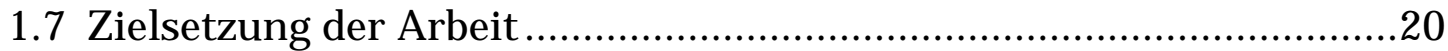

2 Material und Methoden........................................................21

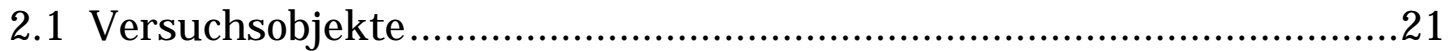

2.1.1 Anzucht der Versuchspflanzen im Gewächshaus.....................................21

2.1.2 Anzucht und Vermehrung von sterilen Tabakpflanzen in vitro...............21

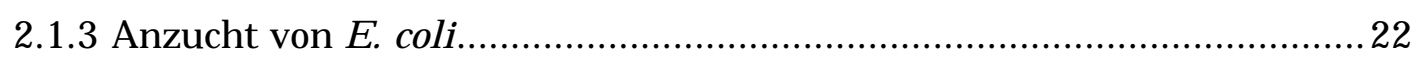

2.2 Herstellung transformationskompetenter E. coli ................................23

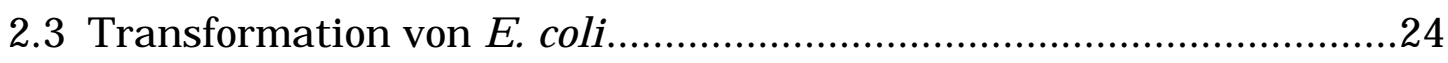

2.4 Isolierung von Plasmid DNA aus E. coli .........................................25

2.4.1 Isolierung im großen Maßstab (Maxi-Präparation).................................... 25

2.4.2 Isolierung im kleinen Maßstab (Mini-Präparation) ..................................22

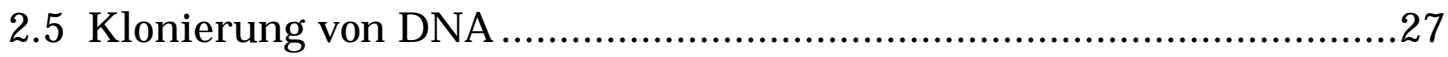

2.5.1 Spaltung von DNA durch Typ II Restriktionsendonukleasen ..................27

2.5.2 Glätten von überhängenden Enden nach der Spaltung ............................28

2.5.3 DNA Dephosphorylierung durch Alkaline Phosphatase ..........................28

2.5.4 Ligation von DNA Fragmenten................................................................2 
2.6 Trennung und Aufreinigung von DNA Fragmenten........................29

2.6.1 Trennung von Fragmenten durch Agarose-Gelelektrophorese ...............29

2.6.2 Extraktion von DNA Fragmenten aus Agarosegelen .............................30

2.6.3 DNA Aufreinigung durch Phenol Extraktion ........................................ 31

2.6.4 Bestimmung von Konzentration und Reinheit der DNA ........................ 31

2.7 DNA Amplifikation durch Polymerase Kettenreaktion (PCR)............32

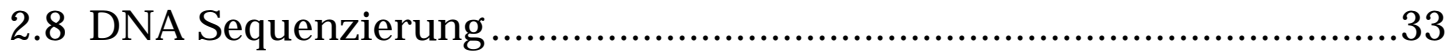

2.9 Expression und Isolation von GST Fusionsproteinen.......................34

2.10 Herstellung von Antikörpern ..............................................36

2.11 Transiente Genexpression in Tabakprotoplasten ........................36

2.11.1 Isolierung von Protoplasten aus Tabakblättern...............................36

2.11.2 Transformation der Tabakprotoplasten durch Elektroporation ..........37

2.11.3 Ernten der Protoplasten und des Kulturmediums .............................38

2.12 Isolierung von cytosolischen Proteinen ....................................39

2.12.1 Isolierung cytosolischer Proteine aus Blumenkohlinfloreszenzen ....... 39

2.12.2 Isolierung cytosolischer Proteine aus Schweinehirn .........................40

2.13 Isolierung von ER- und Golgi-Membranen..................................42

2.13.1 Isolierung von ER- und Golgi-Membranen aus Blumenkohl ............. 42

2.13.2 Isolierung von ER- und Golgi-Membranen aus Tabak.......................43

2.14 Dissoziation der endogenen Hüllproteine der COP Vesikel ..........44

2.15 Rekrutierung der Hüllproteine der COP Vesikel in vitro..............45

2.16 Induktion und Isolierung von COP Vesikeln in vitro ..................46

2.16.1 Induktion von COP Vesikeln in vitro.............................................4 46

2.16.2 Isolierung einer angereicherten COP Vesikel Fraktion .....................46

2.17 Dialyse von Proteinlösungen................................................48

2.18 Messung der $\alpha$-Amylaseaktivität .......................................48

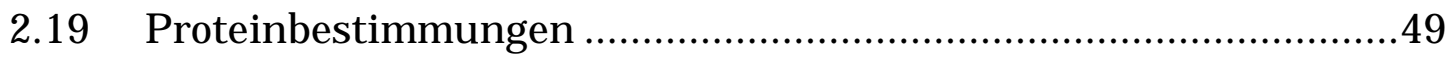

2.19.1 Proteinbestimmung nach Bradford................................................49

2.19.2 Proteinbestimmung nach Peterson ...............................................50

2.20 SDS-Polyacrylamid-Gelelektrophorese...................................51

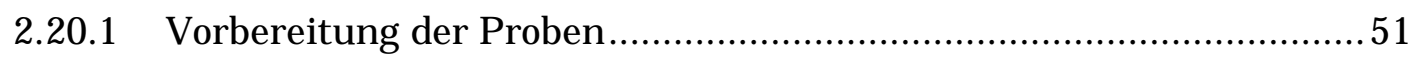

2.20.2 Herstellung der SDS-Polyacrylamidgele ......................................... 52 
2.20.3 Elektrophoretische Auftrennung der Proteine 54

2.20.4 Färbung der Proteine in SDS-Polyacrylamidgelen ...........................54

2.20.5 Elektroelution von Proteinen aus SDS-Polyacrylamidgelen............... 55

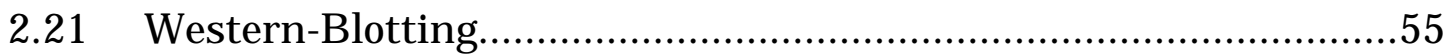

2.21.1 Elektrophoretischer Proteintransfer............................................55

2.21.2 Färbung der Proteine auf Nitrocellulosemembranen........................56

2.21.3 Spezifischer Nachweis von Proteinen mit Antikörpern .....................56

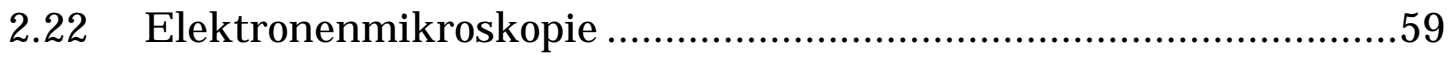

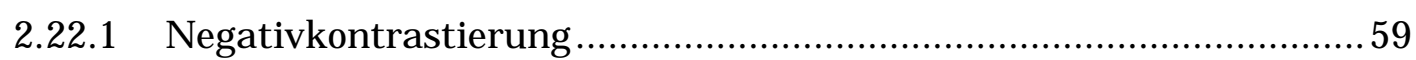

2.22.2 Immunogold-Negativkontrastierung ........................................60

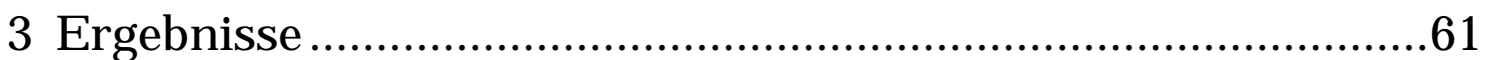

3.1 Herstellung der AtSar1p und AtArf1p Antiseren ...........................61

3.1.1 Herstellung des GST-AtSar1p Fusionsproteins .................................... 61

3.1.2 Charakterisierung des AtSar1p Antiserums .......................................62

3.1.3 Herstellung des GST-AtArf1p Fusionsproteins....................................63

3.1.4 Charakterisierung des AtArf1p Antiserums........................................63

3.2 Rekrutierung der Hüllproteine der COP Vesikel in vitro...................64

3.2.1 Dissoziation der endogenen Hüllproteine der COP Vesikel ....................65

3.2.2 Selektive Rekrutierung der Hüllproteine der COPI Vesikel...................65

3.2.3 Charakterisierung der Rekrutierungsreaktion ...................................67

3.2.4 Heterologe Rekrutierung der Hüllproteine der COPI Vesikel .................70

3.2.5 Charakterisierung der Membranen nach der Rekrutierungsreaktion ....71

3.3 Induktion von COPI Vesikeln in vitro........................................73

3.3.1 Isolation einer angereicherten COP Vesikel Fraktion ............................73

3.3.2 Elektronenmikroskopischer Nachweis der COP Vesikel ........................75

$3.4 \alpha$-Amylase als Reporterprotein zur Charakterisierung des Proteintransports in vivo und in vitro .................................................76

3.4.1 Einfluß der HDEL Sequenz auf die Sekretion der $\alpha$-Amylase in vivo..... 77

3.4.2 Sekretion der Amylase-HDEL durch die Sättigung der ER Retention.... 79

3.4.3 Einfluß der Temperatur auf Sekretion und Retention........................... 80

3.5 Charakterisierung der Fracht der induzierten COPI Vesikel.............81 
3.6 Beteiligung von COPII Vesikeln am ER Proteinexport in vivo .83

3.6.1 COPII Vesikel vermittelter Export von Amylase und Amylase-HDEL ... 83

3.6.2 Charakterisierung der Inhibierung des ER Exports durch AtSec12p .....85

3.7 Selektivität des COPII Vesikel vermittelten ER Exports...................88

3.7.1 Charakterisierung der ER Exportkompetenz löslicher Proteine .............88

3.7.2 Quantifizierung des „bulk-flow“ löslicher Proteinen aus dem ER ...........90

3.7.3 Quantifizierung des ER Exports von Calreticulin in vivo.......................93

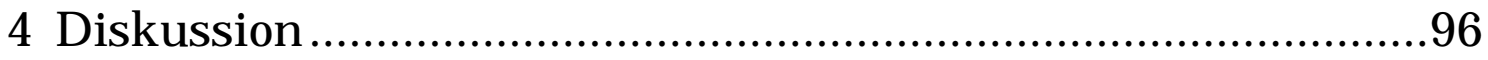

4.1 Rekrutierung der Hüllproteine der COP Vesikel in vitro....................96

4.2 Induktion und Isolation der COPI Vesikel.....................................100

4.3 Sekretion und Rücktransport von löslichen Proteinen......................101

4.4 Nachweis von löslichen HDEL Proteinen in COPI Vesikeln.............104

4.5 Beteiligung der COPII Vesikel am ER Export.................................105

4.6 Selektivität des COPII Vesikel vermittelten ER Exports.................106

4.7 Effizienz des „bulk-flow“ aus dem ER...........................................111

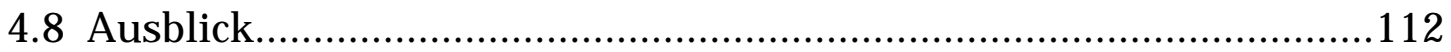

5 Zusammenfassung .......................................................114

6 Literaturverzeichnis .....................................................116 


\section{Abkürzungen und Symbole}

${ }^{\circ} \mathrm{C}$

A

AMPS

$\mathrm{ARF}$

ATP

BFA

BiP

BSA

COP

d

DOC

DTT

E

E. coli

EDTA

EGTA

ER

EtOH

$\mathrm{F}$

g

GA

GDP

GEF

GFP

$\mathrm{g}_{\max }$

GST

GTP

GTPYS

$\mathrm{h}$

HEPES

IDP

IgG

IPTG

KTC

1

M

MES

$\min$

NSF

OD

p.a.

PAT

PEG
Grad Celsius

Ampère

Ammoniumpersulfat

ADP-Ribosylierungsfaktor

Adenosin-5'-triphosphat

Brefeldin A

„binding protein“

Rinderserumalbumin

„coat protein“

Tag

Desoxicholat

1-4-Dithiothreitol

Extinktion

Escherichia coli

Ethylendiamintetraessigsäure

Bis-(aminoethyl)-glycolether-N,N,N,N-tetraessigsäure

Endoplasmatisches Reticulum

Ethanol

Farad

Gramm

Golgi-Apparat

Guanosindiphosphat

"guanine nucleotide exchange factor"

„green fluorescent protein“

Maximales Vielfaches der Erdbeschleunigung

Glutathion-S-Transferase

Guanosintriphosphat

Guanosin-5'-O-(3-thiotriphosphat)

Stunde

2-(4-(2-Hydroxyethyl)-1-piperazinyl)-ethansulfonsäure Inosin-5-Diphosphat

Immunglobulin $\mathrm{G}$

Isopropyl- $\beta$-D-thiogalactosid

Kupfertartrat-Carbonat-Reagenz

Liter

Molar

2-(N-Morpholino)-ethansulfonsäure

Minute

N-Ethylmaleimid-sensitiver Faktor

Optische Dichte

pro analysi

Phosphinothricin-Acetyltransferase

Polyethylenglycol 


$\begin{array}{ll}\text { PMSF } & \text { Phenylmethansulfonylfluorid } \\ \text { RGP } & \text { reversibel glycosyliertes Polypeptid } \\ \text { RT } & \text { Raumtemperatur } \\ \text { s } & \text { Sekunde } \\ \text { SDS } & \text { Natriumdodecylsulfat } \\ \text { SL } & \text { Stammlösung } \\ \text { SNAP } & \text { "soluble NSF attachment protein“ } \\ \text { SRP } & \text { „signal recognition particle“ } \\ \text { TCA } & \text { Trichloressigsäure } \\ \text { TEMED } & \text { N,N,N,N-Tetramethylethylendiamin } \\ \text { TGN } & \text { Trans-Golgi-Netzwerk } \\ \text { Tris } & \text { Tris-(hydroxymethyl)-aminomethan } \\ \text { t-SNARE } & \text {,target SNAP-receptor“ } \\ \text { U } & \text { Enzymeinheit } \\ \text { Upm } & \text { Umdrehungen pro Minute } \\ \text { UTP } & \text { Uridin-5'-triphosphat } \\ \text { V } & \text { Volt } \\ \text { v/v } & \text { Volumen zu Volumen } \\ \text { v-SNARE } & \text { „vesicle SNAP-receptor“ } \\ \text { w/v } & \text { Gewicht zu Volumen } \\ \text { w/w } & \text { Gewicht zu Gewicht } \\ & \end{array}$

Symbole für Aminosäuren
A Alanin
G Glycin
M Methionin
S Serin
C Cystein
$\mathrm{H}$ Histidin
$\mathrm{N}$ Asparagin
$\mathrm{T}$ Threonin
D Asparaginsäure I Isoleucin
$\mathrm{P}$ Prolin
V Valin
E Glutaminsäure K Lysin
Q Glutamin
W Tryptophan
F Phenylalanin L Leucin
$\mathrm{R}$ Arginin
Y Tyrosin 


\section{Einleitung}

Die eukaryotische Zelle ist durch die Gliederung in membranumgebene Kompartimente, die sich sowohl strukturell als auch funktionell voneinander unterscheiden, charakterisiert. Diese subzellulären Kompartimente stellen hoch spezialisierte Reaktionsräume innerhalb der Zelle dar, aus deren Zusammenwirken die Funktionsfähigkeit der Zelle resultiert. Die Kompartimente stehen durch einen intensiven, koordinierten Vesikelfluß in einer dynamischen Verbindung. Durch die Transportvesikel erfolgt sowohl der Erhalt der strukturellen und funktionellen Integrität der Kompartimente durch die Versorgung mit Proteinen, Lipiden und Stoffwechselmetaboliten als auch der Transport sekretorischer Proteine durch das Endomembransystem der Zelle (Palade, 1975).

\subsection{Der sekretorische Transportweg von Proteinen}

Mit Ausnahme der Proteine, die durch plastidäre oder mitochondriale DNA kodiert sind, werden alle Proteine im Cytosol der Zelle synthetisiert und von dort zu ihren Bestimmungsorten transportiert. Erfolgt die Synthese von Proteinen an den freien Ribosomen im Cytosol, so verbleiben sie entweder dort oder gelangen posttranslational durch einen vom Endomembransystem unabhängigen Transport zu den Plastiden, Mitochondrien, Peroxysomen oder dem Nucleus, wo sie durch spezielle Protein-Translokatoren importiert werden. Die Synthese von Proteinen, deren Bestimmungsorte jedoch das Endoplasmatische Reticulum (ER), der Golgi-Apparat, die lytischen Kompartimente (Vakuolen der Hefen und der Pflanzen bzw. Lysosomen der Säugetiere), die Plasmamembran oder der Extrazellularraum sind, erfolgt an den Ribosomen des rauhen ER. Diese Proteine werden, ausgehend vom ER, mit Hilfe von Transportvesikeln durch das Endomembransystem zu ihrem Bestimmungsort transportiert. Dieser Transportweg, der mit dem co- oder posttranslationalen Eintritt der Proteine in das Lumen des ER beginnt, wird auch als „sekretorischer Transportweg“ bezeichnet.

Der Eintritt eines Proteins in den sekretorischen Transportweg erfolgt durch die cotranslationale Translokation in das Lumen des ER, der durch ein Signalpeptid ermöglicht wird. Weisen Proteine kein weiteres Signal auf, werden sie zur Plasmamembran transportiert und sekretiert; dieser Weg wird als „default pathway“ bezeichnet (Pfeffer \& Rothman, 1987; Denecke et al., 1990). Proteine, die nicht sekretiert werden, tragen entsprechende spezifische Signale, die entweder ihren Verbleib in einem Kompartiment des sekretorischen Transportwegs oder ihren selektiven Transport $\mathrm{zu}$ anderen Kompartimenten ermöglichen. (Übersicht in Chrispeels, 1991; Gomord \& Faye, 1996). 


\subsection{Das Endoplasmatische Reticulum}

Im elektronenmikroskopischen Bild erscheint das Endoplasmatische Reticulum als ein äußerst komplexes, kontinuierlich verlaufendes Membransystem, das sich über den gesamten cytoplasmatischen Raum aller eukaryotischen Zellen erstreckt. Eine Besonderheit des ER der pflanzlichen Zellen ist der kontinuierliche Verlauf durch die Plasmodesmata, wodurch eine direkte Verbindung des Endomembransystems benachbarter Zellen entsteht und der Austausch von Proteinen und Lipiden über die Zellgrenzen hinaus ermöglicht wird (Lucas \& Wolf, 1993).

Das ER läßt sich in verschiedene Domänen unterteilen: Kernhülle, transitorisches ER, rauhes ER und glattes ER. Die Kernhülle, durch die der Zellkern vom Cytosol abgegrenzt wird, ist durch eine Vielzahl von Proteinkomplexen, den Kernporen, gekennzeichnet. Durch diese Poren erfolgt der selektive Austausch von Ribonukleinsäuren (RNA) und Proteinen zwischen dem Zellkern und dem Cytosol (Übersicht in Heese-Peck \& Raikhel, 1998). Das transitorische ER ist der Bildungsort von Transportvesikeln, durch die Proteine und Lipide zu anderen Kompartimenten der Zelle transportiert werden. Am auffälligsten sind flache, lamellenförmige, stark mit Ribosomen besetzte Bereiche, die aufgrund ihres Erscheinungsbildes auch als rauhes ER bezeichnet werden. Sie sind der Ort der Synthese von Proteinen, deren Translokation direkt in das Lumen des ER erfolgt. Das rauhe ER geht in ribosomenfreie, tubuläre, netzförmig verzweigte Abschnitte - das glatte ER —über, in dem die Lipide synthetisiert werden (Übersicht in Rose \& Doms, 1988; Sitia \& Meldolesi, 1992; Staehelin, 1997).

\subsubsection{Eintritt der Proteine in das ER}

Der Eintritt von Proteinen in den sekretorischen Transportweg beginnt mit der Translokation in das Lumen des ER. Zur cotranslationalen Translokation ist ein N-terminales Signalpeptid aus 20-50 Aminosäuren erforderlich (von Heijne, 1988). Nach der Translation des Signalpeptids bindet daran ein cytosolischer Signalerkennungspartikel (SRP), wodurch die Translation unterbrochen wird. Durch eine Interaktion des SRP mit dem SRP-Rezeptor, einem integralen Membranprotein (Meyer et al., 1982), lagert sich der gesamte Komplex, bestehend aus Ribosom, Präprotein und SRP, an das ER an (Walter \& Blobel, 1981). Nach dieser Anlagerung erfolgt die Bindung des Ribosoms an einen trimerischen Proteinkomplex (Sec61 $\alpha, \beta, \gamma$ ), der Translokationspore (Hartmann et al., 1994; Kalies et al., 1994),

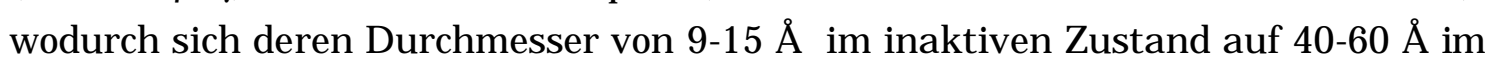
aktiven Zustand vergrößert (Hamman et al., 1997). Durch diese Bindung dissoziiert der SRP vom Signalpeptid, woraufhin die Translation fortgesetzt und das Präprotein direkt in das Lumen des ER transloziert wird (Wanker et al., 1995). Die Abspaltung des Signalpeptids erfolgt cotranslational durch einen membrangebundenen Signalpeptidase-Komplex im Lumen des ER (Evans et al., 1986; Shelness \& 
Blobel, 1990). Lösliche Proteine werden in das Lumen des ER entlassen, während Transmembranproteine durch eine Stop-Transfer-Sequenz oder eine interne Signal-Anker-Sequenz in die Membran integriert werden (Spiess, 1995).

\subsubsection{Faltung und Modifikation der Proteine}

Im Lumen des ER sind eine Vielzahl löslicher residenter Proteine enthalten, die auch als Reticuloplasmine bezeichnet werden (Koch, 1987). Eine bedeutende Gruppe der Reticuloplasmine sind molekulare Chaperone, durch deren Hilfe neu synthetisierte Proteine korrekt gefaltet werden (Hurtley \& Helenius, 1989; Gething \& Sambrook, 1992). Sie zählen zu der Proteinfamilie der Hitzeschockproteine (HSP) und werden anhand ihres Molekulargewichtes klassifiziert. Chaperone sind in allen Kompartimenten der Zelle anzutreffen, in denen die Proteinbiosynthese erfolgt (Hartl, 1996). Zu den wichtigsten Vertretern der molekularen Chaperone im ER zählen das zu der HSP70 Familie gehörende „binding protein“ BiP (Munro \& Pelham, 1986), das Endoplasmin der HSP90 Familie (Melnick et al., 1992), die Proteindisulfidisomerase (PDI) (Freedman, 1989) sowie Calreticulin (Denecke et al., 1995; Nauseef et al., 1995; Hebert et al., 1996) und Calnexin (Rajagopalan et al., 1994; Hebert et al., 1995; Vassilakos et al., 1996; Tatu \& Helenius, 1997). Das am besten charakterisierte Reticuloplasmin ist $\mathrm{BiP}$; es enthält eine N-terminale ATPase Domäne und eine C-terminale Polypeptid Bindungsdomäne (Hendrick \& Hartl, 1993), die hydrophobe Bereiche des noch ungefalteten Proteins cotranslational transient bindet. Erst nach der Faltung des Proteins dissoziiert der BiP-Protein Komplex durch Hydrolyse von ATP. Durch diese transiente Bindung wird die unspezifische Aggregation hydrophober Bereiche verschiedener Proteine verhindert und die korrekte Faltung der Proteine sichergestellt (Hartl, 1996). Darüber hinaus trägt BiP durch die Bindung an die inaktive Translokationspore im Lumen des ER bis zu deren Aktivierung durch den Ribosom-Präprotein-SRP Komplex zur Aufrechterhaltung der Permeabilitätsbarriere zwischen ER und Cytosol bei und ist somit auch maßgeblich an der Erhaltung der strukturellen und funktionellen Integrität des ER beteiligt (Hamman et al., 1998).

Das Lumen des ER stellt im Gegensatz zum Cytosol ein oxidierendes Kompartiment dar, das die Ausbildung von inter- und intramolekularen Disulfidbrücken begünstigt (Hwang et al., 1992). Durch das Reticuloplasmin PDI, das neben seiner Funktion als Chaperon auch Disulfidbrückenbindungen katalysiert und isomerisiert (Wang \& Tsou, 1993), wird sichergestellt, daß nur die korrekten Bindungen ausgebildet werden. Hierdurch wird die Anzahl von nicht funktionellen Proteinen minimiert (Übersicht in Galili et al., 1998). Ein weiterer Mechanismus, dem auch eine Kontrollfunktion bei der Faltung von Proteinen zugeschrieben wird, stellt die Glycosylierung dar. Viele Proteine, die in das Lumen des ER transloziert werden, erfahren eine cotranslationale Glycosylierung der $\mathrm{NH}_{2}$-Gruppe der Seitenkette eines Asparaginrests innerhalb der Aminosäuresequenz Asn-X-Ser oder Asn-X-Thr, 
wobei X eine beliebige Aminosäure außer Prolin sein kann. Dieses wird auch als Ngekoppelte Glycosylierung bezeichnet (Gavel \& von Heijne, 1990). Dabei wird ein Oligosaccharid aus Glucose, Mannose und N-Acetylglucosamin ( $\mathrm{Gl}_{3} \mathrm{Man}_{9} \mathrm{GlcNAc}_{2}$ ) durch einen Multiproteinkomplex, die Oligosaccharyltransferase, übertragen (Silberstein \& Gilmore, 1996) und anschließend durch ER residente Glucosidasen modifiziert. Hierbei spaltet die Glucosidase I den äußeren und die Glucosidase II anschließend nacheinander die beiden inneren Glucosereste des Oligosaccharids ab, wobei kurzzeitig ein monoglucosyliertes Intermediat entsteht (Sturm et al., 1987). Sowohl Calreticulin als auch Calnexin können an diesem Intermediat binden, um dessen Faltung zu unterstützen (Helenius et al., 1997). Nach der Faltung dissoziiert Calreticulin bzw. Calnexin von dem monoglucosylierten Intermediat, woraufhin der noch verbliebene Glucoserest des Oligosaccharids durch die Glucosidase II abgespalten wird. Die eigentliche Kontrolle der korrekten Faltung von Glycoproteinen erfolgt nun durch die UDP-Glucose:Glycoprotein Glucosyltransferase (Trombetta \& Parodi, 1992), die an nicht korrekt gefaltete Glycoproteine bindet, diese reglucosyliert und damit eine erneute Interaktion mit Calreticulin bzw. Calnexin zur korrekten Faltung ermöglicht (Sousa et al., 1992; Sousa \& Parodi, 1995; Übersicht in Crofts \& Denecke, 1998; Vitale \& Denecke, 1999). Durch die Chaperone, die an nicht korrekt gefaltete oder unspezifisch aggregierte Proteinen binden und somit deren Transport zu ihrem Zielkompartiment verhindern, erfüllt das ER die wichtige Funktion der Qualitätskontrolle der neu synthetisierten Proteine (Pelham, 1989; Hammond \& Helenius, 1995). Durch diese Qualtiätskontrolle wird sichergestellt, daß nur funktionsfähige Proteine ihr Zielkompartiment erreichen und somit die Funktionsfähigkeit der Kompartimente der Zelle erhalten bleibt.

Nach ihrer Translokation, Faltung und Modifikation werden sekretorische Proteine durch die COPII Vesikel (siehe 1.5.2) aus dem ER exportiert und zu dem „ERGolgi intermediate compartement“ (ERGIC) der Säugetiere bzw. zum cis-GolgiApparat in Hefen transportiert (Rexach \& Schekman, 1991; Salama et al., 1993; Barlowe et al., 1994).

\subsection{Der Golgi-Apparat}

Der Golgi-Apparat (GA) ist das zentrale Kompartiment des sekretorischen Transportwegs aller eukaryotischen Zellen, da hier die sekretorischen Proteine nach dem Export aus dem ER sortiert und durch verschiedene Transportvesikel zu ihren Zielkompartimenten transportiert werden (Übersicht in Farquhar \& Palade, 1998).

Der Golgi-Apparat der Säugetierzellen läßt sich in drei Subkompartimente unterteilen: das cis-Golgi Netzwerk (CGN), der Golgi-Stapel und das trans-Golgi Netzwerk (TGN) (Rothman \& Orci, 1992). Das cis-Golgi Netzwerk (Rambourg \& Clermont, 1990) wird aufgrund seiner tubulären Struktur, an der zahlreiche Trans- 
portvesikel fusionieren und gebildet werden, auch als „vesicular tubular cluster“ (VTC) bezeichnet (Bannykh et al., 1996) und stellt wahrscheinlich das „ER-Golgi intermediate compartement" (ERGIC) (Schweizer et al., 1990; Schweizer et al., 1991) dar (Teasdale \& Jackson, 1996). Der Golgi-Stapel besteht aus 4-6 abgeflachten, aneinandergelagerten Zisternen, an deren seitlichen Rändern Transportvesikel gebildet werden. Aufgrund seiner polaren Struktur ist eine Gliederung in Subkompartimente möglich, die als cis-, medial- und trans-Golgi bezeichnet werden. Durch verzweigte tubuläre Membranen sind verschiedene Golgi-Stapel direkt miteinander verbunden, wodurch ein den Zellkern umgebendes, komplexes Netzwerk gebildet wird. An den trans-Golgi gliedert sich das Trans-Golgi-Netzwerk (TGN) an, das die letzte, stark gefensterte Zisterne und die abknospenden Vesikel umfaßt. Hier erfolgt die Verpackung der sekretorischen Proteine in verschiedene Transportvesikel, mit deren Hilfe sie ihr Zielkompartiment erreichen (Griffiths \& Simons, 1986).

Der Golgi-Apparat der Hefen und der Pflanzen unterscheidet sich jedoch morphologisch von dem der Säugetierzellen. Selbst innerhalb der Arten findet man Variationen: Während der Golgi-Apparat der Hefe Pichia pastoris einen Golgi-Stapel aus mehreren Zisternen ausbildet, ist er bei der Hefe Saccharomyces cerevisiae auf nur eine stark gefensterte Zisterne reduziert (Duden \& Schekman, 1997; Glick \& Malhotra, 1998). Die Golgi-Stapel der Pflanzenzelle werden als Dictyosomen bezeichnet; weiter sind sie nicht durch ein Membransystem miteinander verbunden, auch sind sie nicht um den Zellkern angeordnet, sondern unregelmäßig im Cytoplasma der Zelle verteilt. Sowohl die Anzahl der Zisternen pro Dictyosom als auch die Anzahl der Dictyosomen selbst unterliegt starken Schwankungen innerhalb der Pflanzenarten (Übersicht in Mollenhauer \& Moreé, 1994; Staehelin \& Moore, 1995). Ebenso wie die Golgi-Stapel der Säugetierzellen zeigen die Dictyosomen einen polaren Aufbau und werden analog in cis-, medial-, und trans-Golgi unterteilt; das Strukturäquivalent des TGN wurde als „partially coated reticulum“ (PCR) beschrieben (Hillmer et al., 1988). Ein Strukturäquivalent des VTC / ERGIC konnte in Pflanzenzellen jedoch nicht charakterisiert werden (Übersicht in Robinson \& Hinz, 1999).

Die Proteine des sekretorischen Transportweges durchlaufen den Golgi-Apparat von cis nach trans unidirektional und werden während des Transports häufig durch O-gekoppelte Glycosylierungen, bei der die Oligosaccharide mit der HydroxyGruppe in einer Seitenkette von Serin oder Threonin verbunden sind oder durch Umwandlung mannosereicher Oligosaccharide in komplexe Glucane, modifiziert. Das Auftreten dieser komplexen Glucane kann daher als Hinweis auf den Transport eines Proteins durch den Golgi-Apparat oder auf dessen Lokalisierung im Golgi-Apparat dienen (Übersicht in Chrispeels, 1991; Lerouge et al., 1998; Varki, 1998). 
Die Hauptfunktion des Golgi-Apparats der Säugetiere besteht jedoch in der Sortierung extrazellulärer und lysosomaler Proteine am TGN (Griffiths \& Simons, 1986). Für eine Sortierung der Proteine zu den lytischen Kompartimenten sind spezifische Signale erforderlich, die in Hefen, tierischen und pflanzlichen Systemen jeweils unterschiedlich sind (Übersicht in Robinson \& Hinz, 1997; Neuhaus \& Rogers, 1998; Hadlington \& Denecke, 2000).

\subsubsection{Sortierung lysosomaler Proteine in Säugetierzellen}

In Säugetierzellen wird die Sortierung von sauren Hydrolasen bereits im cis-Golgi eingeleitet, indem terminale Mannosereste N-gekoppelter Glycosylierungen durch die N-Acetylglucosamin-1-phosphotransferase phosphoryliert werden (Cantor et al., 1992). Diese Phosphorylierung stellt ein Sortierungssignal dar, das durch Mannose-6-Phosphat Rezeptoren (MPRs) erkannt wird. Zwei Typ I integrale Membranproteine wurden in Säugetierzellen als MPRs identifiziert (MPR300 und MPR46). Sie sind hauptsächlich im TGN, aber auch in der Plasmamembran und in prälysosomalen Kompartimenten, den Endosomen, jedoch nicht in Lysosomen lokalisiert. Im Transport von löslichen Enzymen haben beide MPRs überlappende Funktionen, da sowohl MPR300 als auch MPR46 mit hoher Affinität an den phosphorylierten Glycoproteinen bindet. Darüber hinaus ist MPR300 in der Plasmamembran auch an der rezeptorvermittelten Endocytose beteiligt (Sandholzer et al., 2000), da er durch eine weitere Bindungsstelle den „insulin-like growth factor II“ (IGF II) des Extrazellularraums bindet und so spezifisch für dessen Transport zum Endosom sorgt. Aus diesem Grund wird MPR300 auch als Man-6-P/IGF II Rezeptor bezeichnet (Übersicht in Kornfeld, 1992; Ludwig et al., 1995).

Nach der Bindung des MPR an den sauren Hydrolasen im TGN wird der Komplex aus Rezeptor und Ligand in „clathrin-coated vesicles“ (CCVs, siehe 1.5.1) internalisiert und zum Endosom transportiert. Nach der $\mathrm{pH}$ abhängigen Dissoziation des Rezeptor-Ligand Komplexes wird der MPR zurück zum Golgi-Apparat transportiert (Duncan \& Kornfeld, 1988). Dieser Transport scheint jedoch unabhängig von CCVs zu erfolgen (Draper et al., 1990). Es existiert ebenfalls ein MPR unabhängiger Transport zum Lysosom. Hierbei werden lysosomale integrale Membranproteine (LIMPs) zunächst vom TGN zur Plasmamembran transportiert, dort in CCVs internalisiert, die anschließend mit dem Endosom fusionieren (Braun et al., 1989). Durch die Fusion des Endosoms mit dem Lysosom (Futter et al., 1996) gelangen schließlich sowohl die sauren Hydrolasen als auch die LIMPs in das Lysosom (Übersicht in Braulke, 1996; Le Borgne \& Hoflack, 1998). 


\subsubsection{Sortierung vakuolärer Proteine in Hefen}

Die Sortierung vakuolärer Proteine in Hefen erfolgt im Gegensatz zu der Sortierung lysosomaler Proteine in Säugetieren nicht durch MPRs. Am Beispiel des löslichen vakuolären Enzyms Carboxypeptidase Y (CPY) und dem integralen Membranprotein Alkaline Phosphatase (ALP) wurde gezeigt, daß die Sortierung unabhängig von Glycosylierungen erfolgt (Clark et al., 1982; Schwaiger et al., 1982). Im Fall der CPY konnte die N-terminale Aminosäuresequenz QRPL als Sortierungssignal identifiziert werden (Valls et al., 1990). Durch dessen Interaktion mit dem im TGN lokalisierten vakuolären Sortierungsrezeptor Vps10p (Marcusson et al., 1994) erfolgt der Transport durch CCVs (siehe 1.5.1) zu einem prävakuolären Kompartiment (Vida et al., 1993). Analog zu dem Transport von lysosomalen Proteinen zum Endosom der Säugetierzellen erfolgt auch in Hefen der Rücktransport des CPY Rezeptors Vps10p vom prävakuolären Kompartiment zum Golgi-Apparat (Cooper \& Stevens, 1996). Dieser Transportweg wird als CPY Transportweg bezeichnet. Die QRPL Sequenz scheint jedoch nicht das einzige Sortierungssignal zu sein, da die Sortierung der Proteinase A zur Vakuole ohne die QRPL Sequenz und Vps10p unabhängig erfolgt (Klionsky et al., 1988; Marcusson et al., 1994). Im Gegensatz zu dem lysosomalen Transport integraler Membranproteine der Säugetierzellen werden integrale Membranproteine in Hefen nicht zuerst zu der Plasmamembran und anschließend endocytotisch zu einem prälysosomalen bzw. prävakuolären Kompartiment weitertransportiert. Der Transport der ALP erfolgt unabhängig vom CPY Rezeptor und verläuft auch nicht über das prävakuoläre Kompartiment, sondern führt direkt vom TGN zur Vakuole (Cowles et al., 1997; Piper et al., 1997). Dieser Transportweg, der auch als ALP Transportweg bezeichnet wird, ist im Gegensatz zum CPY Transportweg CCV unabhängig. Die Transportvesikel, durch die der ALP Transport erfolgt, sind bisher noch nicht charakterisiert worden (Übersicht in Conibear \& Stevens, 1998).

\subsubsection{Sortierung vakuolärer Proteine in Pflanzen}

Im Rahmen der Sortierung vakuolärer Proteine nimmt die Pflanzenzelle eine besondere Position ein, da sich die Vakuolen der Pflanzen in Funktion und Morphologie von den Lysosomen der Säugetierzellen und den Vakuolen der Hefen unterscheiden. Neben ihrer Funktion als lytisches Kompartiment dienen sie ebenfalls der Erhaltung des Zellturgors sowie der Speicherung von Proteinen, Lektinen, organischen Säuren und Metaboliten des Sekundärstoffwechsels (Wink, 1993). Je nach Funktion und Entwicklungszustand der Zelle variiert auch das Erscheinungsbild ihrer Vakuole (Campbell \& Garber, 1980; Palevitz et al., 1981); so schwankt die Größe der Vakuolen von weniger als einem Mikrometer in meristematischen Zellen bis hin zu den Zentralvakuolen der Mesophyllzellen eines Blattes, die bis zu $90 \%$ des Zellvolumens einnehmen (Leidreiter et al., 1995). Eine weitere Besonderheit von Pflanzenzellen ist jedoch die Existenz funktionell unter- 
schiedlicher Vakuolen nicht nur in verschiedenen pflanzlichen Geweben, sondern auch innerhalb einer Zelle; so konnte die Coexistenz von lytischen Vakuolen (LV) mit Proteinspeichervakuolen (PSV) in den Parenchymzellen reifender Leguminosensamen (Hoh et al., 1995) oder mit Speichervakuolen (SV) in den Wurzelspitzen der Gerste und der Erbse (Paris et al., 1996) sowie in Mesophyllprotoplasten des Tabaks (Di Sansebastiano et al., 1998) nachgewiesen werden. (Übersicht in Robinson \& Hinz, 1997). Die Vakuolen lassen sich anhand spezifischer integraler Membranproteine, den „tonoplast intrinsic proteins“ (TIPs), voneinander unterscheiden (Johnson et al., 1989); so sind lytische Vakuolen (LV) durch die Isoform $\gamma$ TIP und Speichervakuolen (SV) bzw. Proteinspeichervakuolen (PSV) durch die Isoformen $\delta$-TIP bzw. $\alpha$-TIP oder $\alpha$-TIP und $\delta$-TIP charakterisiert (Swanson et al., 1998; Jauh et al., 1999). Hieraus erwächst die Notwendigkeit zusätzlicher Sortierungssignale und Sortierungsmechanismen, durch die Proteine gezielt zu den verschiedenen Vakuolen transportiert werden können.

Ebenso wie in Hefen ist auch die Sortierung vakuolärer Proteine in Pflanzen nicht von Glycosylierungen abhängig, sondern erfolgt durch Sortierungssignale, die aus ihrer Aminosäuresequenz resultieren (Voelker et al., 1989; Sticher et al., 1992). In vielen Fällen ist das vakuoläre Sortierungssignal in einem Propeptid enthalten, das posttranslational in einem prävakuolären Kompartiment oder der Vakuole abgespalten wird. Je nach Lage des Propeptids in der Proteinsequenz wird zwischen N-terminalen Propetiden (Sporamin der Süßkartoffel, Matsuoka et al., 1990; Aleurain, eine Protease der Gerste, Holwerda et al., 1992) und C-terminalen Propeptiden (Gerstenlektin, Bednarek \& Raikhel, 1991) unterschieden. Während einige N-terminale Propeptide eine gemeinsame Aminosäuresequenz (NPIR) zeigen, gibt es innerhalb der C-terminalen Propeptide keine Konsensus-Sequenz. Weiterhin kann sich das Propeptid auch innerhalb der Proteinsequenz befinden (z.B. Ricin des Ricinussamens, Frigerio et al., 1998a). Das Sortierungssignal kann jedoch auch direkt in der Proteinsequenz liegen (Phaseolin der Bohne, Frigerio et al., 1998b) oder über mehrere Domänen eines Proteins verteilt sein (Legumin der Bohne, Saalbach et al., 1991), wodurch das Sortierungssignal erst nach der korrekten Faltung des Proteins zugänglich ist und somit eigentlich ein „strukturelles“ Sortierungssignal darstellt (Übersicht in Neuhaus \& Rogers, 1998; Vitale \& Raikhel, 1999).

Durch Affinitätschromatographie mit dem N-terminalen Propeptid des Aleurain der Gerste konnte ein $80 \mathrm{kDa}$ Typ I Transmembranprotein (BP80) aus isolierten CCVs (siehe 1.5.1) aufgereinigt und als vakuolärer Sortierungsrezeptor (VSR) für Hydrolasen der LV identifiziert werden (Kirsch et al., 1996; Cao et al., 2000). BP80 wird durch eine Genfamilie kodiert, von der bisher sechs Isoformen anhand der Arabidopsis Genom Datenbank identifiziert wurden (Übersicht in Neuhaus \& Rogers, 1998; Hadlington \& Denecke, 2000). 
Durch quantitative Immun-Elektronenmikroskopie konnte in den Parenchymzellen reifender Erbsenkotyledonen in situ gezeigt werden, daß die Speicherproteine der PSV und der VSR BP80 am Golgi-Apparat in unterschiedliche Transportvesikel sortiert werden. Im Gegensatz zu dem VSR BP80 erfolgt der Transport der Speicherproteine Legumin und Vicilin nicht in CCVs, sondern in Vesikeln, die aufgrund ihres elektronendichten Inhalts in elektronenmikroskopischen Aufnahmen als „dense vesicles“ (DVs) bezeichnet werden. DVs werden an den lateralen Enden der Zisternen des Dictyosoms und am TGN gebildet, während die Bildung der CCVs nur am TGN erfolgt. Weiterhin enthalten die DVs das für den Tonoplast der PSV charakteristische $\alpha$-TIP, das in den CCVs nicht vorhanden ist (Hohl et al., 1996; Hinz et al., 1999). Neueste Untersuchungen haben weiterhin gezeigt, daß es sich bei der Sortierung der Speicherproteine in DVs und der Sortierung von BP80 in CCVs um unterschiedliche, voneinander getrennt ablaufende Prozesse handelt. Es konnte gezeigt werden, daß die Konzentration der Speicherproteine innerhalb eines Dictyosoms von cis nach trans aufgrund ihrer Sortierung in DVs deutlich abnimmt. Im Gegensatz dazu reichert sich BP80 von cis nach trans bis hin zum TGN, dem Bildungsort der CCVs, deutlich an (Hillmer et al., 2001). Demnach stellen sowohl der cis-Golgi als auch das TGN unterschiedliche Sortierungsdomänen innerhalb eines Dictyosoms dar.

\subsection{Mechanismen des Vesikel vermittelten Transports}

Dem Vesikel vermittelten Proteintransport liegt ein Mechanismus zugrunde, der sich in drei Schritte unterteilen läßt (siehe Abbildung 1.4-1). Im ersten Schritt erfolgt die Assoziation der Hüllproteine an die Membran, woraufhin zunächst eine Wölbung der Membran entsteht, die sich im weiteren Verlauf als Vesikel ablöst. Im zweiten Schritt erfolgt die Dissoziation der Proteinhülle, wodurch der dritte Schritt, die Anlagerung und Fusion mit der Zielmembran, ermöglicht wird (Übersicht in Rothman \& Wieland, 1996). Die Voraussetzung für einen koordinierten Proteintransport durch Vesikel innerhalb einer Zelle sind Kontrollmechanismen, die nur die Fusion des Vesikels mit seinem Zielkompartiment zulassen. Untersuchungen zur Fusion von Vesikeln der neuronalen Synapsen mit der präsynaptischen Membran führten zur Isolierung eines Komplexes aus SNAP-25 (,synaptosome associated protein“), Synaptobrevin, einem Membranprotein der synaptischen Vesikel und Syntaxin, dem Membranprotein der präsynaptischen Plasmamembran, an dem die Bindung von $\alpha$-SNAP (,soluble NSF-attachment protein“) und der ATPase NSF („N-ethyl-maleimide-sensitive fusion protein“) gezeigt werden konnte (Söllner et al., 1993). Nach der daraufhin postulierten SNARE-Hypothese trägt jeder Vesikel für die Zielmembran charakteristische Proteine, die als vSNAREs („vesicle-SNAP-receptor“) bezeichnet werden und mit spezifischen Proteinen, den t-SNAREs („target-SNAP-receptor“), der Zielmembran in Wechselwirkung 
treten. Durch in vitro Fusionsstudien mit synthetischen Synaptobrevin enthaltenden Donormembranen und Syntaxin sowie SNAP-25 enthaltenden Akzeptormembranen konnte weiterhin gezeigt werden, daß die v-SNARE - t-SNARE Interaktion zur spontanen Fusion der Membranen führt (Weber et al., 1998).

Entgegen früherer Annahmen scheint nun die Funktion der GTPase NSF nicht in der Energiebereitstellung für die Membranfusion, sondern für die Dissoziation des v-SNARE — t-SNARE Komplexes zu liegen, damit die t-SNAREs für eine erneute Fusion zur Verfügung stehen und die v-SNAREs zu ihrem Donorkompartiment zurück transportiert werden können (Übersicht in Jahn \& Hanson, 1998).

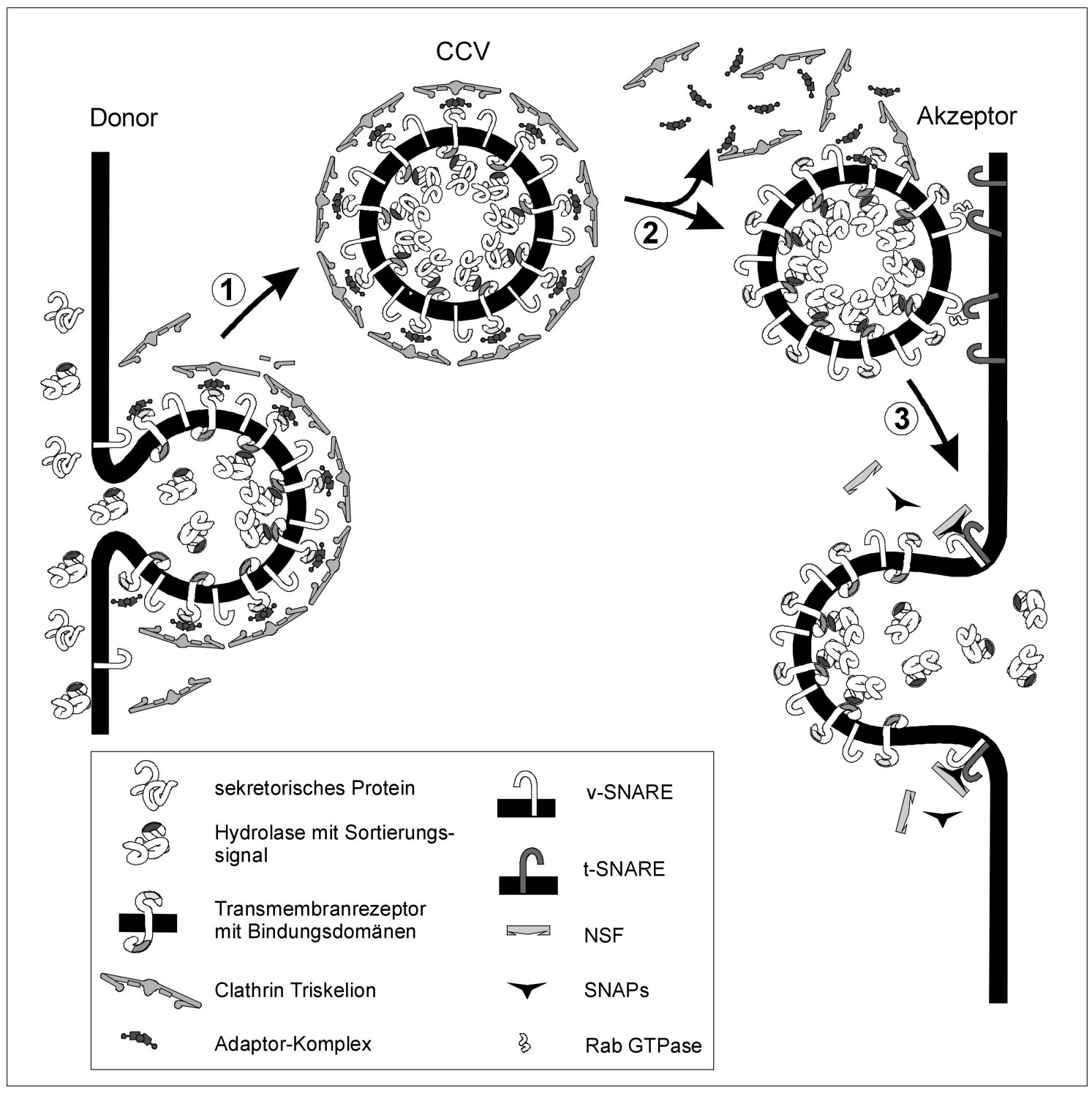

Abbildung 1.4-1:Hypothetischer Mechanismus des vesikelvermittelten Proteintransports.

1. Assoziation der Hüllproteine an der Donormembran und Ablösen des Vesikels.

2. Dissoziation der Proteinhülle und Anlagerung an die Akzeptormembran.

3. Fusion des Vesikels mit der Akzeptormembran. 
An der v-SNARE - t-SNARE Interaktion in vivo sind jedoch noch weitere Proteine beteiligt. Während „SNARE blocker“ durch die Bindung an den SNAREs unspezifische Interaktionen verhindern, unterstützen die Rab GTPasen, die selbst einer Regulation durch Rab Effektoren unterworfen sind, die Initiierung der v-SNARE t-SNARE Interaktion (Übersicht in Robinson et al., 1998; Pfeffer, 1999).

Auch im Transport sekretorischer Proteine konnte die Beteiligung von NSF und SNARE homologen Proteinen nachgewiesen werden (Block et al., 1988; Malhotra et al., 1988; Griff et al., 1992; Ferro-Novick \& Jahn, 1994; Rothman, 1994; Sogaard et al., 1994). Durch die Identifizierung organellspezifischer v- und t-SNAREs in Säugetieren, Hefen und Pflanzen liegt die Vermutung nahe, daß der Erkennung des Zielkompartiments durch die Transportvesikel und deren anschließender Fusion ein gemeinsamer Mechanismus zugrunde liegt, der in allen eukaryotischen Zellen konserviert ist (Übersicht in Robinson et al., 1998; Sanderfoot \& Raikhel, 1999).

\subsection{Transportvesikel}

\subsubsection{CCVs (,clathrin-coated vesicles“)}

"Clathrin coated vesicles“ (CCVs) sind in allen eukaryotischen Zellen vorhanden. Sie vermitteln den selektiven Proteintransport vom TGN zu den prävakuolären bzw. prälysosomalen Kompartimenten (siehe 1.3.1-1.3.3) und sind ebenfalls am endocytotischen Proteintransport beteiligt. Sie haben einen Durchmesser von 70 $100 \mathrm{~nm}$ und unterscheiden sich in elektronenmikroskopischen Aufnahmen deutlich von anderen Transportvesikeln durch ihre charakteristische polygonale Proteinhülle (Übersicht in Pearse \& Robinson, 1990; Robinson, 1996).

Die Proteinhülle der CCVs besteht aus 2 Hauptkomponenten, dem Clathrin Gerüst und den Adaptor-Komplexen, die das Bindeglied zwischen dem Clathrin Gerüst und den Membranproteinen darstellen (siehe Abbildung 1.5-1). Das Clathrin Gerüst setzt sich aus aneinandergelagerten Clathrin Triskelia zusammen. Jedes Triskelion besteht aus drei schweren Clathrin Ketten („clathrin heavy chain“, CHC), die jeweils mit einer leichten Clathrin Kette („clathrin light chain“, CLC) assoziiert sind, und liegt als Proteinkomplex im Cytosol vor (Kirchhausen \& Harrison, 1981; Ungewickell \& Branton, 1981). Die Adaptor-Komplexe (AP-1 / AP-2) sind aus je vier Untereinheiten, den Adaptinen, aufgebaut (AP-1: $\beta_{1}, \gamma, \mu_{1}, \sigma_{1}$; AP-2: $\beta_{2}$, $\alpha, \mu_{2}, \sigma_{2}$ ) und sind im Cytosol als heterotetramere Proteinkomplexe zu finden (Abbildung 1.5-1C). Während die $\beta$-Adaptine der Adaptor-Komplexe die Clathrin Bindungsstelle enthalten (Schröder \& Ungewickell, 1991), erfolgt die Interaktion mit den Membranproteinen durch das $\alpha$ - bzw. $\gamma$-Adaptin. Die $\sigma$ - und $\mu$-Adaptine sind sowohl an der korrekten Assemblierung der Komplexe als auch an der Erkennung der Membranrezeptoren beteiligt (Page \& Robinson, 1995); so werden CCVs 
mit AP-1 am TGN und CCVs mit AP-2 an der Plasmamembran gebildet (Übersicht in Robinson, 1996; Robinson et al., 1998; Kirchhausen, 2000).

A

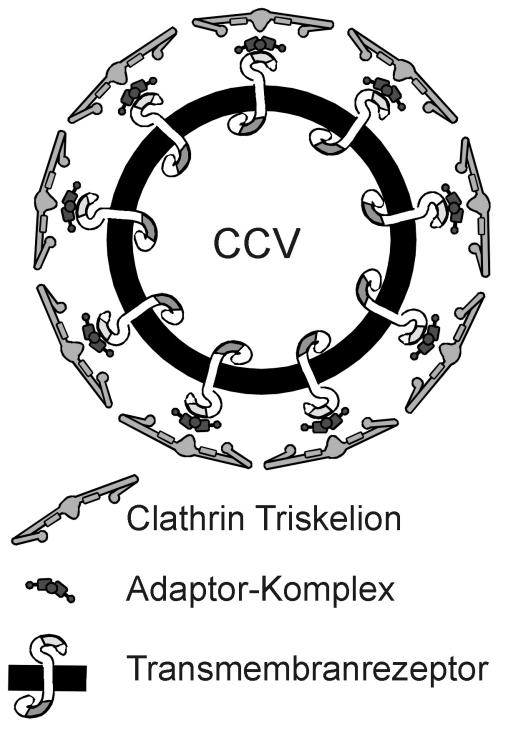

B

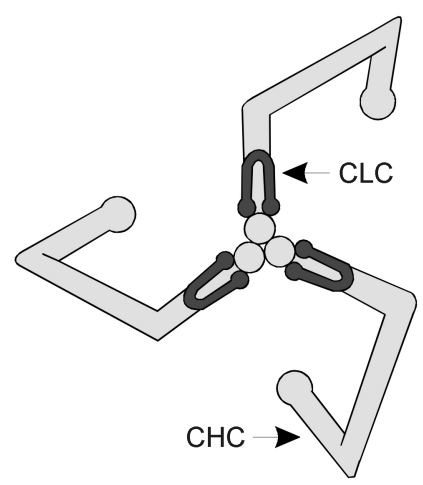

C

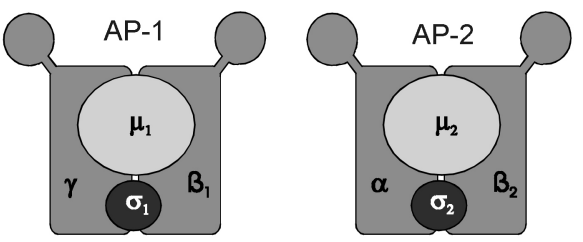

Abbildung 1.5-1:Aufbau der Hüllstruktur der CCVs.

A: Anordnung der Triskelia und der Adaptor-Komplexe an den Transmembranrezeptoren.

B: Aufbau eines Clathrin Triskelion, „clathrin heavy chain" (CHC), „clathrin light chain“ (CLC).

C: Aufbau der Adaptor-Komplexe AP-1 und AP-2.

Die Bildung der Proteinhülle der CCVs wird durch die Bindung des AdaptorKomplexes an einem Transmembranprotein eingeleitet, wobei die $\mu$-Adaptine mit spezifischen Signalsequenzen in den cytoplasmatischen Domänen der Membranproteine interagieren (siehe Abbildung 1.5-2). Sortierungssignale konnten bislang an einer Vielzahl von lysosomalen und vakuolären Proteinen identifiziert werden. So tragen die MPRs der Säugetiere sowohl ein auf Tyrosin basierendes Signal mit der Konsensus-Sequenz YXX $\Phi$, wobei $\Phi$ eine Aminosäure mit einer hydrophoben Seitenkette ist, als auch ein di-Leucin Signal (LLHV). Das di-Leucin Signal wird von dem AP-1 Adaptor-Komplex am TGN erkannt, jedoch zeigen auch beide $\mu$-Adaptine Interaktionen mit dem auf Tyrosin basierenden Signal (Übersicht in Marks et al., 1997). Im Anschluß bindet das Clathrin Triskelion an den AdaptorKomplex. Die weitere Rekrutierung von Adaptor-Komplexen und Clathrin Triskelia sowie der GTPase Dynamin (Hinshaw \& Schmid, 1995) führt zu einer Wölbung des ursprünglich planaren Clathrin Gitters, die durch die Polymerisation des Dynamins schließlich als CCV abgeschnürt wird. 


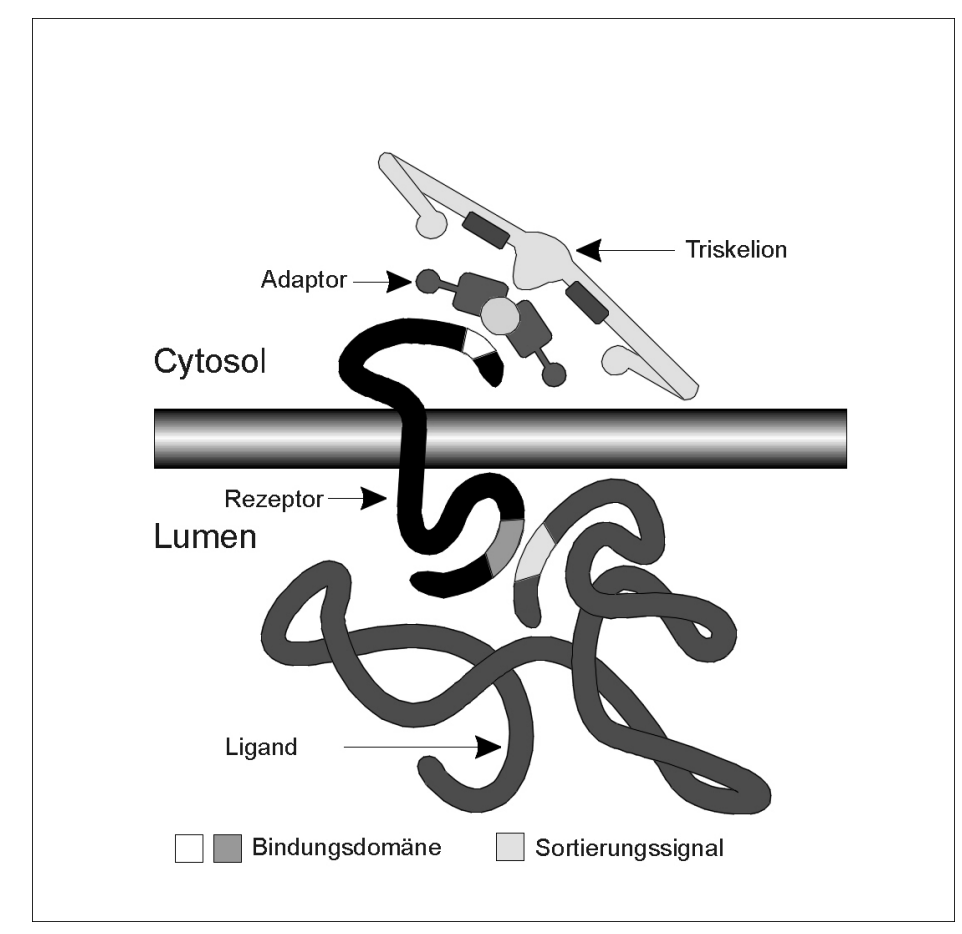

Abbildung 1.5-2:Selektiver Proteintransport durch CCVs.

Die Dissoziation des Clathrin Gerüsts wird durch die Anlagerung eines DnaJähnlichen Proteins, dem Auxilin, an den Clathrin Triskelia initiiert, woraufhin das cytosolische Chaperon Hsp70c rekrutiert werden kann. Durch die Hydrolyse von ATP dissoziieren die Triskelia von den Adaptor-Komplexen (Ungewickell et al., 1995). Die Regulation der Dissoziation der Proteinhülle sowie der Mechanismus der Dissoziation der Adaptor-Komplexe von den Membranproteinen konnte noch nicht aufgeklärt werden (Übersicht in Kirchhausen, 2000).

\subsubsection{COP Vesikel (,coat protein-coated vesicles“)}

Im Rahmen von Untersuchungen zum intra-Golgi Transport der Säugetierzellen wurden „coat protein-coated vesicles“ (COPI Vesikel) als ein neuer Typ von Transportvesikeln identifiziert, dessen Hüllstruktur nicht aus Clathrin besteht und sich in elektronenmikroskopischen Aufnahmen deutlich von den CCVs unterscheiden läßt. Im Gegensatz zu den CCVs zeigen diese Transportvesikel keine geometrische Hüllstruktur, sondern eine diffuse, unregelmäßige Proteinhülle. Weiterhin werden sie auch nicht am TGN, sondern an den lateralen Enden der Zisternen des GolgiApparats gebildet (Orci et al., 1986). Weitere Untersuchungen zur Bildung und Fusion der COP Vesikel (Melançon et al., 1987; Malhotra et al., 1988; Orci et al., 1989) ermöglichten schließlich ihre Isolation (Malhotra et al., 1989) sowie die Charakterisierung ihrer Proteinhülle (Waters et al., 1991). 
Ein weiterer Typ von Transportvesikeln, die ebenfalls keine Clathrin Hüllstruktur aufweisen, konnte aus Hefe isoliert und charakterisiert werden (Barlowe et al., 1994). Diese Transportvesikel werden jedoch nicht am Golgi-Apparat, sondern am ER gebildet, von wo aus sie den Proteintransport zum Golgi-Apparat vermitteln (Salama et al., 1993). Aufgrund ihrer Ähnlichkeit in elektronenmikroskopischen Aufnahmen mit den COPI Vesikeln werden diese weiteren nicht Clathrin bedeckten Vesikel als COPII Vesikel bezeichnet (Barlowe et al., 1994).

Sowohl die Proteinhülle der COPI Vesikel als auch die der COPII Vesikel enthält ein kleines GTP Bindungsprotein (ADP-Ribosylierungsfaktor ARF, Serafini et al., 1991 bzw. Sar1p, Barlowe et al., 1993), das die weiteren Hüllproteine rekrutiert (siehe Abbildung 1.5-3).

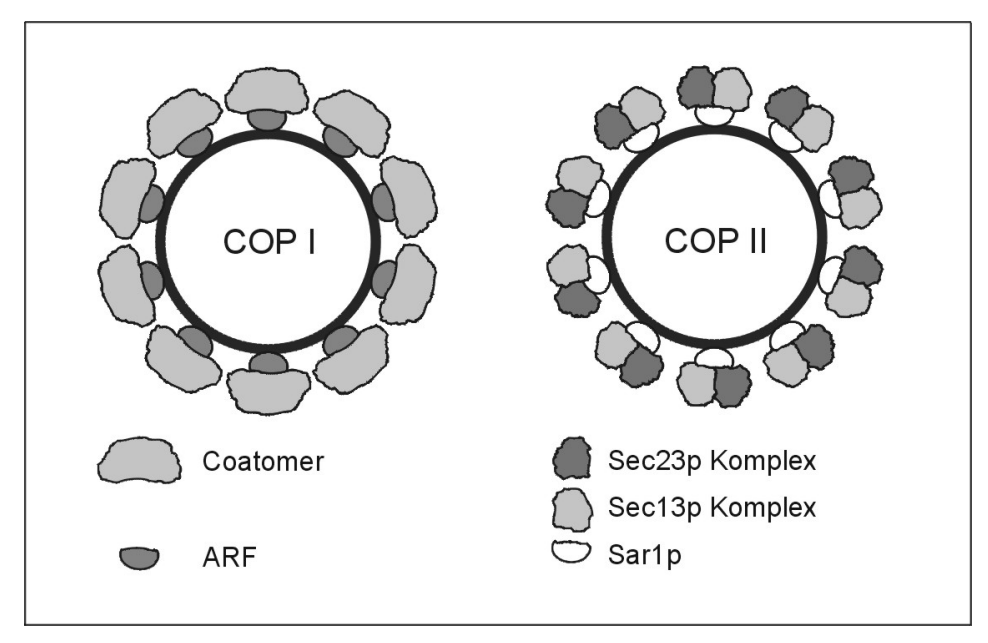

Abbildung 1.5-3:Komponenten der Proteinhülle der COPI- und COPII Vesikel.

Der zweite Hauptbestandteil der COPI Vesikel ist das Coatomer. Es besteht aus sieben Untereinheiten, die jeweils als COP („coat protein“) bezeichnet werden: $\alpha$ COP (160 kDa), $\beta$-COP (110 kDa), $\beta$ 'COP (102 kDa), $\gamma$-COP (98 kDa), $\delta$-COP (61 $\mathrm{kDa}), \varepsilon-\mathrm{COP}(31 \mathrm{kDa})$ und $\zeta$-COP $(20 \mathrm{kDa})$ (Serafini et al., 1991; Waters et al., 1991). Die Assemblierung des Coatomers erfolgt spontan durch die direkte Interaktion der COPs (Lowe \& Kreis, 1995; Faulstich et al., 1996; Lowe \& Kreis, 1996). Ein dem Coatomer homologer Proteinkomplex aus Hefe konnte ebenfalls isoliert und charakterisiert werden (Duden et al., 1991; Hosobuchi et al., 1992; Duden et al., 1994; Cosson et al., 1996; Duden et al., 1998). Die den Säugern homologen COPs aus Hefe sind in Tabelle 1.5-1 dargestellt. 
Tabelle 1.5-1: Homologe Proteine des Coatomers von Säugetieren und Hefe.

\begin{tabular}{|l|l|l|l|l|l|l|l|}
\hline Säugetiere & $\alpha$-COP & $\beta$-COP & $\beta^{\prime}$-COP & $\gamma$-COP & $\delta$-COP & $\varepsilon$-COP & $\zeta$-COP \\
\hline Hefe & Ret1p & $\operatorname{Sec} 26 p$ & $\operatorname{Sec} 27 p$ & $\operatorname{Sec} 21 p$ & $\operatorname{Ret} 2 p$ & $\operatorname{Sec} 28 p$ & $\operatorname{Ret} 3 p$ \\
\hline
\end{tabular}

Die Hülle der COPII Vesikel besteht aus drei Hauptbestandteilen (siehe Abbildung 1.5-3): der GTPase Sar1p (21 kDa), dem Sec23p Proteinkomplex (400 kDa) und dem Sec13p Proteinkomplex (700 kDa) (Barlowe et al., 1994; Matsuoka et al., 1998). Der Sec23p-Proteinkomplex setzt sich aus Sec24p (105 kDa) und Sec23p (85 kDa) zusammen (Hicke \& Schekman, 1989; Hicke et al., 1992), der Sec13p Proteinkomplex besteht aus Sec13p (34 kDa) und Sec31p (150 kDa) (Pryer et al., 1993; Salama et al., 1993; Salama et al., 1997).

Obwohl die Proteinhülle der COPI Vesikel nur aus dem GTP Bindungsprotein ARF und dem Coatomer besteht (Orci et al., 1993a; Orci et al., 1993b; Spang et al., 1998), ist die Bildung und Dissoziation ihrer Proteinhülle ein koordinierter Vorgang, an dem noch weitere Proteine beteiligt sind. Die Bildung von COPI Vesikeln wird durch die Rekrutierung des ARF eingeleitet (siehe Abbildung 1.5-4).

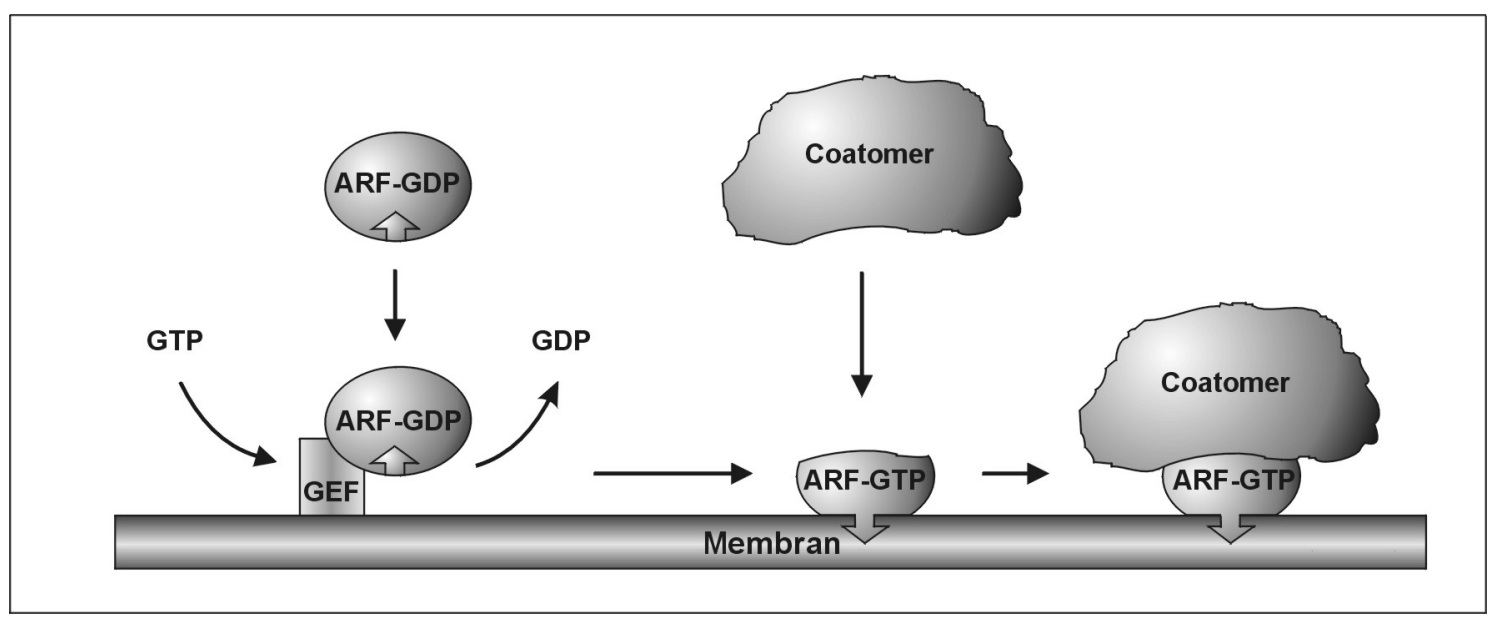

Abbildung 1.5-4:Schematische Darstellung der Rekrutierung der COPI Hüllproteine.

ARF trägt eine N-terminale Myrystoylierung und liegt im Cytosol als ARF-GDP Komplex vor (Palmer et al., 1993). Durch die Interaktion mit einem membrangebundenen „guanine nucleotide exchange factor“ (GEF), der den Austausch von GDP gegen GTP an dem ARF-GDP Komplex katalysiert (Helms \& Rothman, 1992), erfolgt eine Konformationsänderung des ARF, durch die der ARF-GTP Komplex mit der Myrystoylgruppe an der Membran verankert werden kann. Einige ARF spezifische GEFs konnten bereits in Hefen (Gea1p / Gea2p; Peyroche et al., 1996) und 
Säugetieren (ARNO / ARNO3, Chardin et al., 1996; Franco et al., 1998) identifiziert werden. Alle GEFs enthalten eine konservierte Sec7 Domäne, durch die der Austausch von GDP gegen GTP katalysiert wird (Übersicht in Donaldson, 2000).

Eine Interaktion von ARF-GTP mit der membrangebundenen Phospholipase D ermöglicht die direkte Bindung des ARF-GTP Komplexes mit der $\beta$-COP Untereinheit des Coatomers (Zhao et al., 1997), woraufhin dieses „en bloc“ an die Membran rekrutiert wird (Hara-Kuge et al., 1994). Durch die Rekrutierung weiterer ARFs und Coatomer Komplexe entsteht eine Wölbung der Membranoberfläche, die sich schließlich unter dem Einfluß von Acyl-CoA als Vesikel ablöst (Pfanner et al., 1989; Ostermann et al., 1993).

Die Voraussetzung zur Fusion der COP Vesikel mit dem Zielkompartiment ist die Dissoziation der Proteinhülle (Tanigawa et al., 1993). Im Fall der COPI Vesikel wird dies durch die Hydrolyse des gebundenen GTP eingeleitet. Hierzu muß jedoch zunächst die GTPase Aktivität des ARF durch ein cytosolisches GTPase aktivierendes Protein (GAP) unter der Beteiligung des Coatomers (Goldberg, 1999) stimuliert werden (Übersicht in Donaldson, 2000; Donaldson \& Jackson, 2000). Diese Hydrolyse führt zu einer Konformationsänderung des ARF, woraufhin das Coatomer und das ARF-GDP von der Membran dissoziieren. Nach der Dissoziation der Proteinhülle liegen Coatomer und ARF-GDP im Cytosol in ihrem Ausgangszustand zur Bildung eines neuen Vesikels vor (Übersicht in Barlowe, 2000).

Die Dissoziation der Proteinhülle kann durch die Bindung des nicht hydrolysierbaren GTP Analogons GTP $\gamma$ S an das ARF inhibiert werden. Das ARF-GTP $\gamma$ S ermöglicht zwar ebenfalls die Rekrutierung des Coatomers und führt somit auch zu der Bildung der Vesikel, jedoch erfolgt aufgrund der Inhibierung der Dissoziation der Proteinhülle keine Fusion mit ihren Zielmembranen (Melançon et al., 1987). Die daraus resultierende Anreicherung von COPI Vesikeln führte schließlich zu ihrer Isolation Malhotra et al., 1989).

Durch Untersuchungen zur Inhibierung der Sekretion konnte durch die Verwendung von Brefeldin A, einem Stoffwechselmetaboliten aus Pilzen, gezeigt werden, daß die Hüllproteine der COPI Vesikel nicht nur der Vesikelbildung, sondern auch dem Erhalt der strukturellen Integrität des Golgi-Apparates dienen (Orci et al., 1991). Durch die Interaktion von BFA mit dem GEF-ARF-GDP Komplex (Donaldson et al., 1992; Helms \& Rothman, 1992) wird dieser stabilisiert, so daß kein GDP-GTP Austausch und keine Coatomer Rekrutierung erfolgen kann (Peyroche et al., 1999). Durch die Inhibierung der Coatomer Rekrutierung erfolgt die Fusion von Golgi-Membranen mit dem ER (Fukunaga et al., 1998) die, zumindest in Säugetierzellen, zum Verschwinden des Golgi-Apparates führt. 
Die Bildung der Proteinhülle der COPII Vesikel wird durch die kleine GTPase Sar1p initiiert (siehe Abbildung 1.5-5). Ebenso wie ARF liegt auch Sar1p im Cytosol in einer „inaktiven“ GDP gebundenen Form vor und muß zur Bindung an die Membran zunächst durch ein GEF in die „aktive“ GTP gebundene Form überführt werden. Als Sar1p spezifisches GEF konnte Sec12p, ein TYP II Transmembranprotein (Nakano et al., 1988), identifiziert werden (Barlowe \& Schekman, 1993). Nach der Bindung an der Membran rekrutiert Sar1p-GTP den Sec23p Proteinkomplex, an dem im Anschluß der Sec13p Komplex bindet. Durch weitere Rekrutierungen von Sar1p und nachfolgender Bindung der beiden Proteinkomplexe erfolgt eine Deformation der Membran, die schließlich zur Abknospung des Vesikels führt, die im Gegensatz zu den COPI Vesikeln nicht von Acyl-CoA abhängig ist (Übersicht in Kuehn \& Schekman, 1997).

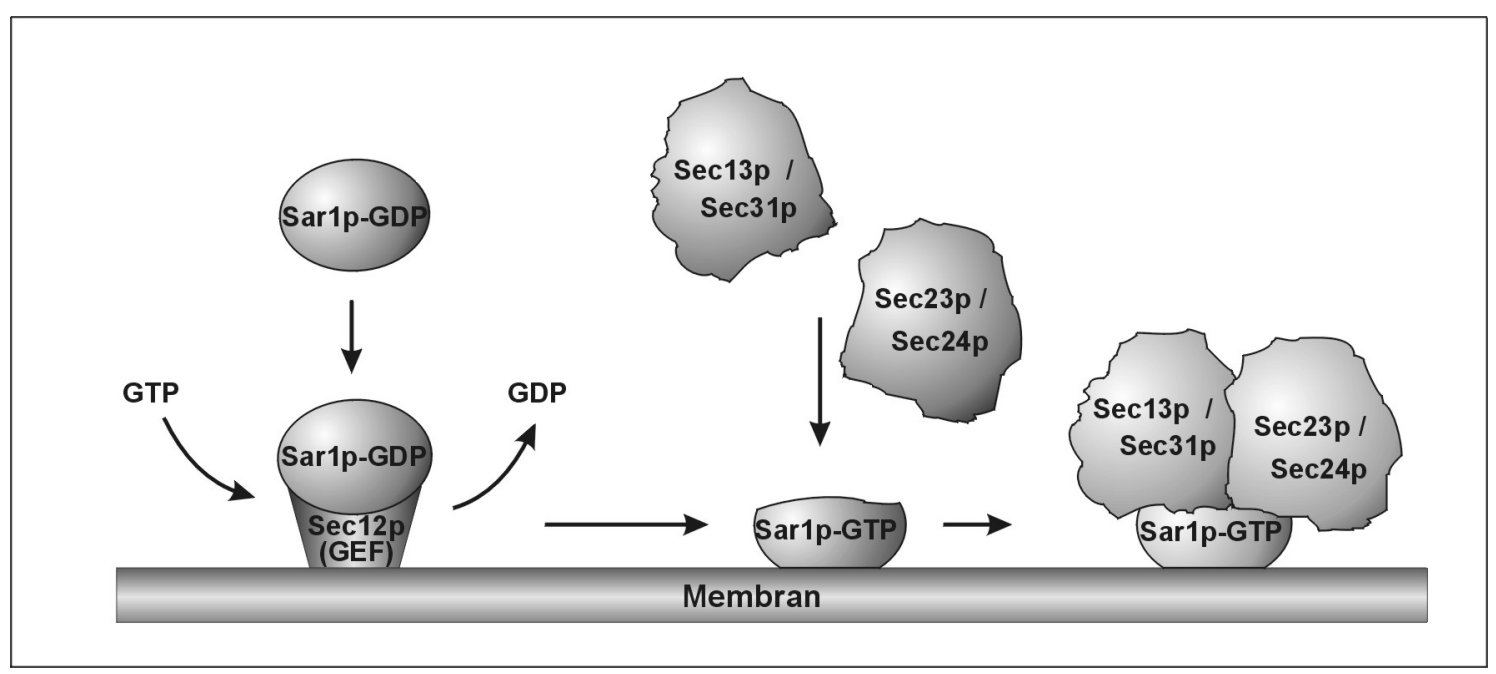

Abbildung 1.5-5: Schematische Darstellung der Rekrutierung der COPII Hüllproteine.

Die Dissoziation der Proteinhülle der COPII Vesikel erfolgt durch die Hydrolyse des am Sar1p gebundenen GTP. Im Gegensatz zu den COPI Vesikeln ist hierbei kein cytosolisches GAP erforderlich, da das im Sec23p Komplex enthaltene Sec23p die GTPase Aktivität des Sar1p spezifisch aktiviert (Yoshihisa et al., 1993; Barlowe et al., 1994). 


\subsection{Sekretion und Retention von löslichen Proteinen}

Das Lumen des ER enthält eine Vielzahl von löslichen ER residenten Proteinen, durch die die Faltung und Modifikation neu synthetisierter Proteine ermöglicht wird (siehe 1.2.2). Hierbei ist die Konzentration der ER residenten Proteine jedoch höher als die Konzentration der Proteine, deren Bestimmungsort die Vakuole oder der extrazelluläre Raum ist (Macer \& Koch, 1988). ER residente Proteine zeigen jedoch die gleiche Mobilität im Lumen des ER wie sekretorische Proteine (Ceriotti $\&$ Colman, 1988). Dieses erfordert Mechanismen zur Sortierung der Proteine, die einerseits den effizienten ER Export von sekretorischen Proteinen ermöglichen, andererseits jedoch den Verlust der ER residenten Proteine, die zum Erhalt der funktionellen und strukturellen Integrität des ER erforderlich sind, begrenzen.

Dies wird durch den COP Vesikel vermittelten Proteintransport erreicht, durch den das ER mit dem Golgi-Apparat in einer dynamischen Verbindung steht. Hierbei erfolgt der Proteintransport vom ER zum Golgi-Apparat durch COPII Vesikel (Barlowe et al., 1994). Dieser vorwärts gerichtete Transport steht in einem dynamischen Gleichgewicht mit einem retrograden Transport vom Golgi-Apparat zum ER, der durch die COPI Vesikel erfolgt (Letourneur et al., 1994). Hierdurch wird sowohl ein Recycling von Proteinen, die am ER $\rightarrow$ Golgi Transport beteiligt sind, ermöglicht als auch der Membranfluß des vorwärtsgerichteten Transports ausgeglichen (Rothman, 1994; Townsley et al., 1994; Lewis \& Pelham, 1996).

Obwohl der Mechanismus der Bildung der COP Vesikel bereits aufgeklärt ist (Matsuoka et al., 1998; Spang et al., 1998) und sowohl der anterograde als auch der retrograde Proteintransport in vitro rekonstituiert werden konnte (Salama et al., 1993; Spang \& Schekman, 1998), sind die Sortierungsmechanismen, die diesem COP Vesikel vermittelten Transport zugrunde liegen, noch weitgehend unverstanden. Die Retention von Proteinen im ER kann hierbei prinzipiell durch zwei unterschiedliche Transportmechanismen erklärt werden: Zum einen kann durch einen selektiven Ausschluß vom COPII Vesikel Transport der Export ER residenter Proteine verhindert werden, zum anderen kann dieses aber auch durch einen selektiven retrograden Transport durch die COPI Vesikel im Anschluß an einen unspezifischen ER Export erreicht werden.

Die Beobachtung, daß unterschiedliche Proteine mit unterschiedlichen Raten sekretiert werden, führte zu der Vermutung, daß der Protein Export aus dem ER selektiv durch einen ER Exportrezeptor vermittelt wird, wobei die unterschiedlichen Sekretionsraten der Proteine auf unterschiedliche Affinitäten zu dem Rezeptor zurückzuführen sind (Fitting \& Kabat, 1982; Lodish et al., 1983). Aufgrund dieser Beobachtungen wurde ein Modell des selektiven ER Exports postuliert. Nach diesem Modell müssen alle Proteine zum Verlassen des ER ein spezifisches ER Exportsignal tragen, während Proteine, die dieses Signal nicht tragen, im ER verbleiben. 
Sekretionsstudien mit synthetischen Tripeptiden mit der Sequenz Asn-X-Ser/Thr (Wieland et al., 1987) und cytosolischen Proteinen, die durch ein N-terminales Signalpeptid artifiziell in das ER transloziert wurden (Denecke et al., 1990; Hunt \& Chrispeels, 1991), zeigten dagegen, daß zur Sekretion kein spezifisches ER Exportsignal erforderlich ist. Dieses führte zu der Postulierung der „bulk flow“ Theorie. Nach dieser Theorie werden alle Proteine, die außer dem N-terminalen Signalpeptid, das den Eintritt in das ER ermöglicht, kein weiteres Sortierungssignal aufweisen, zur Plasmamembran transportiert und sekretiert. Demnach müssen alle Proteine, deren Transport von diesem „default“ Transportweg abzweigt, ein Signal tragen, das ihren Transport zu bzw. ihren Verbleib in einem Kompartiment des sekretorischen Transportwegs ermöglicht (Pfeffer \& Rothman, 1987).

Diese „bulk-flow“ Theorie wurde ebenfalls durch die Identifizierung von Retentionssignalen der ER residenten Proteine unterstützt, die deren Sekretion verhindern und zu einer Retention im ER führen. Am Beispiel der ER residenten Chaperone BiP und PDI konnte gezeigt werden, daß die C-terminale Aminosäure Sequenz HDEL die Retention im ER der Säugetiere (Munro \& Pelham, 1987), KDEL die Retention in Hefen (Pelham, 1988 \#153]) und sowohl HDEL als auch KDEL die Retention in Pflanzen (Denecke et al., 1992; Napier et al., 1992) bewirkt. Weiterhin konnte der HDEL Rezeptor ERD2 (Lewis \& Pelham, 1990; Lewis et al., 1990; Semenza et al., 1990), ein im cis-Golgi-Apparat lokalisiertes Transmembranprotein (Tang et al., 1993), identifiziert werden, der in pH Abhängigkeit HDEL-Liganden bindet (Wilson et al., 1993). Dessen durch HDEL-Liganden induzierte Verlagerung aus dem cis-Golgi-Apparat in das ER (Lewis \& Pelham, 1992) führte zu der Theorie, daß die Retention löslicher Proteine im ER nicht durch die Verhinderung ihres Exports, sondern vielmehr durch einen Rezeptor vermittelten Rücktransport aus dem cis-Golgi-Apparat zum ER resultiert. Auch der Nachweis Golgi-spezifischer Glycosylierungen von Fusionsproteinen, die sich aufgrund eines ER Retentionssignals im ER anreichern, unterstützt die Theorie, daß die Retention im ER aufgrund eines retrograden Transports erfolgt (Pelham, 1988; Dean \& Pelham, 1990; Jackson et al., 1993). Durch die Identifizierung eines di-Lysin Signals (KKXX bzw. KXKXX) in der cytoplasmatischen Domäne ER residenter Membranproteine als Retentionssignal (Nilsson et al., 1989; Jackson et al., 1990; Shin et al., 1991; Jackson et al., 1993) sowie durch den Nachweis der Interaktion dieses di-Lysin Signals mit dem Coatomer der COPI Vesikel (Cosson \& Letourneur, 1994; Letourneur et al., 1994), konnte nachgewiesen werden, daß diese an dem Rücktransport ER residenter Proteine beteiligt sind.

Da ER residente Proteine jedoch nicht in in vitro induzierten COPII Vesikeln nachgewiesen werden konnten (Barlowe et al., 1994), stellt sich auch weiterhin die Frage, durch welche Mechanismen die Retention löslicher ER residenter Proteine erfolgt. 


\subsection{Zielsetzung der Arbeit}

Während in Hefen und in Säugetieren die Beteiligung der COP Vesikel an dem intrazellulären Proteintransport unumstritten ist, konnte ihre Existenz in Pflanzen bis zum Beginn der vorliegenden Arbeit noch nicht nachgewiesen werden. Die Identifizierung und Charakterisierung von pflanzlichen Proteinen, die Homologien zu den Hüllproteinen der COP Vesikel von Hefen und Säugetieren aufweisen, führten zu der Hypothese, daß auch in Pflanzen ein COP Vesikel vermittelter Proteintransport existiert.

Zur Überprüfung dieser Hypothese sollte in einem ersten Schwerpunkt der vorliegenden Arbeit durch biochemische und zellbiologische Methoden in einem in vitro Versuchssystem die Bildung von pflanzlichen COP Vesikeln untersucht werden. Zur Charakterisierung der Rekrutierung von Hüllproteinen sollten zunächst Antiseren gegen GTPasen der COPI und der COPII Vesikel (AtSar1p und AtArf1p) hergestellt werden.

In einem weiteren Schwerpunkt sollte die Beteiligung von COP Vesikeln an dem intrazellulären Proteintransport in einem in vivo Versuchssystem charakterisiert werden. Dabei sollte vor allem die Selektivität des ER Exports sekretorischer Proteine sowie die Retention ER residenter Proteine berücksichtigt werden. Hierzu sollte eine Methode entwickelt werden, die es ermöglicht, sowohl die Sekretion als auch die Retention durch den Nachweis eines Frachtmoleküls der Vesikel quantitativ zu untersuchen. 


\section{Material und Methoden}

\subsection{Versuchsobjekte}

Zur transienten Genexpression in Tabakprotoplasten wurden Tabakpflanzen (Nicotiana tabacum L. var. SR1 „Petit Havanna“) unter sterilen Bedingungen kultiviert.

Die Isolierung von ER- und Golgi-Membranfraktionen erfolgte aus Tabakpflanzen (Nicotiana tabacum L. var. SR1 „Petit Havanna“) und Blumenkohlinfloreszenzen (Brassica oleracea L. var botrytis). Die Tabakpflanzen wurden mit einem Genkonstrukt aus $\alpha$-Amylase mit einer C-terminalen Sequenz, die die HDEL-Aminosäuresequenz kodiert, transformiert. Diese Pflanzen wurden von Dr. J. Denecke (Universität Leeds, U.K.) zur Verfügung gestellt und ebenso wie die Blumenkohlpflanzen in den institutseigenen Gewächshäusern kultiviert.

Die Blumenkohlinfloreszenzen zur Isolierung der cytosolischen Proteine wurden frisch von einem Obst- und Gemüsefachgeschäft bezogen, da die dafür benötigten Mengen nicht in den institutseigenen Gewächshäusern angezogen werden konnten.

Zur Vermehrung von Plasmiden und zur Expression von Proteinen wurde der E. coli Stamm MC1061 eingesetzt (Casadaban \& Cohen, 1980).

\subsubsection{Anzucht der Versuchspflanzen im Gewächshaus}

Die Blumenkohl- und Tabaksamen wurden in ein Gemisch aus gleichen Teilen Sand und Fruhstorfer Erde Typ T-25 (Industrie-Erdenwerk Archut, Deutschland) ausgesät und 14 Tage später pikiert. Die Tabakpflanzen wurden 2 Wochen, die Blumenkohlpflanzen 4-6 Wochen nach dem Pikieren in Fruhstorfer Erde Typ T-25 ausgepflanzt, wobei der Topfdurchmesser $11 \mathrm{~cm}$ für Tabakpflanzen bzw. $30 \mathrm{~cm}$ für Blumenkohlpflanzen betrug. Die Kultivierung der Blumenkohl- und Tabakpflanzen erfolgte in einem Licht-Dunkel-Rhythmus von $16 \mathrm{~h}$ Licht und $8 \mathrm{~h}$ Dunkelheit bei $24{ }^{\circ} \mathrm{C}$.

\subsubsection{Anzucht und Vermehrung von sterilen Tabakpflanzen in vitro}

Die Kultivierung der sterilen Tabakpflanzen erfolgte in einer Klimakammer mit einem Licht-Dunkel-Rhythmus von $16 \mathrm{~h}$ Licht und $8 \mathrm{~h}$ Dunkelheit bei $24^{\circ} \mathrm{C}$ in $1 \mathrm{l}$ WECK Gläsern (WECK, Wehr-Öflingen, Deutschland). Die Anzuchtgläser wurden $4 \mathrm{~h}$ bei $160{ }^{\circ} \mathrm{C}$ durch trockene Hitze sterilisiert. Alle Arbeiten wurden unter sterilen Bedingungen durchgeführt. 
Nährmedium:

0,5 g/l MES/KOH; pH 5,7

4,3 g/l Murashige und Skoog Medium (Sigma, Taufkirchen, Deutschland)

$2 \%(\mathrm{w} / \mathrm{v})$ Saccharose

$0,8 \%(\mathrm{w} / \mathrm{v})$ Agar

in $\mathrm{H}_{2} \mathrm{O}$ bidest.

Das Nährmedium wurde 20 min bei $121{ }^{\circ} \mathrm{C}$ autoklaviert und nach dem $\mathrm{Ab}$ -

kühlen auf ca. $50^{\circ} \mathrm{C}$ in die Anzuchtgläser gefüllt.

Vor der Aussaat wurden die Tabaksamen oberflächensterilisiert. Hierzu wurde eine Spatelspitze der Tabaksamen in ein Eppendorf Reagenzgefäß überführt, mit $1 \mathrm{ml} 12$ \%iger Natriumhypochloritlösung versetzt und 2 min heftig geschüttelt. Im Anschluß an eine Inkubation bei RT für 15 min wurden die Samen in ein $50 \mathrm{ml}$ Reaktionsgefäß überführt, $3 \mathrm{mal}$ mit je $30 \mathrm{ml}$ sterilem $\mathrm{H}_{2} \mathrm{O}$ bidest. gewaschen und auf das erstarrte Nährmedium in den vorbereiteten Anzuchtgläsern aufgeschwemmt. Nach einer Kultivationszeit von 14 Tagen wurden die Tabakpflanzen vereinzelt und nach 6-8 Wochen wurden die Blätter zur Isolation von Protoplasten geerntet (siehe 2.11.1).

Die Tabakpflanzen wurden nach der Ernte der Blätter durch Sproßstecklinge vermehrt. Hierzu wurde die Sproßachse mit einem Skalpell kurz unterhalb der obersten beiden Blätter durchtrennt und die Blattstiele 1-2 mm oberhalb der Achselknospen entfernt. Die Stecklinge wurden im Anschluß mit einer Pinzette in das Nährmedium eines Anzuchtglases überführt und bis zur Blatternte 4-6 Wochen unter den oben genannten Bedingungen angezogen.

\subsubsection{Anzucht von E. coli}

Die Anzucht von E. coli erfolgte, soweit nicht anders angegeben, in Luria-Bertani (LB) Medium unter aeroben Bedingungen entweder in Flüssigkulturen oder auf Agarplatten. Alle Arbeiten zur Anzucht und Selektion von E. coli wurden unter sterilen Bedingungen durchgeführt. Da alle verwendeten Plasmide ein Gen zur Ampicillinresistenz tragen, wurde das Nährmedium zur Selektion von transformierten E. coli nach dem Autoklavieren mit $150 \mu \mathrm{g} / \mathrm{ml}$ Ampicillin ( $\mathrm{LB}_{\mathrm{AMP}}$ ) versetzt.

LB Medium:

$1 \%(\mathrm{w} / \mathrm{v})$ Trypton

$0,5 \%(w / v)$ Hefe Extrakt

$1 \%(\mathrm{w} / \mathrm{v}) \mathrm{NaCl}$

in $\mathrm{H}_{2} \mathrm{O}$ bidest.; mit $1 \mathrm{M} \mathrm{NaOH}$ wurde $\mathrm{pH}$ 7,0 eingestellt

Das Nährmedium wurde 20 min bei $121^{\circ} \mathrm{C}$ autoklaviert. 


\section{LB Agar:}

\section{$1,5 \%(w / v)$ Agar in LB Medium}

Ampicillin SL:

$50 \mathrm{mg} / \mathrm{ml}$ Ampicillin in $\mathrm{H}_{2} \mathrm{O}$ bidest.

Die Lösung wurde sterilfiltriert und in Aliquots bei $20^{\circ} \mathrm{C}$ gelagert.

Zur Anzucht von E. coli in Reinkultur auf Agarplatten wurde das LB Medium mit Agar versetzt und 20 min bei $121^{\circ} \mathrm{C}$ autoklaviert. Nach dem Abkühlen auf ca. $50{ }^{\circ} \mathrm{C}$ wurden jeweils ca. $20 \mathrm{ml}$ in eine Petrischale gegossen. Die Platten wurden nach dem vollständigen Abkühlen noch 30 min mit geöffnetem Deckel unter der Sterilbank getrocknet. Die E. coli wurden mit einer Impföse auf den so vorbereiteten Kulturplatten ausgestrichen und im Anschluß bei $37^{\circ} \mathrm{C}$ für $12-16$ inkubiert. Die so angelegten Kulturen wurden bei $4{ }^{\circ} \mathrm{C}$ aufbewahrt.

Zur Anzucht von E. coli in einer Flüssigkultur wurde zunächst eine Vorkultur angelegt. Hierzu wurden $3 \mathrm{ml} \mathrm{LB} \mathrm{AMP}_{\mathrm{AM}}$ Medium in ein Kulturröhrchen überführt und mit einer E. coli Kolonie von einer Agarplatte mit einer Pipettenspitze angeimpft. Nach der Inkubation auf einer Rundschüttelmaschine bei $230 \mathrm{Upm}$ und $37^{\circ} \mathrm{C}$ für 12-16 h wurden mit dieser Vorkultur $800 \mathrm{ml}$ auf $37^{\circ} \mathrm{C}$ erwärmtes $\mathrm{LB}_{\mathrm{AMP}}$ Medium in einem 21 Erlenmeyerkolben angeimpft und unter den oben genannten Bedingungen 16-20 $\mathrm{h}$ inkubiert.

Zur Langzeitlagerung von E. coli wurden Sicherungskulturen angelegt, indem $850 \mu \mathrm{l}$ einer E. coli Flüssigkultur mit $150 \mu \mathrm{l}$ autoklaviertem Glyzerin versetzt, gut vermischt und in flüssigem Stickstoff eingefroren wurden. Die Lagerung der Sicherungskulturen erfolgte bei $-80^{\circ} \mathrm{C}$.

\subsection{Herstellung transformationskompetenter $E$. coli}

Da E. coli keine natürliche Aufnahmebereitschaft für DNA (Kompetenz) zeigt, ist zur Transformation eine Vorbehandlung erforderlich, durch die sie zur Aufnahme von DNA befähigt werden. Hierzu wurde die Behandlung der Zellen mit Rubidiumchlorid durchgeführt (Hanahan, 1983).

2X YT Medium:

$1,6 \%(\mathrm{w} / \mathrm{v})$ Trypton

$1,0 \%(\mathrm{w} / \mathrm{v})$ Hefe Extrakt

$0,5 \%(\mathrm{w} / \mathrm{v}) \mathrm{NaCl}$

in $\mathrm{H}_{2} \mathrm{O}$ bidest.; mit $1 \mathrm{M} \mathrm{NaOH}$ wurde $\mathrm{pH}$ 7,0 eingestellt

Das Nährmedium wurde 20 min bei $121^{\circ} \mathrm{C}$ autoklaviert. 
TFBI:
$30 \mathrm{mM} \mathrm{KC}_{2} \mathrm{H}_{3} \mathrm{O}_{2}$
$100 \mathrm{mM} \mathrm{RbCl}$
$10 \mathrm{mM} \mathrm{CaCl}_{2} \bullet 2 \mathrm{H}_{2} \mathrm{O}$
$50 \mathrm{mM} \mathrm{MnCl} \mathrm{Mn}_{2} \bullet 4 \mathrm{H}_{2} \mathrm{O}$
$15 \%(\mathrm{v} / \mathrm{v})$ Glyzerin
in $\mathrm{H}_{2} \mathrm{O}$ bidest.; mit 0,2 $\mathrm{M} \mathrm{CH}_{3} \mathrm{COOH}$ wurde $\mathrm{pH} 5,8$ eingestellt
Die Lösung wurde sterilfiltriert und bei $4{ }^{\circ} \mathrm{C}$ gelagert.

TFBII:

$$
\begin{aligned}
& 10 \mathrm{mM} \text { MOPS } \\
& 10 \mathrm{mM} \mathrm{RbCl} \\
& 75 \mathrm{mM} \mathrm{CaCl}_{2} \bullet 2 \mathrm{H}_{2} \mathrm{O} \\
& 15 \%(\mathrm{v} / \mathrm{v}) \text { Glyzerin }
\end{aligned}
$$

in $\mathrm{H}_{2} \mathrm{O}$ bidest.; mit $5 \mathrm{M} \mathrm{KOH}$ wurde $\mathrm{pH}$ 6,6 eingestellt

Die Lösung wurde sterilfiltriert und bei $4{ }^{\circ} \mathrm{C}$ gelagert.

Zur Anzucht der E. coli wurden $20 \mathrm{ml}$ 2X YT Medium mit einer Kolonie von einer am Vortag angelegten Agarkultur angeimpft und auf einer Rundschüttelmaschine mit $250 \mathrm{Upm}$ bei $37^{\circ} \mathrm{C}$ inkubiert. Zur Bestimmung der Zelldichte wurde die optische Dichte der Kultur mit einem Spektralphotometer bei einer Wellenlänge von $\lambda=550 \mathrm{~nm}$ gegen das $2 \mathrm{X}$ YT Medium gemessen. Nach dem Erreichen einer $\mathrm{OD}_{550}$ von 0,3 wurden mit dieser Kultur $200 \mathrm{ml}$ auf $37{ }^{\circ} \mathrm{C}$ vorgewärmtes $2 \mathrm{X}$ YT Medium angeimpft, bis zu einer $\mathrm{OD}_{550}$ von 0,5 angezogen und dann für 10 min auf Eis inkubiert. Im Anschluß wurden die E. coli mit $5.000 \mathrm{~g}_{\max }$ (Sorvall RC5B; Rotor: Sorvall GS3) bei $4{ }^{\circ} \mathrm{C}$ für $10 \mathrm{~min}$ sedimentiert, vorsichtig in $80 \mathrm{ml}$ eiskaltem TFBI resuspendiert und $5 \mathrm{~min}$ auf Eis inkubiert. Nach einer weiteren Sedimentation mit $5.000 \mathrm{~g}_{\max }$ (Sorvall RC5B; Rotor: Sorvall SA 600) bei $4{ }^{\circ} \mathrm{C}$ für $10 \mathrm{~min}$ wurden die Zellen vorsichtig in $8 \mathrm{ml}$ TFBII resuspendiert und 15 min auf Eis inkubiert. Im Anschluß wurden jeweils $100 \mu \mathrm{l}$ der Zellsuspension in auf Eis vorgekühlte 1,5 ml Eppendorf Reaktionsgefäße überführt, sofort in flüssigem Stickstoff eingefroren und bis zur Transformation (siehe 2.3) bei $-80^{\circ} \mathrm{C}$ gelagert.

\subsection{Transformation von $E$. coli}

Die Transformation von E. coli erfolgte durch eine Hitzeschockbehandlung der transformationskompetenten Zellen. Hierzu wurde ein Aliquot der Zellen in Eiswasser aufgetaut, mit 50-100 ng DNA aus einer Plasmidlösung versetzt, kurz gemischt und 15-20 min auf Eis inkubiert. Der Hitzeschock erfolgte durch die Überführung des Transformationsansatzes in einen Heizblock mit $42{ }^{\circ} \mathrm{C}$. Nach einer Inkubation für 3 min wurden die Zellen mit $1 \mathrm{ml}$ auf $37^{\circ} \mathrm{C}$ erwärmtes LB Medium 
versetzt und 15 min bei $37^{\circ} \mathrm{C}$ zur Ausbildung der Antibiotikaresistenz inkubiert. Im Anschluß wurden jeweils $100 \mu \mathrm{l}, 250 \mu \mathrm{l}$ und $500 \mu \mathrm{l}$ des Transformationsansatzes auf einer $\mathrm{LB}_{\mathrm{AMP}}$ Agarplatte ausplattiert und $12-16 \mathrm{~h}$ bei $37^{\circ} \mathrm{C}$ inkubiert.

\subsection{Isolierung von Plasmid DNA aus E. coli}

Je nach Anforderung an Reinheit und Menge der Plasmid DNA erfolgte die Isolation entweder im großen Maßstab (Maxi-Präparation) oder im kleinen Maßstab (Mini-Präparation). Während die relativ arbeitsintensive Präparation im großen Maßstab hochreine Plasmid DNA liefert, die direkt zur Klonierung (siehe 2.5) oder zur transienten Genexpression (siehe 2.11) eingesetzt werden konnte, diente die DNA mit geringerem Reinheitsgrad der relativ schnell durchführbaren Präparation im kleinen Maßstab der Überprüfung von Genkonstrukten.

\subsubsection{Isolierung im großen Maßstab (Maxi-Präparation)}

Die Isolation von Plasmid DNA aus E. coli im großen Maßstab erfolgte ausgehend von einer in 2.1.3 beschriebenen $800 \mathrm{ml} \mathrm{E}$. coli Flüssigkultur.

TE Puffer:

$10 \mathrm{mM}$ Tris/HCl; $\mathrm{pH} 8,0$

0,1 mM EDTA

in $\mathrm{H}_{2} \mathrm{O}$ bidest.

Die Lösung wurde sterilfiltriert und bei RT gelagert.

TE50/1 Puffer:

50 mM Tris/HCl; pH 8,0

$1 \mathrm{mM}$ EDTA

in $\mathrm{H}_{2} \mathrm{O}$ bidest.

Die Lösung wurde sterilfiltriert und bei RT gelagert.

Lysozym Lösung:

$10 \mathrm{mg} / \mathrm{ml}$ Lysozym in $\mathrm{H}_{2} \mathrm{O}$ bidest.

Die Lösung wurde frisch angesetzt.

EDTA Lösung:

$500 \mathrm{mM}$ EDTA

in $\mathrm{H}_{2} \mathrm{O}$ bidest.; mit $\mathrm{HCl}$ wurde $\mathrm{pH} \mathrm{8,0} \mathrm{eingestellt}$

Die Lösung wurde $20 \mathrm{~min}$ bei $121^{\circ} \mathrm{C}$ autoklaviert und bei RT gelagert. 
Ribonuclease A Lösung:

$20 \mathrm{mg} / \mathrm{ml}$ Ribonuclease $\mathrm{A}$ in $\mathrm{H}_{2} \mathrm{O}$ bidest.

Die Lösung wurde in $50 \mu \mathrm{l}$ Aliquots bei $20^{\circ} \mathrm{C}$ gelagert.

Triton X-100 Lösung:

$10 \%(\mathrm{v} / \mathrm{v})$ Triton X-100 in $\mathrm{H}_{2} \mathrm{O}$ bidest.

Phenol Lösung:

Auf $\mathrm{pH}$ 8,0 äquilibriertes, mit 8-Hydroxychinolin stabilisiertes Phenol (AppliChem, Darmstadt, Deutschland)

Natriumperchlorat Lösung:

$5 \mathrm{M} \mathrm{NaClO}_{4}$ in $\mathrm{H}_{2} \mathrm{O}$ bidest.

Das Ernten der E. coli erfolgte durch eine Zentrifugation mit $5.000 \mathrm{~g}_{\max }$ (Sorvall RC5B; Rotor: Sorvall GS3) bei $4{ }^{\circ} \mathrm{C}$ für $30 \mathrm{~min}$. Im Anschluß wurden die Zellen in $8 \mathrm{ml}$ eiskaltem TE50/1 Puffer resuspendiert und in ein auf Eis vorgekühltes Sorvall SA600 Zentrifugationsröhrchen überführt. Die weitere Durchführung erfolgte auf Eis.

Durch die schnelle Zugabe von 2,5 ml der Lysozym Lösung und zehnmaliges Schwenken mit einer nachfolgenden Inkubation auf Eis für 5 min, wurden die Zellen lysiert. Im Anschluß wurden $2 \mathrm{ml}$ der EDTA Lösung zugegeben und durch zehnmaliges Schwenken mit der Suspension gemischt. Nachdem der Ansatz 5 min auf Eis inkubiert worden war, wurden $50 \mu \mathrm{l}$ der Ribonuclease A Lösung und $150 \mu \mathrm{l}$ der Triton X-100 Lösung zugefügt, zehnmal geschwenkt und 30 min auf Eis inkubiert. Zur Abtrennung der Zellreste wurde der Ansatz 50 min mit $50.000 \mathrm{~g}_{\max }$ bei $4{ }^{\circ} \mathrm{C} \mathrm{g}_{\max }$ (Sorvall RC5B; Rotor: Sorvall SA 600) zentrifugiert und der plasmidhaltige Überstand in ein $50 \mathrm{ml}$ Reaktionsgefäß überführt. Zur weiteren Aufreinigung wurde die Plasmidlösung mit $10 \mathrm{ml}$ der Phenol Lösung versetzt, $1 \mathrm{~min}$ heftig geschüttelt und $20 \mathrm{~min}$ bei $3.000 \mathrm{~g}_{\max }$ zentrifugiert (MSE Mistral 3000E; Rotor: 43124-7080). Die obere, wässerige Phase wurde in ein weiteres $50 \mathrm{ml}$ Reaktionsgefäß überführt, mit $10 \mathrm{ml}$ Chloroform versetzt, 1 min geschüttelt und nochmals $5 \mathrm{~min}$ bei $3.000 \mathrm{~g}_{\max }$ zentrifugiert. Im Anschluß wurde die wässerige Phase in ein $30 \mathrm{ml}$ Corex Zentrifugationsröhrchen überführt, und zur Fällung der DNA zunächst mit $1 \mathrm{ml} \mathrm{NaClO}_{4}$ Lösung und dann mit $8 \mathrm{ml}$ Isopropanol versetzt. Nach einer Zentrifugation bei $50.000 \mathrm{~g}_{\max }$ (Sorvall RC5B; Rotor: HB4) wurde der Überstand dekantiert, die DNA für 20 min bei $37^{\circ} \mathrm{C}$ getrocknet und schließlich in $500 \mu \mathrm{TE}$ Puffer vorsichtig resuspendiert und bei $4{ }^{\circ} \mathrm{C}$ gelagert. 


\subsubsection{Isolierung im kleinen Maßstab (Mini-Präparation)}

Die Isolation von Plasmid DNA im kleinen Maßstab erfolgte ausgehend von einer in 2.1.3 beschrieben $3 \mathrm{ml}$ E. coli Flüssigkultur. Alle Zentrifugationsschritte erfolgten in einer Eppendorf Tischzentrifuge mit $13.000 \mathrm{~g}_{\max }$.

TES Puffer:

$10 \mathrm{mM}$ Tris/HCl; $\mathrm{pH} 7,2$

$5 \mathrm{mM}$ EDTA

$250 \mathrm{mM}$ Saccharose

in $\mathrm{H}_{2} \mathrm{O}$ bidest.

Die Lösung wurde sterilfiltriert und bei $4{ }^{\circ} \mathrm{C}$ gelagert.

Von der E. coli Flüssigkultur wurden $1,5 \mathrm{ml}$ in ein Eppendorf Reaktionsgefäß überführt und 1 min zentrifugiert. Nachdem der Überstand quantitativ abgenommen worden war, wurde das E. coli Sediment in $150 \mu \mathrm{l}$ TES Puffer resuspendiert, mit $20 \mu \mathrm{l}$ Lysozym Lösung (siehe 2.4.1) versetzt und 5 min bei Raumtemperatur inkubiert. Nach der schnellen Zugabe von $300 \mu \mathrm{H}_{2} \mathrm{O}$ bidest. wurde die Suspension für 15 min in einem Heizblock bei $73^{\circ} \mathrm{C}$ inkubiert. Im Anschluß an eine Zentrifugation für 15 min wurde der Überstand in ein Eppendorf Reaktionsgefäß überführt, zunächst mit $30 \mu \mathrm{l}$ Natriumperchlorat Lösung (siehe 2.4.1) und dann mit $400 \mu \mathrm{l}$ Isopropanol versetzt, kurz geschüttelt und für 15 min zentrifugiert. Nachdem der Überstand quantitativ abgenommen worden war, wurde das DNA Sediment 15 min bei $37^{\circ} \mathrm{C}$ getrocknet und anschließend in $60 \mu \mathrm{l}$ TE Puffer (siehe 2.4.1) resuspendiert. Die Plasmid Lösung wurde bei $4{ }^{\circ} \mathrm{C}$ gelagert.

\subsection{Klonierung von DNA}

\subsubsection{Spaltung von DNA durch Typ II Restriktionsendonukleasen}

Zur sequenzspezifischen enzymatischen Spaltung von DNA wurde jeweils pro $\mu \mathrm{g}$ DNA eine Enzymeinheit (1 U) der Restriktionsendonuklease eingesetzt. Die Spaltung wurde in dem vom Hersteller der jeweiligen Restriktionsendonuklease mitgelieferten Reaktionspuffer unter den angegebenen Reaktionsbedingungen durchgeführt.

Reaktionsansatz:

$10 \mu \mathrm{l}$ DNA Lösung (10 $\mu \mathrm{g}$ DNA)

$5 \mu \mathrm{l} 10$ fach konzentrierter Reaktionspuffer

$1 \mu \mathrm{l}$ Restriktionsendonuklease (10 U/ $\mathrm{Ul})$

Der Ansatz wurde mit autoklaviertem $\mathrm{H}_{2} \mathrm{O}$ bidest. auf ein Volumen von $50 \mu \mathrm{l}$ aufgefüllt. 
Zur analytischen Spaltung wurde der Reaktionsansatz $1 \mathrm{~h}$, zur präparativen Spaltung $2 \mathrm{~h}$ bei $37^{\circ} \mathrm{C}$ inkubiert. Zur Inaktivierung der Restriktionsendonukleasen nach der Spaltung wurde jeweils eine Phenol Extraktion (siehe 2.6.3) durchgeführt.

\subsubsection{Glätten von überhängenden Enden nach der Spaltung}

Zur Ligation inkompatibler Enden der DNA Fragmente wurden diese unter der Verwendung des Klenow-Fragments der DNA Poymerase I aus E. coli, dem die $5^{\prime} \rightarrow 3^{\prime}$ Exonucleaseaktivität des Holoenzyms fehlt, geglättet.

Reaktionsansatz:

$10 \mu \mathrm{l}$ DNA Lösung (1-5 $\mu \mathrm{g}$ DNA)

$5 \mu \mathrm{l}$ 10fach konzentrierter Reaktionspuffer

5 ul $1 \mathrm{mM}$ dNTP

$0,2 \mu \mathrm{l} \mathrm{Klenow-Fragment} \mathrm{(10} \mathrm{U/ \mu l)}$

Der Ansatz wurde mit autoklaviertem $\mathrm{H}_{2} \mathrm{O}$ bidest. auf ein Volumen von $50 \mu \mathrm{l}$ aufgefüllt.

Nach der Inkubation des Reaktionsansatzes für 15 min bei RT wurde zur Entfernung des Klenow-Fragments eine Phenol Extraktion, wie in 2.6.3 beschrieben, durchgeführt.

\subsubsection{DNA Dephosphorylierung durch Alkaline Phosphatase}

Zur Verhinderung einer Rückligation linearisierter Vektoren wurden die 5' Phosphatreste durch eine Behandlung mit CIP („calf intestinal alkaline phosphatase“) entfernt.

Reaktionsansatz:

$10 \mu \mathrm{DNA}(0,5-2 \mu \mathrm{g})$

5 ul 10fach konzentrierter Reaktionspuffer

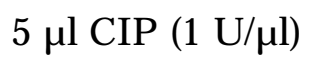

Der Ansatz wurde mit autoklaviertem $\mathrm{H}_{2} \mathrm{O}$ bidest. auf ein Volumen von $50 \mu \mathrm{l}$ aufgefüllt.

Nach der Inkubation des Reaktionsansatzes für 30 min bei $37^{\circ} \mathrm{C}$ wurde die DNA elektrophoretisch mit einem präparativen Agarosegel gereinigt (siehe 2.6.1) und, wie in 2.6 .2 beschrieben, isoliert. 


\subsubsection{Ligation von DNA Fragmenten}

Die Ligation von DNA Fragmenten mit der linearisierten Vektor DNA erfolgte in einem molaren Verhältnis von 3:1 unter der Verwendung der T4-DNA Ligase und dem vom Hersteller mitgelieferten Reaktionspuffer.

Ligationsansatz:

20 ng Vektor DNA

60 ng Fragment DNA

$2 \mu \mathrm{l} 10$ fach konzentrierter Reaktionspuffer

$1 \mu \mathrm{l}$ Ligase $(1 \mathrm{U} / \mu \mathrm{l})$

Der Ansatz wurde mit TE Puffer (siehe 2.4.1) auf ein Volumen von $20 \mu \mathrm{l}$ aufgefüllt.

Nach der Inkubation des Reaktionsansatzes für $1 \mathrm{~h}$ bei RT wurden mit $5 \mu \mathrm{l}$ des Ansatzes $100 \mu \mathrm{l}$ kompetente E. coli (siehe 2.2), wie in 2.3 beschrieben, transformiert.

\subsection{Trennung und Aufreinigung von DNA Fragmenten}

\subsubsection{Trennung von Fragmenten durch Agarose-Gelelektrophorese}

Die elektrophoretische Trennung von DNA Fragmenten beruht auf der negativen Ladung ihrer Phosphatgruppen, durch die eine Bewegung im elektrischen Feld zur Anode hervorgerufen wird. Die Trennung der DNA Fragmente erfolgt durch eine Matrix aus Agarose, in der die Fragmente entsprechend ihrer Größe mit unterschiedlichen Geschwindigkeiten wandern.

Lösungen:

TBE (0,5fach konzentriert):

$5,4 \mathrm{~g} / 1$ Tris

$2,75 \mathrm{~g} / 1$ Borsäure

$2 \mathrm{ml}$ 0,5 M EDTA in $\mathrm{H}_{2} \mathrm{O}$ bidest.; $\mathrm{pH} 8,0$

in $\mathrm{H}_{2} \mathrm{O}$ bidest.

DNA Probenpuffer (6fach konzentriert):

0,25\% (w/v) Bromphenolblau

$0,25 \%$ (w/v) Xylencyanol FF

$15 \%(w / v)$ Ficoll 400

in $\mathrm{H}_{2} \mathrm{O}$ bidest. 
Ethidiumbromid Lösung:

$10 \mathrm{mg} / \mathrm{ml}$ Ethidiumbromid in $\mathrm{H}_{2} \mathrm{O}$ bidest.

Die zur Auftrennung der DNA Fragmente benötigte Menge Agarose (siehe Tabelle 2.6-1) wurde mit TBE versetzt und durch Aufkochen gelöst. Nach dem Abkühlen auf ca. $50^{\circ} \mathrm{C}$ wurde die Lösung mit $0,5 \mu \mathrm{g} / \mathrm{ml}$ Ethidiumbromid für analytische Gele bzw. 0,05 $\mu \mathrm{g} / \mathrm{ml}$ Ethidiumbromid für präparative Gele versetzt, in einen Flachbett Gelträger gegossen und mit einem Kamm zur Formung der Probentaschen versehen. Nach dem vollständigen Erstarren des Gels wurde der Kamm entfernt, das Gel in die Elektrophoresekammer eingesetzt und mit TBE überschichtet. Nach dem Versetzen der DNA Proben mit Probenpuffer wurden diese in die Probentaschen gefüllt und mit $10 \mathrm{~V} / \mathrm{cm}$ für analytische Gele bzw. $5 \mathrm{~V} / \mathrm{cm}$ für präparative Gele elektrophoretisch aufgetrennt. Zur Bestimmung der Größe der DNA Fragmente wurde zusätzlich mit der Restriktionsendonuklease PstI gespaltene Lambda DNA (MBI Fermentas, St. Leon-Rot, Deutschland) als Längenstandard aufgetrennt. Die Detektion der DNA in dem Gel erfolgte mit Hilfe eines Transilluminators bei einer Wellenlänge von $366 \mathrm{~nm}$ anhand der UV Licht induzierten Fluoreszenz des mit der DNA interagierenden Ethidiumbromids. Im Anschluß an die präparative Agarose-Gelelektrophorese wurde die DNA aus dem Agarosegel extrahiert (siehe 2.6.2).

Tabelle 2.6-1: Trennbereich von Agarosegelen

\begin{tabular}{|c|c|}
\hline Agarose \% (w/v) & Trennbereich $(\mathrm{kb})$ \\
\hline 0,7 & $0,8-10$ \\
\hline 0,9 & $0,5-7$ \\
\hline 1,2 & $0,4-6$ \\
\hline 1,5 & $0,2-3$ \\
\hline
\end{tabular}

\subsubsection{Extraktion von DNA Fragmenten aus Agarosegelen}

Nach der elektrophoretischen Auftrennung der DNA Fragmente in Agarosegelen wurden die DNA enthaltenden Banden unter UV-Licht mit einem sterilen Skalpell aus dem Agarosegel ausgeschnitten. Zur Extraktion der DNA aus dem Gel wurde der „QIAquick Gel Extraction Kit“ (Qiagen, Hilden, Deutschland) verwendet. Die Durchführung erfolgte entsprechend den Angaben des Herstellers. 


\subsubsection{DNA Aufreinigung durch Phenol Extraktion}

Zur Entfernung der zur enzymatischen Modifikation der DNA eingesetzten Proteine aus dem Reaktionsansatz nach der Reaktion wurde eine Phenol Extraktion durchgeführt. Alle Zentrifugationsschritte erfolgten bei $13.000 \mathrm{~g}_{\max }$ in einer Eppendorf Tischzentrifuge.

\section{Lösungen:}

Phenol Lösung:

Auf $\mathrm{pH}$ 8,0 equilibriertes, mit 8-Hydroxychinolin stabilisiertes Phenol (AppliChem, Darmstadt, Deutschland)

$\mathrm{NaClO}_{4}$ Lösung:

$5 \mathrm{M} \mathrm{NaClO}_{4}$ in $\mathrm{H}_{2} \mathrm{O}$ bidest.

$50 \mu \mathrm{l}$ der zu extrahierenden DNA Lösung wurden nacheinander mit $25 \mu \mathrm{l}$ Phenol und $50 \mu \mathrm{l}$ Chloroform in einem Eppendorf Reaktionsgefä $ß$ versetzt und jeweils heftig geschüttelt. Nach einer Zentrifugation für 5 min zur Trennung der wäßrigen, DNA-haltigen Phase von der phenolischen, proteinhaltigen Phase wurde die wäßrige Phase abgenommen, mit $50 \mu$ Chloroform versetzt und nochmals heftig geschüttelt. Im Anschluß an eine Zentrifugation für 5 min wurde die wäßrige Phase abgenommen, nacheinander mit $5 \mu \mathrm{l}$ der $\mathrm{NaClO}_{4}$ Lösung und $60 \mu \mathrm{l}$ Isopropanol versetzt, sorgfältig vermischt und 10 min zentrifugiert. Danach wurde die Lösung vollständig mit einer ausgezogenen Pasteurpipette abgesaugt, das DNA Sediment 1 min bei RT getrocknet und schließlich in TE Puffer (siehe 2.4.1) resuspendiert.

\subsubsection{Bestimmung von Konzentration und Reinheit der DNA}

Die Konzentration von DNA in wäßrigen Lösungen wurde photometrisch durch die Messung der Extinktion der Lösung bei einer Wellenlänge von $260 \mathrm{~nm}$ bestimmt. Hierbei entspricht ein Extinktionswert von 1 einer Konzentration von $50 \mu \mathrm{g} / \mathrm{ml}$ doppelsträngiger DNA, $40 \mu \mathrm{g} / \mathrm{ml}$ einzelsträngiger DNA und $20 \mu \mathrm{g} / \mathrm{ml}$ einzelsträngiger Oligonukleotide. Durch die zusätzliche Messung der Extinktion bei einer Wellenlänge von $280 \mathrm{~nm}$, dem Extinktionsmaximum von Proteinen und Phenol, und der Berechnung des Quotienten aus $\mathrm{E}_{280} / \mathrm{E}_{260}$, der bei reinen DNA Lösungen zwischen 1,8 und 2 liegt, wurde die Reinheit der DNA Lösung beurteilt.

Als weitere Methode zur Konzentrationsbestimmung diente die AgaroseGelelektrophorese, indem die Intensitäten der Fluoreszenz des Ethidiumbromids in den zu analysierenden Proben mit Lösungen bekannter DNA Konzentration verglichen wurden. Diese Methode wurde angewandt, wenn eine genauere Bestimmung nicht erforderlich oder nicht möglich war. 


\subsection{DNA Amplifikation durch Polymerase Kettenreaktion (PCR)}

Die Polymerase Kettenreaktion ist ein zyklischer Prozeß, der die selektive in vitro Amplifikation bekannter DNA Sequenzen mit Hilfe von zwei sequenzspezifischen Oligonukleotidprimern ermöglicht. Im Verlauf eines Reaktionszyklus wird zunächst die als Matrize zur Amplifikation dienende doppelsträngige DNA bei $95^{\circ} \mathrm{C}$ in ihre Einzelstränge getrennt (Schmelzen). Nach dem Abkühlen lagert sich der „sense“ Primer an den codogenen DNA Strang und der „antisense“ Primer an den komplementären DNA Strang an. Im weiteren Verlauf werden die Oligonukleotidprimer durch den Einbau von Desoxynukleotiden (dNTP) von der DNA Polymerase verlängert (Polymerisation). Durch die erneute Trennung der nun doppelsträngigen DNA bei $95^{\circ} \mathrm{C}$ wird ein neuer Amplifikationszyklus eingeleitet.

Die zur PCR Amplifikation als Matrize eingesetzte „first-strand“ cDNA aus 5 Tage alten Arabidopsis thaliana Keimlingen wurde von Dr. J. Denecke (Universität York, UK) zur Verfügung gestellt. Die Synthese der eingesetzten Oligonukleotidprimer wurde bei der Firma NAPS (Göttingen, Deutschland) in Auftrag gegeben.

ARF sense Primer: 5'- GATCAGGATCCGGTTGTCATTCGG -3'

ARF antisense Primer: 5'- GCTAGAATTCCATCTATGCCTTGCTTGCGAT -3'

PCR Reaktionsansatz:

5 ul 10fach konzentrierter Reaktionspuffer

$3 \mathrm{mM} \mathrm{MgCl}{ }_{2}$

$0,2 \mathrm{mM}$ dNTP

10 pmol ARF sense Primer

10 pmol ARF antisense Primer

$1 \mathrm{ng}$,total first-strand“ cDNA

$0,2 \mu \mathrm{l}$ Taq-Polymerase (5 U/ $\mu \mathrm{l})$

Der Reaktionsansatz wurde mit sterilem $\mathrm{H}_{2} \mathrm{O}$ bidest. auf $50 \mu \mathrm{l}$ aufgefüllt.

PCR Programm (40 Reaktionszyklen):

1. Schmelzen: $\quad 95{ }^{\circ} \mathrm{C} ; 30 \mathrm{~s}$

2. Anlagerung: $\quad 55^{\circ} \mathrm{C} ; 60 \mathrm{~s}$

3. Polymerisation: $\quad 72^{\circ} \mathrm{C} ; 60 \mathrm{~s}$

Nach dem letzten Reaktionszyklus wurde der Reaktionsansatz für weitere $30 \mathrm{~min}$ bei $72^{\circ} \mathrm{C}$ inkubiert und anschließend auf $4{ }^{\circ} \mathrm{C}$ abgekühlt.

In ein PCR Reaktionsgefäß wurde der Reaktionspuffer, die $\mathrm{MgCl}_{2}$ Lösung, die dNTP Lösung, beide Primer, die cDNA und das $\mathrm{H}_{2} \mathrm{O}$ bidest. vorgelegt und mit PCR Öl überschichtet. Nach der Inkubation des Ansatzes für 1 min bei $95{ }^{\circ} \mathrm{C}$ wurde die Reaktion durch die Zugabe der Taq-Polymerase gestartet und das Programm des 
Thermocyclers (MJ Research PTC-200, Watertown, USA) aktiviert. Im Anschluß an die Reaktion wurde das Amplifikationsprodukt durch AgaroseGelelektrophorese analysiert (siehe 2.6.1) und im weiteren Verlauf durch eine Phenol Extraktion (siehe 2.6.3) aus dem Reaktionsansatz isoliert.

\subsection{DNA Sequenzierung}

Die Sequenzierung von DNA erfolgte nach dem Funktionsprinzip der Kettenabbruchmethode (Sanger et al., 1977) und wurde in einer modifizierten Form durchgeführt. Hierbei wurde zur Sequenzierung eine PCR Reaktion (siehe 2.7) mit der zu sequenzierenden DNA als Matrize, nur einem Primer („cycle sequencing“), den dNTP und mit unterschiedlich fluoreszierenden Farbstoffen markierte DidesoxydNTP (ddNTP), die bei ihrem Einbau durch die Polymerase zu einem Abbruch der Polymerasereaktion führen, durchgeführt.

Sequenzierprimer:

M13/pUC: 5'-d (GTAAAACGACGGCCAGT) -3’

M13/pUC reverse: 5'-d (CAGGAAACAGCTATGAC) -3'

(MBI Fermentas, St. Leon-Rot, Deutschland)

PCR Ansatz zur Sequenzierung:

$2 \mu \mathrm{l}$ AmpliTaq FS BigDye Terminator „ready-reaction mix“ (PE Applied Biosystems, Foster City, USA)

2 pmol Primer 350 ng DNA

Der Reaktionsansatz wurde mit sterilem $\mathrm{H}_{2} \mathrm{O}$ bidest. auf $10 \mu \mathrm{l}$ aufgefüllt.

PCR Programm (25 Reaktionszyklen):

1. Schmelzen: $\quad 95{ }^{\circ} \mathrm{C} ; 10 \mathrm{~s}$

2. Anlagerung: $\quad 50{ }^{\circ} \mathrm{C} ; 5 \mathrm{~s}$

3. Polymerisation: $\quad 60^{\circ} \mathrm{C} ; 4$ min

Nach dem letzten Reaktionszyklus wurde der Reaktionsansatz auf $4{ }^{\circ} \mathrm{C}$ abgekühlt.

Nach Beendigung des PCR Programms wurde der Reaktionsansatz in ein Eppendorf Reaktionsgefäß überführt, mit $100 \mu \mathrm{EtOH}$ versetzt, geschüttelt und 15 min bei RT inkubiert. Nachdem die DNA in einer Eppendorf Zentrifuge 15 min bei $14.000 \mathrm{~g}_{\max }$ sedimentiert worden war, wurde sie erneut mit $100 \mu \mathrm{LtOH}$ versetzt und nochmals zentrifugiert. Im Anschluß wurde der Überstand vollständig mit einer ausgezogenen Pasteurpipette abgenommen und das DNA Sediment 1 min bei $90{ }^{\circ} \mathrm{C}$ getrocknet. Im weiteren Verlauf wurde die DNA mit $15 \mu \mathrm{TSR}$ (PE Applied 
Biosystems, Foster City, USA) versetzt, 2 min bei $95{ }^{\circ} \mathrm{C}$ gekocht und sofort auf Eis überführt. Im Anschluß wurden die DNA Fragmente mit Hilfe eines Sequenziergeräts (Abi Prism 310, PE Applied Biosystems, Foster City, USA) in einem Kapillargel elektrophoretisch aufgetrennt und anhand ihrer Fluoreszenz analysiert.

\subsection{Expression und Isolation von GST Fusionsproteinen}

Die Expression von GST Fusionsproteinen in E. coli erfolgte mit Hilfe des Expressionsvektors pGEX-3X (Pharmacia, Freiburg, Deutschland).

Lösungen:

IPTG Lösung:

$100 \mathrm{mM}$ IPTG in $\mathrm{H}_{2} \mathrm{O}$ bidest.

Die Lösung wurde sterilfiltriert und bei $20^{\circ} \mathrm{C}$ gelagert.

PBS:

$16 \mathrm{mM} \mathrm{Na}_{2} \mathrm{HPO}_{4}$

$4 \mathrm{mM} \mathrm{NaH}_{2} \mathrm{PO}_{4}$

$150 \mathrm{mM} \mathrm{NaCl}$

in $\mathrm{H}_{2} \mathrm{O}$ bidest.; mit $\mathrm{HCl}$ wurde $\mathrm{pH}$ 7,3 eingestellt.

PBS-T:

$1 \%(\mathrm{v} / \mathrm{v})$ Triton X-100 in PBS

PMSF Lösung:

$10 \mathrm{mM}$ PMSF in Isopropanol

Die Lösung wurde bei $20^{\circ} \mathrm{C}$ gelagert.

Waschpuffer:

$50 \mathrm{mM}$ Tris/HCl; $\mathrm{pH} 8,0$

Elutionspuffer:

50 mM Tris/HCl; pH 8,0

$10 \mathrm{mM}$ Glutathion

in $\mathrm{H}_{2} \mathrm{O}$ bidest.

Dialysepuffer:

$10 \mathrm{mM}$ Tris/HCl; $\mathrm{pH}$ 7,5

in $\mathrm{H}_{2} \mathrm{O}$ bidest. 
Zur Expression von Fusionsproteinen wurde von einem transformierten Klon eine $100 \mathrm{ml}$ Flüssigkultur in $\mathrm{LB}_{\mathrm{AMP}}$ Medium angelegt und, wie in 2.1.3 beschrieben, $12 \mathrm{~h}$ inkubiert. Mit je $50 \mathrm{ml}$ dieser Vorkultur wurden je $500 \mathrm{ml} \mathrm{LB} \mathrm{LMP}_{\mathrm{AM}}$ Medium angeimpft und bis zum Erreichen einer optischen Dichte (OD) von 0,6 bei einer Wellenlänge von $580 \mathrm{~nm}$ inkubiert. Zur Induktion der Genexpression wurden beide Kulturen final mit $1 \mathrm{mM}$ IPTG aus einer $100 \mathrm{mM}$ Stammlösung in $\mathrm{H}_{2} \mathrm{O}$ bidest. versetzt. Die Expression erfolgte über einen Zeitraum von $3 \mathrm{~h}$ auf einer Rundschüttelmaschine bei $230 \mathrm{Upm}$ und $28^{\circ} \mathrm{C}$. Im Anschluß wurden die E. coli durch eine Zentrifugation bei $5.000 \mathrm{~g}_{\max }$ für 15 min (Sorvall RC5B; Rotor: Sorvall GS3) geerntet, mit $250 \mathrm{ml}$ PBS gewaschen und nochmals bei $5.000 \mathrm{~g}_{\max }$ für $15 \mathrm{~min}$ zentrifugiert (Sorvall RC5B; Rotor: Sorvall SLA 1000). Nach der Abnahme des Überstands wurden die Zellen in flüssigem Stickstoff eingefroren und bis zur Isolation der Fusionsproteine bei $-80^{\circ} \mathrm{C}$ gelagert.

Zur Kontrolle der Proteinexpression wurde von den Kulturen vor der Induktion der Expression und nach der dreistündigen Expression jeweils $1 \mathrm{ml}$ abgenommen und die Zellen in einer Eppendorf Zentrifuge 5 min bei $13.000 \mathrm{~g}_{\max }$ sedimentiert. Im Anschluß wurden die Zellen in $120 \mu \mathrm{l}$ PBS resuspendiert, mit $60 \mu \mathrm{l}$ dreifach konzentriertem Probenpuffer (siehe 2.20.1) versetzt, 5 min bei $95{ }^{\circ} \mathrm{C}$ gekocht und elektrophoretisch aufgetrennt (siehe 2.20.3). Nach dem Western-Blotting (siehe 2.21) wurden die GST Fusionsproteine mit Hilfe von GST Antikörpern (siehe 2.21.3) detektiert.

Zur Isolation der Fusionsproteine wurden die E. coli Sedimente auf Eis aufgetaut und mit $40 \mathrm{ml}$ eiskaltem PBS-T resuspendiert. Nach der Zugabe von 0,1 mM PMSF und $0,1 \%(\mathrm{v} / \mathrm{v}) \beta$-Mercaptoethanol wurde die Suspension mit Ultraschall durch sechs Impulse zu je $30 \mathrm{~s}$ homogenisiert (Branson Ultrasonic, Danbury, USA). Nachdem die Zelltrümmer durch eine Zentrifugation bei $12.000 \mathrm{~g}_{\max }$ für $30 \mathrm{~min}$ (Sorvall RC5B; Rotor: HB4) abgetrennt worden waren, wurde der Überstand mit $500 \mu \mathrm{l}$ zuvor in PBS-T äquilibrierter Glutathion-Sepharose 4B (Pharmacia, Freiburg, Deutschland) versetzt und auf einem Rotationsinkubator für $30 \mathrm{~min}$ bei $4{ }^{\circ} \mathrm{C}$ inkubiert. Im Anschluß wurde die Sepharose mit den gebundenen Fusionsproteinen durch eine $20 \mathrm{~cm} * 1 \mathrm{~cm}$ Leersäule filtriert, zweimal mit je $20 \mathrm{ml}$ PBS-T und zweimal mit je $20 \mathrm{ml}$ Waschpuffer gewaschen. Nachdem die Fusionsproteine mit $2 \mathrm{ml}$ Elutionspuffer von der Sepharose eluiert worden waren, wurde das Eluat zu gleichen Teilen mit zweifach konzentriertem Probenpuffer versetzt (siehe 2.20.1), 5 min bei $95{ }^{\circ} \mathrm{C}$ gekocht und elektrophoretisch aufgetrennt (siehe 2.20.3). Nach der Färbung der Proteine in dem SDS-Polyacrylamidgel (siehe 2.20.4) wurden diese durch Elektroelution isoliert (siehe 2.20.5) und dreimal $4 \mathrm{~h}$ gegen je 11 Dialysepuffer dialysiert (siehe 2.17). Im Anschluß daran wurden die Proteine lyophylisiert und zur Herstellung von Antikörpern als Antigen eingesetzt. 


\subsection{Herstellung von Antikörpern}

Zur Herstellung von Antikörpern gegen die isolierten Fusionsproteine wurden Kaninchen dreimal im Abstand von 14 Tagen und nochmals nach weiteren 28 Tagen mit je $100 \mu \mathrm{g}$ des Fusionsproteins immunisiert. Zur Beurteilung des Verlaufs der Immunantwort wurde den Kaninchen unmittelbar vor der ersten Immunisierung und 38 Tage bzw. 66 Tage nach der ersten Immunisierung Blut entnommen, bevor nach 80 Tagen die finale Blutung erfolgte. Die Immunisierung und die Gewinnung der Seren wurde bei der Firma Eurogentec (Herstal, Belgien) in Auftrag gegeben.

\subsection{Transiente Genexpression in Tabakprotoplasten}

\subsubsection{Isolierung von Protoplasten aus Tabakblättern}

Die Isolierung von Protoplasten aus Tabakblättern erfolgte ausgehend von den in 2.1.2 beschriebenen Tabakpflanzen unter sterilen Bedingungen.

TEX Puffer:

$500 \mathrm{mg} / \mathrm{l} \mathrm{MES} / \mathrm{KOH} ; \mathrm{pH}$ 5,7

3,1 g/l Gamborg B5 Medium

$400 \mathrm{mM}$ Saccharose

$750 \mathrm{mg} / 1 \mathrm{CaCl}_{2} \cdot 2 \mathrm{H}_{2} \mathrm{O}$

$250 \mathrm{mg} / \mathrm{l} \mathrm{NH} \mathrm{NO}_{3}$

in $\mathrm{H}_{2} \mathrm{O}$ bidest.

Die Lösung wurde sterilfiltriert und bei RT gelagert.

Elektroporationspuffer:

10 mM HEPES/KOH; $\mathrm{pH} 7,2$

$400 \mathrm{mM}$ Saccharose

$600 \mathrm{mg} / \mathrm{l} \mathrm{CaCl}_{2}$

$6 \mathrm{~g} / \mathrm{KCl}$

in $\mathrm{H}_{2} \mathrm{O}$ bidest.

Die Lösung wurde sterilfiltriert und bei RT gelagert.

Enzymlösung:

$0,4 \%(\mathrm{w} / \mathrm{v})$ Cellulase R10 ONOZUKA

$0,2 \%(\mathrm{w} / \mathrm{v})$ Mazerozym R10 ONOZUKA

in TEX Puffer

Die Lösung wurde sterilfiltriert und in $50 \mathrm{ml}$ Aliquots bei $-80^{\circ} \mathrm{C}$ gelagert.

Zur Isolation von Protoplasten wurden zunächst 7 Petrischalen mit jeweils $7 \mathrm{ml}$ Enzymlösung befüllt. Nachdem die Hauptleitbündel der Tabakblätter mit einem 
Skalpell entfernt und die untere Epidermis der Blatthälften in $1 \mathrm{~mm}$ Abständen vorsichtig eingeschnitten worden waren, wurden diese mit der Unterseite auf die Enzymlösung aufgelegt. Nach einer Inkubation für $20 \mathrm{~h}$ bei $26{ }^{\circ} \mathrm{C}$ wurden die Protoplastierungsansätze zur vollständigen Freisetzung der Protoplasten kurz geschüttelt und nochmals für $1 \mathrm{~h}$ bei $26^{\circ} \mathrm{C}$ inkubiert.

Zur Isolation der Protoplasten aus den Reaktionsansätzen wurden diese durch ein Nylonnetz mit einer Maschenweite von $100 \mu \mathrm{m}$ filtriert, in zwei 50 ml Reaktionsgefäße überführt und bei $80 \mathrm{~g}_{\max }$ für $15 \mathrm{~min}$ mit ungebremstem Auslauf zentrifugiert (Sigma 4K15; Rotor: 111563). Nachdem die Schicht der flotierten Protoplasten mit einer Pasteurpipette vorsichtig durchstochen worden war, wurde die Enzymlösung sowie die sedimentierten Zelltrümmer mit einer peristaltischen Pumpe (Watson Marlow 13S; $80 \mathrm{ml} / \mathrm{min}$ ) abgesaugt und die Protoplasten in je $25 \mathrm{ml}$ Elektroporationspuffer vorsichtig resuspendiert. Im Anschluß an eine Zentrifugation bei $100 \mathrm{~g}_{\max }$ für 10 min wurde die Lösung und sedimentierte Zelltrümmer erneut abgesaugt, die Protoplasten in je $10 \mathrm{ml}$ Elektroporationspuffer resuspendiert und in einem $50 \mathrm{ml}$ Reaktionsgefäß vereinigt. Dieser Waschschritt wurde noch 2 mal wiederholt, wobei nach der letzten Flotation die Protoplasten in ca. 5-8 ml Elektroporationspuffer aufgenommen wurden. Im Anschluß daran wurde die Anzahl der Protoplasten in der Suspension mit Hilfe einer Fuchs-Rosenthal Zählkammer (Tiefe 0,2 mm) bestimmt und mit Elektroporationspuffer auf eine Anzahl von ca. $4 * 10^{6}$ Protoplasten/ml eingestellt.

\subsubsection{Transformation der Tabakprotoplasten durch Elektroporation}

Die Transformation der in 2.11.1 isolierten Protoplastensuspension erfolgte unter sterilen Bedingungen bei Raumtemperatur.

Zur Transformation wurde zunächst eine Elektroporationslösung aus der für das jeweilige Experiment benötigten Plasmid DNA (siehe 2.4.1) hergestellt. Hierzu wurde die entsprechende Menge einer Plasmid Lösung oder der verschiedenen Plasmid Lösungen bei Co-Elektroporationsexperimenten in ein Eppendorf Reaktionsgefäß vorgelegt, mit Elektroporationspuffer (siehe 2.11.1) auf $100 \mu$ l aufgefüllt und sorgfältig gemischt. Im Anschluß wurden je $500 \mu \mathrm{l}$ der Protoplastensuspension in eine Halbmikroküvette vorgelegt, mit der Elektroporationslösung versetzt, kurz geschüttelt und 5 min inkubiert. Nach dem Einführen der Elektroden in die Küvette wurden die Protoplasten bei $160 \mathrm{~V}$ und $910 \mu \mathrm{F}$ elektroporiert und 30 min inkubiert. Die Elektroden wurden nach der Elektroporation zunächst in $\mathrm{H}_{2} \mathrm{O}$ bidest., dann in EtOH gewaschen, abgeflammt und mit Elektrodenpuffer für die nachfolgende Elektroporation abgekühlt. Im Anschluß wurden die Protoplasten in eine kleine Petrischale mit einem Durchmesser von $4 \mathrm{~cm}$ überführt, mit $2 \mathrm{ml}$ TEX Puffer (siehe 2.11.1) versetzt, kurz vorsichtig geschwenkt und zur Genexpression $24 \mathrm{~h}$ bei $25^{\circ} \mathrm{C}$ inkubiert. 
Plasmide zur transienten Genexpression:

$\boldsymbol{\alpha}$-Amylase: 35S-amylase-3‘nos in pUC18 (Crofts et al., 1999)

$\alpha$-Amylase-HDE L: 35S-amylase-HDEL-3'nos in pUC18 (Crofts et al., 1999)

AtSec12p: 35S-AtSec12-3'nos in pUC18 (Phillipson et al., 2001)

Calreticulin-myc: 35S-Calreticulin-myc-3‘nos in pUC18 (Crofts et al., 1999)

Cal reticulin-myc-HDE L: 35S-Calreticulin-myc-HDEL-3'nos in pUC18 (Crofts et al., 1999)

PAT: 35S-ssPAT-3'nos in pUC18 (Denecke et al., 1992)

PAT-HDEL: 35S-ssPAT-HDEL-3‘nos in pUC18 (Denecke et al., 1992)

PAT-KDEL: 35S-ssPAT-KDEL-3‘nos in pUC18 (Denecke et al., 1992)

PAT-RDEL: 35S-ssPAT-RDEL-3‘nos in pUC18 (Denecke et al., 1992)

PAT-SDEL: 35S-ssPAT-SDEL-3‘nos in pUC18 (Denecke et al., 1992)

PAT-KDDL: 35S-ssPAT-KDDL-3‘nos in pUC18 (Denecke et al., 1992)

PAT-KEEL: 35S-ssPAT-KEEL-3‘nos in pUC18 (Denecke et al., 1992)

PAT-KDEI : 35S-ssPAT-KDEI-3'nos in pUC18 (Denecke et al., 1992)

PAT-KDEV: 35S-ssPAT-KDEV-3‘nos in pUC18 (Denecke et al., 1992)

PAT cyt: 35S-PATcyt-3‘nos in pUC18 (Denecke et al., 1992)

AtSar 1p: 35S-AtSar1-3'nos in pUC18 (Phillipson et al., 2001)

AtSar 1p H 74L: 35S-AtSar1H74L-3‘nos in pUC18 (Phillipson et al., 2001)

Die Plasmide wurden von Dr. J. Denecke (Universität Leeds, UK) zur Verfügung gestellt.

\subsubsection{Ernten der Protoplasten und des Kulturmediums}

Zum Ernten der Protoplasten und des Kulturmediums nach der Genexpression (siehe 2.11.2) wurde der Ansatz in ein $15 \mathrm{ml}$ Reaktionsgefäß überführt und $5 \mathrm{~min}$ bei $100 g_{\max }$ zentrifugiert (Sigma 4K15; Rotor: 111563). Mit einer ausgezogenen Pasteurpipette wurde die Schicht der flotierten Protoplasten vorsichtig durchstochen und $1 \mathrm{ml}$ des Kulturmediums langsam abgesaugt, auf Eis überführt und im weiteren Verlauf zur Abtrennung von Zelltrümmern $10 \mathrm{~min}$ bei $4^{\circ} \mathrm{C}$ mit $13.000 \mathrm{~g}_{\max }$ in einer Eppendorf Zentrifuge zentrifugiert. Nach der Abnahme des Überstands wurde das Kulturmedium für weitere biochemische Charakterisierungen auf Eis aufbewahrt. Die verbliebenen Protoplasten wurden mit $10 \mathrm{ml}$ einer 250 $\mathrm{mM} \mathrm{NaCl}$ Lösung versetzt, kurz geschwenkt und 5 min bei $100 \mathrm{~g}_{\max }$ sedimentiert. 
Im Anschluß wurde die Lösung mit einer Wasserstrahlpumpe vollständig abgesaugt und das Protoplastensediment auf Eis überführt. Im weiteren Verlauf wurde entweder ein Gesamtzellextrakt der Protoplasten hergestellt oder die Endomembranen isoliert.

Zur Herstellung des Gesamtextrakts wurde das Protoplastensediment in einem finalen Volumen von $500 \mu$ l Extraktionspuffer (siehe 2.18) resuspendiert und mit Ultraschall durch einen Impuls für $5 \mathrm{~s}$ homogenisiert (Branson Ultrasonic, Danbury, USA). Nachdem die Zelltrümmer durch eine Zentrifugation mit $13.000 \mathrm{~g}_{\max }$ für 5 min bei $4^{\circ} \mathrm{C}$ sedimentiert worden waren, wurde der Überstand bis zur weiteren biochemischen Charakterisierung auf Eis aufbewahrt.

Zur Isolation der Endomembranen wurde das Protoplastensediment in einem finalen Volumen von $500 \mu \mathrm{l}$ mit Extraktionspuffer (siehe 2.18), der zuvor mit $12 \%$ (w/v) Saccharose versetzt worden war, resuspendiert und durch mehrmaliges Aufsaugen und Ausdrücken durch eine Injektionskanüle homogenisiert. Im Anschluß wurden die Membranen durch eine Zentrifugation bei $25.000 \mathrm{~g}_{\max }$ für 30 min sedimentiert, der cytosolhaltige Überstand auf Eis überführt, das Membransediment in Extraktionspuffer resuspendiert und bis zur weiteren Charakterisierung auf Eis aufbewahrt.

\subsection{Isolierung von cytosolischen Proteinen}

\subsubsection{Isolierung cytosolischer Proteine aus Blumenkohlinfloreszenzen}

Der Blumenkohl wurde frisch von einem Obst- und Gemüsefachgeschäft bezogen. Alle Arbeitsschritte wurden bei $4{ }^{\circ} \mathrm{C}$ durchgeführt.

\section{Lösungen:}

Homogenisationsmedium:

25 mM HEPES/KOH; $\mathrm{pH} 8,0$

$300 \mathrm{mM}$ Saccharose

$500 \mathrm{mM} \mathrm{KCl}$

$3 \mathrm{mM}$ EDTA

$1 \mathrm{mM}$ DTT

$2 \mathrm{mM}$ 1,10-Phenanthrolin

$1 \mu \mathrm{g} / \mathrm{ml}$ E64

$1,4 \mu \mathrm{g} / \mathrm{ml}$ Pepstatin

$1 \mu \mathrm{g} / \mathrm{ml}$ Leupeptin

$2 \mu \mathrm{g} / \mathrm{ml}$ Aprotinin

in $\mathrm{H}_{2} \mathrm{O}$ bidest. 
Dialysepuffer:

$25 \mathrm{mM}$ HEPES/KOH; $\mathrm{pH}$ 7,2

$50 \mathrm{mM} \mathrm{KCl}$

$1 \mathrm{mM}$ DTT

$10 \%(\mathrm{v} / \mathrm{v})$ Glyzerin

in $\mathrm{H}_{2} \mathrm{O}$ bidest.

Mit einem Skalpell wurden die obersten Zellschichten $(3 \mathrm{~mm})$ der Infloreszenzen abgeschnitten und sofort in eine Petrischale auf Eis überführt. Im Anschluß wurden $500 \mathrm{~g}$ der Infloreszenzen in $500 \mathrm{ml}$ Homogenisationsmedium mit Hilfe eines Waring-Blendors durch 3 Impulse von je 15 s homogenisiert. Das Rohhomogenat wurde durch eine Lage Miracloth (Calbiochem, Bad Soden, Deutschland) und zwei Lagen Mull filtriert und anschließend 15 min bei $10.000 \mathrm{~g}_{\max }$ zentrifugiert (Sorvall RC5B; Rotor: Sorvall SLA 1000). Der Überstand wurde abgenommen und 60 min bei $156.000 \mathrm{~g}_{\max }$ in einer Ultrazentrifuge (Kontron CENTRIKON T-1170; Rotor: Kontron TFT 50.38) zentrifugiert.

Nachdem der Überstand abgenommen worden war, wurden die darin enthaltenen Proteine unter langsamen Rühren durch die Zugabe von Ammoniumsulfat (65\% Sättigung) und einer einstündigen Inkubation auf Eis gefällt. Durch eine Zentrifugation bei $10.000 \mathrm{~g}_{\max }$ für 15 min (Sorvall OTD 65B; Rotor: Sorvall SLA 1000) wurden die gefällten Proteine sedimentiert, in $70 \mathrm{ml}$ Dialysepuffer mit Hilfe eines Glashomogenisators resuspendiert und fünfmal 25 min gegen je 21 Dialysepuffer dialysiert (siehe 2.17). Um das bei der Dialyse entstandene Präzipitat zu entfernen, wurde das Dialysat 60 min bei $156.000 \mathrm{~g}_{\max }$ mit einer Ultrazentrifuge (Kontron CENTRIKON T-1170; Rotor: Kontron TFT 50.38) zentrifugiert. Nach der Bestimmung des Proteingehalts (siehe 2.19.1) wurden die isolierten cytosolischen Proteine in $2 \mathrm{ml}$ Aliquots in flüssigem Stickstoff eingefroren und bei $-80{ }^{\circ} \mathrm{C}$ aufbewahrt.

\subsubsection{Isolierung cytosolischer Proteine aus Schweinehirn}

Die Isolierung von cytosolischen Proteinen aus Schweinehirn erfolgte im Anlehnung an die Methode von Malhotra et al., 1989. Das Schweinehirn wurde von einer Schlachterei (Dörbaum, Oberweser, Deutschland) sofort nach der Schlachtung zur Verfügung gestellt. Der Transport des Hirns erfolgte in einem Transportpuffer auf Eis. Nach dem Transport wurde das Hirn entweder zur Präparation der cytosolischen Proteine sofort verarbeitet oder zur späteren Verarbeitung in flüssigem Stickstoff eingefroren und bei $-80^{\circ} \mathrm{C}$ aufbewahrt. 
Lösungen:

Transportpuffer:

25 mM Tris/HCl; pH 7,4

$320 \mathrm{mM}$ Saccharose

in $\mathrm{H}_{2} \mathrm{O}$ bidest.

Homogenisationsmedium:

25 mM Tris/HCl; pH 8,0

$500 \mathrm{mM} \mathrm{KCl}$

$250 \mathrm{mM}$ Saccharose

$1 \mathrm{mM}$ DTT

2 mM EGTA

$2 \mu \mathrm{g} / \mathrm{ml}$ Aprotinin

$0,5 \mu \mathrm{g} / \mathrm{ml}$ Leupeptin

$2 \mu \mathrm{M}$ Pepstatin A

0,5 mM 1,10-Phenanthrolin

$1 \mathrm{mM}$ PMSF

in $\mathrm{H}_{2} \mathrm{O}$ bidest.

Dialysepuffer:

25 mM HEPES/KOH; pH 7,2

$50 \mathrm{mM} \mathrm{KCl}$

$1 \mathrm{mM}$ DTT

$10 \%$ (v/v) Glyzerin

in $\mathrm{H}_{2} \mathrm{O}$ bidest.

Die gesamte Durchführung erfolgte bei einer Temperatur von $4{ }^{\circ} \mathrm{C}$.

$200 \mathrm{~g}$ Hirn wurden in $200 \mathrm{ml}$ Homogenisationsmedium mit Hilfe eines WaringBlendors durch 2 Impulse von je $30 \mathrm{~s}$ homogenisiert. Nach einer Zentrifugation von $60 \mathrm{~min}$ bei $10.000 \mathrm{~g}_{\max }$ (Sorvall OTD 65B; Rotor: Sorvall SLA 1000) wurde der Überstand abgenommen und $120 \mathrm{~min}$ bei $156.000 \mathrm{~g}_{\max }$ in einer Ultrazentrifuge (Kontron CENTRIKON T-1170; Rotor: Kontron TFT 50.38) zentrifugiert. Der resultierende Überstand wurde abgenommen und zweimal $5 \mathrm{~h}$ gegen je $15 \mathrm{l}$ Dialysepuffer dialysiert (siehe 2.17). Das Präzipitat, das sich während der Dialyse gebildet hatte, wurde durch eine Zentrifugation bei $156.000 \mathrm{~g}_{\max }$ für $120 \mathrm{~min}$ (Kontron CENTRIKON T-1170; Rotor: Kontron TFT 50.38) sedimentiert.

Zur Fällung der Proteine wurde der Überstand abgenommen, langsam mit Ammoniumsulfat (60\% Sättigung) versetzt und $1 \mathrm{~h}$ auf Eis gerührt. Die gefällten Proteine wurden durch eine Zentrifugation bei $10.000 \mathrm{~g}_{\max }$ für $10 \mathrm{~min}$ (Sorvall OTD 65B; Rotor: Sorvall SLA 1000) sedimentiert, in $100 \mathrm{ml}$ Dialysepuffer mit Hilfe eines 
Glashomogenisators resuspendiert und $16 \mathrm{~h}$ gegen $15 \mathrm{l}$ Dialysepuffer, mit einem Pufferwechsel nach $8 \mathrm{~h}$, dialysiert. Das bei der Dialyse entstandene Präzipitat wurde durch eine Zentrifugation bei $156.000 \mathrm{~g}_{\max }$ für $120 \mathrm{~min}$ (Kontron CENTRIKON T-1170; Rotor: Kontron TFT 50.38) sedimentiert. Nach einer Bestimmung des Proteingehalts (siehe 2.19.1) wurde der Überstand in $2 \mathrm{ml}$ Aliquots in flüssigem Stickstoff eingefroren und bei $-80{ }^{\circ} \mathrm{C}$ aufbewahrt.

\subsection{Isolierung von ER- und Golgi-Membranen}

\subsubsection{Isolierung von ER- und Golgi-Membranen aus Blumenkohl}

Der Blumenkohl zur Isolierung einer angereicherten ER- und GolgiMembranfraktion wurde frisch aus dem institutseigenen Gewächshaus geerntet. Alle Arbeitsschritte wurden bei $4{ }^{\circ} \mathrm{C}$ durchgeführt.

Lösungen:

Homogenisationsmedium:

$25 \mathrm{mM}$ HEPES/KOH; $\mathrm{pH} 7,5$

$300 \mathrm{mM}$ Saccharose

$20 \mathrm{mM} \mathrm{KCl}$

$1 \mathrm{mM}$ DTT

$2 \mathrm{mM}$ 1,10-Phenanthrolin

$1 \mu \mathrm{g} / \mathrm{ml} \mathrm{E} 64$

$1,4 \mu \mathrm{g} / \mathrm{ml}$ Pepstatin

$1 \mu \mathrm{g} / \mathrm{ml}$ Leupeptin

$2 \mu \mathrm{g} / \mathrm{ml}$ Aprotinin

in $\mathrm{H}_{2} \mathrm{O}$ bidest.

Gradientengrundmedium:

$25 \mathrm{mM}$ HEPES/KOH; pH 7,2

$3 \mathrm{mM} \mathrm{MgCl}_{2}$

$0,1 \mathrm{mM}$ EDTA

$20 \mathrm{mM} \mathrm{KCl}$

in $\mathrm{H}_{2} \mathrm{O}$ bidest.

Saccharose Lösungen für diskontinuierliche Dichtegradienten:

$30 \%(\mathrm{w} / \mathrm{w})$ Saccharose in Gradientengrundmedium

$35 \%(\mathrm{w} / \mathrm{w})$ Saccharose in Gradientengrundmedium 
Mit einem Skalpell wurden die obersten Zellschichten $(3 \mathrm{~mm})$ der Infloreszenzen abgeschnitten und sofort in eine Petrischale auf Eis überführt. Je $35 \mathrm{~g}$ Frischgewicht wurden mit $30 \mathrm{ml}$ eiskaltem Homogenisationsmedium versetzt und $10 \mathrm{~min}$ mit einer Rasierklinge zerhackt. Im Anschluß wurde das grobe Homogenat $10 \mathrm{~min}$ gemörsert und durch eine Lage Miracloth (Calbiochem, Bad Soden, Deutschland) und zwei Lagen Mull filtriert. Zur Sedimentation von Zellwänden, Zellkernen, Mitochondrien und Plastiden wurde das Homogenat bei $10.000 \mathrm{~g}_{\max } 15 \mathrm{~min}$ vorzentrifugiert (Sorvall OTD 65B; Rotor: Sorvall HB4). Je $25 \mathrm{ml}$ des Überstands wurden auf einen diskontinuierlichen Saccharosedichtegradienten, der durch die Überschichtung von $5 \mathrm{ml}$ einer $35 \%$ igen Saccharose Lösung mit $5 \mathrm{ml}$ einer $30 \%$ igen Saccharose Lösung hergestellt worden war, aufgetragen. Nach einer isopyknischen Zentrifugation bei $100.000 \mathrm{~g}_{\max }$ für $3 \mathrm{~h}$ (Kontron CENTRIKON T-1170; Rotor: Kontron TST 28.38) wurden die Membranen der 30/35 \% Interphase der Saccharose Lösungen mit einer Pipette abgenommen, zu gleichen Volumenteilen mit Gradientengrundmedium verdünnt und mit Hilfe eines Glashomogenisators vorsichtig resuspendiert. Nach der Bestimmung der Proteinkonzentration (siehe 2.19.1) wurde die Membranfraktion $\left(\mathrm{M}_{0}\right)$ bis $\mathrm{zu}$ ihrer weiteren Verwendung auf Eis aufbewahrt.

\subsubsection{Isolierung von ER- und Golgi-Membranen aus Tabak}

Die Isolierung einer angereicherten ER- und Golgi-Membranfraktion aus Tabak erfolgte ausgehend von 8 Wochen alten Tabakpflanzen. Alle Arbeitsschritte wurden bei $4^{\circ} \mathrm{C}$ durchgeführt.

\section{Lösungen:}

Homogenisationsmedium:

$25 \mathrm{mM}$ HEPES/KOH; $\mathrm{pH} 7,5$

$300 \mathrm{mM}$ Saccharose

$20 \mathrm{mM} \mathrm{KCl}$

$10 \mathrm{mM}$ Ascorbat

$2 \mathrm{mM} \mathrm{Na}_{2} \mathrm{~S}_{2} \mathrm{O}_{5}$

$1 \mathrm{mM}$ DTT

$1 \mathrm{~g} / \mathrm{l}$ Polyvinylpyrrolidon

2 mM 1,10-Phenanthrolin

$1 \mu \mathrm{g} / \mathrm{ml} \mathrm{E64}$

$1,4 \mu \mathrm{g} / \mathrm{ml}$ Pepstatin

$1 \mu \mathrm{g} / \mathrm{ml}$ Leupeptin

$2 \mu \mathrm{g} / \mathrm{ml}$ Aprotinin

in $\mathrm{H}_{2} \mathrm{O}$ bidest. 
Gradientengrundmedium (siehe 2.13.1)

Saccharose Lösungen für diskontinuierliche Dichtegradienten:

$33 \%(\mathrm{w} / \mathrm{w})$ Saccharose in Gradientengrundmedium

$40 \%(\mathrm{w} / \mathrm{w})$ Saccharose in Gradientengrundmedium

Die Tabakblätter wurden mit einer Rasierklinge geerntet und mit $\mathrm{H}_{2} \mathrm{O}$ bidest. gewaschen, mit saugfähigem Papier kurz getrocknet und in eine Petrischale mit einem Durchmesser von $20 \mathrm{~cm}$ auf Eis überführt. Nach der Entfernung der großen Blattleitbündel wurden die Blattstücke zur Bestimmung des Frischgewichts gewogen. Die Homogenisation erfolgte indem $10 \mathrm{~g}$ Frischgewicht mit $30 \mathrm{ml}$ Homogenisationsmedium für 10 min gemörsert wurden. Zur Verringerung der Scherkräfte wurde das Homogenisationsmedium bis zum Gefrierpunkt abgekühlt und im halbgefrorenen Zustand verwendet. Dadurch blieb der größte Teil der Chloroplasten intakt, wodurch die Freisetzung von Tylakoidmembranen reduziert werden konnte. Das Rohhomogenat wurde danach durch eine Lage Miracloth (Calbiochem, Bad Soden, Deutschland) und zwei Lagen Mull filtriert und bei $10.000 \mathrm{~g}_{\max } 15$ min vorzentrifugiert (Sorvall OTD 65B; Rotor: Sorvall HB4). Je $15 \mathrm{ml}$ des Homogenats wurden auf einen diskontinuierlichen Saccharosedichtegradienten, der durch die Überschichtung von $5 \mathrm{ml}$ einer $40 \%$ igen Saccharose Lösung mit $15 \mathrm{ml}$ einer 33 \%igen Saccharose Lösung hergestellt worden war, aufgetragen. Im Anschluß an eine isopyknischen Zentrifugation bei $100.000 \mathrm{~g}_{\max }$ für $3 \mathrm{~h}$ (Kontron CENTRIKON T-1170; Rotor: Kontron TST 28.38) wurde die Interphase zwischen beiden Saccharose Lösungen mit einer Pipette abgenommen, mit gleichen Volumenteilen Gradientengrundmedium verdünnt und mit einem Glashomogenisator vorsichtig homogenisiert.

Nach der Bestimmung des Proteingehalts (siehe 2.19.1) wurde die angereicherte ER- Golgi-Membranfraktion $\left(\mathrm{M}_{0}\right)$ bis zu ihrer Verwendung auf Eis aufbewahrt.

\subsection{Dissoziation der endogenen Hüllproteine der COP Vesikel}

Die Dissoziation der endogenen Hüllproteine der COP Vesikel erfolgte ausgehend von den in 2.13 beschriebenen angereicherten ER- und Golgi-Membranfraktionen. Alle Zentrifugationsschritte wurden in einer Beckman TL-100 Zentrifuge mit dem Beckman Rotor TLA-100.3 durchgeführt.

Dissoziationspuffer:

$25 \mathrm{mM}$ HEPES/KOH; $\mathrm{pH} 7,2$

$200 \mathrm{mM}$ Saccharose

$300 \mathrm{mM} \mathrm{KJ}$

in $\mathrm{H}_{2} \mathrm{O}$ bidest. 
Induktionspuffer:

$25 \mathrm{mM}$ HEPES/KOH; $\mathrm{pH}$ 7,2

$200 \mathrm{mM}$ Saccharose

$20 \mathrm{mM} \mathrm{KCl}$

in $\mathrm{H}_{2} \mathrm{O}$ bidest.

Zur Überführung der Membranen in den Dissoziationspuffer wurden jeweils 1,5 ml der Fraktion bei $70.000 \mathrm{~g}_{\max }$ für 20 min zentrifugiert. Nach der Abnahme des Überstands wurde das Membransediment in $500 \mu$ Dissoziationspuffer durch mehrmaliges Aufsaugen und Ausdrücken mit einer Pipette resuspendiert. Im Anschluß wurden die Membranen 45 min auf einem Rotationsinkubator bei $4{ }^{\circ} \mathrm{C}$ inkubiert. Nach einer weiteren Zentrifugation bei $70.000 \mathrm{~g}_{\max }$ für 20 min wurden die Membranen in $200 \mu \mathrm{l}$ Induktionspuffer mit einer Pipette vorsichtig resuspendiert und der Proteingehalt bestimmt (siehe 2.19.1). Die Aufbewahrung dieser mit KJ behandelten Membranen $\left(\mathrm{M}_{\mathrm{KJ}}\right)$ bis zu den Rekrutierungs- bzw. Induktionsexperimenten erfolgte auf Eis.

\subsection{Rekrutierung der Hüllproteine der COP Vesikel in vitro}

Die Experimente zur in vitro Rekrutierung der Hüllproteine der COP Vesikel wurden sowohl an den Kaliumjodid behandelten Membranen $\left(\mathrm{M}_{\mathrm{KJ}}\right.$, siehe 2.14) als auch an den angereicherten ER- und Golgi-Membranfraktionen $\left(\mathrm{M}_{0}\right.$, siehe 2.13) jeweils in $4 \mathrm{ml}$ Ansätzen durchgeführt.

Induktionspuffer:

$25 \mathrm{mM}$ HEPES/KOH; $\mathrm{pH} 7,2$

$200 \mathrm{mM}$ Saccharose

$20 \mathrm{mM} \mathrm{KCl}$

in $\mathrm{H}_{2} \mathrm{O}$ bidest.

Zusammensetzung des Rekrutierungs-Ansatzes (4 ml):

$24 \mathrm{mg}$ cytosolische Proteine

$0,8 \mathrm{mg}$ Membranen

$50 \mu \mathrm{M}$ ATP

$250 \mu \mathrm{M}$ UTP

$20 \mu \mathrm{M}$ GTP $\gamma \mathrm{S}$

$200 \mu \mathrm{M}$ DTT

28 U Kreatinkinase

2 mM Kreatinphosphat

in Induktionspuffer 
Saccharose Lösungen für diskontinuierliche Dichtegradienten:

$20 \%(\mathrm{w} / \mathrm{w})$ Saccharose in Induktionspuffer

$25 \%(\mathrm{w} / \mathrm{w})$ Saccharose in Induktionspuffer

Der eiskalte Induktionspuffer mit ATP, UTP, GTP $\gamma$ S, DTT, der Kreatinkinase, dem Kreatinphosphat sowie den cytosolischen Proteinen wurde in einem $10 \mathrm{ml}$ Erlenmeyerkolben vorgelegt. Nach dem Start der Rekrutierungsreaktion durch die Zugabe der Membranen wurde der Rekrutierungsansatz in einem Wasserbad 25 min bei $20^{\circ} \mathrm{C}$ unter leichtem Schütteln inkubiert. Nach der Inkubation wurde der Ansatz zum Abkühlen 5 min in Eiswasser inkubiert und auf einen diskontinuierlichen Saccharosedichtegradienten, bestehend aus $4 \mathrm{ml} 25 \%$ iger und $4 \mathrm{ml} 20 \%$ iger Saccharose Lösung, aufgetragen. Durch eine isopyknische Zentrifugation für $3 \mathrm{~h}$ bei $100.000 \mathrm{~g}_{\max }$ (Kontron CENTRIKON T-1170; Rotor: Kontron TST 28.38) wurden die Membranen von den im Reaktionsansatz verbliebenen löslichen Proteinen getrennt. Nachdem die Stufen des Gradienten von oben nach unten vorsichtig abgesaugt worden waren, wurde das Membransediment $\left(\mathrm{M}_{R}\right)$ in Induktionspuffer resuspendiert. Direkt im Anschluß wurde die Proteinkonzentration des Gradientenüberstands $\left(\ddot{U}_{R}\right)$ und der Membranfraktion $\left(\mathrm{M}_{R}\right)$ bestimmt (siehe 2.19.1) und sofort mit Chloroform / Methanol gefällt (siehe 2.20.1).

\subsection{Induktion und Isolierung von COP Vesikeln in vitro}

\subsubsection{Induktion von COP Vesikeln in vitro}

Die Experimente zur in vitro Induktion von COP Vesikeln erfolgten an den Membranfraktionen $\mathrm{M}_{0}$ (siehe 2.13) und $\mathrm{M}_{\mathrm{KJ}}$ (siehe 2.14) in $8 \mathrm{ml}$ Induktionsansätzen. Die Zusammensetzung der Induktionsansätze und die Durchführung erfolgte analog zu den in 2.15 beschriebenen Rekrutierungsexperimenten bis zur Überführung des Ansatzes auf Eis.

\subsubsection{Isolierung einer angereicherten COP Vesikel Fraktion}

Die Isolierung einer angereicherten COP Vesikel Fraktion erfolgte im Anschluß an die in 2.16.1 beschriebene Induktion der Vesikel. Die gesamte Durchführung erfolgte bei $4{ }^{\circ} \mathrm{C}$.

Lösungen:

Dissoziationspuffer II:

$25 \mathrm{mM}$ HEPES/KOH; pH 7,2

$300 \mathrm{mM}$ Saccharose

$500 \mathrm{mM} \mathrm{KCl}$

in $\mathrm{H}_{2} \mathrm{O}$ bidest. 
Gradientenpuffer:

25 mM HEPES / KOH; $\mathrm{pH} 7,2$

$20 \mathrm{mM} \mathrm{KCl}$

2,5 mM Magnesiumacetat

in $\mathrm{H}_{2} \mathrm{O}$ bidest.

Lösungen für diskontinuierliche Saccharosedichtegradienten:

$20 \%(\mathrm{w} / \mathrm{w})$ Saccharose in Gradientenpuffer

$30 \%(\mathrm{w} / \mathrm{w})$ Saccharose in Gradientenpuffer

$40 \%$ (w/w) Saccharose in Gradientenpuffer

$50 \%(\mathrm{w} / \mathrm{w})$ Saccharose in Gradientenpuffer

$55 \%$ (w/w) Saccharose in Gradientenpuffer

$60 \%(\mathrm{w} / \mathrm{w})$ Saccharose in Gradientenpuffer

Schritt 1: Trennung von Membranen und löslichen cytosolischen Proteinen

In zwei $12 \mathrm{ml}$ Zentrifugenröhrchen wurden je $1 \mathrm{ml}$ der $55 \%$ igen Saccharose Lösung vorgelegt und mit jeweils $7 \mathrm{ml}$ der 20 \%igen Saccharose Lösung überschichtet. Nachdem je $4 \mathrm{ml}$ des Induktionsansatzes auf die Gradienten aufgetragen worden waren, wurden diese $3 \mathrm{~h}$ bei $100.000 \mathrm{~g}_{\max }$ zentrifugiert (Kontron CENTRIKON T-1170; Rotor: Kontron TST 28.38). Im Anschluß wurden die sedimentierten Membranen aus der 20/55\% Interphase der beiden Gradienten in einem Volumen von $1 \mathrm{ml}$ mit einer Pipette aufgenommen, vorsichtig resuspendiert und vereinigt.

Schritt 2: Dissoziation der Vesikel von den Membranen durch chaotrope Agenzien

Die $2 \mathrm{ml}$ Membranfraktion aus Schritt 1 wurde zur Dissoziation der induzierten Vesikel von den Membranen mit $2 \mathrm{ml}$ Dissoziationspuffer II verdünnt und für $45 \mathrm{~min}$ auf einem Rotationsinkubator bei $4{ }^{\circ} \mathrm{C}$ inkubiert. Im Anschluß wurde der Ansatz zur Trennung der Membranen und Vesikel $30 \mathrm{~min}$ bei $30.000 \mathrm{~g}_{\max }$ zentrifugiert (Beckman TL-100; Rotor: TLA-100.3). Der Überstand wurde abgenommen und zur weiteren Anreicherung der Vesikel eingesetzt.

\section{Schritt 3: Anreicherung der Vesikel}

Der $4 \mathrm{ml}$ Überstand aus Schritt 2 wurde auf einen linearen Saccharosedichtegradienten von $8 \mathrm{ml}$ Volumen aufgetragen, der durch die Überschichtung von je 1,6 ml der 60 \%igen, 50 \%igen, 40 \%igen, 30 \%igen und 20 \%igen Saccharose Lösung mit einer anschließenden Diffusionszeit von $2 \mathrm{~h}$ bei Raumtemperatur hergestellt worden war. Nach einer isopyknischen Zentrifugation bei $100.000 \mathrm{~g}_{\max }$ für $12 \mathrm{~h}$ (Kontron CENTRIKON T-1170; Rotor: Sorvall AH 
650) wurde der Saccharose Dichtegradient mit Hilfe einer peristaltischen Pumpe geerntet und in Fraktionen zu je 0,5 ml in Eppendorf Reaktionsgefäßen aufgefangen. Von jeder Fraktion wurde mit einem Handrefraktometer der Saccharosegehalt sowie die Proteinkonzentration (siehe 2.19.2) bestimmt.

\subsection{Dialyse von Proteinlösungen}

Zur Eliminierung von anhaftenden Proteasen wurden die Dialysemembranen (Typ 20, Biomol, Hamburg, Deutschland)) zunächst $30 \mathrm{~min}$ in einer $100 \mathrm{mM}$ EDTALösung und anschließend $30 \mathrm{~min}$ in $\mathrm{H}_{2} \mathrm{O}$ bidest. gekocht. Nachdem die Dialysemembranen noch fünfmal mit $\mathrm{H}_{2} \mathrm{O}$ bidest. für je $10 \mathrm{~min}$ gespült worden waren, wurden sie bei $4{ }^{\circ} \mathrm{C}$ in $30 \%$ (v/v) EtOH p.a. aufbewahrt. Vor der Verwendung wurden die Dialysemembranen dreimal mit $\mathrm{H}_{2} \mathrm{O}$ bidest. für je 15 min gespült. Die vorbereiteten Dialyseschläuche wurden mit der Proteinlösung befüllt, mit einer Klammer verschlossen und in den kalten Dialysepuffer $\left(4^{\circ} \mathrm{C}\right)$ gehängt. Die Dialyse erfolgte unter langsamen Rühren bei $4{ }^{\circ} \mathrm{C}$.

\subsection{Messung der $\alpha$-Amylaseaktivität}

Die Messung der Aktivität der $\alpha$-Amylase wurde mit Hilfe des „Cereal $\alpha$-amylase assay“ (Megazyme, Bray, Irland) durchgeführt. Hierbei trägt das zur Messung der $\alpha$-Amylaseaktivität eingesetzte Substrat p-Nitrophenol-Maltoheptaosid (BPNPG7) am nicht reduzierenden Ende eine 4,6-O-verknüpfte Benzylidingruppe, so daß seine Hydrolyse durch $\beta$-Amylase, Glucoamylase und $\alpha$-Glucosidase blockiert wird. Erst nach der Hydrolyse einer $\alpha$-1,4-glycosidischen Bindung innerhalb des Oligomers durch die $\alpha$-Amylase wird das entstandene p-Nitrophenyl-Maltosaccharid durch Glucoamylase und $\alpha$-Glucosidase in Glucose und p-Nitrophenol gespalten, wobei die Konzentration des freigesetzten p-Nitrophenols photometrisch bestimmt wird.

Lösungen:

Extraktionspuffer:

$50 \mathrm{mM}$ Maleinsäure

$80 \mathrm{mM} \mathrm{NaOH}$

$50 \mathrm{mM} \mathrm{NaCl}$

$2 \mathrm{mM} \mathrm{CaCl}{ }_{2}$

$0,005 \%(\mathrm{w} / \mathrm{v})$ Natriumazid

in $\mathrm{H}_{2} \mathrm{O}$ bidest.; $\mathrm{pH} 5,2$ mit $1 \mathrm{M} \mathrm{HCl}$ einstellen 
Substrat Lösung:

54,5 mg BPNPG7

$100 \mathrm{U} \alpha$-Glucosidase (bei pH 5,2)

100 U Glucoamylase (bei pH5,2)

in $10 \mathrm{ml} \mathrm{H}_{2} \mathrm{O}$ bidest.

Tris Lösung:

$1 \%(\mathrm{w} / \mathrm{v})$ Tris in $\mathrm{H}_{2} \mathrm{O}$ bidest.

Zur Messung der $\alpha$-Amylaseaktivität wurden die zu analysierenden Proben zunächst mit Extraktionspuffer verdünnt. Im Anschluß wurden je $30 \mu \mathrm{l}$ der Probe in ein Eppendorf Reaktionsgefäß vorgelegt, mit $30 \mu \mathrm{l}$ Substratlösung versetzt, kurz vermischt und in ein Wasserbad mit $40{ }^{\circ} \mathrm{C}$ überführt. Nach einer Inkubationszeit von 5-30 min wurde die Reaktion durch die Zugabe von je $150 \mu \mathrm{d}$ der Tris Lösung abgebrochen. Im Anschluß wurden die Reaktionsansätze in eine Mikrotestplatte (8*12 Vertiefungen) überführt und die Extinktion der Proben mit Hilfe eines Spektralphotometers bei einer Wellenlänge von $405 \mathrm{~nm}$ gemessen. Als Blindwert diente ein Testansatz, der anstelle der Probe das gleiche Volumen an Extraktionspuffer enthielt.

\subsection{Proteinbestimmungen}

\subsubsection{Proteinbestimmung nach Bradford}

Diese Methode der quantitativen Proteinbestimmung basiert auf der Bindung von Coomassie Blau an Argininresten von Proteinen, wodurch die Genauigkeit der Methode von dem Arginingehalt des zu untersuchenden Proteingemisches abhängig ist (Bradford, 1976). Der Vorteil der Methode liegt in der schnellen Durchführung.

Bradford Lösung:

70 mg Serva Blue G 250 (Serva 35050)

$50 \mathrm{ml}$ EtOH p.a.

$100 \mathrm{ml}$ o-Phosphorsäure (85\%)

$850 \mathrm{ml} \mathrm{H}_{2} \mathrm{O}$ bidest.

Zur Herstellung der Bradford Lösung wurden $70 \mathrm{mg}$ Serva Blue G250 in $50 \mathrm{ml}$ EtOH p.a. gelöst. Im Anschluß wurden dieser Lösung $850 \mathrm{ml} \mathrm{H}_{2} \mathrm{O}$ bidest. und $100 \mathrm{ml}$ o-Phosphorsäure zugesetzt.

In einem Eppendorf Reaktionsgefäß wurden $50 \mu \mathrm{l}$ Probe mit $1 \mathrm{ml}$ Bradford Lösung versetzt, kurz geschüttelt und 2 min bei Raumtemperatur inkubiert. Im Anschluß wurde die Extinktion mit Hilfe eines Spektralphotometers (Kontron, Uvikon 810) 
bei einer Wellenlänge von $595 \mathrm{~nm}$ gegen einen Nullwert, der aus dem jeweiligen Puffer der Probe bestand, gemessen. Zur Quantifizierung der gemessenen Extinktionswerte wurde mit BSA in $\mathrm{H}_{2} \mathrm{O}$ bidest. eine Eichreihe erstellt $(0-1,0 \mathrm{mg} / \mathrm{ml})$.

\subsubsection{Proteinbestimmung nach Peterson}

Die Grundlage dieses quantitativen Verfahrens ist die Bildung eines BiuretKomplexes aus $\mathrm{Cu}^{2+}$-Ionen und Peptidbindungen in alkalischen Lösungen, der das Folin-Ciocalteu-Phenol Reagenz, ein Phosphowolframat-Phosphomolybdat Komplex, reduziert, wodurch eine intensive Blaufärbung entsteht (Peterson, 1977).

Lösungen:

TCA Lösung:

$72 \%(\mathrm{w} / \mathrm{w})$ Trichloressigsäure in $\mathrm{H}_{2} \mathrm{O}$ bidest.

DOC Lösung:

$0,15 \%(\mathrm{w} / \mathrm{v})$ Natriumdesoxycholat in $\mathrm{H}_{2} \mathrm{O}$ bidest.

Kupfer-Tartrat-Carbonat (KTC) Lösung:

Lösung A: $\quad 10 \mathrm{~g} \mathrm{Na}_{2} \mathrm{CO}_{3}$ in $50 \mathrm{ml} \mathrm{H}_{2} \mathrm{O}$ bidest.

Lösung B: $\quad 0,2 \mathrm{~g}$ di-Kaliumtartrat $\bullet 0,5 \mathrm{H}_{2} \mathrm{O}$

$0,1 \mathrm{~g}$ Kupfersulfat $\bullet 0,5 \mathrm{H}_{2} \mathrm{O}$

in $40 \mathrm{ml} \mathrm{H}_{2} \mathrm{O}$ bidest.

Lösung A wurde langsam in Lösung $\mathrm{B}$ eingerührt und mit $\mathrm{H}_{2} \mathrm{O}$ bidest. auf ein Endvolumen von $100 \mathrm{ml}$ aufgefüllt.

SDS Lösung:

$10 \%(\mathrm{w} / \mathrm{v})$ Natriumdodecylsulfat in $\mathrm{H}_{2} \mathrm{O}$ bidest.

Folin Lösung:

1 Volumenteil Folin-Ciocalteau-Phenolreagenz (Sigma F 9252)

5 Volumenteile $\mathrm{H}_{2} \mathrm{O}$ bidest.

$\mathrm{NaOH}$ Lösung:

$0,8 \mathrm{M} \mathrm{NaOH}$ in $\mathrm{H}_{2} \mathrm{O}$ bidest. 
Lowry Reagenz:

5 Volumenteile $\mathrm{H}_{2} \mathrm{O}$ bidest.

1 Volumenteil $\mathrm{NaOH}$ Lösung

1 Volumenteil KTC Lösung

1 Volumenteil SDS Lösung

10-20 $\mu \mathrm{l}$ der Probe wurden in einem Eppendorf Reaktionsgefäß vorgelegt, mit $\mathrm{H}_{2} \mathrm{O}$ bidest. auf ein Volumen von $1 \mathrm{ml}$ aufgefüllt, mit $100 \mu \mathrm{l}$ DOC Lösung versetzt und 10 min bei Raumtemperatur inkubiert. Nach der Zugabe von $100 \mu$ l eiskalter TCALösung und einer weiteren Inkubation von 10 min auf Eis wurde der Reaktionsansatz in einer Eppendorf Zentrifuge 15 min bei $9000 \mathrm{~g}_{\max }$ zentrifugiert. Nach dem Abnehmen des Überstandes und dem Trocknen des verbliebenen Proteinsediments in dem Eppendorf Reaktionsgefäß bei Raumtemperatur wurde das Sediment in $1 \mathrm{ml}$ Lowry Reagenz resuspendiert und nach einer Inkubationszeit von exakt 10 min mit $250 \mu \mathrm{l}$ Folin Lösung versetzt. Mit Hilfe eines Spektralphotometers wurde 30 min später die Extinktion bei einer Wellenlänge von $750 \mathrm{~nm}$ gegen einen Nullwert, der anstelle der Probe nur den jeweiligen Puffer enthielt, gemessen.

Zur Berechnung der Proteinkonzentration wurde eine Eichreihe mit BSA von 0$15 \mu \mathrm{g}$ erstellt, deren gemessene Extinktionswerte gegen die eingesetzte BSA Konzentration aufgetragen wurden. Aus der Steigung dieser Eichkurve wurde unter Berücksichtigung des anfangs eingesetzten Probenvolumens und der gemessenen Extinktionswerte die Proteinkonzentration $[\mathrm{mg} / \mathrm{ml}]$ der Proben berechnet.

\subsection{SDS-Polyacrylamid-Gelelektrophorese}

Die Auftrennung von Proteinen nach ihrem Molekulargewicht erfolgte durch Natriumdodecylsulfat-Polyacrylamid-Gelelektrophorese (SDS-PAGE) mit diskontinuierlichen Gelen (Laemmli, 1970).

\subsubsection{Vorbereitung der Proben}

Probenpuffer:

$230 \mathrm{mM}$ Tris/HCl; $\mathrm{pH} 6,8$

$2 \%(\mathrm{w} / \mathrm{v}) \mathrm{SDS}$

$36 \%(\mathrm{v} / \mathrm{v})$ Glyzerin

$0,05 \%(\mathrm{w} / \mathrm{v})$ Bromphenolblau

4,5\% (v/v) 2-Mercaptoethanol

in $\mathrm{H}_{2} \mathrm{O}$ bidest. 
Zur Vorbereitung der Proben für die SDS-Gelelektrophorese wurde der Proteingehalt (siehe 2.19.2) bestimmt und im Anschluß daran eine Proteinfällung mit Chloroform / MeOH durchgeführt (Wessel \& Flugge, 1984). Hierzu wurden $100 \mu \mathrm{der}$ Probe nacheinander mit $400 \mu \mathrm{l} \mathrm{MeOH}, 100 \mu \mathrm{l}$ Chloroform und $300 \mu \mathrm{H}_{2} \mathrm{O}$ bidest. versetzt und jeweils mit einem Vortex Mixer sorgfältig gemischt. Nach einer Zentrifugation für $3 \mathrm{~min}$ bei $10.000 \mathrm{~g}_{\max }$ in einer Eppendorf Zentrifuge wurde die obere Phase abgenommen und die untere Phase mit $300 \mu \mathrm{MeOH}$ versetzt, mit einem Vortex Mixer gründlich durchmischt und $10 \mathrm{~min}$ bei $10.000 \mathrm{~g}_{\max }$ nochmals zentrifugiert. Im Anschluß wurde der Überstand sorgfältig mit einer Pipette abgenommen, das Proteinsediment für $1 \mathrm{~h}$ bei Raumtemperatur getrocknet und danach mit Probenpuffer versetzt. Nach einer zehnminütigen Inkubation in einem Heizblock bei $60{ }^{\circ} \mathrm{C}$ wurden die Proben 20 min geschüttelt und in einer Eppendorf Zentrifuge $2 \mathrm{~min}$ bei $9000 \mathrm{~g}_{\max }$ zentrifugiert.

Die Identifizierung der Molekularmassen der elektrophoretisch aufgetrennten Proteine erfolgte anhand des „Low molecular-weight markerkit“ (LMW-Marker) der Firma Pharmacia, der entsprechend der Herstellervorschrift nach der Aufnahme in Probenpuffer für $1 \mathrm{~min}$ bei $100{ }^{\circ} \mathrm{C}$ gekocht worden war.

Proteine des LMW-Markers:

$\begin{array}{ll}\text { Phosphorylase b } & 94 \mathrm{kDa} \\ \text { BSA } & 67 \mathrm{kDa} \\ \text { Ovalbumin } & 43 \mathrm{kDa} \\ \text { Carboanhydrase } & 30 \mathrm{kDa} \\ \text { Sojabohnen-Trypsin-Inhibitor } & 20 \mathrm{kDa} \\ \text { Lactalbumin } & 14 \mathrm{kDa}\end{array}$

\subsubsection{Herstellung der SDS-Polyacrylamidgele}

Die Herstellung der diskontinuierlichen SDS-Polyacrylamidgele, die jeweils aus einem 3,75 \%igen Sammelgel und einem 10 bzw. 12 \%igen Trenngel der Größe $185 * 70 * 1 \mathrm{~mm}$ bestanden, erfolgte ebenso wie die Gelelektrophorese mit Hilfe eines selbstkonstruierten Elektrophorese Systems. 
Lösungen:

Trenngelpuffer:

1,5 mM Tris / HCl; $\mathrm{pH} \mathrm{8,8}$

$0,4 \%(\mathrm{w} / \mathrm{v}) \mathrm{SDS}$

in $\mathrm{H}_{2} \mathrm{O}$ bidest.

Sammelgelpuffer:

$0,5 \mathrm{mM}$ Tris / $\mathrm{HCl} ; \mathrm{pH} 6,8$

$0,4 \%(\mathrm{w} / \mathrm{v}) \mathrm{SDS}$

in $\mathrm{H}_{2} \mathrm{O}$ bidest.

Acrylamid Lösung:

$30 \%(\mathrm{w} / \mathrm{w})$ Acrylamid

$0,8 \%(\mathrm{w} / \mathrm{w}) \mathrm{N}-\mathrm{N}-$ Methylen-bis-acrylamid

in $\mathrm{H}_{2} \mathrm{O}$ bidest.

Ammoniumpersulfat (APS) Lösung:

$2,4 \%(\mathrm{w} / \mathrm{v})$ Ammoniumpersulfat in $\mathrm{H}_{2} \mathrm{O}$ bidest.

Zusammensetzung des Sammelgels:

\begin{tabular}{|l|c|}
\hline Lösungen & $3,5 \%$ \\
\hline Sammelgelpuffer & $2,4 \mathrm{ml}$ \\
\hline Acrylamid Lösung & $1,2 \mathrm{ml}$ \\
\hline $\mathrm{H}_{2} \mathrm{O}$ bidest. & $3,7 \mathrm{ml}$ \\
\hline TEMED & $7,9 \mu \mathrm{l}$ \\
\hline APS Lösung & $400 \mu \mathrm{l}$ \\
\hline
\end{tabular}

Zusammensetzung des Trenngels:

\begin{tabular}{|l|c|c|}
\hline Lösungen & $10 \%$ & $12 \%$ \\
\hline Trenngelpuffer & $4,5 \mathrm{ml}$ & $4,5 \mathrm{ml}$ \\
\hline Acrylamid Lösung & $6,1 \mathrm{ml}$ & $7,3 \mathrm{ml}$ \\
\hline $\mathrm{H}_{2} \mathrm{O}$ bidest. & $7,3 \mathrm{ml}$ & $6,1 \mathrm{ml}$ \\
\hline TEMED & $8,8 \mu \mathrm{l}$ & $8,8 \mu \mathrm{l}$ \\
\hline APS Lösung & $400 \mu \mathrm{l}$ & $400 \mu \mathrm{l}$ \\
\hline
\end{tabular}

Nachdem das $\mathrm{H}_{2} \mathrm{O}$, der Trenngelpuffer die Acrylamid Lösung und das TEMED in einem Erlenmeyerkolben vorgelegt worden war, wurde die radikalische Polymerisationsreaktion durch die Zugabe der AMPS Lösung gestartet, sofort zwischen die zuvor mit Aceton gereinigten Glasplatten gegossen und vorsichtig mit 2-Propanol überschichtet. Nach einer Polymerisationszeit von 45 min wurde das 2-Propanol 
abgegossen und die Oberkante des Trenngels mit $\mathrm{H}_{2} \mathrm{O}$ bidest. gespült. Das Sammelgel wurde sofort nach der Zugabe der AMPS Lösung auf das auspolymerisierte Trenngel gegossen. Zur Formung der Probentaschen wurde ein Kamm zwischen die Glasplatten in das flüssige Sammelgel eingeführt, der nach einer Polymerisationszeit von 30 min vorsichtig entfernt werden konnte.

\subsubsection{Elektrophoretische Auftrennung der Proteine}

Elektrodenpuffer:

$25 \mathrm{mM}$ Tris

$192 \mathrm{mM}$ Glycin

$0,1 \%(\mathrm{w} / \mathrm{v})$ SDS

in $\mathrm{H}_{2} \mathrm{O}$ bidest.

Nach dem Einsetzen des in 2.20.2 hergestellten Polyacrylamidgels in die Elektrophoresekammer wurde diese mit Elektrodenpuffer befüllt. Das Auftragen der in 2.20.1 vorbereiteten Proben und des LMW-Markers in die Probentaschen des Sammelgels erfolgte mit Hilfe einer Hamiltonspritze. Die Elektrophorese wurde bei einer Stromstärke von $40 \mathrm{~mA}$ durchgeführt, wobei die Spannung maximal $220 \mathrm{~V}$ betrug.

\subsubsection{Färbung der Proteine in SDS-Polyacrylamidgelen}

Zur Visualisierung der elektrophoretisch aufgetrennten Proteine in dem SDSPolyacrylamidgel wurde eine Färbung mit Coomassie Blue durchgeführt (Neuhoff et al., 1985).

Neuhoff Lösung:

$2 \%(\mathrm{w} / \mathrm{w})$ Phosphorsäure

$10 \%(\mathrm{w} / \mathrm{w})$ Ammoniumsulfat

$0,1 \%(\mathrm{w} / \mathrm{w})$ Coomassie G (Serva Blue G 250)

in $\mathrm{H}_{2} \mathrm{O}$ bidest.

Die Lösung wurde vor der Färbung mit MeOH p.a. im Verhältnis 4:1 (v/v) verdünnt.

Nachdem das SDS-Polyacrylamidgel 4-6 h bei Raumtemperatur in der Neuhoff Lösung auf einer Laborwippe inkubiert worden war, wurde die Hintergrundfärbung durch eine weitere Inkubation für $6 \mathrm{~h}$ in $\mathrm{H}_{2} \mathrm{O}$ bidest. ausgewaschen.

Zur Dokumentation der Proteinauftrennung wurde das gefärbte Gel gescannt (Epson GT-9500) und anschließend mit Hilfe eines Geltrockners (Modell 543, BioRad, München, Deutschland) 90 min bei $60{ }^{\circ} \mathrm{C}$ unter Vakuum getrocknet. 


\subsubsection{Elektroelution von Proteinen aus SDS-Polyacrylamidgelen}

Zur Elektroelution von Proteinen aus SDS-Polyacrylamidgelen wurden die Proteinbanden nach ihrer Färbung (siehe 2.20.4) mit einem Skalpell ausgeschnitten und in den Gelhalter des Biotrap Elektroelutionssystems (Schleicher \& Schüll, Dassel, Deutschland) eingelegt, nachdem dieser mit den Gelrückhaltefiltern und dem Proteinsperrfilter versehenen worden war. Im Anschluß wurde der Halter in eine mit Elektrodenpuffer (siehe 2.20.3) befüllte Flachbettelektrophoresekammer eingelegt, wobei der Proteinsperrfilter am Ende des Halters in Richtung Anode zeigte. Die Proteine wurden mit $50 \mathrm{~mA}$ für $24 \mathrm{~h}$ bei $4{ }^{\circ} \mathrm{C}$ eluiert und anschließend aus der Kammer zwischen Gelrückhaltefilter und Proteinsperrfilter des Gelhalters entnommen.

\subsection{Western-Blotting}

Der elektrophoretische Proteintransfer von SDS-Polyacrylamidgelen auf Nitrocellulosemembranen (NC Membranen), der auch als Western-Blotting bezeichnet wird, erfolgte nach Towbin et al., 1979.

\subsubsection{Elektrophoretischer Proteintransfer}

Blotpuffer:

$25 \mathrm{mM}$ Tris

$150 \mathrm{mM}$ Glycin

$10 \%$ (v/v) Methanol p.a.

in $\mathrm{H}_{2} \mathrm{O}$ bidest.

Vor dem elektrophoretischen Proteintransfer, der mit Hilfe eines Semi-Dry Blot Systems (Bio-Rad, München, Deutschland) erfolgte, wurden die NC Membran (SC 128/02 um Sartorius, Göttingen, Deutschland) und 8 Blatt Whatman Chromatographiepapier auf die Größe von 18,5*7 cm zurechtgeschnitten und $10 \mathrm{~min}$ in Blotpuffer äquilibriert. Anschließend wurden nacheinander 4 Blatt Chromatographiepapier, die NC Membran, das SDS-Polyacrylamidgel mit den elektrophoretisch aufgetrennten Proteinen und nochmals 4 Blatt Chromatographiepapier luftblasenfrei auf der Anode der Blotkammer gestapelt. Nach dem Verschließen der Blotkammer erfolgte der Proteintransfer für $1 \mathrm{~h}$ mit $200 \mathrm{~mA}$. 


\subsubsection{Färbung der Proteine auf Nitrocellulosemembranen}

Nach dem elektrophoretischen Proteintransfer wurden die Proteine auf der NC Membran gefärbt (Salinovich \& Montelaro, 1986).

Ponceau Lösung:

$0,2 \%(\mathrm{w} / \mathrm{w})$ Ponceau S

$3 \%(\mathrm{w} / \mathrm{w})$ Trichloressigsäure

in $\mathrm{H}_{2} \mathrm{O}$ bidest.

Die NC Membran wurde für 5 min bei Raumtemperatur in der Ponceau Lösung auf einer Laborwippe inkubiert. Zur Entfernung der Hintergrundfärbung wurde die NC Membran zweimal 5 min in $\mathrm{H}_{2} \mathrm{O}$ bidest. gewaschen. Im Anschluß wurde die Membran durch eine Inkubation in TBS-T (siehe 2.21.3) für 10 min auf einer Laborwippe entfärbt.

\subsubsection{Spezifischer Nachweis von Proteinen mit Antikörpern}

Lösungen:

TBS:

$50 \mathrm{mM}$ Tris/HCl; $\mathrm{pH} 7,4$

$0,9 \%(\mathrm{w} / \mathrm{v}) \mathrm{NaCl}$

in $\mathrm{H}_{2} \mathrm{O}$ bidest.

Waschpuffer (TBS-T):

$0,05 \%(\mathrm{v} / \mathrm{v})$ Tween 20 in TBS

Blocklösung:

$5 \%(\mathrm{w} / \mathrm{v})$ Magermilchpulver

$1 \%(\mathrm{w} / \mathrm{v}) \mathrm{BSA}$

in TBS-T

Dissoziationspuffer:

62,5 mM Tris/HCl; pH 6,7

$100 \mathrm{mM}$ 2-Mercaptoethanol

$2 \%(\mathrm{w} / \mathrm{v}) \mathrm{SDS}$

in $\mathrm{H}_{2} \mathrm{O}$ bidest. 
Verdünnungsmedium für Antikörper:

$1 \%(\mathrm{w} / \mathrm{v}) \mathrm{BSA}$

$0,02 \%(\mathrm{w} / \mathrm{v}) \mathrm{NaN}_{3}$

in TBS

Primärantikörper:

- polyklonaler Antikörper aus Kaninchen gegen $\gamma$-COP aus Arabidopsis thaliana (Aty-COP), (Movafeghi et al., 1999), Verdünnung: 1:2500

- polyklonaler Antikörper aus Kaninchen gegen $\varepsilon$-COP aus Zea mays (ZmeCOP), (Pimpl et al., 2000), Verdünnung: 1:1000

- polyklonaler Antikörper aus Kaninchen gegen Sec23p aus Arabidopsis thaliana (AtSec23p), (Movafeghi et al., 1999), Verdünnung: 1:2500

- polyklonaler Antikörper aus Kaninchen gegen ARF1p aus Arabidopsis thaliana (AtARF1p), (Pimpl et al., 2000), Verdünnung: 1:2500

- polyklonaler Antikörper aus Kaninchen gegen Sar1p aus Arabidopsis thaliana (AtSar1p), (Pimpl et al., 2000), Verdünnung: 1:2500

- polyklonaler Antikörper aus Kaninchen gegen Sec12p aus Arabidopsis thaliana (AtSec12p), (Bar-Peled \& Raikhel, 1997), Verdünnung 1:2500

- polyklonaler Antikörper aus Kaninchen gegen BiP aus Nicotiana tabacum, (Denecke et al., 1991), Verdünnung: 1:10.000

- polyklonaler Antikörper aus Kaninchen gegen Calreticulin aus Ricinus communis, (Coughlan et al., 1997), Verdünnung: 1:10.000

- polyklonaler Antikörper aus Kaninchen gegen Calnexin aus Ricinus communis, (Pimpl et al., 2000), Verdünnung: 1:10.000

- polyklonaler Antikörper aus Kaninchen gegen ein 40 kDa reversibel glycosyliertes Polypeptid (RGP1) des trans-Golgi-Apparats aus Pisum sativum, (Dhugga et al., 1997), Verdünnung: 1:20.000

- polyklonaler Antikörper aus Kaninchen gegen c-Myc (Clontech, Heidelberg, Deutschland), Verdünnung 1:5.000

- monoklonaler Antikörper aus Maus gegen GST aus Schistosoma japonicum (Sigma-Aldrich, Taufkirchen, Deutschland), Verdünnung: 1:1000 
Sekundärantikörper:

- Meerrettich Peroxidase konjugierter polyklonaler Antikörper aus Ziege gegen Kaninchen IgG (Sigma-Aldrich, Taufkirchen, Deutschland), Verdünnung: 1:15.000

- Meerrettich Peroxidase konjugierter polyklonaler Antikörper aus Ziege gegen Maus IgG (Sigma-Aldrich, Taufkirchen, Deutschland), Verdünnung : $1: 10.000$

Alle Inkubationen erfolgten, wenn nicht anders beschrieben, bei Raumtemperatur auf einer Laborwippe.

Nach dem elektrophoretischen Transfer der Proteine von dem SDSPolyacrylamidgel auf die NC-Membran wurde diese zur Absättigung unspezifischer Bindungsstellen 60 min in der Blocklösung inkubiert und anschließend dreimal für je 10 min in TBS-T gewaschen.

Zum spezifischen Nachweis von Proteinen wurde die Membran für $1 \mathrm{~h}$ mit dem Primärantikörper inkubiert und anschließend dreimal für je 15 min mit TBS-T gewaschen. Nach der darauf folgenden Inkubation mit dem Sekundärantikörper für $1 \mathrm{~h}$ wurde die NC-Membran erneut dreimal für je 15 min mit TBS-T gewaschen.

Mit Hilfe des ECL Detektionssystems (Amersham Pharmacia Biotech, Freiburg, Deutschland) wurde die an den Sekundärantikörper gekoppelte Meerrettich Peroxidase durch ein auf Chemilumineszenz basierendes Testverfahren mit einem lichtempfindlichen Film (Hyperfilm-ECL, Amersham Pharmacia Biotech) entsprechend der Vorschrift des Herstellers detektiert. Nach dem Exponieren des Films wurde dieser 1 min entwickelt (Agfa Neutol Liquid NE) und 1 min gewässert. Im Anschluß an eine einminütige Fixierung (Expressfixiersalz, Tetenal) wurde der Film nochmals 2 min gewässert und danach bei Raumtemperatur getrocknet.

Durch eine Inkubation in Dissoziationspuffer für $30 \mathrm{~min}$ bei $50{ }^{\circ} \mathrm{C}$ in einem Schüttelwasserbad und drei 15 minütige Waschschritte in TBS-T konnten die Antikörper wieder von der NC-Membran abgelöst werden. Nachdem die unspezifischen Bindungsstellen der NC Membran erneut durch eine 60minütige Inkubation in Blocklösung abgesättigt worden waren, konnte diese Membran zum spezifischen Proteinnachweis mit anderen Primärantikörpern erneut verwendet werden. 


\subsection{Elektronenmikroskopie}

Die elektronenmikroskopischen Untersuchungen isolierter COP Vesikel Fraktionen (siehe 2.16.2) wurden an einem Transmissions-Elektronenmikroskop der Firma Philips (CM10) bei $80 \mathrm{kV}$ durchgeführt.

\subsubsection{Negativkontrastierung}

Die Negativkontrastierung von Membranfraktionen zur elektronenmikroskopischen Untersuchung erfolgte in einem modifizierten Verfahren nach Robinson et al., 1985 mit Kohle bedampften Glimmerplättchen und unbeschichteten Trägernetzen (Plano, Wetzlar, Deutschland).

Lösungen:

Kaliumphosphatpuffer (KPP):

$50 \mathrm{mM} \mathrm{KH}_{2} \mathrm{PO}_{4} / 50 \mathrm{mM} \mathrm{K}_{2} \mathrm{HPO}_{4} ; \mathrm{pH} \mathrm{7,0}$

in $\mathrm{H}_{2} \mathrm{O}$ bidest.

Fixativ:

$2,5 \%(\mathrm{v} / \mathrm{v})$ Glutaraldehyd in KPP

Uranylacetat Lösung:

$3 \%(\mathrm{w} / \mathrm{v})$ Uranylacetat in $\mathrm{H}_{2} \mathrm{O}$ bidest.

Zur Adsorbtion der Membranen an dem Kohlefilm wurde ein ca. $3 * 3 \mathrm{~mm}$ großes Glimmerplättchen in einem $45^{\circ}$ Winkel $15 \mathrm{~s}$ so in einen Tropfen der zu untersuchenden Probe getaucht, daß der Kohlefilm auf dem Tropfen flotierte, sich jedoch nicht vollständig von dem Glimmerplättchen löste. Im Anschluß wurde das Glimmerplättchen auf die gleiche Weise jeweils $10 \mathrm{~s}$ in einen Tropfen Fixativ, KPP und zwei Tropfen $\mathrm{H}_{2} \mathrm{O}$ bidest. getaucht. Zur Nachkontrastierung wurde das Glimmerplättchen zum vollständigen Ablösen des Kohlefilms in die Uranylacetat Lösung gesenkt. Im Anschluß wurde der flotierende Kohlefilm mit einem Trägernetz von der Oberfläche der Lösung abgenommen, die überschüssige Lösung mit einem Filterpapier abgesaugt und die Probe bis zu elektronenmikroskopischen Untersuchung 15 min bei RT getrocknet. 


\subsubsection{Immunogold-Negativkontrastierung}

Die Immunogold-Negativkontrastierung der COP Vesikel Fraktionen wurde mit Formvar beschichteten und mit Kohle bedampften Nickel Trägernetzen (Plano, Wetzlar, Deutschland) durchgeführt.

Lösungen:

Fixativ:

$2,5 \%(\mathrm{v} / \mathrm{v})$ Glutaraldehyd in KPP

TBS:

$50 \mathrm{mM}$ Tris/HCl; $\mathrm{pH} 7,4$

$0,9 \%(\mathrm{w} / \mathrm{v}) \mathrm{NaCl}$

in $\mathrm{H}_{2} \mathrm{O}$ bidest.

Blocklösung:

$1 \%(\mathrm{w} / \mathrm{v}) \mathrm{BSA}$ in TBS

Primärantikörper:

Polyklonaler Antikörper gegen Zme-COP (siehe 2.21.3), Verdünnung:

$1: 1.000$ in TBS

Sekundärantikörper:

$10 \mathrm{~nm}$ Gold konjugierter polyklonaler Antikörper aus Ziege gegen Kaninchen

IgG (British BioCell, Cardiff, UK); Verdünnung: 1:100 in TBS

Zur Immunogold-Negativkontrastierung wurden $10 \mu \mathrm{l}$ der $\mathrm{zu}$ untersuchenden Membranfraktion auf einem Trägernetz für 30 min auf Eis inkubiert. Alle weiteren Inkubations- und Waschschritte erfolgten, indem das Trägernetz mit der anhaftenden Probe auf einen Tropfen der entsprechenden Lösung bei RT aufgelegt wurde. Im weiteren Verlauf wurde die Probe für $10 \mathrm{~s}$ fixiert, dreimal für je $30 \mathrm{~s}$ in TBS gewaschen und 5 min zur Absättigung von unspezifischen Bindungsstellen auf die Blocklösung aufgelegt. Nachdem die Probe $1 \mathrm{~h}$ auf der Primärantikörper Lösung inkubiert worden war, wurde sie dreimal 5 min mit TBS gewaschen und 45 min auf der Sekundärantikörper Lösung inkubiert. Im Anschluß wurde die Probe dreimal 5 min mit TBS, zweimal 1 min mit $\mathrm{H}_{2} \mathrm{O}$ bidest. gewaschen und zur Nachkontrastierung $5 \mathrm{~s}$ auf der Uranylacetat Lösung (siehe 2.22.1) inkubiert. Nachdem die überschüssige Uranylacetat Lösung mit einem Filterpapier abgesaugt worden war, wurde die Probe 15 min bei RT getrocknet und anschließend elektronenmikroskopisch untersucht. 


\section{Ergebnisse}

\subsection{Herstellung der AtSar1p und AtArf1p Antiseren}

Die Entwicklung der Methoden zur in vitro Induktion und Isolation von COP Vesikeln an pflanzlichen Membranen erforderte Antiseren zur Detektion ihrer Hüllproteine. Hierbei ist die Detektion der GTPasen Sar1p und Arf1p von entscheidender Bedeutung, da diese die Bildung der Proteinhülle initiieren, indem sie die weiteren Proteinkomplexe aus dem Cytosol an die Membranen rekrutieren (siehe 1.5.2). Da zu Beginn der experimentellen Arbeiten jedoch lediglich Antiseren zur Detektion von Aty-COP, einer Untereinheit des Coatomer Komplexes der COPI Vesikel, und AtSec23p, einer Untereinheit des Sec23p Komplexes der COPII Vesikel, zur Verfügung standen (Movafeghi et al., 1999), mußten zunächst Antiseren gegen die den Hefen und Säugetieren homologen GTPasen Sar1p und Arf1p aus Pflanzen hergestellt werden. Dazu wurden GST Fusionsproteine der GTPasen aus Arabidopsis als Antigene zur Immunisierung von Kaninchen eingesetzt.

\subsubsection{Herstellung des GST-AtSar1p Fusionsproteins}

Zur Herstellung des GST-AtSar1p Fusionsproteins wurde die für Arabidopsis thaliana Sar1p (AtSar1p) kodierende DNA (GenBank Nr. M95795) aus dem Plasmid pJPT1 (zur Verfügung gestellt von Dr. J. Denecke; Universität Leeds, UK) mit BamHI ausgeschnitten (siehe 2.5.1). Nachdem die überhängenden Enden mit dem Klenow-Fragment geglättet worden waren (siehe 2.5.2), wurde das AtSar1 Fragment im Anschluß an eine Phenolextraktion (siehe 2.6.3) mit BglII geschnitten und nach der präparativen Agarose-Gelelektrophorese isoliert (siehe 2.6.2). Der GST Expressionsvektor pGEX-3X (siehe 2.9) wurde zunächst mit EcoRI linearisiert und nach dem Glätten der überhängenden Enden durch das Klenow-Fragment und nachfolgender Phenolextraktion mit BglII gespalten und anschließend dephosphoryliert (siehe 2.5.3). Nachdem die Vektor DNA durch präparative AgaroseGelelektrophorese aufgereinigt worden war, erfolgte die Ligation mit dem isolierten AtSar1p Fragment (siehe 2.5.4). Im Anschluß an die Expression des GSTAtSar1p Fusionsproteins in E. coli wurde dieses zunächst mit GlutathionSepharose 4B affinitätschromatographisch isoliert und im weiteren Verlauf nochmals durch SDS-Polyacrylamid-Gelelektrophorese gereinigt (siehe 2.9). Zur Herstellung von Antikörpern wurden im Anschluß Kaninchen mit dem isolierten Fusionsprotein (siehe Abbildung 3.1-1) immunisiert (siehe 2.10). 


\subsubsection{Charakterisierung des AtSar1p Antiserums}

Zur Charakterisierung des Antiserums wurden Western-Blot Analysen mit dem als Antigen eingesetzten $40 \mathrm{kDa}$ Fusionsprotein sowie mit isolierten cytosolischen Proteinen aus Blumenkohlinfloreszenzen und Schweinehirn (siehe 2.12) durchgeführt (siehe Abbildung 3.1-1). Das Antiserum zeigte in einer Konzentrationsreihe des Fusionsproteins von 1-30 ng bereits mit 10 ng des Fusionsproteins eine Kreuzreaktion. Zur Detektion von AtSar1p homologen Proteinen in Fraktionen der isolierten cytosolischen Proteine aus Blumenkohlinfloreszenzen und Schweinehirn wurden jeweils $20 \mu \mathrm{g}$ der Proteinfraktion mit dem Antiserum analysiert. Abbildung 3.1-1 zeigt die Detektion eines Proteins in der Fraktion der cytosolischen Proteine aus Blumenkohl, dessen apparentes Molekulargewicht von $22 \mathrm{kDa}$ mit dem beschriebenen Molekulargewicht des Sar1p aus Arabidopsis (Bar-Peled \& Raikhel, 1997) übereinstimmt. Im Gegensatz dazu zeigte das Antiserum mit den cytosolischen Proteinen aus Schweinehirn keine Kreuzreaktion. Zur Beurteilung der Spezifität wurde die Konzentrationsreihe des Fusionsproteins sowie die Fraktionen der cytosolischen Proteine ebenfalls mit dem Präimmunserum analysiert. Da dieses keinerlei Kreuzreaktion zeigte, ist die Kreuzreaktion des Antiserums spezifisch auf die Immunantwort des Kaninchens auf das GST-Sar1p Fusionsprotein zurückzuführen.

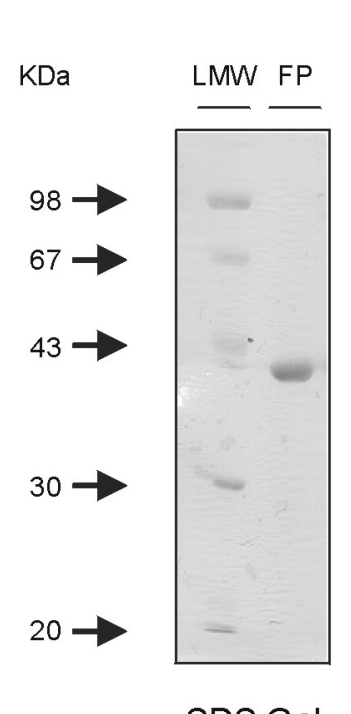

\section{Fusionsprotein [ng]}

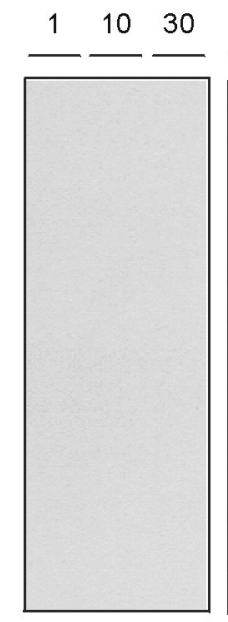

PIS

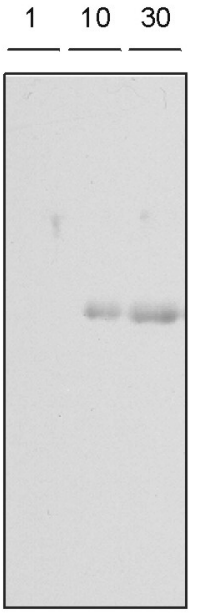

Antiserum
Cytosol

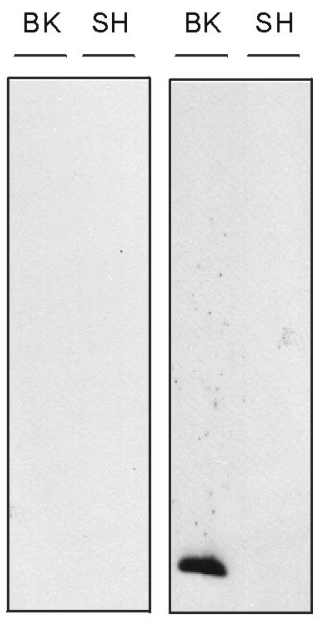

PIS Antiserum

Abbildung 3.1-1: Charakterisierung von GST-AtSar1p Fusionsprotein und Antiserum. Links: Charakterisierung des zur Immunisierung eingesetzten GST-AtSar1p Fusionsproteins (FP) nach SDS-Polyacrylamid-Gelelektrophorese im Vergleich zum Molekulargewichtsmarker $(L M W)$.

Mitte: Kreuzreaktionen von Präimmunserum (PIS) und Antiserum mit dem GST-AtSar1p Fusionsprotein (FP) nach Western-Blotting.

Rechts: Kreuzreaktionen von Präimmunserum (PIS) und Antiserum mit cytosolischen Proteinen (Cytosol; 20 Mg/Bahn) aus Blumenkohl (BK) und Schweinehirn (SH) nach Western-Blotting. 


\subsubsection{Herstellung des GST-AtArf1p Fusionsproteins}

Zur Herstellung des GST-AtArf1p Fusionsproteins wurde zunächst die AtArf1p kodierende DNA Sequenz (GenBank Nr. M95166) aus „first-strand“ cDNA aus 5 Tage alten Arabidopsis Keimlingen durch die Polymerase Kettenreaktion amplifiziert (siehe 2.7). Hierbei wurde durch die Verwendung des „sense“ Primers 5'GATCAGGATCCGGTTGTCATTCGG -3’ eine Spaltungsstelle für die Restriktionsendonuklease BamHI und durch die Verwendung des „antisense“ Primers 5'GCTAGAATTCCATCTATGCCTTGCTTGCGAT -3’ eine EcoRI Spaltungsstelle in die Sequenz des Amplifikationsprodukts eingeführt. Nach der Polymerase Kettenreaktion wurde das Amplifikationsprodukt durch eine Phenolextraktion gereinigt und mit dem Vektor pUC57/T (MBI Fermentas, St. Leon-Rot, Deutschland) ligiert (siehe 2.5.4). Im Anschluß wurde die Identität des Amplifikationsprodukts mit der AtArf1p kodierenden DNA Sequenz (GenBank Nr. M95166) durch die Sequenzanalyse des Amplifikationsprodukts in dem Vektor pUC/57/T unter Verwendung der Sequenzierprimer M13/pUC und M13/pUC reverse (siehe 2.8) bestätigt. Im weiteren Verlauf wurde mit BamHI und EcoRI die AtArf1p kodierende Sequenz aus dem Vektor pUC/57T ausgeschnitten und der GST Expressionsvektor pGEX-3X linearisiert. Nach der präparativen Agarose-Gelelektrophorese (siehe 2.6.1) wurde die AtArf1p kodierende Sequenz mit dem linearisierten Vektor pGEX-3X ligiert (siehe 2.5.4). Expression und Isolation des GST-AtArf1p Fusionsproteins sowie die Immunisierung der Kaninchen zur Herstellung des Antiserums erfolgte analog zur Herstellung des GST-Sar1p Fusionsproteins (siehe 2.9).

\subsubsection{Charakterisierung des AtArf1p Antiserums}

Zur Charakterisierung des AtArf1p Antiserums wurden Western-Blot Analysen mit einer Konzentrationsreihe von 1-30 ng des zur Immunisierung als Antigen eingesetzten GST-AtArf1p Fusionsproteins sowie mit je $20 \mu \mathrm{g}$ cytosolischen Proteinen aus Blumenkohlinfloreszenzen und aus Schweinehirn durchgeführt (siehe Abbildung 3.1-2). Das Antiserum zeigte mit 10 ng des Fusionsproteins bereits eine deutliche Kreuzreaktion während das Präimmunserum auch mit $30 \mathrm{ng}$ keine Kreuzreaktion zeigte. In der Fraktion der cytosolischen Proteine aus Blumenkohlinfloreszenzen konnte ein Protein mit einem apparenten Molekulargewicht von $20 \mathrm{kDa}$ detektiert werden. Ebenso wie das AtSar1p Antiserum (siehe Abbildung 3.1-1) zeigte auch das AtArf1p Antiserum keinerlei Kreuzreaktion mit der Fraktion der cytosolischen Proteine des Schweinehirns (Abbildung 3.1-2). Die Spezifität der Kreuzreaktion des Antiserums mit dem $20 \mathrm{kDa}$ Protein des Blumenkohls wird auch hier durch den Vergleich mit dem Präimmunserum deutlich, da dieses keinerlei Kreuzreaktion zeigte. 


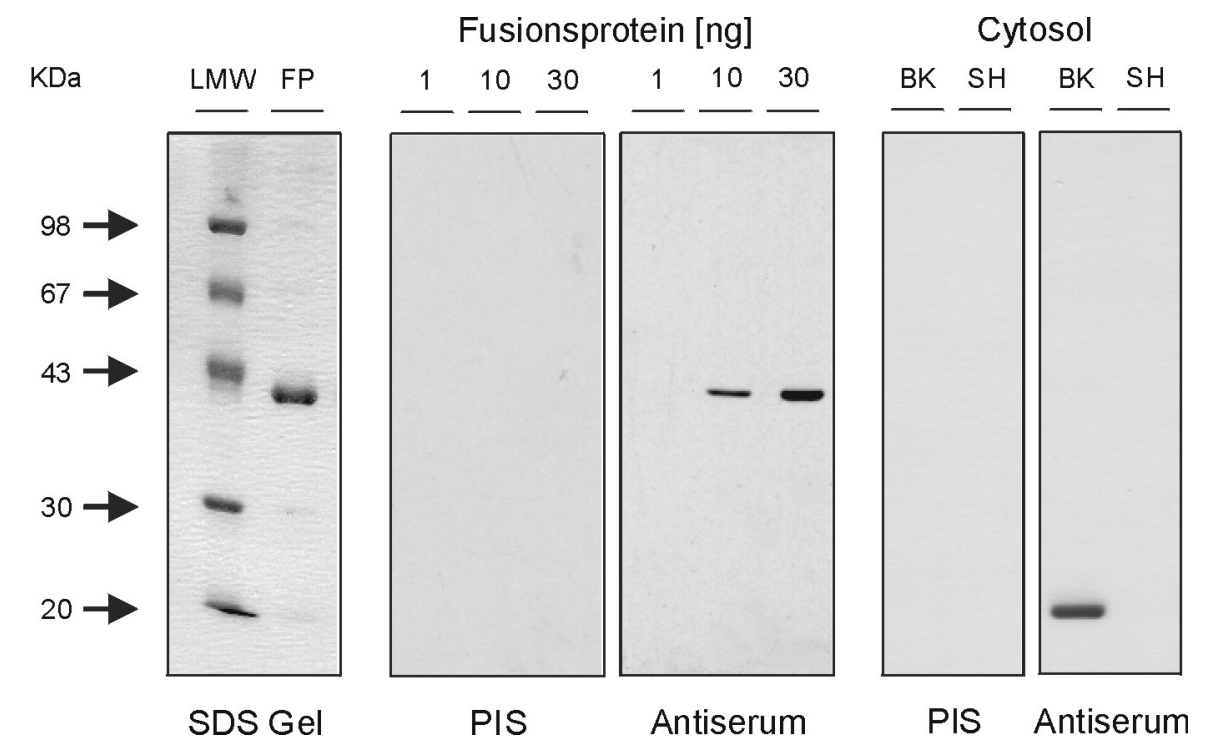

Abbildung 3.1-2: Charakterisierung von GST-AtArf1p Fusionsprotein und Antiserum. Links: Charakterisierung des zur Immunisierung eingesetzten GST-AtArf1p Fusionsproteins (FP) nach SDS-Polyacrylamid-Gelelektrophorese im Vergleich zum Molekulargewichtsmarker $(L M W)$.

Mitte: Kreuzreaktionen von Präimmunserum (PIS) und Antiserum mit dem GST-AtArf1p Fusionsprotein (FP) nach Western-Blotting.

Rechts: Kreuzreaktionen von Präimmunserum (PIS) und Antiserum mit cytosolischen Proteinen (Cytosol; 20 Mg/Bahn) aus Blumenkohl (BK) und Schweinehirn (SH) nach Western-Blotting.

\subsection{Rekrutierung der Hüllproteine der COP Vesikel in vitro}

Die Rekrutierung der cytosolischen Hüllproteine der COP Vesikel an die Membran ist im Verlauf der Bildung des Vesikels von zentraler Bedeutung, da hierdurch eine Wölbung der Membranoberfläche hervorgerufen wird, aus der sich im weiteren Verlauf der Vesikel bildet (Übersicht in Robinson et al., 1998; Klumperman, 2000). Die Entwicklung der Methode zur in vitro Induktion und Isolation von COP Vesikeln an pflanzlichen Membranen erforderte daher zunächst die Charakterisierung der Reaktionsbedingungen, die dieser Rekrutierungsreaktion zugrunde liegen.

In den Rekrutierungsstudien diente eine durch Ammoniumsulfat gefällte Fraktion cytosolischer Proteine aus Blumenkohl (siehe 2.12.1) als Quelle der zu rekrutierenden Hüllproteine und eine angereicherte ER- und Golgi-Membranfraktion $\left(\mathrm{M}_{0}\right)$ aus Blumenkohl, die durch isopyknische Dichtegradientenzentrifugation mit diskontinuierlichen Saccharosegradienten isoliert worden war (siehe 2.13.1), als Akzeptormembranen für die Hüllproteine. Da mit diesen Membranen jedoch bereits $\gamma$-COP und Sec23p homologe Proteine (Movafeghi et al., 1999) sowie Arf1p und Sar1p homologe Proteine assoziiert sind (siehe Abbildung 3.2-1; $0 \mathrm{mM} \mathrm{KJ}$ ) wurde vor den Untersuchungen zur Rekrutierung die Dissoziierbarkeit dieser endogenen Hüllproteine durch das chaotrope Agens KJ untersucht. 


\subsubsection{Dissoziation der endogenen Hüllproteine der COP Vesikel}

Zur Ermittlung der Dissoziationsbedingungen wurden die Membranen $\left(\mathrm{M}_{0}\right)$ mit steigenden KJ Konzentrationen, wie in 2.14 beschrieben, inkubiert und durch Western-Blot Analyse nach gleichen Volumina untersucht. Nach Behandlung der Membranfraktion mit $300 \mathrm{mM}$ KJ waren die $\gamma$-COP, Sec23p und AtSar1p homologen Proteine vollständig von den Membranen dissoziiert und in der Membranfraktion $\left(\mathrm{M}_{\mathrm{KJ}}\right)$ nicht mehr detektierbar (siehe Abbildung 3.2-1). Im Gegensatz dazu war das AtArf1p homologe Protein auch bei dieser KJ Konzentration nicht dissoziierbar. Dieses unterschiedliche Dissoziationsverhalten der GTPasen ist möglicherweise darauf zurückzuführen, daß Arf1p im Gegensatz zum Sar1p durch eine Nterminale Myrystoylgruppe in der Membran verankert ist (Kahn et al., 1992).

Da nach der Behandlung der Membranfraktion mit 300 mM KJ die endogenen AtyCOP, AtSec23p und AtSar1p homologen Proteine nicht mehr nachweisbar waren, wurden diese Membranen $\left(\mathrm{M}_{\mathrm{KJ}}\right)$ als Ausgangsmaterial zur in vitro Rekonstruktion der Rekrutierungsreaktion eingesetzt.

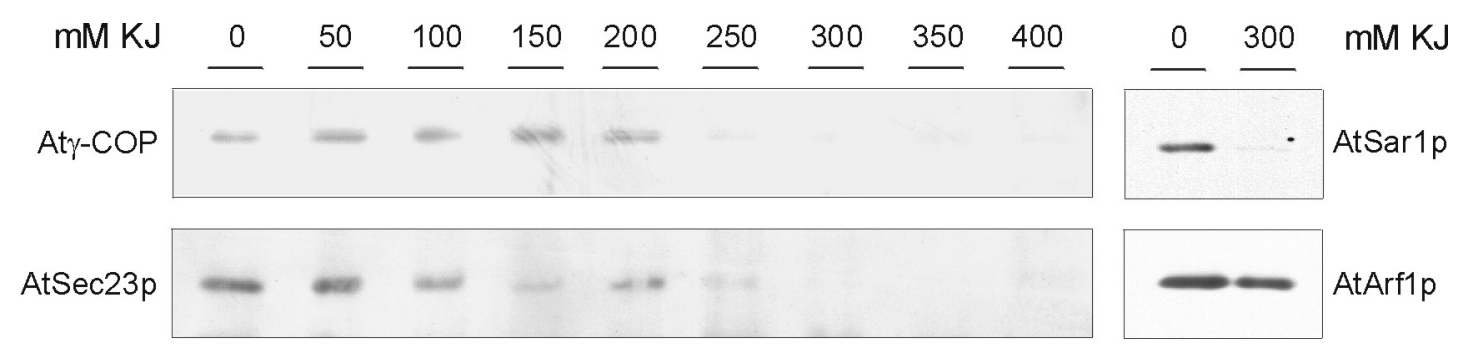

Abbildung 3.2-1: Dissoziation der endogenen Hüllproteine durch KJ.

Links: Dissoziation der Aty-COP und Sec23p homologen Proteine durch steigende KJ Konzentration.

Rechts: Dissoziation des AtSar1p homologen Proteins bei 300 mM KJ im Vergleich zu dem nicht dissoziierbaren AtArf1p homologen Protein.

\subsubsection{Selektive Rekrutierung der Hüllproteine der COPI Vesikel}

Zur in vitro Rekonstruktion der Rekrutierung der Hüllproteine der COP Vesikel wurden die Membranen $\left(\mathrm{M}_{\mathrm{KJ}}\right)$ mit den isolierten cytosolischen Proteinen aus Blumenkohl (siehe 2.12.1) in einem Proteinverhältnis von $0,2: 6 \mathrm{mg} / \mathrm{ml}$ Rekrutierungsansatz in Gegenwart von GTP $\gamma$ S, ATP und einem ATP regenerierenden System 25 min bei $20^{\circ} \mathrm{C}$ inkubiert (siehe 2.15). Nach der Rekrutierungsreaktion wurden die Membranen durch eine isopyknische Zentrifugation mit einem diskontinuierlichen Saccharosedichtegradienten von den löslichen Proteinen des Reaktionsansatzes getrennt. Zur Beurteilung der erfolgten Rekrutierungsreaktion wurden im Anschluß die Ausgangsmembranen $\left(\mathrm{M}_{\mathrm{KJ}}\right)$, die Membranen nach der Rekrutierungssreaktion $\left(\mathrm{M}_{\mathrm{R}}\right)$ sowie die Fraktion der im Überstand des Gradienten verbliebenen löslichen Proteine $\left(\ddot{U}_{R}\right)$ durch Western-Blot Analysen nach gleichen Vo- 
lumina untersucht. Hierbei dienten das AtArf1p und das Aty-COP homologe Protein als Markerproteine der Proteinhülle der COPI Vesikel sowie das AtSar1p und das AtSec23p homologe Protein als Markerproteine der Hülle der COPII Vesikel.

Da die Bildung der Proteinhülle der COP Vesikel durch die Rekrutierung der GTPasen ARF1p und Sar1p initiiert wird, wurde zunächst die Rekrutierung der AtArf1p und AtSar1p homologen Proteine untersucht. Die in Abbildung 3.2-2 dargestellte Western-Blot Analyse mit dem AtArf1p und AtSar1p Antiserum zeigt die deutliche Anreicherung des AtArf1p homologen Proteins in der Membranfraktion $\mathrm{M}_{\mathrm{R}}$ als Folge der Rekrutierungsreaktion im Vergleich zu dem endogenen, membrangebundenen AtArf1p der Ausgangsmembranen $\left(\mathrm{M}_{\mathrm{KJ}}\right)$. Für das AtSar1p homologe Protein konnte im Vergleich der Membranfraktionen $M_{K J}$ und $M_{R}$ ebenfalls eine deutliche Anreicherung durch die Rekrutierungsreaktion gezeigt werden. Da sowohl das AtArf1p homologe Protein als auch das AtSar1p homologe Protein in der Fraktion der löslichen Proteine nach der Rekrutierungsreaktion $\left(\ddot{U}_{R}\right)$ mit den Antiseren nicht detektierbar war, läßt sich daraus schließen, daß beide Proteine mit hoher Effizienz an die Membranen rekrutiert worden waren.

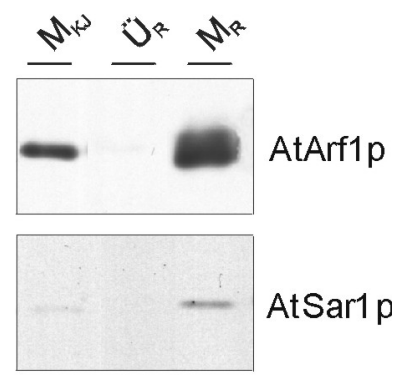

\footnotetext{
Abbildung 3.2-2: Rekrutierung der AtArf1p und AtSar1p homologen Proteine. $M_{K J}$ : Membranen vor der Rekrutierung; $\ddot{U}_{R}$ : Lösliche Proteine nach der Rekrutierung; $M_{R}:$ Membranen nach der Rekrutierung.
}

Da zur Bildung der Proteinhülle der COP Vesikel nach der Rekrutierung der GTPasen jedoch noch die Rekrutierung des Coatomer Komplexes im Fall der COPI Vesikel und die Rekrutierung des Sec23p/Sec24p sowie des Sec13p/Sec31p Proteinkomplexes im Fall der COPII Vesikel erforderlich ist, wurde mit Hilfe der Aty-COP und AtSec23p Antiseren die Rekrutierung der weiteren Komponenten der Proteinhüllen untersucht. Die in Abbildung 3.2-3 dargestellte Western-Blot Analyse zeigt die Assoziation der At $\gamma$-COP und AtSec23p homologen Proteine nach jedem Arbeitsschritt im Verlauf der Durchführung der Rekrutierungsreaktion in vitro. Die Assoziation der At $\gamma$-COP und AtSec23p homologen Proteine mit der als Ausgangsmaterial dienenden isolierten angereicherten ER und Golgi Membranfraktion $\left(\mathrm{M}_{0}\right)$ verdeutlicht die potentielle Fähigkeit dieser Membranfraktion sowohl die Hüllproteine der COPI als auch die der COPII Vesikel zu binden. Nach ihrer quantitativen 
Dissoziation durch $\mathrm{KJ}\left(\mathrm{M}_{\mathrm{KJ}}\right)$ wurde im Verlauf der Inkubation mit der Fraktion der isolierten cytosolischen Proteine (Cyt.), in der sowohl das Aty-COP als auch das AtSec23p homologe Protein enthalten war, jedoch selektiv nur das At $\gamma$-COP homologe Protein quantitativ an die Membranen rekrutiert. Im Gegensatz dazu konnte keine Rekrutierung des AtSec23p homologen Proteins beobachtet werden, da es vollständig in der Fraktion der löslichen Proteine des Gradientenüberstands verblieb $\left(\ddot{U}_{R}\right)$ und in der Membranfraktion $\left(M_{R}\right)$ nicht detektierbar war.

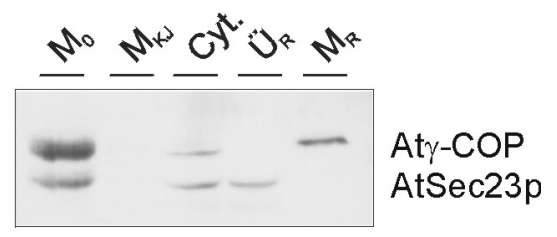

Abbildung 3.2-3: Selektive Rekrutierung des At $\gamma$-COP homologen Proteins. Detektion der Aty-COP und AtSec23p homologen Proteine im Verlauf der in vitro Rekrutierung: Ausgangsmembranen $\left(M_{0}\right)$, Membranen nach KJ Behandlung $\left(M_{K J}\right)$, Fraktion der isolierten cytosolischen Proteine zur Rekrutierung (Cyt.), lösliche Proteine des Gradientenüberstands nach der Rekrutierungsreaktion $\left(\ddot{U}_{R}\right)$ und Membranen nach der Rekrutierungsreaktion $\left(M_{R}\right)$

\subsubsection{Charakterisierung der Rekrutierungsreaktion}

Zur Charakterisierung der Rekrutierungsreaktion wurde im nächsten Schritt die Bedeutung des eingesetzten Verhältnisses von $6 \mathrm{mg}$ cytosolischen Proteinen zu 0,2 mg Membranen pro ml Reaktionsansatz untersucht. Durch die Erhöhung der Konzentration der cytosolischen Proteine relativ zu den eingesetzten Membranen um $30 \%, 100 \%$ und $200 \%$ sollte im Fall der COPI Hüllproteine die Sättigung der Rekrutierungsreaktion untersucht werden. Im Fall der COPII Hüllproteine sollte diese Versuchsanordnung zeigen, ob die Erhöhung der Konzentration der cytosolischen Proteine zur Rekrutierung des Sec23p homologen Proteins führt, da dieses bei dem Standard Inkubationsverhältnis nicht rekrutiert worden war (siehe Abbildung 3.2-3).

Die in Abbildung 3.2-4 dargestellte Western-Blot Analyse der löslichen Proteine der Gradientenüberstände und der Membranfraktionen nach der Rekrutierung zeigt, daß selbst eine Konzentrationserhöhung um $200 \%$ nicht zur Sättigung der Rekrutierung der COPI Hüllproteine führte, da sowohl das AtArf1p als auch das Aty-COP homologe Protein nicht mehr in der Fraktion der löslichen Proteine des Gradientenüberstands, sondern nur in der Membranfraktion detektierbar waren

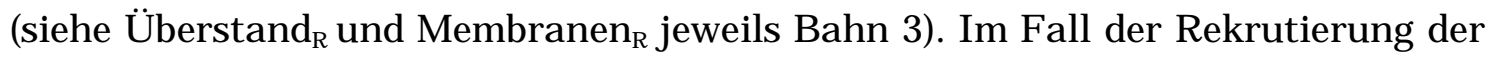
COPII Hüllproteine wurde bei der Konzentrationserhöhung der cytosolischen Proteine um $200 \%$ das AtSar1p homologe Protein ebenfalls quantitativ an die Membranen rekrutiert. Trotz dieser quantitativen Rekrutierung des AtSar1p homolo- 
gen Proteins wurde das AtSec23p homologe Protein auch in diesem Reaktionsansatz nicht an die Membranen rekrutiert.

Da die Membranen nach der Rekrutierungsreaktion durch eine Zentrifugation von den löslichen cytosolischen Proteinen getrennt worden waren, wurde zur Kontrolle

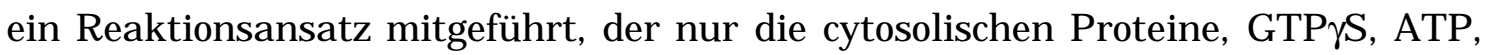
das ATP regenerierende System und anstelle der Membranen Induktionspuffer enthielt. Keines der Markerproteine der Proteinhüllen der COP Vesikel wurde jedoch durch die Zentrifugation sedimentiert (siehe Abbildung 3.2-4 links). Daraus ließ sich schließen, daß die Detektion der Hüllproteine der COP Vesikel in den Membranfraktionen (siehe Abbildung 3.2-4 rechts) nicht auf die Sedimentation von unspezifischen Aggregaten der cytosolischen Proteine, sondern auf deren selektive Rekrutierung zurückzuführen ist.

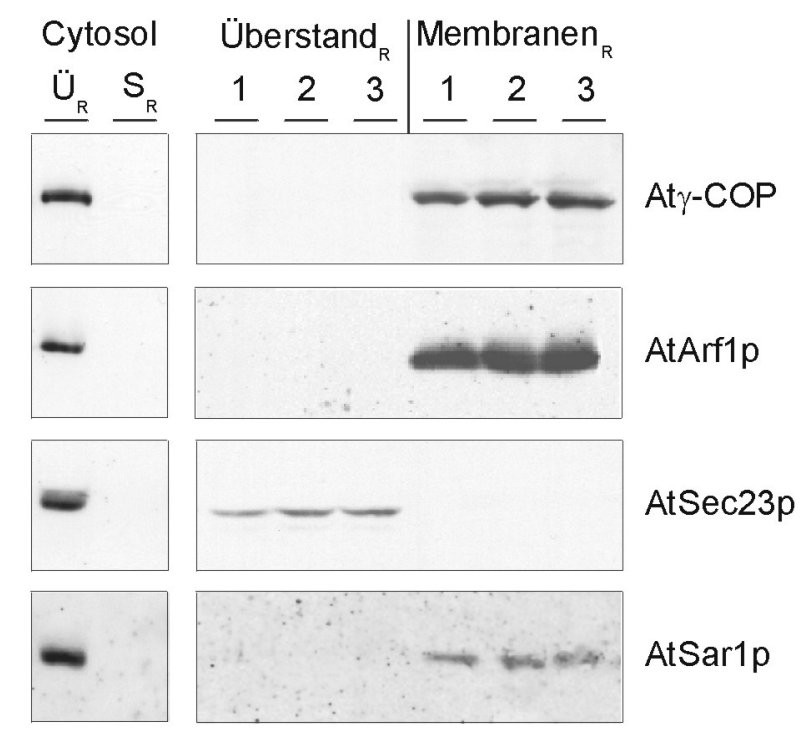

Abbildung 3.2-4: Rekrutierung der Hüllproteine mit erhöhten Verhältnissen von cytosolischen Proteinen zu Membranen.

Links: Kontrollansatz ohne Membranen ( $\ddot{U}_{R}$ : lösliche Proteine des Gradientenüberstands nach der Rekrutierungsreaktion; $S_{R}$ : Sediment des Gradienten).

Rechts: Lösliche Proteine des Gradientenüberstands sowie Membranen nach der Rekrutierungsreaktion mit um 30 \% (1), 100 \% (2) und 200 \% (3) erhöhtem Verhältnis von cytosolischen Proteinen zu Membranen. 
Nachdem sich die Selektivität der Rekrutierungsreaktion für die COPI Hüllproteine im Vergleich zu den COPII Hüllproteinen herausgestellt hatte, sollte nun die Spezifität dieser Rekrutierungsreaktion gezeigt werden.

Um auszuschließen, daß die durch die in vitro Reaktion herbeigeführte Membranassoziation der Hüllproteine auf unspezifische, oberflächenbedingte Anlagerungen zurückzuführen ist, wurde im nächsten Schritt der Einfluß von BFA auf die Rekrutierungsreaktion untersucht. Dieser Stoffwechselmetabolit aus Pilzen stabilisiert den GEF-ARF-GDP Komplex und inhibiert so spezifisch die Rekrutierung des Coatomers in Hefen und Säugetierzellen (siehe 1.5.2). Hierzu wurden Rekrutierungsreaktionen durchgeführt (siehe 2.15), bei denen der Reaktionsansatz vor der Zugabe der Membranen mit einer finalen Konzentration von $300 \mu$ M BFA versetzt worden war. Zur Kontrolle wurden jeweils Reaktionsansätze ohne BFA mitgeführt. Die quantitative Auswertung der Western-Blot Analysen der Membranfraktion zeigte beim Vergleich der in Gegenwart von BFA durchgeführten Reaktionen mit den Kontrollansätzen ohne BFA eine um $60 \%$ reduzierte Rekrutierung der COPI Hüllproteine (siehe Abbildung 3.2-5). Da sowohl die Rekrutierung des AtArf1p als auch die des At $\gamma$-COP homologen Proteins durch BFA inhibiert worden war, ließ darauf schließen, daß es sich bei ihrer Rekrutierung um eine spezifisch ablaufende Reaktion handelt.

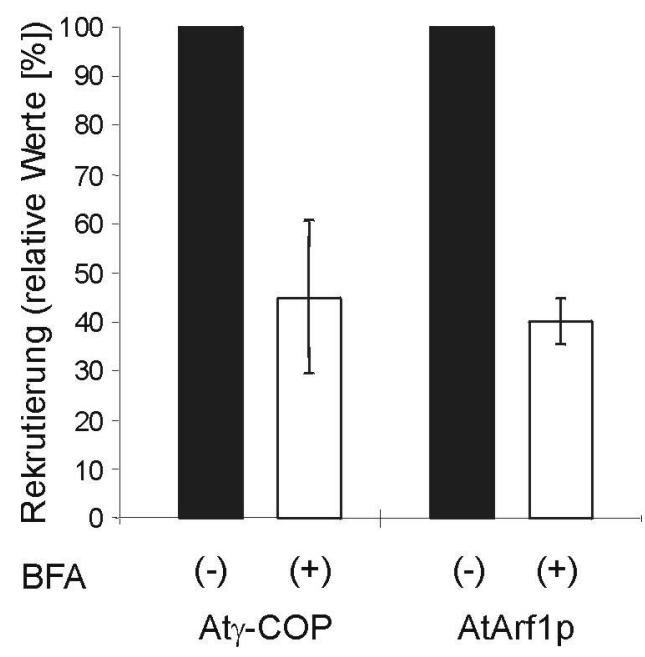

Abbildung 3.2-5: Inhibierung der Rekrutierung der COPI Hüllproteine durch BFA. Vergleich der Rekrutierung des Aty-COP (links) und des AtArf1p homologen Proteins (rechts) +/- 300 MM BFA durch die quantitative Auswertung der Western-Blot Analyse der Membranfraktion nach der Rekrutierungsreaktion. 


\subsubsection{Heterologe Rekrutierung der Hüllproteine der COPI Vesikel}

Da durch die homologen Rekrutierungsstudien mit cytosolischen Proteinen und einer angereicherten ER —und Golgi-Membranfraktion aus Blumenkohl die selektive, spezifische Rekrutierung der Hüllproteine der COPI Vesikel gezeigt worden war (siehe 3.2.2 und 3.2.3), sollte nun die heterologe Rekrutierung dieser cytosolischen Proteine aus Blumenkohl an einer Membranfraktion aus Tabak untersucht werden. Es wurde Tabak ausgewählt, da er im Gegensatz zu Blumenkohl die Möglichkeit bietet, durch genetische Modifikationen Reporterproteine in das Versuchssystem einzuführen, die weiterführende Untersuchungen des COPI Vesikel vermittelten Proteintransports ermöglichen (siehe 3.5).

Zur heterologen Rekrutierung wurden eine angereicherte ER- und GolgiMembranfraktion, wie in 2.13.2 beschrieben, isoliert und nach der Behandlung mit $300 \mathrm{mM}$ KJ zur Dissoziation von endogenen Hüllproteinen der COP Vesikel (siehe 2.14) mit cytosolischen Proteinen aus Blumenkohl in Gegenwart von GTP $\gamma$ S, ATP und einem ATP regenerierenden System inkubiert (siehe 2.15). Die in Abbildung 3.2-6 dargestellte Western-Blot Analyse zeigt eindeutig, daß auch in diesem heterologen Versuchssystem sowohl das AtArf1p als auch das Aty-COP homologe Protein an die Tabakmembranen rekrutiert worden waren. Dieses Ergebnis läßt darauf schließen, daß der Mechanismus der Rekrutierungsreaktion auch innerhalb der dikotylen Pflanzen konserviert ist.

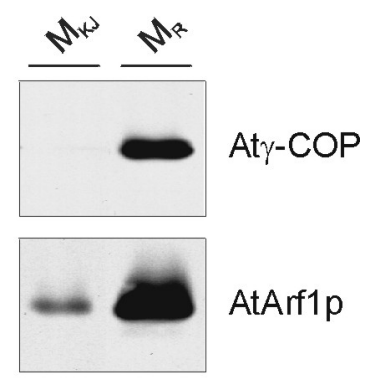

Abbildung 3.2-6: Heterologe Rekrutierung der Hüllproteine der COPI Vesikel mit cytosolischen Proteinen aus Blumenkohl und einer ER- und Golgi-Membranfraktion aus Tabak. ( $M_{K J}$ : Membranen nach Behandlung mit KJ; $M_{R}$ : Membranen nach der Rekrutierungsreaktion) 


\subsubsection{Charakterisierung der Membranen nach der Rekrutierungsreaktion}

Nachdem die in vitro Rekrutierungsreaktion der Hüllproteine der COP Vesikel charakterisiert worden war, wurden im nächsten Schritt die Auswirkungen dieser Reaktion auf die eingesetzten Membranen untersucht. Hierzu wurden Rekrutierungsexperimente, wie in 2.15 beschrieben, durchgeführt, jedoch wurden die Membranen nach der Inkubation durch eine isopyknische Zentrifugation mit kontinuierlichen Saccharosedichtegradienten von 30-50 \% (w/w) Saccharose von den löslichen Proteinen des Ansatzes getrennt. Zum Vergleich wurden Reaktionsansätze, die anstelle der cytosolischen Proteine Induktionspuffer enthielten, mitgeführt. Zur Differenzierung der Auswirkungen der Rekrutierungsreaktion auf die eingesetzten Membranen wurde die Verteilung von Calnexin und BiP als Markerproteine für das ER und RGP als Markerprotein für den Golgi-Apparat (Dhugga et al., 1997) sowie das AtSar1p, das AtSec23p und das Aty-COP homologe Protein als Markerproteine der Proteinhüllen der COP Vesikel in den Fraktionen der Saccharosedichtegradienten durch Western-Blot Analysen detektiert.

Nach der Rekrutierungsreaktion zeigten sowohl Calnexin und BiP als auch RGP in dem Saccharosedichtegradienten ein Verteilungsmaximum im Bereich von 30-38 \% (w/w) Saccharose und im Gegensatz zu der Kontrolle ein zweites Verteilungsmaximum im Bereich von 43-48 \% (w/w) Saccharose (siehe Abbildung 3.2-7). Die Lokalisierung sowohl des Aty-COP als auch des AtSar1p homologen Proteins in diesem Bereich zeigt, daß die Erhöhung der Schwebedichte der ER- und Golgi-Membranen auf die Rekrutierungsreaktionen zurückzuführen ist. Weiterhin konnte durch diese Kolokalisation von Membranen und Hüllproteinen die Sedimentation unspezifischer Proteinaggregate ausgeschlossen werden. Darüber hinaus war das AtSar1p

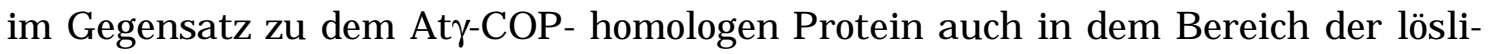
chen Proteine des Gradienten detektierbar. Dieses deutete darauf hin, daß eine Sättigung der Rekrutierung dieses Proteins erreicht worden war. Trotz dieser Sättigung wurde das AtSec23p homologe Protein jedoch nicht an die Membranen rekrutiert, sondern verblieb in dem Bereich der löslichen Proteine des Gradienten $(<30 \%(\mathrm{w} / \mathrm{w})$ Saccharose).

Da durch die Rekrutierungsreaktion sowohl die Schwebedichte der Golgi- als auch die der ER-Membranen deutlich erhöht worden war, eröffnete sich die Frage, ob die Erhöhung der Schwebedichte der ER-Membranen tatsächlich auf die Rekrutierung des $22 \mathrm{kDa}$ AtSar1p homologen Proteins oder vielmehr auf die Anlagerung der als Folge einer kontinuierlich ablaufenden Rekrutierung von Hüllproteinen in vitro gebildeten COPI Vesikel an den ER-Membranen als Akzeptor zurückzuführen sei. Zur Untersuchung dieser Fragestellung wurden im nächsten Schritt Experimente zu Induktion und Isolation von COPI Vesikeln durchgeführt. 


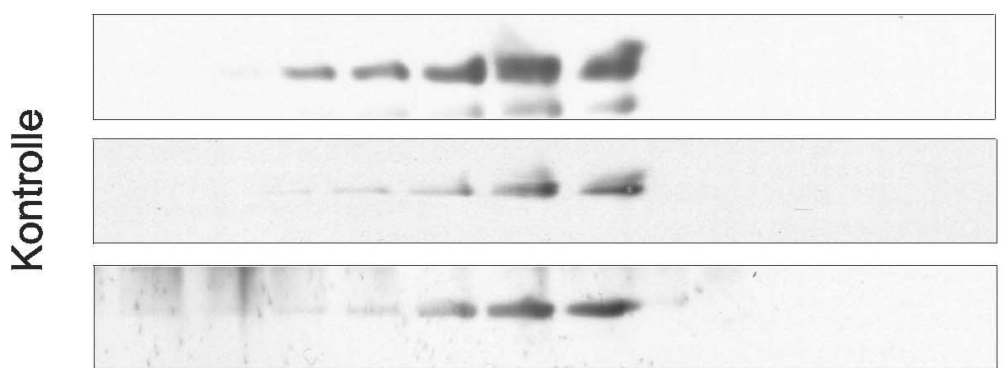

Calnexin

BiP

RGP

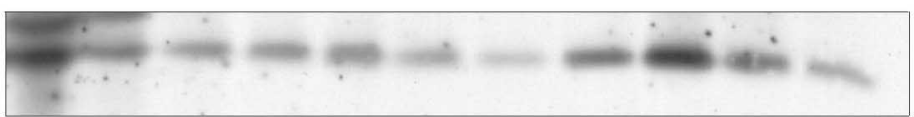

AtSar1p

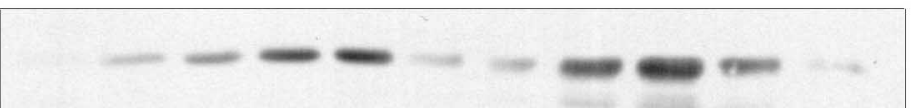

Calnexin

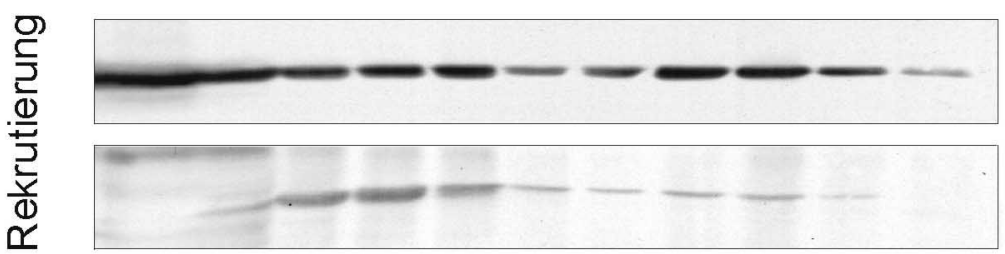

BiP

RGP

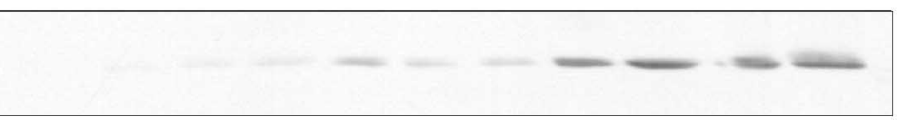

At $\gamma-\mathrm{COP}$

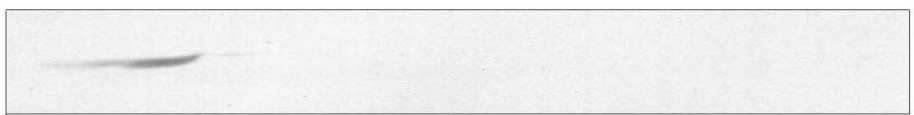

AtSec23p

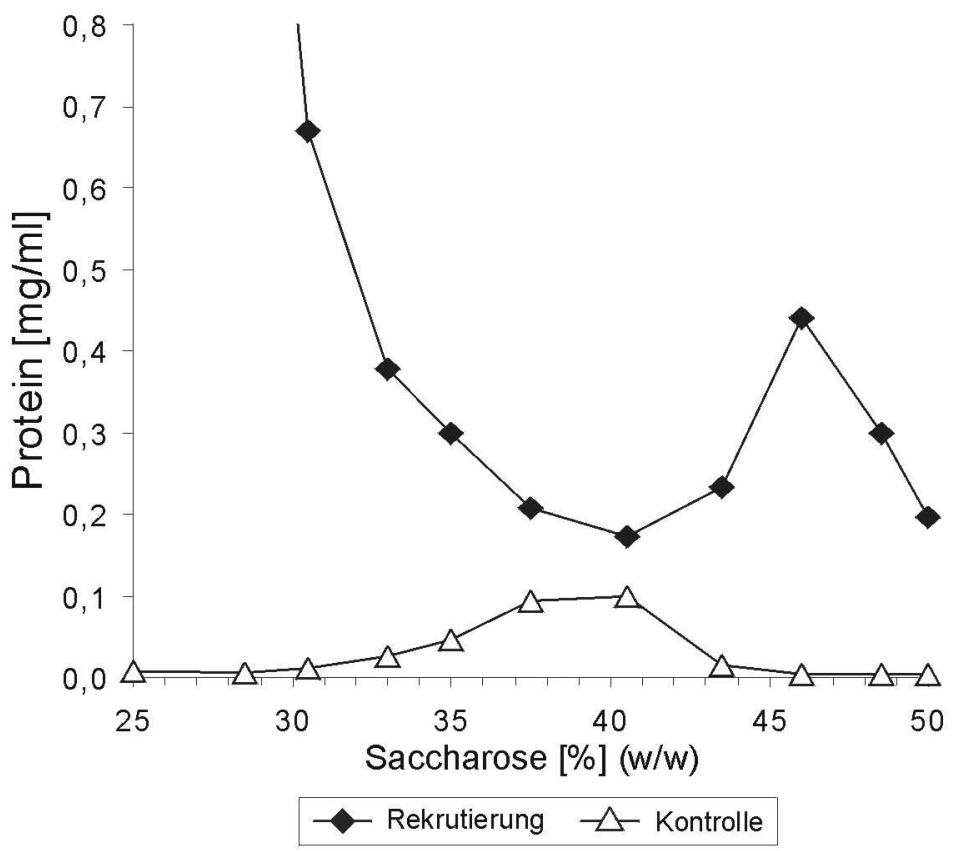

Abbildung 3.2-7: Rekrutierungsinduzierte Änderung der Schwebedichte der Membranen. Oben: Verteilung der Markerproteine Calnexin, BiP und RGP des ohne cytosolische Proteine mitgeführten Kontrollansatzes im kontinuierlichen Saccharosedichtegradienten.

Mitte: Verteilung der Markerproteine Calnexin, BiP, RGP sowie des Sar1p, At $\gamma$-COP und des AtSec23p homologen Proteins nach der Rekrutierungsreaktion im kontinuierlichen Saccharosedichtegradienten.

Unten: Vergleich der Proteinverteilung des Rekrutierungsansatzes mit der des Kontrollansatzes in den kontinuierlichen Saccharosedichtegradienten. 


\subsection{Induktion von COPI Vesikeln in vitro}

Nachdem die selektive Rekrutierung der Hüllproteine der COPI Vesikel sowohl mit einem homologen als auch mit einem heterologen Versuchssystem in vitro rekonstruiert und charakterisiert worden war, wurde nun untersucht, ob die induzierte Rekrutierung der COPI Hüllproteine zur Bildung von COPI Vesikeln führt. Da alle Reaktionsansätze zur in vitro Rekrutierung der Hüllproteine bereits GTP $\gamma$ S zur Stabilisierung der rekrutierten Hüllproteine (siehe 1.5.2) sowie ATP und ein ATP regenerierendes System, das die Bildung und Freisetzung von COP Vesikel begünstigt, enthielten, bestand die Möglichkeit, daß unter diesen Reaktionsbedingungen COPI Vesikel als Konsequenz der erfolgten Rekrutierung gebildet und freigesetzt worden waren. In den nachfolgenden Experimenten sollte die in vitro Induktion der COPI Vesikel durch die Isolation einer angereicherten COPI Vesikel Fraktion bewiesen werden.

\subsubsection{Isolation einer angereicherten COP Vesikel Fraktion}

Zur Isolation einer angereicherten COPI Vesikel Fraktion wurden zunächst die ER- und Golgi-Membranen mit den cytosolischen Proteinen, wie in 2.16 .1 beschrieben, inkubiert und im Anschluß durch eine isopyknische Zentrifugation mit diskontinuierlichen Saccharosedichtegradienten von den löslichen Proteinen des Induktionsansatzes getrennt. Da sich die in Gegenwart von GTP $\gamma \mathrm{S}$ gebildeten COPI Vesikel aufgrund ihrer nicht dissoziierbaren Proteinhülle zwar an ihre Akzeptormembranen anlagern, jedoch nicht mit ihnen fusionieren können (Melançon et al., 1987), wird ihre Isolation durch eine $\mathrm{KCl}$ induzierte Dissoziation von den Akzeptormembranen ermöglicht (Malhotra et al., 1989). Hierzu wurden die Membranen mit einer finalen Konzentration von $250 \mathrm{mM} \mathrm{KCl}$ versetzt und $30 \mathrm{~min}$ auf einem Rotationsinkubator inkubiert (2.16.2). Zur Anreicherung der dissoziierten Vesikel wurden zunächst die Donor- bzw. Akzeptormembranen des Dissoziationsansatzes durch eine Zentrifugation bei $30.000 \mathrm{~g}_{\max }$ für $30 \mathrm{~min}$ sedimentiert. Im Anschluß wurde der Überstand dieser Zentrifugation auf einen kontinuierlichen Saccharosedichtegradienten aufgetragen und $16 \mathrm{~h}$ bei $100.000 \mathrm{~g}_{\max }$ zentrifugiert (2.16.2). Die in Abbildung 3.3-1 dargestellten Western-Blot Analysen der Fraktionen des Saccharosedichtegradienten nach gleichen Volumina zeigt das Verteilungsprofil des Aty-COP, des AtArf1p und des AtSar1p homologen Proteins, der ERMarkerproteine BiP und Calnexin sowie des Markerproteins der Golgi-Membranen RGP. Hierbei zeigten sowohl BiP, Calnexin und RGP als auch das AtSar1p homologe Protein ein breites Verteilungsmaximum in dem Dichtebereich von 30-41,5 \% (w/w) Saccharose (Fraktionen 6-10). In der nachfolgenden Fraktion (42\% (w/w) Saccharose fielen die Signalstärken dieser Proteine drastisch ab und waren in Fraktion 12 (45\% (w/w) Saccharose) nicht mehr detektierbar. Im Gegensatz dazu lag das Verteilungsmaximum des Aty-COP und des AtArf1p homologen Proteins in dem Dichtebereich von 41-45 \% (w/w) Saccharose (Fraktion 10-12). Die Tatsache, 
daß in der Fraktion 12 (45\% (w/w) Saccharose ) sowohl das Aty-COP als auch das AtArf1p homologe Protein deutlich detektierbar war, die Markerproteine der ERund Golgi-Membranen jedoch nicht nachgewiesen werden konnten, führte zu der Vermutung, daß diese Fraktion tatsächlich in vitro induzierte COPI Vesikel enthielt. Weiterhin war die mit 42-45 \% (w/w) Saccharose beschriebene Schwebedichte von induzierten COPI Vesikeln der Säugetierzellen (Malhotra et al., 1989) mit der Saccharosedichte dieser Fraktion vergleichbar. Da das Ergebnis dieser biochemischen Charakterisierung auf die erfolgte Induktion und Anreicherung von COPI Vesikeln schließen ließ, sollte deren Existenz im Anschluß durch die elektronenmikroskopische Charakterisierung der Fraktion 12 (45\% (w/w) Saccharose) bewiesen werden.

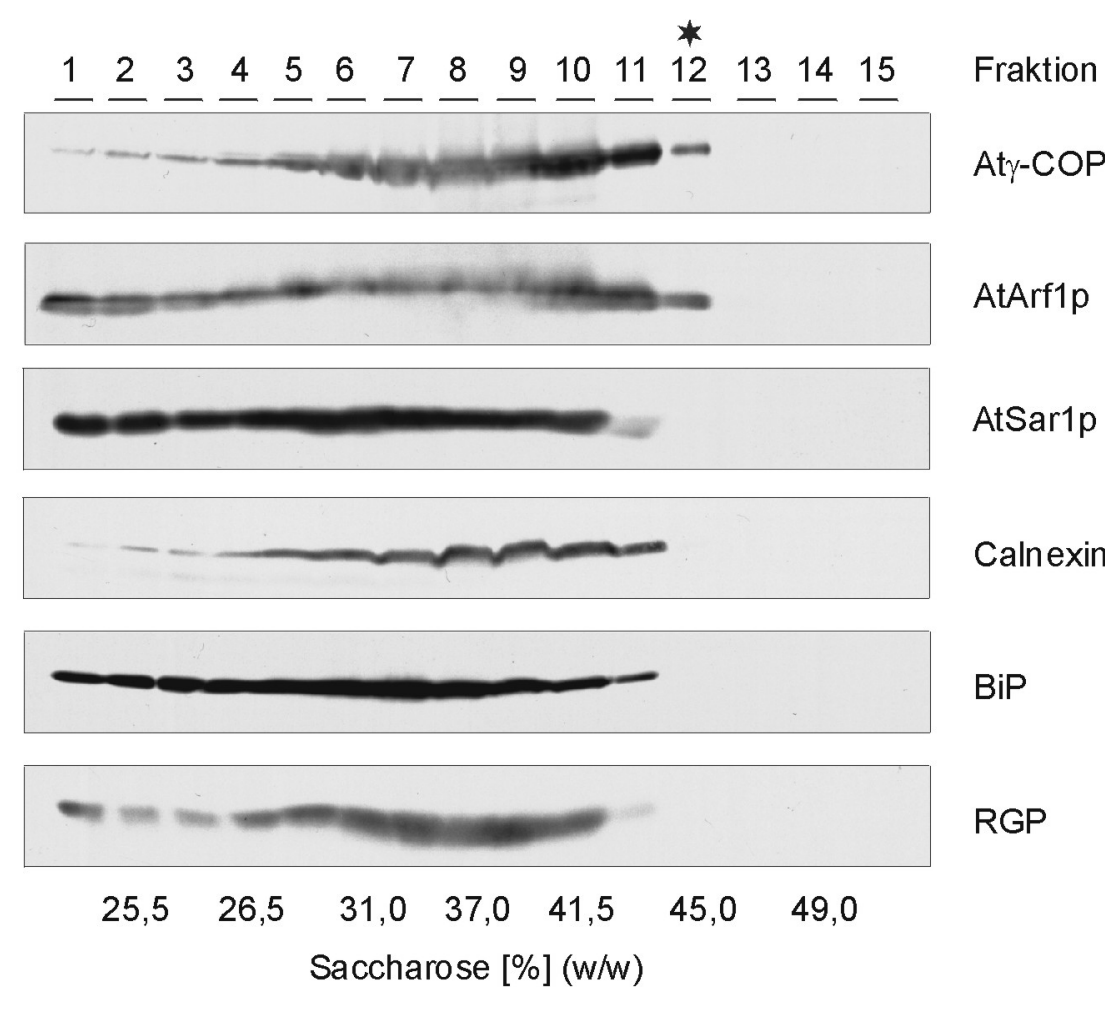

Abbildung 3.3-1: Isolation einer angereicherten COPI Vesikel Fraktion. Analyse des $30.000 \mathrm{~g}_{\max }$ Zentrifugationsüberstands nach der Behandlung der Membranen mit $250 \mathrm{mM} \mathrm{KCl}$ durch isopyknische Zentrifugation mit kontinuierlichen Saccharosedichtegradienten. Verteilungsprofil des Aty-COP, AtArf1p und AtSar1p homologen Proteins, des GolgiMarkerproteins RGP und der ER-Markerproteine BiP und Calnexin in den Fraktionen des kontinuierlichen Dichtegradienten. (Hypothetische COPI Vesikel Fraktion; (45 \% (w/w) Saccharose) 


\subsubsection{Elektronenmikroskopischer Nachweis der COP Vesikel}

Zur elektronenmikroskopischen Charakterisierung der in 3.3.1 isolierten Fraktion (siehe Abbildung 3.3-1, Fraktion 12 (45\% (w/w) Saccharose) wurde aufgrund der geringen Proteinmenge von ca. $20 \mu \mathrm{g}$ das Verfahren der Negativkontrastierung gewählt (siehe 2.22.1). In der in Abbildung 3.3-2 A dargestellten Übersichtsaufnahme zur Charakterisierung der Fraktion sind zahlreiche Vesikel mit einem Durchmesser von ca. 50-60 nm erkennbar. Weiterhin sind in dieser Fraktion jedoch auch deutlich größere, nicht näher charakterisierbare membranöse Strukturen sowie CCVs vorhanden. Der Vergleich eines CCVs mit den deutlich kleineren 50$60 \mathrm{~nm}$ Vesikeln (siehe Abbildung 3.3-2 B) zeigt, daß die Proteinhülle dieser Vesikel keine regelmäßigen Strukturen aufweist.
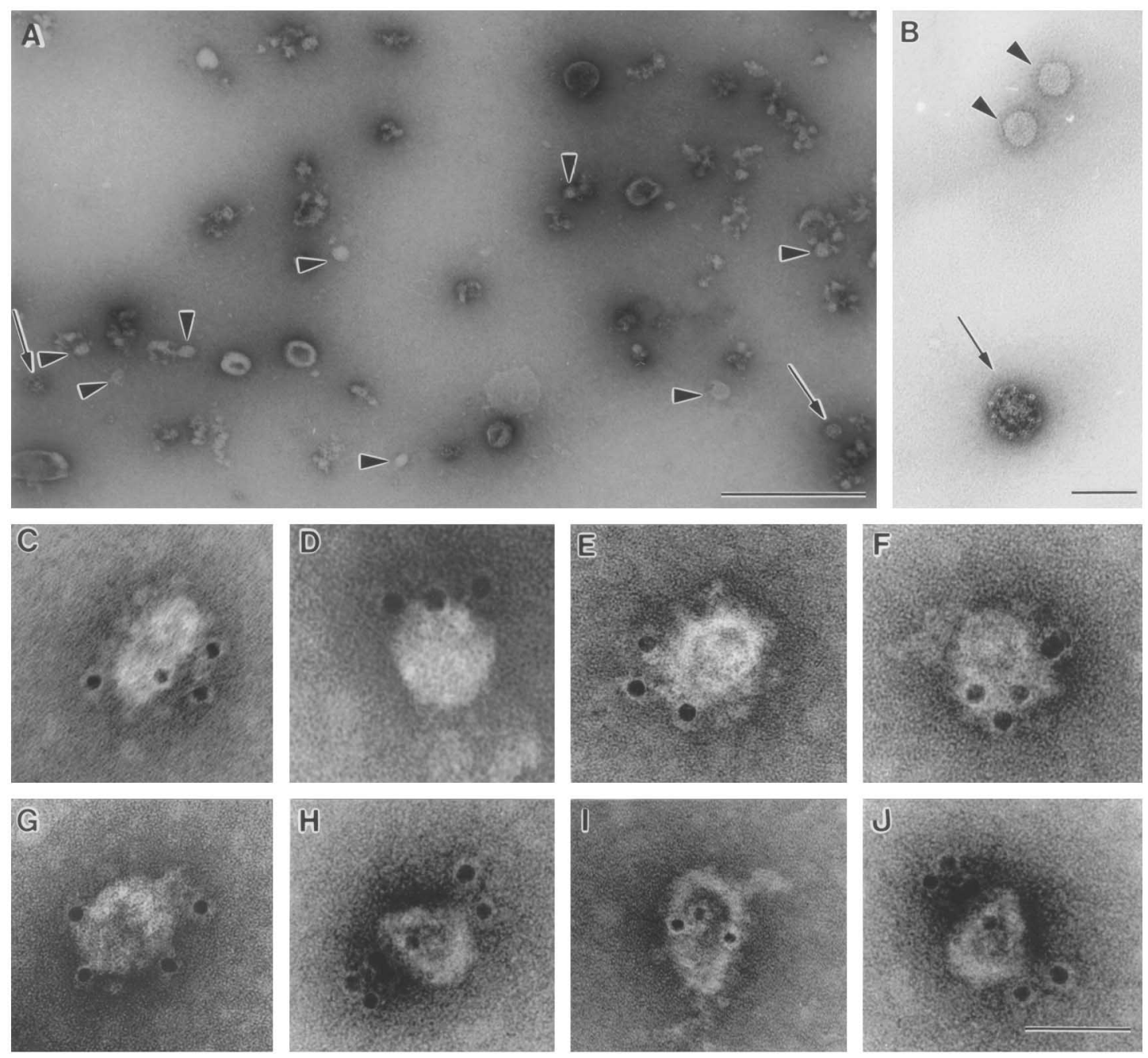

Abbildung 3.3-2: Elektronenmikroskopische Charakterisierung der angereicherten COPI Vesikel Fraktion (siehe Abbildung 3.3-1, Fraktion 12 (45\% (w/w) Saccharose).

A: Übersichtsaufnahme der negativkontrastierten Fraktion. Die Pfeile weisen auf CCVs, die Pfeilspitzen weisen auf mögliche COP Vesikel (Strichlänge $1 \mu \mathrm{m}$ ).

B: Direkter Vergleich der durch Pfeilspitzen gekennzeichneten COP Vesikel mit einem durch einen Pfeil gekennzeichneten CCV (Strichlänge $100 \mathrm{~nm}$ ).

C-J: Immunogold-Negativkontrastierung der COP Vesikel mit dem Zme-COP Antiserum (Strichlänge $100 \mathrm{~nm}$ ). 
Zur Identifizierung von COPI Vesikeln in der Fraktion wurde diese einer Immunogold-Negativkontrastierung unterzogen. Hierzu wurde ein gegen das $\varepsilon$-COP homologe Protein aus Mais (Zme-COP) hergestelltes Antiserum (Pimpl et al., 2000) eingesetzt, da $\varepsilon$-COP im Vergleich zu $\gamma$-COP an der Oberfläche des Coatomer Komplexes lokalisiert ist (Duden et al., 1998). Das Zme-COP Antiserum markierte spezifisch nur die 50-60 nm Vesikel. Durch die hohe Markierungsdichte der in Abbildung 3.3-2 C-J dargestellten Vesikel konnte eindeutig bewiesen werden, daß es sich bei diesem Typ von Vesikeln um pflanzliche COPI Vesikel handelt.

\section{$3.4 \alpha$-Amylase als Reporterprotein zur Charakterisierung des Proteintransports in vivo und in vitro}

Nachdem die Methoden zur in vitro Induktion und Isolation von pflanzlichen COPI Vesikeln entwickelt worden waren, sollte im weiteren Verlauf die Fracht dieser induzierten COPI Vesikel charakterisiert werden. Hierzu sollte die $\alpha$-Amylase der Gerste als Reporterprotein dienen, da es sich hierbei um ein sekretorisches Protein handelt, das aufgrund seiner enzymatischen Aktivität quantitativ detektierbar ist (siehe 2.18).

Da den COPI Vesikeln in Hefen und Säugetierzellen auch die Beteiligung an der Retention von ER residenten Proteinen durch deren selektiven Rücktransport vom cis-Golgi-Apparat zum ER zugeschrieben wird, sollte zur Charakterisierung potentieller Frachtmoleküle der COPI Vesikel ein Fusionsprotein aus $\alpha$-Amylase mit dem C-terminalen ER Retentionssignal HDEL (Amylase-HDEL) als Reporterprotein eingesetzt werden. Hierzu mußte jedoch zunächst sowohl die Funktionalität des ER Retentionssignals in Kombination mit der $\alpha$-Amylase sowie dessen Einflu $\beta$ auf die enzymatische Aktivität untersucht werden. Dieses sollte durch transiente Genexpressionsstudien an Tabakprotoplasten erfolgen (siehe 2.11), da diese den direkten Vergleich des Sekretionsverhaltens der Amylase bzw. Amylase-HDEL in Abhängigkeit des ER Retentionssignals ermöglichen. 


\subsubsection{Einfluß der HDEL Sequenz auf die Sekretion der $\alpha$-Amylase in vivo}

Zur Charakterisierung der Auswirkung des ER Retentionssignals auf die Sekretion der $\alpha$-Amylase wurde zunächst die Sekretion der Reporterproteine Amylase und Amylase-HDEL in Tabakprotoplasten über einen Zeitraum von $30 \mathrm{~h}$ untersucht. Hierzu wurden die Protoplasten (siehe 2.11.1) mit dem Amylase bzw. AmylaseHDEL kodierenden Plasmid zur Genexpression durch Elektroporation transfiziert (siehe 2.11.2). In einem Zeitintervall von $2 \mathrm{~h}$ wurden Protoplasten sowie Kulturmedium geerntet (siehe 2.11.3) und die Aktivität der $\alpha$-Amylase gemessen (siehe Abbildung 3.4-1).

Amylase
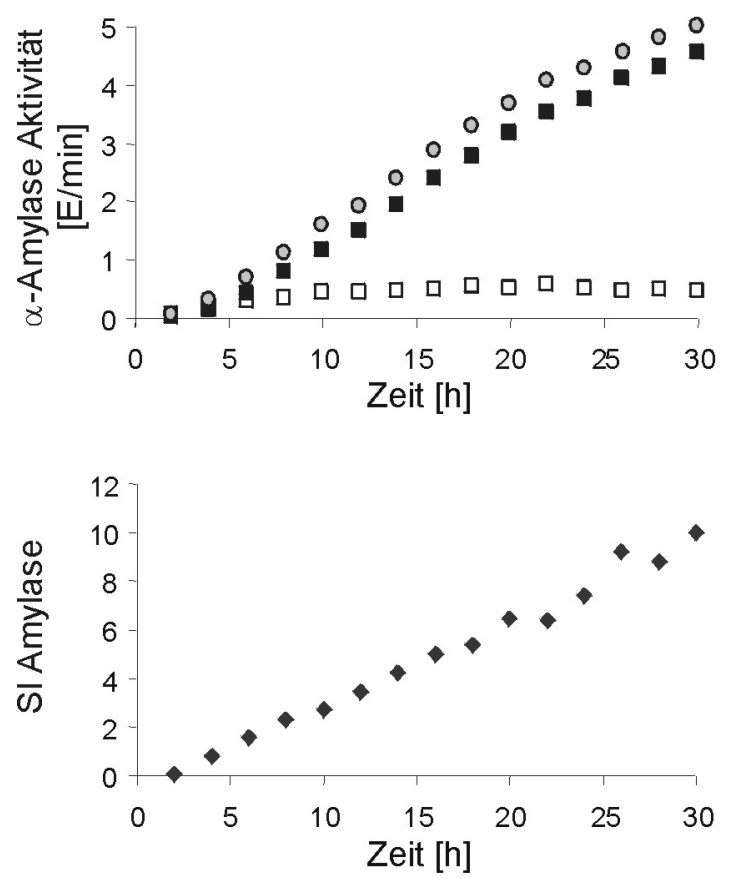

Amylase-HDEL
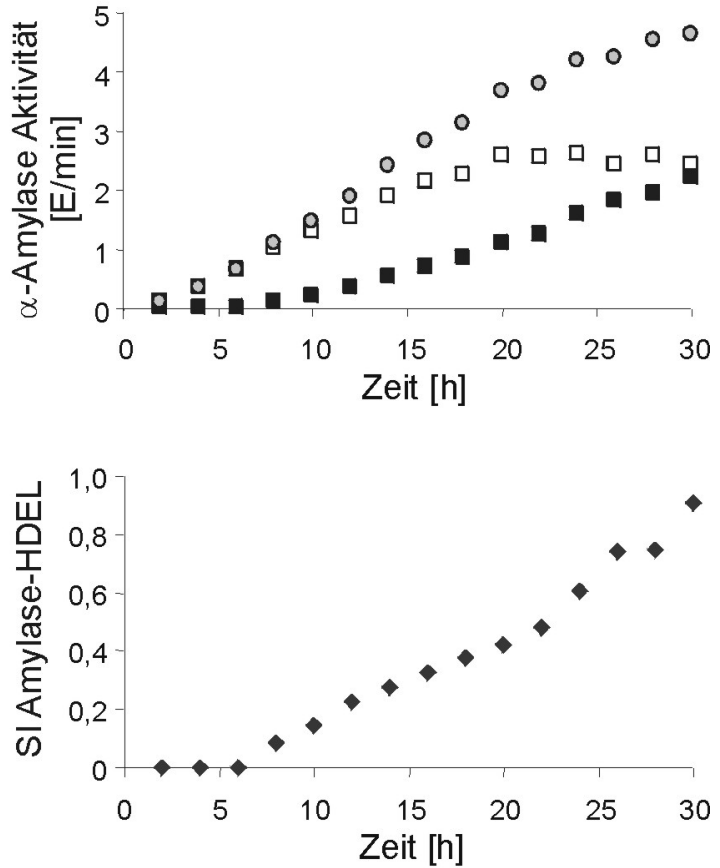

Abbildung 3.4-1: Transiente Genexpression von Amylase und Amylase-HDEL in Tabakprotoplasten über einen Zeitraum von $30 \mathrm{~h}$.

Oben: Analyse der Sekretion von Amylase und Amylase-HDEL differenziert in $\alpha$-Amylase Aktivität des Kulturmediums (Medium), der Protoplasten (Zellen) und Gesamtaktivität von Medium und Zellen.

Unten: Vergleich des Sekretionsindexes (SI) von Amylase und Amylase-HDEL. 
Durch die Bestimmung des Sekretionsindexes (SI), dem Quotienten aus der $\alpha$-Amylase Aktivität des Mediums und der $\alpha$-Amylase Aktivität der Zellen, wurde die Kontinuität der Sekretion untersucht. Der in Abbildung 3.4-1 dargestellte Vergleich der $\alpha$-Amylase Gesamtaktivitäten in Medium und Zellen der Amylase und der Amylase-HDEL zeigt, daß beide Reporterproteine über den gesamten Zeitraum von $30 \mathrm{~h}$ konstant in gleichen Mengen synthetisiert wurden. Dieses zeigt weiterhin, daß die HDEL Sequenz keinen Einfluß auf die Synthese und die enzymatische Aktivität der Reporterproteine hatte.

Die Verteilung der $\alpha$-Amylase Aktivität in Medium und Zellen wies in Abhängigkeit der HDEL Sequenz jedoch charakteristische Unterschiede auf. Im Fall der Amylase konnte bereits $4 \mathrm{~h}$ nach der Transfektion die enzymatische Aktivität in dem Medium detektiert werden. Bereits $6 \mathrm{~h}$ nach der Transfektion überstieg die $\alpha$-Amylase Aktivität des Mediums die der Zellen. Da im weiteren Zeitverlauf die Aktivität in den Zellen auf diesem niedrigen Niveau verblieb, während die Aktivität in dem Medium kontinuierlich anstieg, ließ darauf schließen, daß die gesamte de novo synthetisierte Amylase sekretiert worden war. Im Gegensatz dazu war im Fall der Amylase-HDEL in den ersten $10 \mathrm{~h}$ nach der Transfektion zunächst ein stetiger Anstieg der $\alpha$-Amylase Aktivität in den Zellen meßbar, bevor diese im Medium detektiert werden konnte. Im weiteren Verlauf stieg die intrazelluläre Aktivität kontinuierlich an und erreichte erst $20 \mathrm{~h}$ nach der Transfektion ihr Maximum. Während die Amylase bereits nach $6 \mathrm{~h}$ höhere Aktivitäten in dem Medium als in den Zellen zeigte, wurde dieser Zustand im Fall der Amylase-HDEL auch nach 30 h nicht erreicht. Die Abhängigkeit der Sekretion der Amylase-HDEL von der intrazellulären Konzentration ließ darauf schließen, daß bis zum Erreichen eines intrazellulären Schwellenwertes die Retention der Amylase-HDEL in den Zellen erfolgte und daß die Sekretion erst beim Überschreiten dieses Schwellenwertes als Folge der Sättigung des im cis-Golgi lokalisierten HDEL-Rezeptors ERD2 einsetzte. Der Vergleich der Sekretionsindizes von Amylase und AmylaseHDEL zeigt für beide Reporterproteine einen linearen Anstieg, wobei die Sekretion der Amylase-HDEL um den Faktor 10 geringer war als die der Amylase. Dieser lineare Verlauf ermöglichte es, in den weiteren Experimenten die Sekretionsraten der Reporterproteine durch die Bestimmung der Sekretionsindizes zu einem festen Zeitpunkt miteinander zu vergleichen. 


\subsubsection{Sekretion der Amylase-HDEL durch die Sättigung der ER Retention}

Da die zeitabhängige Expression der Amylase-HDEL Hinweise auf die Sättigung des ER Retentionssystems lieferte, sollte im nächsten Schritt der Einfluß der Proteinmenge auf die Sekretion untersucht werden. Hierzu wurden transiente Genexpressionen mit verschiedenen Konzentrationen der Amylase bzw. Amylase-HDEL kodierenden Plasmide durchgeführt (siehe 2.11). 24 h nach der Transfektion wurden die Protoplasten und das Kulturmedium zur Messung der $\alpha$-Amylase Aktivität geerntet (siehe 2.11.3 bzw. 2.18). Die in Abbildung 3.4-2 links dargestellte Analyse der $\alpha$-Amylase Gesamtaktivitäten der Medien und der Zellen zeigt nahezu identische Syntheseraten von Amylase und Amylase-HDEL. Die Sekretionsindizes der Reporterproteine zeigen jedoch ein entgegengesetztes Verhalten (siehe Abbildung 3.4-2 rechts). In Übereinstimmung mit der zeitabhängigen Sekretion (siehe Abbildung 3.4-1) erfolgte auch hier bei einer geringen Konzentration der AmylaseHDEL nahezu keine Sekretion und somit die fast vollständige Retention des Proteins im ER. Der deutliche Anstieg der Sekretionsrate mit steigender Proteinkonzentration, ließ darauf schließen, daß die Sekretion der Amylase-HDEL auf die Sättigung der ER Retentionskapazität zurückzuführen ist. Im Gegensatz dazu sanken die Sekretionsraten der Amylase mit steigender Proteinkonzentration stark ab. Diese unterschiedlichen Sekretionsraten in Abhängigkeit des ER Retentionssignals zeigten, daß nicht nur die Retention, sondern auch die Sekretion von Proteinen einer Sättigung unterliegt. Weiterhin verdeutlichte dieses Ergebnis, daß es sich bei der Sekretion und der Retention um zwei unterschiedlich ablaufende intrazelluläre Vorgänge handelt.
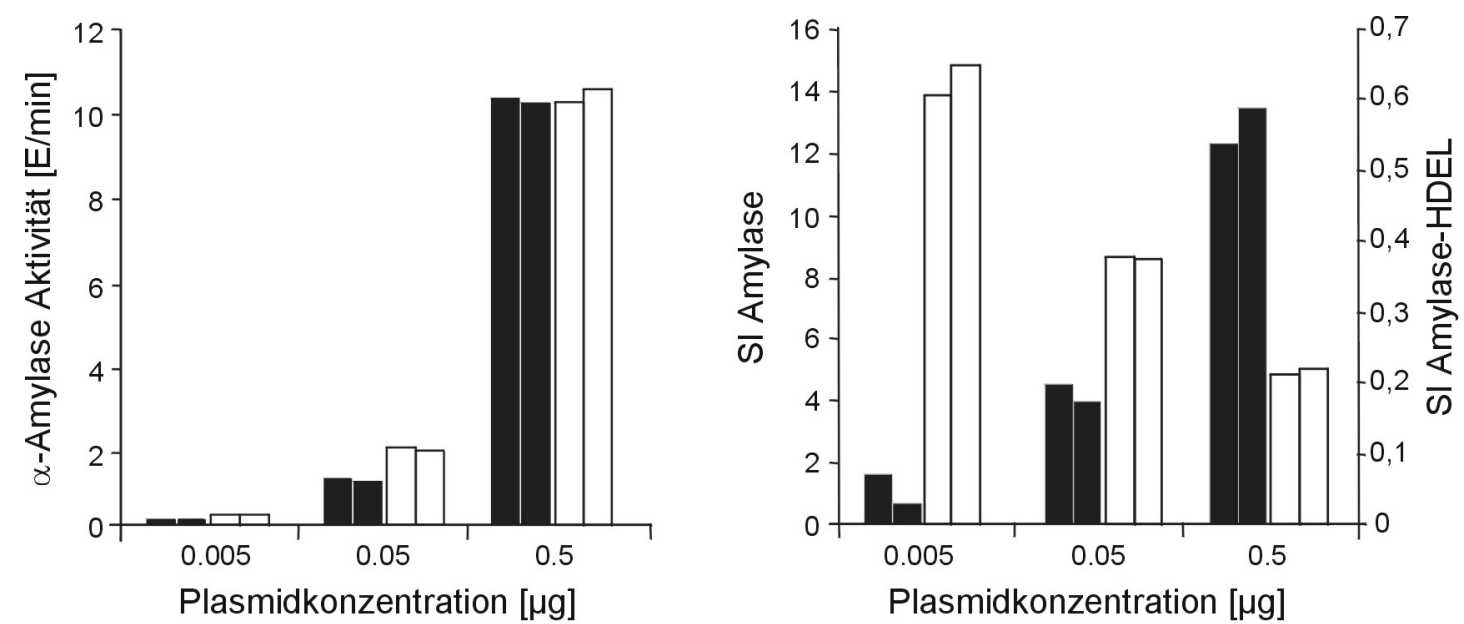

$$
\square \text { Amylase }
$$

Amylase-HDEL

Abbildung 3.4-2: Konzentrationsabhängige Sekretion von Amylase und Amylase-HDEL. Vergleich der $\alpha$-Amylase Gesamtaktivität (Medium und Zellen) von Amylase und AmylaseHDEL (links) sowie der Vergleich der entsprechenden Sekretionsindizes (rechts) in Abhängigkeit der Plasmidkonzentration (Darstellung von zwei unabhängigen Experimenten). 


\subsubsection{Einfluß der Temperatur auf Sekretion und Retention}

Da die vorhergehenden Versuche deutliche Hinweise darauf lieferten, daß es sich bei der Sekretion und der Retention um zwei unterschiedliche intrazelluläre Vorgänge handelt, sollte weiterhin der Einfluß der Temperatur auf die Synthese- und Sekretionsraten beider Reporterproteine untersucht werden. Hierzu wurden Protoplasten nach der Transfektion (siehe 2.11) bei verschiedenen Temperaturen $24 \mathrm{~h}$ inkubiert. Die in Abbildung 3.4-3 links dargestellten Analysen der $\alpha$-Amylase Gesamtaktivitäten zeigt den Einfluß der Temperatur auf die Syntheseraten der Reporterproteine. Mit steigender Temperatur stiegen auch die Syntheseraten beider Reporterproteine an und erreichten ihr Maximum bei einer Temperatur von $25{ }^{\circ} \mathrm{C}$. Bei einer Temperatur von $29^{\circ} \mathrm{C}$ sanken die Syntheseraten bereits ab und erreichten bei einer weiteren Erhöhung auf $34{ }^{\circ} \mathrm{C}$ nur noch ihren halbmaximalen Wert. Da trotz unterschiedlicher physiologischer Bedingungen nahezu identische Gesamtaktivitäten von Amylase und Amylase-HDEL erreicht worden waren, konnte daraus geschlossen werden, daß das ER Retentionssignal keinen Einfluß auf die Synthese und die Stabilität der $\alpha$-Amylase ausübt.
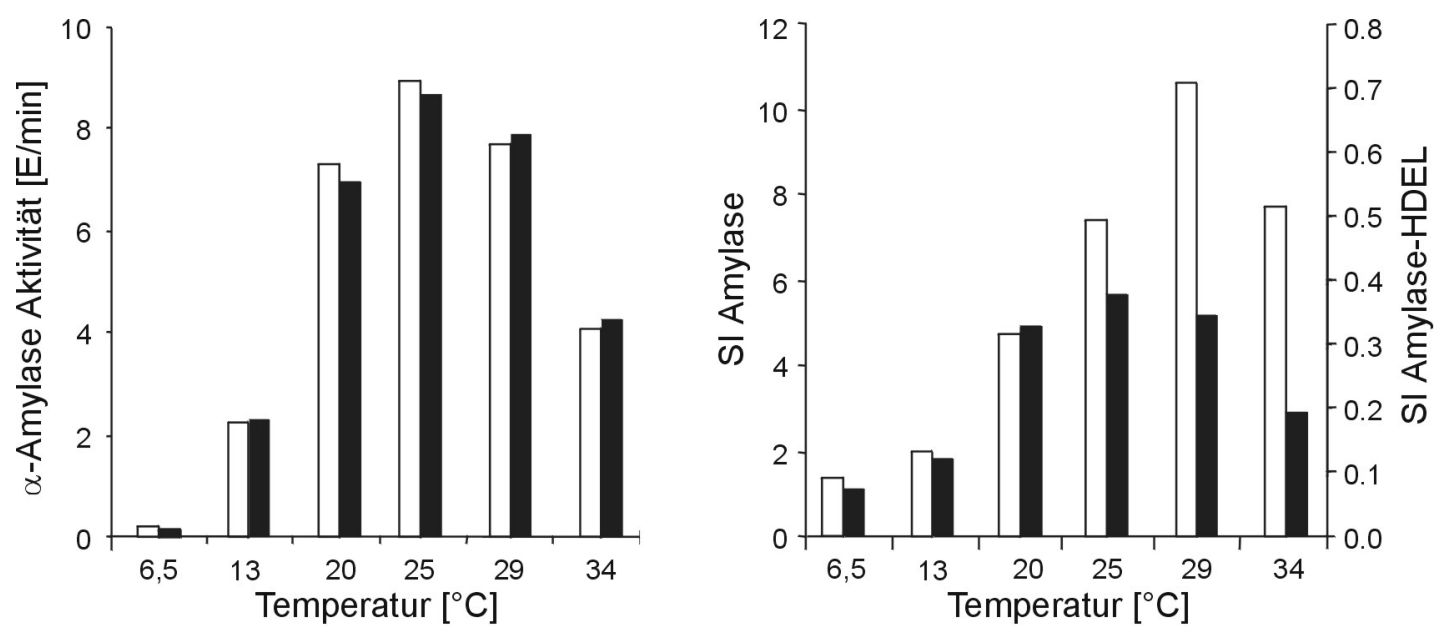

$\square$ Amylase

Amylase-HDEL

Abbildung 3.4-3: Sekretion von Amylase und Amylase-HDEL in Abhängigkeit der Temperatur.

Vergleich der $\alpha$-Amylase Gesamtaktivität (Medium und Zellen) von Amylase und AmylaseHDEL (links) sowie der Vergleich der entsprechenden Sekretionsindizes (rechts).

Der Vergleich der Sekretionsraten der Reporterproteine bei den verschiedenen Temperaturen wies jedoch in Abhängigkeit des ER Retentionssignals signifikante Unterschiede auf (siehe Abbildung 3.4-3 rechts). Während die Amylase ihr Sekretionsmaximum bei $29^{\circ} \mathrm{C}$ erreichte, war hier bereits ein Rückgang der Sekretion der Amylase-HDEL zu verzeichnen, da diese ihr Sekretionsmaximum schon bei einer Temperatur von $25^{\circ} \mathrm{C}$ erreichte. Der Vergleich der Amylase bzw. Amylase-HDEL 
Sekretionsraten bei $20^{\circ} \mathrm{C}$ mit denen von $29{ }^{\circ} \mathrm{C}$ zeigt deutlich, daß diese Unterschiede tatsächlich auf den Einfluß der Temperatur und nicht auf den in Abbildung 3.4-2 dargestellten Einfluß der Proteinkonzentration zurückzuführen sind, da bei diesen beiden Temperaturen nahezu gleiche Mengen von Amylase bzw. Amylase-HDEL synthetisiert worden waren. Die unterschiedlichen Auswirkungen der Temperatur auf die Sekretion von Amylase und Amylase-HDEL zeigte sich auch durch den deutlich schnelleren Rückgang der Sekretionsraten der AmylaseHDEL in dem Temperaturbereich von $25-34{ }^{\circ} \mathrm{C}$. Dieses führte zu der Vermutung, daß durch die Erhöhung der Temperatur auch die Effizienz der Retention von Proteinen im ER ansteigt.

\subsection{Charakterisierung der Fracht der induzierten COPI Vesikel}

Nachdem die Funktionalität des ER Retentionssignals der Amylase-HDEL gezeigt worden war und auch bewiesen werden konnte, daß dieses keinen Einfluß auf die enzymatische Aktivität ausübt, sollte weiterhin untersucht werden, ob dieses Reporterprotein ein Frachtmolekül der in vitro induzierten COPI Vesikel ist.

Hierzu wurden in vitro Induktionsreaktionen mit einem heterologen Versuchssystem aus cytosolischen Proteinen aus Blumenkohl (siehe 2.12.1) und einer angereicherten ER- und Golgi-Membranfraktion $\left(\mathrm{M}_{0}\right)$ aus Tabakpflanzen durchgeführt. Die Tabakpflanzen waren mit dem Genkonstrukt der Amylase-HDEL transformiert worden (siehe 2.1 und 2.13.2). Als Kontrolle diente hierbei ein Induktionsansatz in dem ATP, das ATP regenerierende System und das GTP $\gamma$ S durch Induktionspuffer ersetzt worden waren. Zur Steigerung der Bildung von Vesikeln als Folge der Rekrutierungsreaktion wurden die endogenen Hüllproteine vor der Induktionsreaktion jedoch nicht durch die Behandlung mit KJ von den Membranen dissoziiert. Nachdem die Membranen im Anschluß an die Induktionsreaktion durch die isopyknische Zentrifugation von den löslichen Proteinen des Induktionsansatzes getrennt worden waren, wurden diese zur Dissoziation der induzierten Vesikel von den Akzeptormembranen mit $250 \mathrm{mM} \mathrm{KCl}$ versetzt. Zur Charakterisierung der Verteilung der Frachtmoleküle in Donormembranen und Vesikeln wurde der Dissoziationsansatz direkt auf einen kontinuierlichen Dichtegradienten von 43-50 \% (w/w) Saccharose aufgetragen, der zuvor mit einer Gradientenstufe aus $40 \%$ (w/w) Saccharose als Diffusionsbarriere überschichtet worden war. Nach der Zentrifugation mit $100.000 \mathrm{~g}_{\max }$ für $16 \mathrm{~h}$ wurde die Verteilung der $\alpha$-Amylase (siehe 2.18), des ER residenten Proteins Calreticulin und des At $\gamma$-COP homologen Proteins in dem Kontrollgradienten (siehe Abbildung 3.5-1 A) mit der des Induktionsgradienten (siehe Abbildung 3.5-1 B) verglichen. 
A

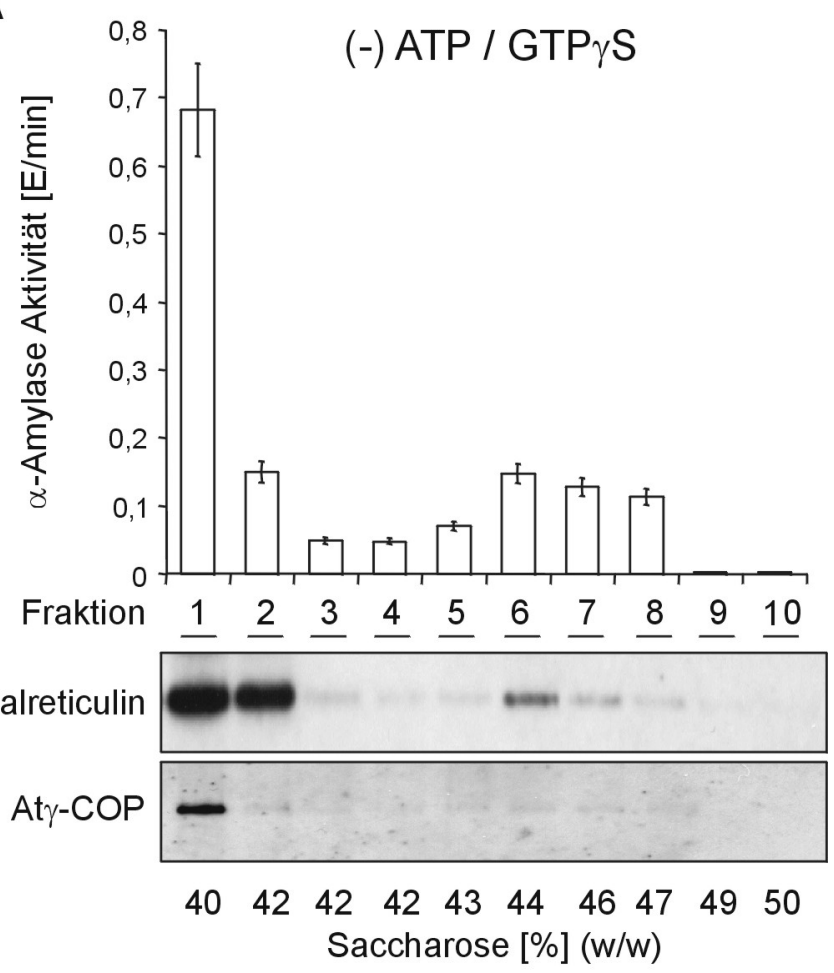

B
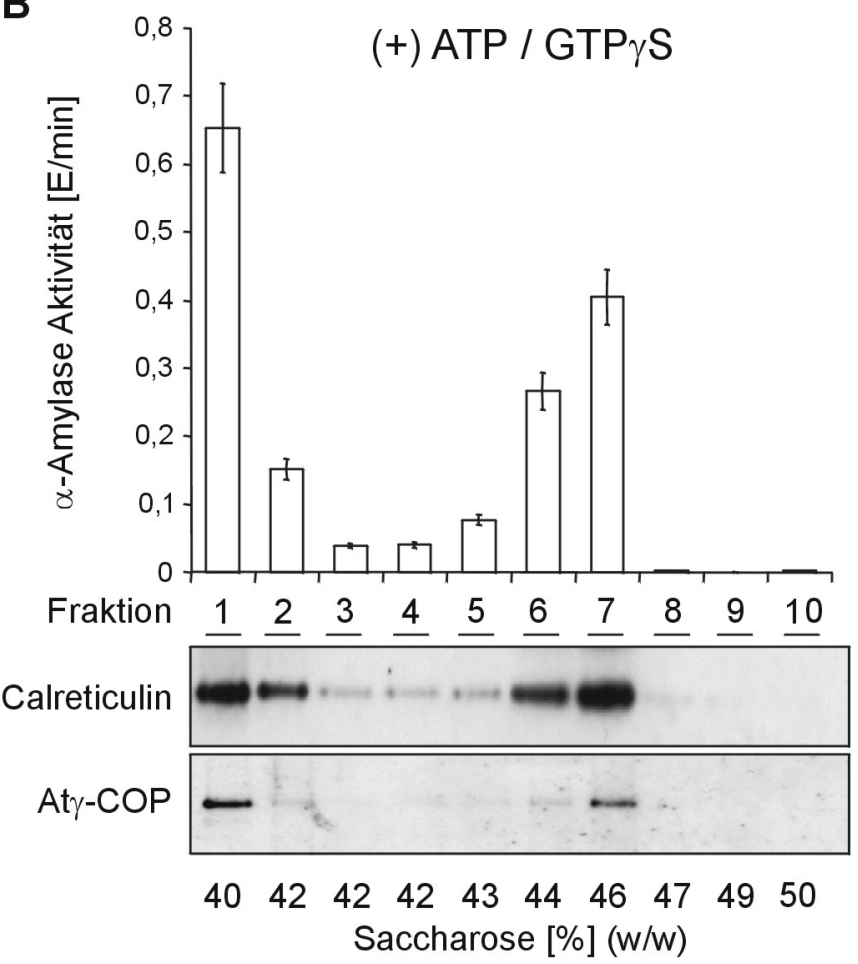

Abbildung 3.5-1: Charakterisierung der Fracht der in vitro induzierten COPI Vesikel. A: Kontrollansatz der heterologen Induktion von COPI Vesikeln ohne GTP $\mathcal{}$ S, ATP und das ATP regenerierende System. Vergleich der Verteilung von $\alpha$-Amylase, Calreticulin und des At $\gamma$-COP homologen Proteins.

B: Heterologe Induktion der COPI Vesikel in Gegenwart von GTP YS, ATP und des ATP regenerierenden Systems. 
Die Analyse des Induktionsgradienten zeigte im Vergleich zu dem Kontrollgradienten das Auftreten eines Aty-COP Signals in dem hohen Dichtebereich von $46 \%$ (w/w) Saccharose (siehe Abbildung 3.5-1 B; Fraktion 7) als Folge der Bildung von COPI Vesikeln.

Die Abhängigkeit des Auftretens dieses Signals von ATP und GTP $\gamma$ S verdeutlicht, daß es sich hierbei nicht um eine unspezifische Anlagerung an die Membranen, sondern um einen spezifisch ablaufenden Reaktionsmechanismus handelt. Weiterhin konnte in dieser Fraktion ebenfalls die deutliche Anreicherung von Calreticulin und $\alpha$-Amylase-HDEL in Abhängigkeit von ATP und GTP $\gamma$ S nachgewiesen werden. Das kongruente Auftreten des At $\gamma$-COP homologen Proteins, Calreticulin und der $\alpha$-Amylase-HDEL in Abhängigkeit von ATP/GTP $\gamma \mathrm{S}$ in dem Saccharosedichtebereich von $46 \%(\mathrm{w} / \mathrm{w})$ des Induktionsgradienten ließ darauf schließen, daß es sich sowohl bei der $\alpha$-Amylase-HDEL als auch bei dem ER residenten Protein Calreticulin um die Frachtmoleküle der in vitro induzierten COPI Vesikel handelt.

\subsection{Beteiligung von COPII Vesikeln am ER Proteinexport in vivo}

Da die Amylase-HDEL und das ER residente Protein Calreticulin als Frachtmoleküle der in vitro induzierten COPI Vesikel identifiziert werden konnten, sollte nun in einem zweiten Schwerpunkt der vorliegenden Arbeit anhand eines in vivo Versuchssystems die physiologische Bedeutung dieser Ergebnisse durch die Charakterisierung des COPII Vesikel vermittelten Exports löslicher Proteine aus dem ER überprüft werden. Dieses erforderte zunächst den Nachweis der Beteiligung von COPII Vesikeln am Export löslicher Proteine aus dem ER. Dieses sollte durch die Charakterisierung der Auswirkung der Inhibierung des COPII Vesikel vermittelten Proteintransports auf den Transport von sekretorischen Proteinen erfolgen. Hierbei sollte der COPII Vesikel vermittelte Transport durch die Überproduktion von Sec12p inhibiert werden, da dieses spezifisch die Bildung der COPII Vesikel verhindert (d'Enfert et al., 1991a; Barlowe \& Schekman, 1993; Nishikawa et al., 1994).

\subsubsection{COPII Vesikel vermittelter Export von Amylase und Amylase-HDEL}

Zum Nachweis der Beteiligung von COPII Vesikeln am Transport der Amylase bzw. Amylase-HDEL wurde in den nachfolgenden Experimenten der Einfluß der Überproduktion eines dem Sec12p der Hefen homologen Proteins aus Arabidopsis (AtSec12p) auf die Sekretion der beiden Reporterproteine untersucht. Hierzu wurden Tabakprotoplasten mit je $2 \mu \mathrm{g}$ des Amylase bzw. Amylase-HDEL und einer steigenden Konzentration von 1-20 $\mu \mathrm{g}$ des AtSec12p kodierenden Plasmids transfiziert (siehe 2.11). Als Kontrolle diente je eine Transfektion mit den Amylase bzw. den Amylase-HDEL kodierenden Plasmiden. Nach der Inkubation bei $25^{\circ} \mathrm{C}$ für $24 \mathrm{~h}$ wurden die $\alpha$-Amylase Aktivitäten des Kulturmediums und der Zellen gemes- 
sen. Zur Überprüfung der Expression des AtSec12p wurden zusätzlich WesternBlot Analysen der Protoplasten mit dem AtSec12p Antiserum durchgeführt (siehe 2.21). Die in Abbildung 3.6-1 dargestellten Sekretionsraten von Amylase und Amylase-HDEL zeigen deutlich die Inhibierung der Sekretion beider Reporterproteine in Abhängigkeit der Konzentration von AtSec12p. Hierbei zeigten hohe Expressionsraten des AtSec12p (10 und $20 \mu \mathrm{g}$ des Plasmids) eine noch stärkere Auswirkung auf die Inhibierung der Sekretion der Amylase-HDEL als auf die der Amylase. Die Inhibierung beider Reporterproteine ließ darauf schließen, daß sowohl die Amylase als auch die Amylase-HDEL in die COPII Vesikel gelangen und somit durch den COPII Vesikel abhängigen Proteintransport aus dem ER exportiert werden. Dieses Ergebnis unterstützt weiterhin die Theorie, daß die Retention von Proteinen im ER nicht durch die Verhinderung ihres Exports, sondern vielmehr durch ihren selektiven Rücktransport vom Golgi-Apparat erreicht wird.

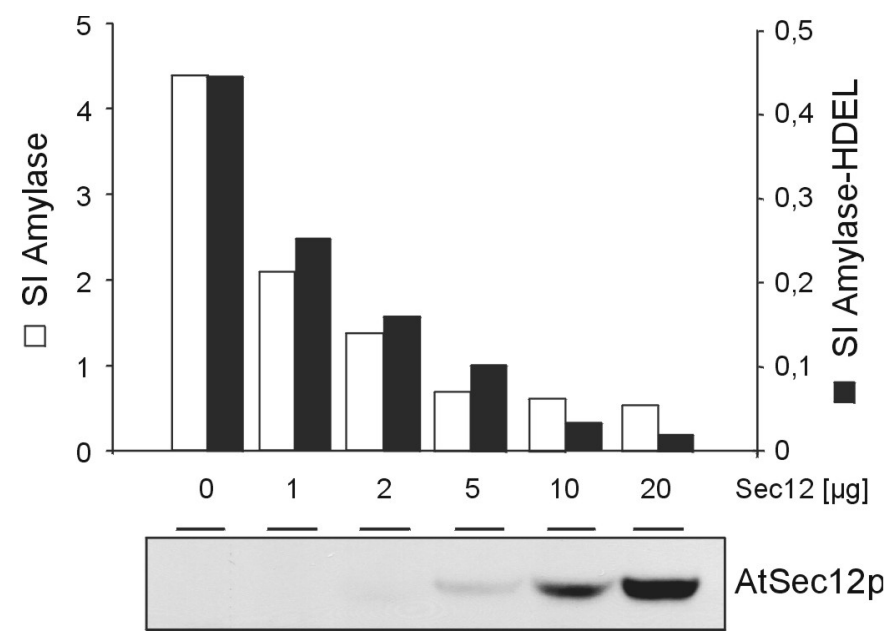

Abbildung 3.6-1: Inhibierung der Sekretion von Amylase und Amylase-HDEL durch AtSec12p.

Transiente Genexpression von je $2 \mu g$ des Amylase bzw. Amylase-HDEL kodierenden Plasmids ohne das AtSec12p kodierende Plasmid als Kontrolle der Sekretion (Säulenpaar 1). Inhibierung der Sekretion durch Koexpression des Amylase bzw. Amylase-HDEL kodierenden Plasmids mit 1, 2, 5, 10 und $20 \mu \mathrm{g}$ des AtSec12p kodierenden Plasmids (Säulenpaare 2-6). Die Western-Blot Analyse mit dem AtSec12p Antiserum dokumentiert die Expression des Proteins. 


\subsubsection{Charakterisierung der Inhibierung des ER Exports durch AtSec12p}

Da Sec12p den GDP/GTP Austausch des Sar1p katalysiert und somit die Bindung des cytosolischen Sar1p an die Membran ermöglicht, wurde vermutet, daß die Inhibierung der Bildung der COPII Vesikel durch die Überproduktion von Sec12p zu einer Titration des cytosolischen Sar1p führt (d'Enfert et al., 1991b). Zur Überprüfung dieser Hypothese wurde untersucht, ob die gleichzeitige Überproduktion von AtSar1p und AtSec12p die Sec12p induzierte Inhibierung der Sekretion kompensiert. Hierzu wurden Tabakprotoplasten mit je $2 \mu \mathrm{g}$ des Amylase bzw. AmylaseHDEL, je $10 \mu \mathrm{g}$ des AtSec12p und einer steigenden Konzentration von 1-20 $\mu \mathrm{g}$ des AtSar1p kodierenden Plasmids transfiziert (siehe 2.11.2). Zur Kontrolle der Genexpression beider Effektoren wurden Western-Blot Analysen der Protoplasten mit den AtSec12p und AtSar1p Antiseren durchgeführt. Die in Abbildung 3.6-2 dargestellte Analyse der Sekretionsraten von Amylase und Amylase-HDEL zeigt, daß bereits die Koexpression von $1 \mu \mathrm{g}$ des AtSar1p kodierenden Plasmids zu einer Abschwächung der durch die Expression von $10 \mu \mathrm{g}$ des AtSec12p kodierenden Plasmids induzierten Inhibierung beider Reporterproteine führt (Vergleich Säulenpaar 2 und 3).

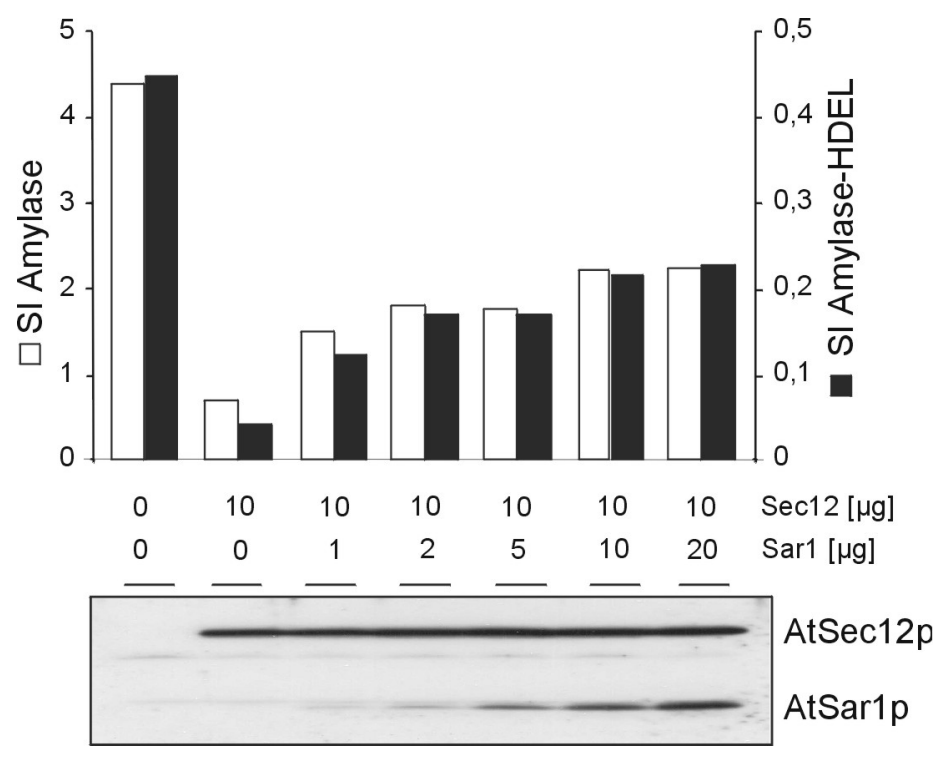

Abbildung 3.6-2: Partielle Rekonstitution der AtSec12p induzierten Inhibierung der Sekretion von Amylase und Amylase-HDEL durch AtSar1p Überproduktion.

Transiente Genexpression von je $2 \mu \mathrm{g}$ des Amylase bzw. Amylase-HDEL kodierenden Plasmids ohne das AtSec12p kodierende Plasmid als Kontrolle der maximalen Sekretion (Säulenpaar 1). Inhibierung der Sekretion durch Koexpression des Amylase bzw. Amylase-HDEL kodierenden Plasmids mit $10 \mu \mathrm{g}$ des AtSec12p kodierenden Plasmids (Säulenpaar 2).Partielle Rekonstitution der AtSec12p induzierten Inhibierung durch die Koexpression einer steigenden Konzentration von 1-20 $\mu \mathrm{g}$ des AtSar1p kodierenden Plasmids (Säulenpaar 3-7). Die Western-Blot Analyse der Protoplasten mit dem AtSec12p und dem AtSar1p Antiserum dokumentiert die Expression beider Proteine. 
Dieses zeigt deutlich, daß im Verlauf der Inhibierung der Sekretion durch die Sec12p Überproduktion die GTPase Sar1p der COPII Vesikel zum limitierenden Faktor der Sekretion wird. Die darüber hinausgehende Erhöhung der zur Koexpression eingesetzten Konzentration des AtSar1p kodierenden Plasmids auf $20 \mu \mathrm{g}$ führte im Vergleich zu der nicht inhibierten, maximalen Sekretion der Reporterproteine (Säulenpaar 1) jedoch nur zu dem Erreichen der halbmaximalen Sekretionsraten (Säulenpaar 7). Um auszuschließen, daß die Expression des AtSar1p einen unspezifischen, AtSec12p unabhängigen Einfluß auf die Sekretionsraten der Reporterproteine ausübt, wurde in einem weiteren Experiment die Auswirkung der Überproduktion des AtSar1p auf die Sekretionsraten der Amylase untersucht. Die Abbildung 3.6-3 zeigt, daß die Koexpression des Amylase und des AtSar1p kodierenden Plasmids (Säulenpaar 4) im Vergleich zu der Expression des Amylase kodierenden Plasmids allein (Säulenpaar 1) keinen Einfluß auf deren Sekretionsrate ausübt. Da die Expression des AtSar1p kodierenden Plasmids nur in Kombination mit dem AtSec12p kodierenden Plasmid zu einer Erhöhung der Sekretionsrate der Amylase führte (vergleiche Säulenpaare 2 und 3), konnte daraus geschlossen werden, daß die partielle Rekonstitution der AtSec12p induzierten Sekretionsinhibierung der Amylase auf einer spezifischen Interaktion des AtSar1p mit dem AtSec12p basiert.

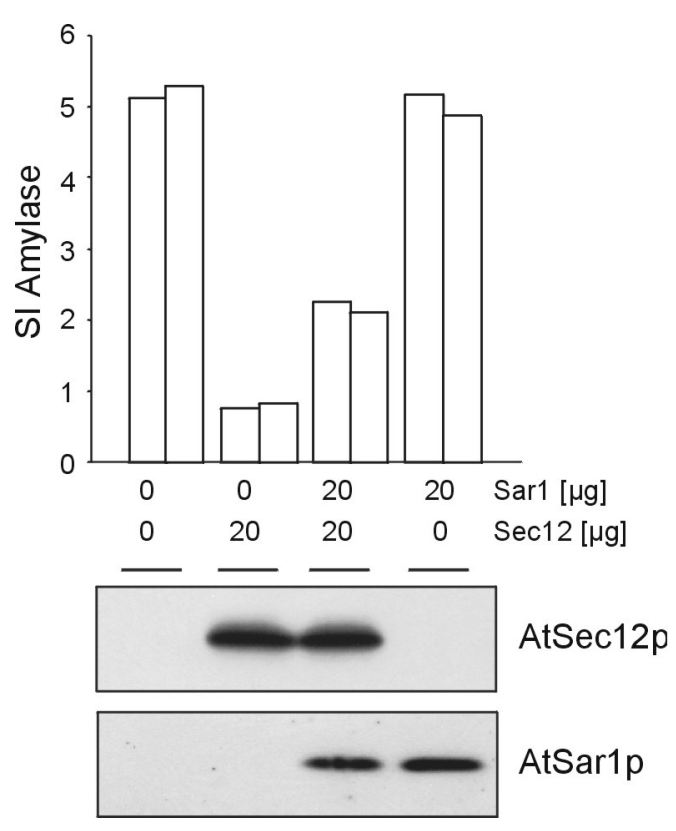

Abbildung 3.6-3: Einfluß der AtSar1p Überproduktion auf die Sekretion der Amylase. Transiente Genexpression von je $2 \mu \mathrm{g}$ des Amylase kodierenden Plasmids ohne das AtSec12p kodierende Plasmid als Kontrolle der maximalen Sekretion der Amylase (Säulenpaar 1). Inhibierung der Amylase Sekretion durch Koexpression von $2 \mu \mathrm{g}$ des Amylase kodierenden Plasmids mit $20 \mu \mathrm{g}$ des AtSec12p kodierenden Plasmids (Säulenpaar 2). Partielle Rekonstitution der AtSec12p induzierten Inhibierung durch die Koexpression von $20 \mu \mathrm{g}$ des AtSar1p kodierenden Plasmids (Säulenpaar 3). Koexpression von $2 \mu \mathrm{g}$ des Amylase kodierenden Plasmids mit $20 \mu \mathrm{g}$ des Sar1p kodierenden Plasmids (Säulenpaar 4). Die Darstellung zeigt die Amylase Sekretionsraten von zwei unabhängigen Experimenten. Die Western-Blot Analyse der Protoplasten mit dem AtSec12p und dem AtSar1p Antiserum dokumentiert die Expression beider Proteine. 
$\mathrm{Da}$ in den vorangegangenen Versuchen bereits die Interaktion des AtSec12p mit dem AtSar1p indirekt anhand ihrer Auswirkung auf die Sekretionsraten der Amylase und der Amylase-HDEL bewiesen worden war, sollte diese Interaktion nun in einem direkten Verfahren nachgewiesen werden. Hierzu wurden Tabakprotoplasten mit je $5 \mu \mathrm{g}$ des AtSar1p kodierenden Plasmids und einer steigenden Konzentration des AtSec12p kodierenden Plasmids transfiziert (siehe 2.11). Nach der Inkubation für $24 \mathrm{~h}$ bei $25^{\circ} \mathrm{C}$ wurden die Protoplasten geerntet und durch mehrmaliges Aufsaugen und Ausdrücken mit Hilfe einer Injektionskanüle homogenisiert. Im Anschluß wurden die Endomembranen durch eine Zentrifugation von den cytosolischen Proteinen getrennt (siehe 2.11.3). Die in Abbildung 3.6-4 dargestellten Western-Blot Analysen der Endomembranfraktion sowie der Fraktion der cytosolischen Proteine nach gleichen Volumina zeigt, daß das überproduzierte AtSar1p ebenso wie das endogene AtSar1p homologe Protein der Tabakprotoplasten (1. Bahn von links) hauptsächlich in der cytosolischen Form vorliegt und in der Membranfraktion nahezu nicht detektierbar ist. Durch die Koexpression des AtSec12p nimmt die Signalstärke des AtSar1p mit steigenden Expressionsraten in der Fraktion der cytosolischen Proteine jedoch deutlich ab und in der Membranfraktion deutlich zu. Diese Signalverlagerung des AtSar1p ließ darauf schließen, daß das AtSar1p durch die spezifische Interaktion mit AtSec12p in vivo an die Membranen rekrutiert worden war.

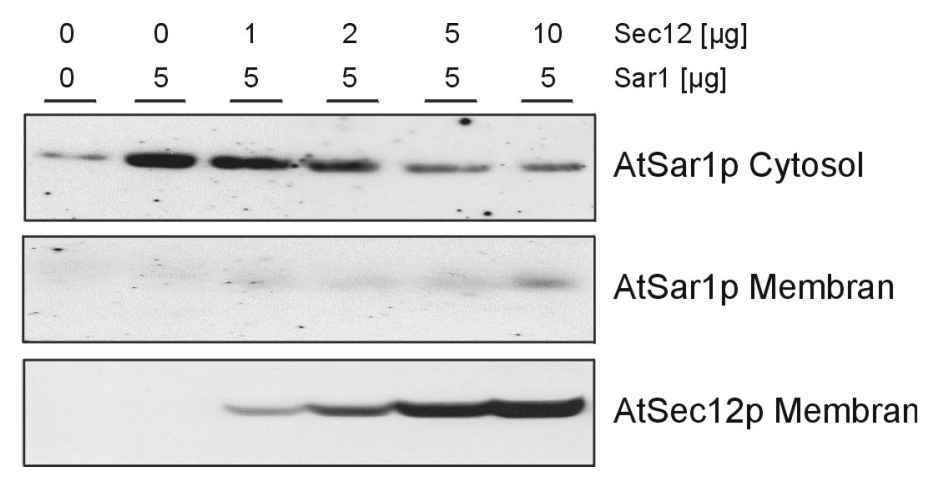

Abbildung 3.6-4: AtSec12p induzierte Rekrutierung des AtSar1p homologen Proteins. Western-Blot Analyse der cytosolischen- und der Membranfraktion nach der transienten Genexpression von $5 \mu \mathrm{g}$ des AtSar1p kodierenden Plasmids sowie nach der Koexpression des AtSar1p mit einer steigenden Konzentration von 1-10 $\mu \mathrm{g}$ des AtSec12p kodierenden Plasmids mit dem AtSar1p Antiserum. Zur Kontrolle der Expression des AtSec12p wurde dieses ebenfalls in der Membranfraktion detektiert. 


\subsection{Selektivität des COPII Vesikel vermittelten ER Exports}

Da die Selektivität des COPII Vesikel vermittelten Proteintransports noch immer umstritten ist (Klumperman, 2000), sollte untersucht werden, ob neben den sekretorischen Proteinen auch ein „bulk-flow“ Marker (PhosphinothricinAcetyltransferase (PAT); Denecke et al., 1990) und ein ER residentes Protein (Calreticulin) durch COPII Vesikel aus dem ER exportiert werden.

Nachdem nachgewiesen werden konnte, daß sowohl Amylase-HDEL als auch Calreticulin Frachtmoleküle der COPI Vesikel sind (siehe 3.5), und daß die Amylase und die Amylase-HDEL durch den COPII Vesikel vermittelten Transport aus dem ER exportiert werden, konnte daraus geschlossen werden, daß das ER Retentionssignal nicht den Eintritt in die COPII Vesikel verhindert (siehe 3.6.1). Dieses deutete auf einen nicht selektiven Proteintransport der COPII Vesikel hin. Im Fall der $\alpha$-Amylase besteht jedoch die Möglichkeit der Existenz eines bisher noch nicht charakterisierten intrinsischen Exportsignals, das ihre selektive Sortierung in die COPII Vesikel trotz des ER Retentionssignals ermöglicht. Zur Überprüfung dieser Möglichkeit wurde in den nachfolgenden Experimenten die Exportkompetenz der PAT und des Calreticulins untersucht, da in diesen beiden Fällen die Existenz eines intrinsischen ER Exportsignals äußerst unwahrscheinlich ist.

\subsubsection{Charakterisierung der ER Exportkompetenz löslicher Proteine}

Die Inhibierung des COPII Vesikel vermittelten Transports führt folglich auch zu einer Inhibierung der Sekretion der Proteine, die in diesen Vesikeln transportiert werden. Somit ermöglicht die Inhibierung dieses Transports die Charakterisierung der Exportkompetenz der transportierten Proteine.

Zur Inhibierung des COPII Vesikel vermittelten Proteintransports wurde neben der Überproduktion des AtSec12p (siehe 3.6.1) in weiteren Experimenten die Überproduktion der GTPase defizienten H74L Mutante des AtSar1p (Nakano et al., 1994) angewandt. Im Gegensatz zu der Überproduktion des AtSec12p führt die Überproduktion des Sar1p H74L zur Bildung der COPII Vesikel. Aufgrund der GTP Hydrolysedefizienz des AtSar1p H74L erfolgt nach der Bildung der Vesikel jedoch nicht die Dissoziation der Proteinhülle, wodurch die Fusion dieser Vesikel mit ihrem Zielkompartiment inhibiert wird (Saito et al., 1998). Die Verwendung dieser beiden Effektoren ermöglicht somit die spezifische Inhibierung unterschiedlicher Stadien des COPII Vesikel vermittelten Transports. Da zu der Beurteilung einer erfolgten Inhibierung der Sekretion die Detektion des Proteins sowohl in den Zellen als auch in dem Kulturmedium erforderlich ist, wurde zur Charakterisierung der Exportkompetenz im Fall des Calreticulins ein sekretierbares Derivat ohne das C-terminale ER Retentionssignal HDEL (Cal $\triangle \mathrm{HDEL}$ ) eingesetzt. 
Zur Untersuchung der Exportkompetenz wurden Tabakprotoplasten mit $2 \mu \mathrm{g}$ des PAT bzw. $2 \mu \mathrm{g}$ des Cal $\Delta$ HDEL und jeweils einer steigenden Konzentration des AtSec12p sowie des AtSar1p H74L kodierenden Plasmids transfiziert (siehe 2.11). Für die Überexpression (ÜE) des Cal $\triangle$ HDEL wurden zur Transfektion $20 \mu \mathrm{g}$ des Plasmids eingesetzt. Nach dem Ernten des Kulturmediums und der Protoplasten wurde die Sekretion durch Western-Blot Analyse nach gleichen Volumina mit den entsprechenden Antiseren untersucht.

Die in Abbildung 3.7-1 dargestellte Western-Blot Analyse des „bulk-flow“ Markers PAT zeigt, daß diese effizient von den Protoplasten in das Kulturmedium sekretiert wurde (Kontrolle). Durch die Koexpression des AtSec12p bzw. AtSar1p H74L sank die PAT Konzentration in dem Kulturmedium mit steigenden Expressionsraten der Effektoren ab, und die intrazelluläre PAT Konzentration stieg als Folge der Inhibierung des COPII Vesikel vermittelten Transports drastisch an. Dieses ließ darauf schließen, daß der „bulk-flow“ Marker PAT in Abhängigkeit von COPII Vesikeln transportiert wird.

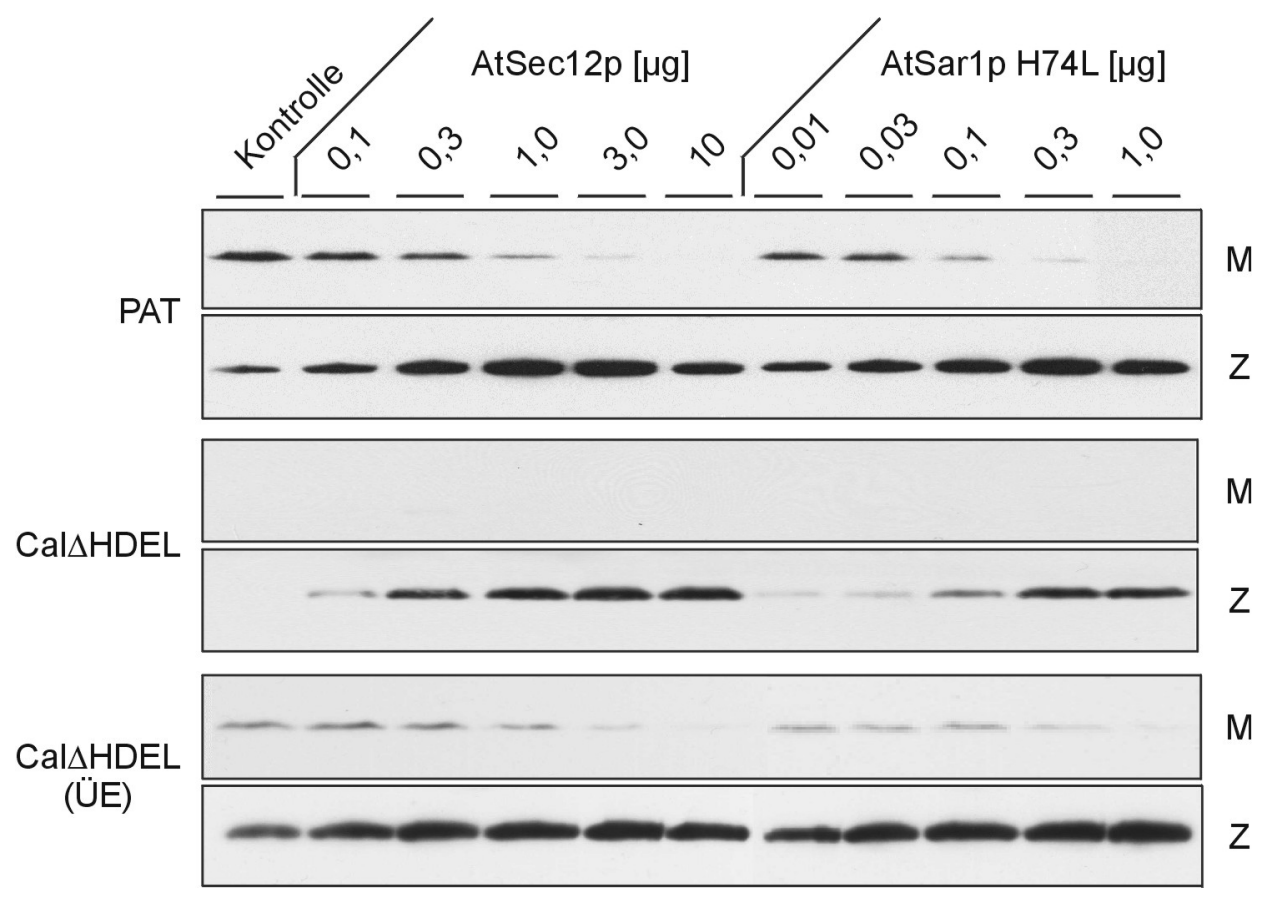

Abbildung 3.7-1: COPII Vesikel abhängiger Transport von PAT und Cal $\triangle \mathrm{HDEL}$. Western-Blot Analyse nach gleichen Volumina des Kulturmediums (M) und der Protoplasten (Z) nach der Genexpression.

Oben: Expression von $2 \mu \mathrm{g}$ des PAT kodierenden Plasmids (Kontrolle) und dessen Koexpression mit 0,1-10 $\mu \mathrm{g}$ des AtSec12p kodierenden Plasmids sowie der Koexpression mit 0,001-1 $\mu \mathrm{g}$ des AtSar1p H74L kodierenden Plasmids.

Mitte: Expression von $2 \mu \mathrm{g}$ des Cal $\triangle H D E L$ kodierenden Plasmids (Kontrolle) sowie dessen Koexpression mit den AtSec12p bzw. AtSa1p H74L kodierenden Plasmiden.

Unten: Überexpression des Cal $\triangle H D E L$ mit jeweils $20 \mu \mathrm{g}$ des kodierenden Plasmids (Kontrolle) sowie dessen Koexpression mit den AtSec12p bzw. AtSa1p H74L kodierenden Plasmiden. 
Im Fall des Cal $\triangle$ HDEL war nach der Expression von $2 \mu \mathrm{g}$ des kodierenden Plasmids das Protein weder in den Protoplasten noch in dem Kulturmedium des Kontrollansatzes detektierbar. Im Vergleich hierzu führte erst die Überexpression des Cal $\Delta$ HDEL durch den Einsatz von $20 \mu \mathrm{g}$ des Cal $\Delta$ HDEL kodierenden Plasmids (ÜE) zu der Detektion des intrazellulären und des sekretierten Cal $\Delta$ HDEL in dem Kontrollansatz. Die Koexpression von AtSec12p bzw. AtSar1p H74L im Rahmen dieser Überexpression zeigt deutlich die Abnahme der Konzentration des sekretierten Cal $\triangle \mathrm{HDEL}$ in dem Kulturmedium bei steigenden Expressionsraten der Effektoren. Obwohl nach der Expression von $2 \mu \mathrm{g}$ des Cal $\Delta$ HDEL kodierenden Plasmids das Protein weder in dem Medium noch in den Zellen detektiert werden konnte, führte die Inhibierung des COPII Vesikel vermittelten Transports durch die Koexpression von AtSec12p bzw. AtSar1p H74L mit steigenden Expressionsraten zu einem drastischen Anstieg der intrazellulären Konzentration des Cal $\Delta$ HDEL. Dieser drastische Anstieg zeigt, daß Cal $\triangle$ HDEL sehr effizient durch COPII Vesikel transportiert wird und somit auch exportkompetent ist. Durch diese Untersuchungen konnte deutlich gezeigt werden, daß sowohl lösliche Proteine ohne ein spezielles Sortierungssignal wie die PAT als auch lösliche ER residente Proteine wie Calreticulin durch "bulk-flow“ in einem COPII Vesikel vermittelten Transport aus dem ER exportiert werden. Dieses läßt weiterhin darauf schließen, daß der Transport löslicher Proteine durch die COPII Vesikel nicht ausschließlich selektiv erfolgt.

Die drastische Anreicherung des Cal $\triangle$ HDEL in den Zellen als Folge der Inhibierung des COPII Vesikel vermittelten Transports im Vergleich zu dem Kontrollansatz ohne die Koexpression der Effektoren ließ weiterhin darauf schließen, daß das Protein, da es in dem Kontrollansatz weder in den Protoplasten noch in dem Kulturmedium detektiert werden konnte, nach dem Export aus dem ER in einem postER Kompartiment degradiert worden war. Dieses scheint auch für die PAT zuzutreffen, da auch hier die Anreicherung des Proteins in den Zellen aufgrund der Inhibierung die im Kontrollansatz detektierten Mengen von zellulären und sekretierten PAT deutlich übersteigt.

\subsubsection{Quantifizierung des „bulk-flow“ löslicher Proteine aus dem ER}

Im Rahmen der Untersuchungen zur Charakterisierung der Exportkompetenz wurde bereits gezeigt, daß sowohl PAT als auch das Cal $\Delta$ HDEL durch einen COPII Vesikel vermittelten Transport aus dem ER exportiert werden. Weiterhin wiesen diese Untersuchungen darauf hin, daß ein Großteil des jeweiligen Proteins nach dem ER Export in einem post-ER Kompartiment degradiert wird. Aus diesem Grund zeigen quantitative Western-Blot Analysen der Protoplasten und des Kulturmediums nicht das tatsächliche Ausmaß des durch die COPII Vesikel vermittelten „bulk-flows“ (siehe Abbildung 3.7-1). Um dennoch eine Abschätzung des tatsächlich erfolgten „bulk-flows“ vornehmen zu können, wurde in den nachfolgenden 
Experimenten untersucht, ob die durch „bulk-flow“ transportierte Menge der PAT mit einem C-terminalen ER Retentionssignal (PAT-HDEL) ausreichend ist, um die Sekretionsrate der Amylase-HDEL aufgrund einer Kompetition der beiden HDELLiganden um die Bindung an dem HDEL-Rezeptor Erd2 im cis-Golgi-Apparat zu beeinflussen. Da die Sekretion der Amylase-HDEL bereits aus der Sättigung des HDEL-Rezeptors resultiert (siehe 3.4.1-3.4.2), sollte im Fall einer durch zusätzliche Liganden ausgelösten Kompetition ein Anstieg der Sekretionsrate der AmylaseHDEL zu verzeichnen sein. Zur Charakterisierung der Spezifität dieser Kompetition wurde sowohl die Amylase als auch die Amylase-HDEL mit PAT und PATKonstrukten mit den verschiedenen C-terminalen Tetrapeptiden KDEL, HDEL, RDEL, SDEL, KDDL, KEEL KDEI und KDEV (Denecke et al., 1992) koexprimiert. Da die transiente Genexpression von sekretorischen Proteinen in Tabakprotoplasten durch die Translokationskapazität des ER limitiert wird ist sichergestellt, daß in allen Expressionsansätzen die gleiche Anzahl von potentiellen Liganden vorliegt, wodurch der direkte Vergleich der Sekretionsraten der Amylase-HDEL ermöglicht wird. Zur Quantifizierung der Kompetition wurde eine Koexpression von Amylase bzw. Amylase-HDEL mit einem PAT-Konstrukt ohne das N-terminale Signalpeptid (PAT $\Delta \mathrm{SP}$ ), das den Eintritt in das Lumen des ER ermöglicht (siehe 1.2.1), durchgeführt. Da in diesem Ansatz nur Amylase-HDEL als artifizieller Ligand synthetisiert wird, zeigt deren Sekretionsrate in diesem Ansatz das Ausmaß der Sättigung des HDEL-Rezeptors. Im Fall der Koexpression der verschiedenen PAT-Konstrukte wird aufgrund der limitierenden Translokationskapazität des ER bei gleichbleibender Gesamtzahl aller Liganden lediglich ein Teil der AmylaseHDEL durch einen anderen potentiellen Liganden ersetzt.

Die in Abbildung 3.7-2 dargestellte Western-Blot Analyse des Kulturmediums und der Protoplasten mit dem PAT Antiserum zeigt die spezifische Anreicherung von PAT in Abhängigkeit der Tetrapeptide HDEL, KDEL und RDEL in den Zellen gegenüber dem sekretierten PAT im Kulturmedium. Der Vergleich dieser Anreicherung mit der des nicht sekretierten cytosolischen PAT $\Delta$ SP ließ auf eine sehr effiziente ER Retention dieser PAT-Konstrukte schließen. Der Sekretionsindex der Amylase-HDEL in den Koexpressionsexperimenten mit PAT $\Delta \mathrm{SP}$ zeigte die maximal mögliche Sekretion als Folge der Sättigung des HDEL-Rezeptors durch die Amylase-HDEL (siehe Abbildung 3.7-2). Im Vergleich dazu sank die AmylaseHDEL Sekretionsrate durch die Koexpression der sekretierten PAT sowie der PATKonstrukte mit den Tetrapeptiden RDEL, SDEL, KDDL, KEEL, KDEI und KDEV drastisch ab. Dieses ließ darauf schließen, daß diese PAT Moleküle, die im Vergleich zu der Koexpression des PAT $\Delta$ SP einen Teil der synthetisierten AmylaseHDEL ersetzten, nicht mit der Amylase-HDEL um den HDEL Rezeptor kompetitieren. Die Koexpression von PAT-HDEL sowie PAT-KDEL hingegen führte als Folge der eingetretenen Kompetition zwischen Amylase-HDEL und PAT-HDEL bzw. Amylase-HDEL und PAT-KDEL zu annähernd den gleichen Amylase-HDEL 
Sekretionsraten wie die Koexpression des PAT $\Delta$ SP. Der Vergleich der enzymatischen Gesamtaktivitäten der Amylase-HDEL zeigte, daß in den Fällen der Koexpression von PAT und den PAT-Konstrukten mit den unterschiedlichen Tetrapeptiden nahezu identische Mengen der Amylase-HDEL synthetisiert worden waren, während die Koexpression des PAT $\Delta$ SP aufgrund der Abwesenheit einer Konkurrenzreaktion während der Translokation in das ER zu einer deutlich erhöhten Gesamtaktivität führte.

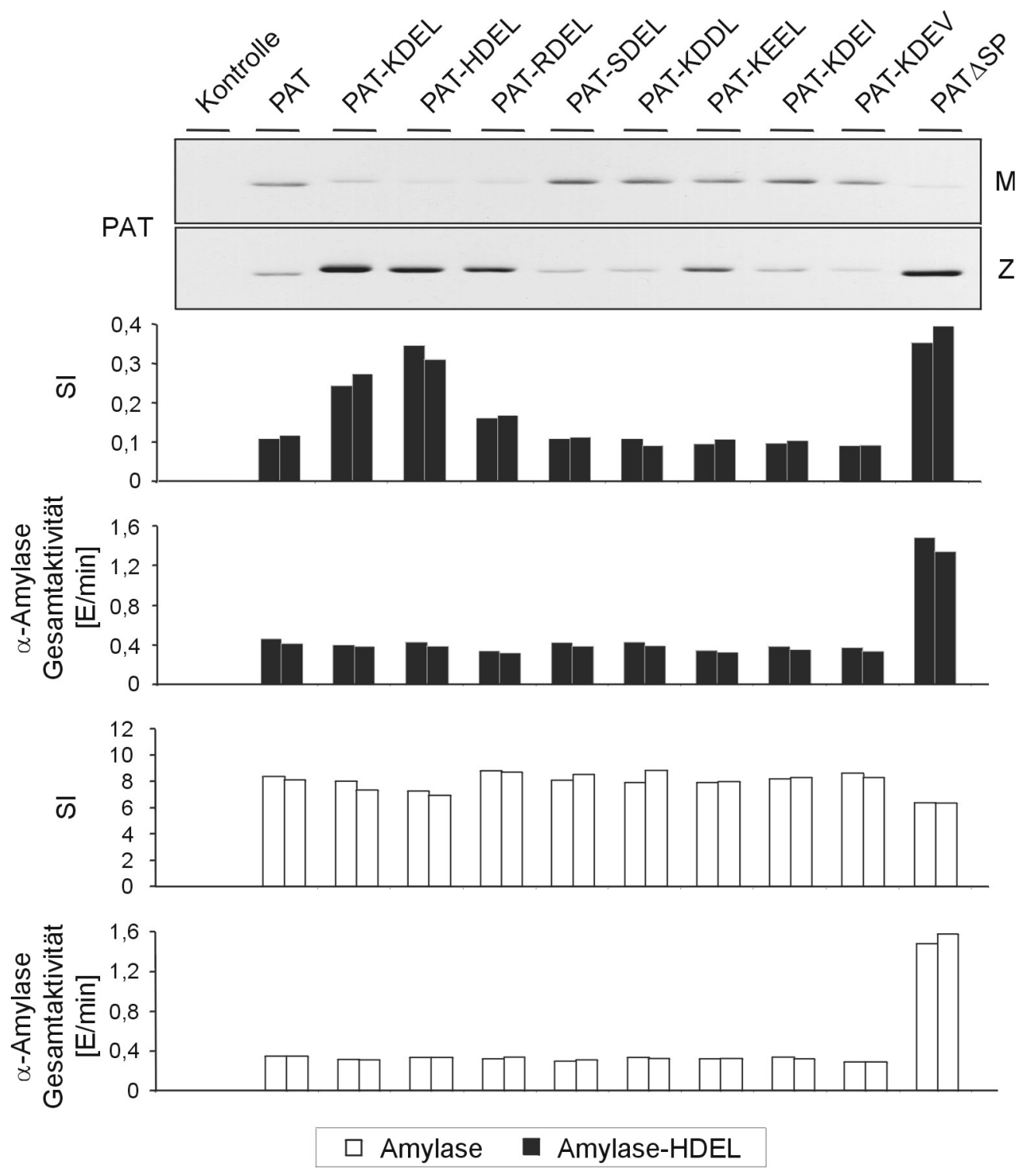

Abbildung 3.7-2: Quantifizierung des „,bulk-flow“ der COPII Vesikel

Koexpression von je $2 \mu \mathrm{g}$ des Amylase-HDEL bzw. Amylase kodierenden Plasmids mit je $10 \mu \mathrm{g}$ des jeweiligen PAT-Konstrukts.

Oben: Western-Blot Analysen von Kulturmedium (M) und Protoplasten (Z) mit dem PAT Antiserum zur Beurteilung des Sekretionsverhaltens der verschiedenen PAT-Konstrukte.

Mitte: Sekretionsindex und $\alpha$-Amylase Gesamtaktivität der Amylase-HDEL in Abhängigkeit des jeweils koexprimierten PAT-Konstrukts. (schwarze Säulen). Darstellung der Meßwerte von zwei unabhängigen Experimenten.

Unten: Sekretionsindex und $\alpha$-Amylase Gesamtaktivität der Amylase in Abhängigkeit des jeweils koexprimierten PAT-Konstrukts (weiße Säulen). Darstellung der Meßwerte von zwei unabhängigen Experimenten. 
Diese Ergebnisse ließen darauf schließen, daß der „bulk-flow“ Marker PAT-HDEL und die sekretorische Amylase-HDEL in vergleichbaren Mengen durch den COPII Vesikel vermittelten Proteintransport vom ER zum Golgi-Apparat transportiert wird. Die Koexpression der Amylase mit PAT sowie mit allen weiteren PATKonstrukten zeigte jedoch keine differenzielle Beeinflussung der Sekretionsraten der Amylase (siehe Abbildung 3.7-2). Die Koexpression von Amylase mit PAT $\Delta$ SP im Vergleich zu den Koexpressionen mit den anderen PAT Derivaten führte lediglich aufgrund der unterschiedlichen Mengen der synthetisierten Gesamtaktivität zu einem geringen Anstieg der Sekretionsraten der Amylase (vergleiche Abbildung 3.4-2).

\subsubsection{Quantifizierung des ER Exports von Calreticulin in vivo}

In den Untersuchungen zur Quantifizierung des „bulk-flow“ durch die Konkurrenzreaktion verschiedener artifizieller HDEL-Liganden um die Bindung an dem HDEL-Rezeptor im cis-Golgi konnte gezeigt werden, daß ein „bulk-flow“ Marker (PAT-HDEL) in vergleichbaren Mengen wie die Amylase-HDEL durch den COPII Vesikel vermittelten Transport aus dem ER exportiert wird und den cis-Golgi erreicht (siehe 3.7.2). Im weiteren Verlauf sollte nach dem gleichen Funktionsprinzip untersucht werden, ob das ER residente Protein Calreticulin in Abhängigkeit seiner C-terminalen HDEL-Sequenz ebenfalls in der Lage ist, mit der Amylase-HDEL um die Bindung an dem HDEL-Rezeptor zu konkurrieren.

Hierzu wurden jeweils $2 \mu \mathrm{g}$ des Amylase bzw. Amylase-HDEL kodierenden Plasmids mit je $10 \mu \mathrm{g}$ des Calreticulin bzw. Cal $\Delta$ HDEL koexprimiert. Als Kontrolle diente hierbei die Expression von je $2 \mu \mathrm{g}$ des Amylase bzw. Amylase-HDEL kodierenden Plasmids. Dieses ermöglicht es, zumindest im Fall der Amylase-HDEL, das Ausmaß der Sättigung des HDEL-Rezeptors durch die Kompetition der AmylaseHDEL Moleküle untereinander mit der durch die Koexpression von Calreticulin bzw. Cal $\triangle$ HDEL hervorgerufenen Kompetition zu vergleichen. Die in Abbildung 3.7-3 dargestellte Western-Blot Analyse der Protoplasten und des Kulturmediums zeigt die Sekretion des Calreticulins in Abhängigkeit des ER Retentionssignals. Während Cal $\Delta$ HDEL in das Kulturmedium sekretiert worden war, konnte das Calreticulin nur in den Protoplasten nachgewiesen werden. Die Koexpression von Calreticulin bzw. Cal $\triangle$ HDEL mit der Amylase zeigte keinen signifikanten differenziellen Einfluß auf die Sekretion der Amylase (Abbildung 3.7-3), da auch in diesem Versuch der leichte Anstieg der Sekretionsrate durch die Koexpression von Calreticulin bzw. Cal $\triangle$ HDEL im Vergleich zu der des Kontrollansatzes auf die geringere Anzahl der synthetisierten Amylase Moleküle zurückzuführen ist. 


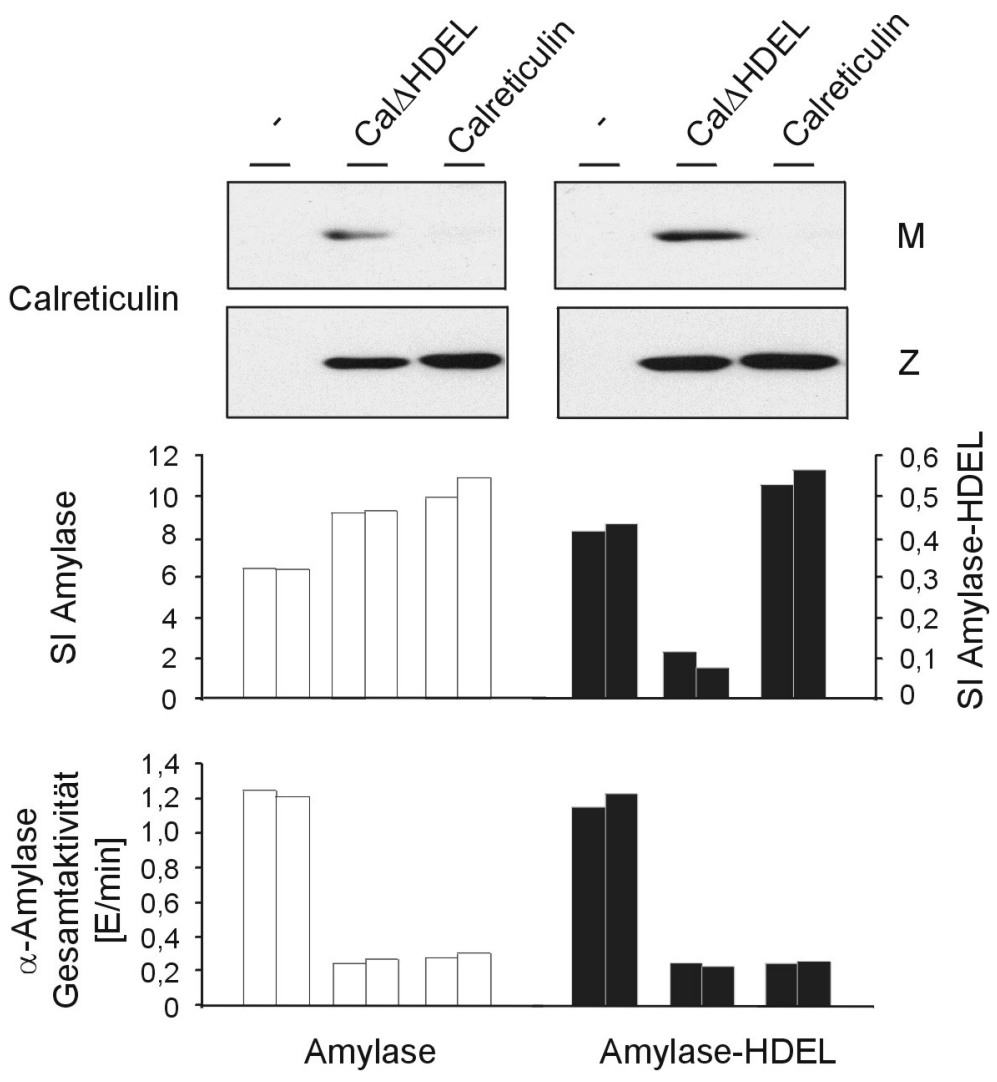

Abbildung 3.7-3: Quantifizierung des ER Exports des Calreticulin.

Expression von je $2 \mu \mathrm{g}$ des Amylase bzw. Amylase-HDEL kodierenden Plasmids, sowie die Koexpression von je $2 \mu \mathrm{g}$ des Amylase-HDEL bzw. Amylase kodierenden Plasmids mit je $10 \mu \mathrm{g}$ des Calreticulin bzw. des Cal $\triangle H D E L$ kodierenden Plasmids.

Oben: Western-Blot Analysen des Kulturmediums (M) und der Protoplasten (Z) mit dem PAT Antiserum zur Beurteilung des Sekretionsverhaltens von Calreticulin bzw. Cal $\triangle H D E L$.

Mitte: Sekretionsindex von Amylase und Amylase-HDEL in Abhängigkeit des jeweils koexprimierten Calreticulin bzw. CalAHDEL. Darstellung der Meßwerte von zwei unabhängigen Experimenten.

Unten: $\alpha$-Amylase Gesamtaktivität von Amylase und Amylase-HDEL in Abhängigkeit des jeweils koexprimierten Calreticulin bzw. Cal $\triangle H D E L$. Darstellung der Meßwerte von zwei unabhängigen Experimenten.

Der in Abbildung 3.7-3 dargestellte Sekretionsindex der Amylase-HDEL des Kontrollansatzes ohne Calreticulin bzw. Cal $\triangle$ HDEL zeigt das Ausmaß der Sättigung des HDEL-Rezeptors durch die Kompetition der Amylase-HDEL Moleküle untereinander. Im Vergleich dazu führte die Koexpression des Cal $\Delta$ HDEL zu einer deutlichen Verringerung der Sekretionsrate der Amylase-HDEL. Das Absinken der Sekretion der Amylase-HDEL im Vergleich zu der Kontrolle war auch hier darauf zurückzuführen, daß aufgrund der Sättigung der Translokationskapazität des ER ein Teil der in dem Kontrollansatz vorhandenen Amylase-HDEL in diesem Ansatz durch Cal $\triangle$ HDEL ersetzt wurde, und daß dieses nicht mit der Amylase-HDEL um den HDEL-Rezeptor kompetitierte. Die Koexpression des Calreticulin hingegen führte als Folge der eingetretenen Kompetition zwischen Amylase-HDEL und Calreticulin zu einer Sekretionsrate der Amylase-HDEL, die mit der des Kontrollan- 
satzes vergleichbar war. Da auch in diesem Experiment die $\alpha$-Amylase Gesamtaktivitäten in den Koexpressionen von Amylase-HDEL mit Calreticulin bzw. Cal $\triangle$ HDEL nahezu identisch waren, konnte aus diesem Ergebnis geschlossen werden, daß das ER residente Protein Calreticulin in dem gleichen Maßstab durch den COPII Vesikel vermittelten Proteintransport vom ER zum cis-Golgi transportiert wird wie die Amylase-HDEL. Dieses läßt weiterhin darauf schließen, daß die Retention von ER residenten löslichen Proteinen nicht auf deren Ausschluß von dem COPII Vesikel vermittelten Transport, sondern vielmehr auf deren selektiven Rücktransport vom Golgi-Apparat zum ER durch COPI Vesikel zurückzuführen ist. 


\section{Diskussion}

\subsection{Rekrutierung der Hüllproteine der COP Vesikel in vitro}

Die Bildung der COP Vesikel in Hefen und Säugetierzellen ist die Folge der Rekrutierung von cytosolischen Proteinkomplexen an die Membran (siehe 1.5.2). Hierdurch wird eine Wölbung der Membranoberfläche hervorgerufen, die sich im weiteren Verlauf als Vesikel ablöst (Orci et al., 1993a; Matsuoka et al., 1998; Spang et al., 1998). Die Initiierung der Bildung der Proteinhüllen von COPI bzw. COPII Vesikeln erfolgt durch die GTPasen ARF1p bzw. Sar1p. Beide GTPasen liegen im Cytosol in ihrer GDP gebundenen Form vor. Erst der Austausch des GDP gegen GTP, der jeweils durch einen spezifischen GEF katalysiert wird, ermöglicht ihre Bindung an die Membran, woraufhin sie die weiteren Hüllproteine aus dem Cytosol rekrutieren (Übersicht in Schekman \& Orci, 1996; Robinson et al., 1998; Barlowe, 2000).

In Pflanzen wurden zwar einzelne Hüllproteine der COPI und COPII Vesikel bereits identifiziert und charakterisiert (d'Enfert et al., 1992; Regad et al., 1993; BarPeled \& Raikhel, 1997; Movafeghi et al., 1999; Contreras et al., 2000), jedoch konnten die COP Vesikel der Pflanzen bis zum Beginn der vorliegenden Arbeit weder identifiziert, noch ihre Beteiligung an intrazellulären Transportprozessen bewiesen werden (Robinson et al., 1998). Der Nachweis und die Charakterisierung der Assoziation von At $\gamma$-COP und AtSec23p homologen Proteinen mit Golgi- bzw. ERMembranen aus Blumenkohlinfloreszenzen verstärkte zwar die Vermutung der Existenz eines COP Vesikel vermittelten Proteintransports in Pflanzen, jedoch blieb die Isolation endogener COP Vesikel erfolglos (Movafeghi et al., 1999). Da auch die Isolation von COP Vesikeln aus Hefen und Säugetierzellen erst nach ihrer in vitro Induktion möglich war (Malhotra et al., 1989; Barlowe et al., 1994), wurde im Rahmen der vorliegenden Arbeit eine Methode zur in vitro Induktion pflanzlicher COP Vesikel entwickelt. Dieses erforderte zunächst die Charakterisierung der Rekrutierungsreaktion der Hüllproteine, die der Bildung der Vesikel zugrunde liegt.

Als Versuchsobjekt diente hierbei zunächst Blumenkohl (Brassica oleracea). Aufgrund seiner Verwandtschaft mit Arabidopsis thaliana (Dozolme et al., 1995) sollten so möglichst hohe Homologien der in Blumenkohl am Vesikeltransport beteiligten Proteine zu den bereits charakterisierten und zur Herstellung von Antiseren eingesetzten Proteinen aus Arabidopsis gewährleistet sein. Die Untersuchung des intrazellulären Proteintransports erfordert sekretorisch aktive Zellen. Diese Anforderung an das Versuchsmaterial wird durch die Verwendung von Blumenkohlinfloreszenzen erfüllt, da es sich hierbei um ein meristematisches Gewebe handelt, das aufgrund seiner hohen Zellteilungsrate durch einen intensiven intrazellulären Proteintransport gekennzeichnet ist (Medford et al., 1991). Darüber hinaus sind 
die Zellen in den oberen Zellagen der Infloreszenz nahezu nicht vakuolisiert, wodurch die Freisetzung vakuolärer Proteasen während des Zellaufbruchs deutlich reduziert wird. Dieses ermöglicht die Isolation einer Fraktion cytosolischer Proteine, die deutlich geringere proteolytische Aktivität zeigt als vergleichbare Fraktionen aus Erbsen (Pisum sativum) oder Zucchinihypokotylen (Cucurbita pe po)(Drucker, 1995).

Als Ausgangsmaterial zur Charakterisierung der Rekrutierungsreaktion diente eine angereicherte ER- und Golgi-Membranfraktion. Neben der endogenen Membranassoziation des Aty-COP und des AtSec23p homologen Proteins (Movafeghi et al., 1999) konnte durch die hergestellten Antiseren gegen die GST Fusionsproteine des Arf1p und Sar1p aus Arabidopsis ebenfalls die Membranassoziation des AtArf1p und des AtSar1p homologen Proteins nachgewiesen werden (siehe Abbildung 3.2-1). Die Membranassoziation dieser endogenen Proteine beweist die potentielle Fähigkeit der pflanzlichen Membranen, die Hüllproteine von COPI und COPII Vesikeln zu rekrutieren und zeigt somit deren Eignung zur Charakterisierung der Rekrutierungsreaktion. Vor der Rekonstitution der Rekrutierungsreaktion wurde zunächst die Dissoziierbarkeit dieser endogenen Hüllproteine durch das chaotrope Agens KJ (Hinz et al., 1997) untersucht. Hierbei zeigte sich, daß sowohl das Aty-COP als auch das AtSec23p homologe Protein mit KJ quantitativ von den Membranen dissoziiert werden kann (siehe Abbildung 3.2-1). Im Fall der beiden GTPasen zeigte sich jedoch ein differenzieller Effekt. Während das AtSar1p homologe Protein ebenfalls von den Membranen dissoziiert werden konnte, blieb das AtArf1p homologe Protein überwiegend membrangebunden. Dieses läßt darauf schließen, daß das AtArf1p homologe Protein, wie das der Säugetiere, nach dem Austausch von GDP gegen GTP durch eine N-terminale Myristoylgruppe in der Membran verankert wird (Kahn et al., 1992).

In Hefen und Säugetieren liegen die Hüllproteine der COP Vesikel bereits im Cytosol als Bestandteile verschiedener Proteinkomplexe vor. Im Fall der COPI Vesikel lagern sich die sieben Untereinheiten im Cytosol spontan zu dem ca. $700 \mathrm{kDa}$ schweren Coatomer zusammen (Salama et al., 1993; Lowe \& Kreis, 1995; Lowe \& Kreis, 1996). Im Fall der COPII Vesikel bilden sich jedoch zwei heterodimere Komplexe: der Sec23p Proteinkomplex mit 400 kDa (Hicke \& Schekman, 1989; Paccaud et al., 1996) und der Sec13p Proteinkomplex mit 700 kDa (Pryer et al., 1993). Auch in cytosolischen Extrakten aus Blumenkohlinfloreszenzen wurde das At $\gamma$-COP bzw. das AtSec23p homologe Protein als Bestandteil unterschiedlicher Proteinkomplexe mit Molekulargewichten von ca. $700 \mathrm{kDa}$ bzw. ca. $200 \mathrm{kDa}$ beschrieben (Movafeghi et al., 1999). Die Assemblierung der Untereinheiten scheint ähnlich zu verlaufen wie in Säugetierzellen, daher ist zu vermuten, daß auch in Pflanzen die Rekrutierungsmechanismen zur Bildung der COP Vesikel vergleichbar sind. Da in den cytosolischen Fraktionen auch das AtArf1p und das AtSar1p homologe Protein nachgewiesen werden konnte (siehe Abbildung 3.1-1 und 3.1-2), diente eine mit 
Ammoniumsulfat gefällte Fraktion cytosolischer Proteine als Quelle der zu rekrutierenden Hüllproteine.

Durch die Inkubation der mit KJ behandelten Membranen mit den cytosolischen Proteinen gelang die Rekrutierung der Hüllproteine der COPI Vesikel. Da diese Reaktion von ATP und GTP S abhängig war, handelt es sich hierbei mit großer Wahrscheinlichkeit um eine spezifische Rekrutierung der Hüllproteine und nicht um eine unspezifische Anlagerung, die durch eine Änderung der Oberflächeneigenschaften der Membranen durch die KJ Behandlung hervorgerufen wurde.

Im Fall der COPII Hüllproteine erfolgte dagegen offensichtlich nur die Initiierung der Bildung der Proteinhülle durch die Rekrutierung des AtSar1p homologen Proteins, während der nachfolgende Schritt, die Rekrutierung des AtSec23p homologen Proteins (Barlowe et al., 1994; Aridor et al., 1998), nicht eintrat (siehe Abbildung 3.2-3). Diese Beobachtung unterstützt ebenfalls die Vermutung, daß es sich bei der Rekrutierung der COPI Hüllproteine um eine spezifische Reaktion handelt. Aus welchem Grund das AtSec23p homologe Protein jedoch nicht an die Membranen rekrutiert wurde, ist unklar. Eine Erklärungsmöglichkeit hierfür ist, daß die Menge des rekrutierten AtSar1p homologen Proteins nicht ausreichend war, um die weiteren Proteinkomplexe zu rekrutieren. Weiterhin könnte auch diese selektive Blockade der Rekrutierung des AtSec23p homologen Proteins auf das Fehlen eines noch nicht bekannten Faktors im Reaktionsansatz zurückzuführen sein, wodurch die Reaktion nach der Rekrutierung des AtSar1p unterbrochen wurde. Hierfür spräche auch die Beobachtung, daß selbst eine Erhöhung des zur Rekrutierung eingesetzten Mengenverhältnisses von cytosolischen Proteinen zu Membranproteinen zwar zu einer deutlichen Rekrutierung des AtSar1p homologen Proteins, aber nicht zu der Rekrutierung des AtSec23p homologen Proteins führte (siehe Abbildung 3.2-4). Um zwischen diesen beiden Möglichkeiten zu unterscheiden, könnte in weiterführenden Experimenten untersucht werden, ob eine gezielte Erhöhung der AtSar1p Konzentration durch die Verwendung von rekombinantem AtSar1p zu einer Rekrutierung der weiteren COPII Hüllproteine und somit auch zur Bildung der COPII Vesikel führt.

Im Fall der Proteinhülle der COPI Vesikel war die Rekrutierung nicht sättigbar, da selbst bei einem deutlich erhöhten Verhältnis von cytosolischen Proteinen zu Membranproteinen während der Rekrutierungsreaktion sowohl das AtArf1p als auch das At $\gamma$-COP homologe Protein weiterhin quantitativ an die Membranen rekrutiert werden konnten (siehe Abbildung 3.2-4). Die Tatsache, daß in einem Kontrollansatz ohne Membranen alle Hüllproteine der COP Vesikel in dem Überstand des Gradienten verblieben und keines der Hüllproteine sedimentiert werden konnte, verdeutlicht, daß die Detektion der Hüllproteine in der Membranfraktion auf eine Rekrutierungsreaktion und nicht auf die Sedimentation unspezifischer Proteinaggregate zurückzuführen ist. 
Eine zusätzliche Kontrolle dafür, daß die Rekrutierung des Coatomers tatsächlich aus einer spezifischen Interaktion mit dem ARF1p resultiert, ermöglichte die Verwendung des Inhibitors BFA. BFA interagiert mit dem GEF-ARF-GDP Komplex (Donaldson et al., 1992; Helms \& Rothman, 1992) und stabilisiert diesen (Peyroche et al., 1999). Als Folge dieser Stabilisierung wird die Rekrutierung des Coatomers inhibiert (Orci et al., 1991; Dascher \& Balch, 1994). Die hierzu erforderlichen Konzentrationen unterliegen jedoch starken Schwankungen in Abhängigkeit der verwendeten Zellen. So wurden bei verschiedenen Säugetierzellen bis zu 500fache Unterschiede in der wirksamen Konzentration des BFA beschrieben (Torii et al., 1995). Die in Pflanzen eingesetzten Konzentrationen liegen bei Untersuchungen in vivo meist zwischen 2 und $200 \mu \mathrm{M}$ (Satiat-Jeunemaitre et al., 1996). Weiterhin erfordert die Inhibierung der Rekrutierung des Coatomers in vitro 10fach höhere BFA Konzentrationen als die Inhibierung in vivo (Orci et al., 1991). Der Grund hierfür ist jedoch noch ungeklärt. In den hier gezeigten Untersuchungen konnte die Rekrutierung sowohl des AtArf1p als auch des Aty-COP homologen Proteins durch $300 \mu \mathrm{M}$ BFA deutlich reduziert werden (siehe Abbildung 3.2-5). Die beobachteten Rekrutierungen des AtArf1p und des Aty-COP homologen Proteins (siehe Abbildung 3.2-2, 3.2-3 und 3.2-4) sind demnach auf die spezifische Interaktion zwischen dem AtArf1p homologen Protein und dem GEF bzw. des AtArf1p mit dem Aty-COP homologen Protein zurückzuführen und nicht auf eine unspezifische Anlagerung der cytosolischen Proteine. Allerdings war hierbei auffällig, daß die Rekrutierung des Aty-COP homologen Proteins durch BFA nicht vollständig inhibiert werden konnte. Dieses beruht wahrscheinlich darauf, daß das endogene AtArf1p homologe Protein durch die Behandlung mit KJ nicht von den Membranen dissoziiert werden konnte (siehe Abbildung 3.2-1) und somit bereits in aktiver, GTPgebundener Form an den zur Rekrutierung eingesetzten Membranen vorlag und dadurch die weitere Rekrutierung des Aty-COP homologen Proteins ermöglichte. Dieses erklärt auch die höhere Varianz der BFA induzierten Inhibierung der Rekrutierung des Aty-COP homologen Proteins im Vergleich zu der des AtArf1p homologen Proteins, da je nach Konzentration des bereits vorhandenen membranassoziierten AtArf1p homologen Proteins auch der Anteil der nicht durch BFA inhibierbaren Rekrutierung variierte.

Mit diesen Versuchen konnte die spezifische, selektive Rekrutierung der Hüllproteine der COPI Vesikel in einem homologen System etabliert werden. Diese Ergebnisse konnten auch in einem heterologen Versuchssystem mit einer cytosolischen Fraktion aus Blumenkohl einerseits und einer ER und Golgi-Membranfraktion aus Tabak andererseits wiederholt werden (siehe 3.2.4). Die Rekrutierung in dem heterologenVersuchssystem war von besonderer Bedeutung, denn sie zeigte, daß der Mechanismus, der dieser Rekrutierungsreaktion zugrunde liegt, innerhalb der dikotylen Pflanzen konserviert zu sein scheint. 
Darüber hinaus eröffnete dieses Ergebnis die Möglichkeit, Tabak anstelle des Blumenkohls zur Untersuchung des Vesikel vermittelten Proteintransports verwenden zu können. Dieses ist von großer Bedeutung, da der Tabak aufgrund seiner genetischen Modifikationsmöglichkeiten eine gezielte Einführung von Reporterproteinen in das Versuchssystem erlaubt, wodurch eine weitere Charakterisierung der molekularen Mechanismen, die diesem Transport zugrunde liegen, ermöglicht wird.

\subsection{Induktion und Isolation der COPI Vesikel}

Als Folge der Rekrutierungsreaktion konnte eine deutliche Erhöhung der isopyknischen Schwebedichte der Membranen beobachtet werden (siehe Abbildung 3.2-7). Da auch in Pflanzen sowohl das Aty-COP als auch das AtArf1p homologe Protein in situ hauptsächlich an dem cis-Golgi-Apparat lokalisiert ist (Pimpl et al., 2000), kann man daher annehmen, daß die Erhöhung der Schwebedichte der GolgiMembranen auf die Rekrutierung des AtArf1p und des At $\gamma$-COP homologen Proteins zurückzuführen ist. Da nie eine Rekrutierung des AtSec23p homologen Proteins beobachtet werden konnte, erschien es jedoch fraglich, ob die Erhöhung der Schwebedichte im Fall der ER-Membranen nur durch die Rekrutierung des $22 \mathrm{kDa}$ AtSar1p homologen Proteins hervorgerufen wurde. Die Reaktionsansätze zur Rekonstitution der Rekrutierungsreaktion enthielten sowohl ATP als auch GTP $\gamma$ S. Aus diesem Grund bestand die Möglichkeit, daß an den Golgi-Membranen als Folge einer kontinuierlich verlaufenden Rekrutierung von COPI Hüllproteinen COPI Vesikel gebildet worden waren (Balch et al., 1984; Orci et al., 1986; Melançon et al., 1987). Da die Anlagerung der COPI Vesikel an ihre Akzeptormembranen, die ER-Membranen, unabhängig von der Dissoziation ihrer Proteinhülle zu sein scheint (Tanigawa et al., 1993), bestand die Möglichkeit, daß die Erhöhung der Schwebedichte der ER-Membranen auf der Anlagerung von gebildeten COPI Vesikeln zurückzuführen war.

Auch die Isolation der COPI Vesikel der Säugetiere wurde erst nach deren Dissoziation von den Membranen durch das chaotrope Agens $\mathrm{KCl}$ erreicht (Malhotra et al., 1989). Aus diesem Grund wurde ebenfalls eine Behandlung der Membranfraktion nach der Rekrutierungsreaktion mit $\mathrm{KCl}$ durchgeführt. Aufgrund der morphologischen Unterschiede des Golgi-Apparats von Säugetieren und Pflanzen erforderte die Trennung der Donor- bzw. Akzeptormembranen von den dissoziierten Vesikeln ein differenzielles Vorgehen. Während die Golgi-Membranen der Säugetiere bereits durch eine Zentrifugation mit $15.000 \mathrm{~g}_{\max }$ sedimentiert werden können (Malhotra et al., 1989), erforderte die partielle Sedimentation der pflanzlichen Donor- bzw. Akzeptormembranen jedoch eine Zentrifugation von $30.000 \mathrm{~g}_{\max }$. Durch eine anschließende Zentrifugation mit linearen Saccharosedichtegradienten gelang schließlich die Isolation einer Fraktion, in der das AtArf1p und das Aty-COP ho- 
mologe Protein im Gegensatz zu den Markerproteinen für das ER und den GolgiApparat angereichert war (siehe Abbildung 3.3-1, Fraktion 12). Hierbei entsprach die Dichte der Fraktion von $45 \%$ (w/w) Saccharose der beschriebenen Schwebedichte der COPI Vesikel der Säugetiere (Malhotra et al., 1989). Die elektronenmikroskopische Untersuchung zeigte, daß in dieser Fraktion neben zahlreichen Vesikeln mit einem Durchmesser von ca. 50-60 nm auch CCVs sowie weitere membranöse Strukturen enthalten waren (siehe Abbildung 3.3-2 A, B). Da durch eine Immunogold-Negativkontrastierung mit dem Zme-COP spezifisch nur die 50-60 nm Vesikel markiert worden waren, konnten diese eindeutig als COPI Vesikel identifiziert werden (siehe Abbildung 3.3-2 C-J).

Die im Rahmen der vorliegenden Arbeit entwickelten Methoden zur selektiven in vitro Induktion und Isolation pflanzlicher COPI Vesikel bietet die Möglichkeit, in weiterführenden Untersuchungen die molekularen Mechanismen, die der Bildung dieser Vesikel zugrunde liegen, näher zu charakterisieren.

\subsection{Sekretion und Rücktransport von Iöslichen Proteinen}

Ausgehend von der Beobachtung, daß verschiedene Proteine mit unterschiedlichen Raten sekretiert werden, wurde zunächst die Existenz eines ER Exportrezeptors vorgeschlagen und die Unterschiede in den Sekretionsraten mit unterschiedlichen Affinitäten der Proteine zu dem Rezeptor begründet (Fitting \& Kabat, 1982; Lodish et al., 1983). Die Identifizierung der C-terminalen Tetrapeptide H/KDEL als Retentionssignale (Munro \& Pelham, 1987; Pelham et al., 1988) sowie die Entdeckung, daß sowohl synthetische Tripeptide ohne ein offensichtliches Sortierungssignal als auch cytosolische Proteine mit einem N-terminalen Signalpeptid nach ihrem Eintritt in das ER in den extrazellulären Raum sekretiert werden (Wieland et al., 1987; Denecke et al., 1990; Hunt \& Chrispeels, 1991), führte dagegen zu der Postulierung der „bulk-flow“ Theorie. Hiernach werden alle Proteine, die kein spezifisches Sortierungssignal enthalten, das ihren Transport zu bzw. Verbleib in einem Kompartiment des sekretorischen Transportwegs ermöglicht, per „default“ entlang des sekretorischen Transportwegs in den extrazellulären Raum sekretiert. Die Identifizierung des HDEL-Rezeptors ERD2 (Lewis et al., 1990) sowie dessen durch HDEL-Liganden induzierte Verlagerung aus dem cis-Golgi in das ER (Lewis \& Pelham, 1992) unterstützte die „bulk-flow“ Theorie und führte weiterhin zu der Hypothese, daß die Retention der ER residenten Proteine erst nach ihrem unspezifischen Export aus dem ER durch einen selektiven Rücktransport vom cis-Golgi erfolgt.

Die Überprüfung dieser Hypothese erforderte zunächst die Entwicklung eines Versuchssystems, das sowohl die Charakterisierung der Sekretion als auch die Charakterisierung der Retention löslicher Proteine in vivo ermöglicht. Hierfür wurde 
die $\alpha$-Amylase der Gerste (Rogers, 1985) als Reporterprotein ausgewählt. Der Einsatz eines pflanzlichen sekretorischen Proteins sollte ausschließen, daß der Transport des Reporterproteins aufgrund einer Inkompatibilität mit dem Transportsystem der pflanzlichen Zelle beeinflußt wird. Weiterhin ist für die Sekretion von Proteinen auch deren korrekte Faltung von zentraler Bedeutung (Gething et al., 1986). Da die Detektion der $\alpha$-Amylase anhand ihrer enzymatischen Aktivität erfolgt, stellt dieses gleichzeitig die Kontrolle der korrekten Faltung des Proteins dar.

Die Verwendung der $\alpha$-Amylase mit dem C-terminalen ER Retentionssignal (Amylase-HDEL) als ein artifizieller Ligand des HDEL-Rezeptors sollte hierbei die Charakterisierung der Retention löslicher Proteine im ER ermöglichen. Dieses erforderte jedoch zunächst die Charakterisierung der Funktionalität des ER Retentionssignals im Zusammenhang mit der $\alpha$-Amylase. Die Sekretion beider Reporterproteine über einen Zeitraum von 30 Stunden zeigte deutliche Unterschiede in Abhängigkeit vom ER Retentionssignal (siehe Abbildung 3.4-1). Während im Fall der Amylase bereits 6 Stunden nach der Transfektion der Protoplasten höhere $\alpha$-Amylase Aktivitäten im Kulturmedium als in den Zellen detektiert werden konnten, trat dieser Zustand im Fall der Amylase-HDEL erst nach 24 Stunden ein. Weiterhin zeigte sich, daß die Sekretion der Amylase-HDEL im Vergleich zu der Amylase erst nach dem Erreichen eines intrazellulären Schwellenwerts einsetzt. Dieses ließ auf die Funktionalität des ER Retentionssignals HDEL im Zusammenhang mit der $\alpha$-Amylase schließen, da bei einem nicht funktionellen ER Retentionssignal die Sekretion, ebenso wie im Fall der Amylase, sofort erfolgt wäre. Das Einsetzen der Sekretion der Amylase-HDEL nach dem Erreichen eines intrazellulären Schwellenwerts läßt vielmehr vermuten, daß die Sekretion als Folge der Sättigung des HDEL-Rezeptors eintrat. Auch die Experimente, in denen verschiedene Mengen der Amylase-HDEL exprimiert worden waren, unterstützten diese Vermutung, da sich hierbei zeigte, daß mit steigender Proteinkonzentration auch ein deutlicher Anstieg der Sekretion zu verzeichnen war (siehe Abbildung 3.4-2).

Die Analyse der Sekretion der Amylase führte zu einer weiteren interessanten Beobachtung: Ihre Sekretion sank mit steigender Proteinkonzentration deutlich ab. Dieses zeigt, daß offenbar auch die Sekretion von löslichen Proteinen einer Sättigung unterliegt. Diese Beobachtung unterstützt die Hypothese der Existenz eines ER Exportrezeptors für lösliche Proteine (Lodish et al., 1983). Da es sich bei der $\alpha$-Amylase um ein sekretorisches Protein handelt, kann auch die Existenz eines intrinsischen ER Exportsignals, das ihren Export durch die Interaktion mit einem Rezeptor ermöglicht, nicht ausgeschlossen werden.

Der Vergleich der Sekretion der Amylase und Amylase-HDEL in Abhängigkeit der Proteinkonzentration zeigte weiterhin, daß die Sättigung des HDEL-Rezeptors schneller erreicht wird als die Sättigung des ER Exports. Das ließ darauf schließen, daß es sich bei dem Export und der Retention um getrennt ablaufende Vor- 
gänge handelt. Dieses wurde auch bei der Temperaturabhängigkeit von Sekretion und Retention deutlich: Während das Sekretionsmaximum der Amylase bei $29{ }^{\circ} \mathrm{C}$ erreicht wurde, war im Fall der Amylase-HDEL bei $29^{\circ} \mathrm{C}$ bereits ein Rückgang der Sekretion zu verzeichnen. Im Temperaturbereich von $25-34{ }^{\circ} \mathrm{C}$ war ein deutlich schnellerer Rückgang der Sekretion der Amylase-HDEL als der Amylase zu beobachten. Dieses zeigt, daß bei hohen Temperaturen die Effizienz der Retention von Proteinen im ER ansteigt. Die physiologische Bedeutung der Erhöhung der ER Retentionseffizienz bei hohen Temperaturen könnte in einem gesteigerten Bedarf von ER residenten Proteinen bei auftretendem Hitzestreß liegen (Vierling, 1991). Da viele der löslichen ER residenten Proteine als molekulare Chaperone fungieren und somit die korrekte Faltung von Proteinen im ER ermöglichen (siehe 1.2.2), scheint diese Erklärung der experimentellen Daten nicht unwahrscheinlich zu sein. Dieses Experiment zeigte weiterhin, daß in Pflanzenzellen trotz stark verringerter Proteinsynthese auch bei Temperaturen bis $6,5^{\circ} \mathrm{C}$ die Sekretion von Proteinen erfolgt. Im Gegensatz dazu führen Temperaturen von weniger als $20^{\circ} \mathrm{C}$ in Säugetierzellen zur vollständigen Inhibierung der Sekretion, wobei bei $20^{\circ} \mathrm{C}$ der Proteintransport aus dem Golgi-Apparat (Griffiths \& Simons, 1986; Tartakoff, 1986) und bei $15^{\circ} \mathrm{C}$ der Transport in den Golgi-Apparat (Saraste \& Kuismanen, 1984) inhibiert wird. Dieses Ergebnis wird ebenfalls von Untersuchungen gestützt, in denen gezeigt wurde, daß die Sekretion von GFP in Tabakblättern auch bei $4^{\circ} \mathrm{C}$ als Folge einer Adaption nach 12-18 h wieder einsetzt (Boevink et al., 1999). Die biochemische Charakterisierung der Membranassoziation von Hüllproteinen der COP Vesikel zeigte, daß eine Inkubation von Pflanzen für $14 \mathrm{~h}$ bei $4^{\circ} \mathrm{C}$ zu einer verringerten Membranassoziation des AtSar1p (Bar-Peled \& Raikhel, 1997), des Aty-COP und des AtSec23p (Movafeghi et al., 1999) führt. Ob dieses jedoch die Ursache oder die Auswirkung der verringerten Sekretion ist, bedarf weiterer Untersuchungen. Die graduelle Reduktion der Sekretion der Pflanzen könnte ein Mechanismus sein, der zum Überleben der Pflanzen bei niedrigen Temperaturen beiträgt.

Zusammenfassend zeigen diese Ergebnisse auch, daß das ER Retentionssignal HDEL weder die Synthese noch die enzymatische Aktivität der $\alpha$-Amylase beeinflußt, da selbst unter verschiedenen physiologischen Bedingungen nahezu identische Gesamtaktivitäten synthetisiert worden waren (siehe Abbildung 3.4-3). Die transiente Genexpression der $\alpha$-Amylase in Tabakprotoplasten stellt somit ein geeignetes Versuchssystem zur quantitativen Analyse des intrazellulären Proteintransports in vivo dar. In Abhängigkeit des ER Retentionssignals HDEL ermöglicht dieses Versuchssystem sowohl die Charakterisierung der Proteinsekretion als auch die Charakterisierung der ER Retention. 


\subsection{Nachweis von Iöslichen HDEL Proteinen in COPI Vesikeln}

Um Hinweise auf die Funktion der in vitro induzierten COPI Vesikel im intrazellulären Proteintransport der Pflanzen zu erhalten, wurden in weiteren Experimenten die Frachtmoleküle der Vesikel charakterisiert. Den COPI Vesikeln wird die Beteiligung an dem selektiven retrograden Proteintransport vom Golgi-Apparat zum ER zugeschrieben, der letztlich zu der Retention der löslichen Proteine im ER führt (Cosson \& Letourneur, 1994; Letourneur et al., 1994; Martinez-Menarguez et al., 1999). Aus diesem Grund wurde untersucht, ob ein Protein mit einem ER Retentionssignal ein potentielles Frachtmolekül der in vitro induzierten COPI Vesikel darstellt. Da bisher noch nicht bekannt ist, welche Proteine in Blumenkohlinfloreszenzen transportiert werden, wurde die $\alpha$-Amylase mit einem ER Retentionssignal (Amylase-HDEL) als Reporterprotein in das Versuchssystem eingeführt. Hierbei konnte in Abhängigkeit von ATP und GTP $\gamma$ S sowohl das At $\gamma$-COP homologe Protein als auch die Amylase-HDEL und große Mengen Calreticulin als Folge der Vesikelbildung in einem Saccharosedichtebereich von $46 \%$ (w/w) detektiert werden (siehe Abbildung 3.5-1). Im Rahmen der Untersuchungen zur Sekretion der $\alpha$-Amylase konnte jedoch gezeigt werden, daß auch die Amylase-HDEL aufgrund der Sättigung des HDEL Rezeptors sekretiert wird. Aus diesem Grund kann auch nicht mit Sicherheit ausgeschlossen werden, daß die induzierten Vesikel den Teil der Amylase-HDEL enthalten, der innerhalb des Golgi-Apparats vorwärts transportiert wird. Da das Calreticulin jedoch nicht sekretiert wird (Crofts et al., 1999; Pagny et al., 2000), ist es wahrscheinlicher, daß diese Vesikel an einem retrograden Proteintransport beteiligt sind. In Säugetieren wurde durch quantitative ImmunoElektronenmikroskopie die Existenz von zwei Populationen von COPI Vesikeln nachgewiesen, von denen die eine Population das vorwärts gerichtete Frachtmolekül Proinsulin und die andere den KDEL-Rezeptor enthält (Orci et al., 1997). Dieses deutet darauf hin, daß Amylase-HDEL und Calreticulin nicht zwangsläufig in den selben Transportvesikeln enthalten sein müssen. Auffällig ist jedoch die deutliche Anreicherung von Calreticulin in der Fraktion der COPI Vesikel (siehe Abbildung 3.5-1). Dieses läßt ungeachtet des Transportwegs der Vesikel darauf schließen, daß Calreticulin aus dem ER exportiert wird. Diese Beobachtung steht jedoch im Gegensatz zu den Untersuchungen des COPII Vesikel vermittelten ER Exports der Hefen: Die Frachtanalysen in vitro induzierter COPII Vesikel ergaben, daß diese keine ER residenten Proteine enthalten (Barlowe et al., 1994). Um eine Erklärung für diese gegensätzlichen Beobachtung zu finden, wurde in einem zweiten Schwerpunkt der vorliegenden Arbeit der Export löslicher Proteine aus dem ER untersucht. 


\subsection{Beteiligung der COPII Vesikel am ER Export}

Während in Hefen und in Säugetieren die Beteiligung der COPII Vesikel am Export von Proteinen aus dem ER unumstritten ist (Klumperman, 2000), konnten die COPII Vesikel in Pflanzen bisher noch nicht identifiziert werden. Die Identifizierung von Proteinen aus Arabidopsis, die Homologien zu den am COPII Vesikel vermittelten Proteintransport von Hefen und Säugetieren aufweisen, stützt jedoch die Annahme, daß ein COPII Vesikel vermittelter Proteintransport in Pflanzen existiert. (Übersicht in Robinson et al., 1998; Sanderfoot \& Raikhel, 1999).

Untersuchungen zur Charakterisierung des Vesikel vermittelten Transports in Hefen zeigten, daß die Interaktion von Sec12p (Nakano et al., 1988) mit dem Sar1p zur Bildung von COPII Vesikeln und somit für den Export von Proteinen aus dem ER von zentraler Bedeutung ist. Der Nachweis der Interaktion von Sec12p mit Sar1p (d'Enfert et al., 1991b; d'Enfert et al., 1991a) führte zu der Entdeckung der Beteiligung von Sar1p an der Bildung von COPII Vesikeln (Barlowe et al., 1993). Während die Überproduktion von Sar1p keinen Einfluß auf den intrazellulären Proteintransport ausübt, inhibiert die Überproduktion des Sec12p jedoch spezifisch die Bildung der COPII Vesikel und somit den Proteintransport vom ER zum GolgiApparat in vivo (Hardwick et al., 1992; Nishikawa et al., 1994).

Zum Nachweis der Beteiligung von COPII Vesikeln am Export von Proteinen aus dem pflanzlichen ER wurde deswegen die Auswirkung der Überproduktion des Sec12p homologen Proteins aus Arabidopsis (AtSec12p) auf die Sekretion der $\alpha$-Amylase untersucht (siehe Abbildung 3.6-1). Als Folge der Überproduktion des AtSec12p sank die Sekretion der Amylase und der Amylase-HDEL mit steigenden Expressionsraten des AtSec12p drastisch ab. Dieses Ergebnis läßt darauf schließen, daß die Amylase und die Amylase-HDEL in Abhängigkeit von COPII Vesikeln transportiert werden. Im Fall der Amylase-HDEL führten hohe Expressionsraten zu einer stärkeren Reduktion der Sekretion als bei der Amylase. Dieses ist durch die Überlagerung zweier Effekte zu erklären: Während die sinkenden Sekretionsraten der Amylase direkt auf die Reduktion des COPII Vesikel vermittelten Transports zurückzuführen sind, führt dieses im Fall der Amylase-HDEL zu einer verringerten Zahl von Liganden des HDEL-Rezeptors im cis-Golgi-Apparat, wodurch zusätzlich eine Erhöhung der Effizienz des Rücktransports eintritt (vergleiche Abbildung 3.4-2).

Die durch die Überproduktion des AtSec12p induzierte Inhibierung der Sekretion der $\alpha$-Amylase wird durch die Koexpression von AtSar1p partiell rekonstituiert (siehe Abbildung 3.6-2). Hierdurch läßt sich ausschließen, daß die beobachtete Anreicherung der $\alpha$-Amylase in den Zellen aus einer Erhöhung der ER Retentionskapazität durch Überproduktion eines Membranproteins resultiert. Da auch die Überproduktion des AtSar1p allein keine Erhöhung der Sekretion der Amylase bewirkte (siehe Abbildung 3.6-3), ließ die Rekonstitution der Sekretion auf eine 
spezifische AtSec12p-AtSar1p Interaktion schließen. Um dieses zu beweisen, wurde eine konstante Menge AtSar1p mit einer steigenden Konzentration des AtSec12p koexprimiert und die Verteilung des AtSar1p in Cytosol und der Membranfraktion analysiert (siehe Abbildung 3.6-4). Hierbei zeigte sich, daß AtSar1p mit steigender Konzentration von AtSec12p aus dem Cytosol an die Membranen rekrutiert wurde. Das überproduzierte AtSar1p liegt in den Protoplasten, ebenso wie in AtSar1p überproduzierenden Pflanzen (Bar-Peled \& Raikhel, 1997), ohne die gleichzeitige Überproduktion von AtSec12p hauptsächlich in der inaktiven, cytosolischen Form vor. Dieses erklärt auch die Beobachtung, daß die alleinige Überproduktion von Sar1p keinen Einfluß auf die Sekretion der Amylase ausübt.

Die in vivo Charakterisierung der AtSec12p induzierten Inhibierung der Sekretion der $\alpha$-Amylase zeigt eindeutig Parallelen zu der Sec12p induzierten Inhibierung des COPII Vesikel vermittelten Transports der Hefen (Hardwick et al., 1992; Nishikawa et al., 1994). Neueste Untersuchungen zur Sekretion von löslichen Proteinen in Arabidopsis und in Tabak zeigten ebenfalls, daß der ER Export durch die Manipulation einer Komponente der COPII Vesikel inhibiert werden kann (Takeuchi et al., 2000). Hierbei führte die Expression einer GTP hydrolysedefizienten Sar1 Mutante (Sar1p H74L; Nakano et al., 1994) AtSar1p H74L ebenfalls zur Inhibierung des Proteinexports aus dem ER.

Zusammenfassend lassen die in dieser Arbeit beschriebenen Experimente den Schluß zu, daß der COPII Vesikel vermittelte Export von Proteinen auch in Pflanzen existiert. Die Ergebnisse der Inhibierung der $\alpha$-Amylase Sekretion durch die Inhibierung des COPII Vesikel vermittelten Transports zeigen weiterhin, daß sekretorische Proteine unabhängig von einem ER Retentionssignal in die COPII Vesikel gelangen und aus dem ER exportiert werden. Dieses unterstützt die Theorie, daß die Retention von Proteinen im ER nicht durch die Verhinderung ihres Exports, sondern durch ihren selektiven Rücktransport vom Golgi-Apparat zum ER erreicht wird.

\subsection{Selektivität des COPII Vesikel vermittelten ER Exports}

Die Demonstration der Existenz des „bulk-flow“ (Wieland et al., 1987; Denecke et al., 1990; Hunt \& Chrispeels, 1991; Crofts et al., 1999) steht im Gegensatz zu der Beobachtung, daß in vitro induzierte COPII Vesikel aus Hefezellen als lösliche Fracht zwar $\alpha$-Faktor, jedoch keine ER residenten Proteine enthalten (Barlowe et al., 1994; Rexach et al., 1994; Bednarek et al., 1995). Da ER residente Proteine jedoch die gleiche Mobilität im Lumen des ER zeigen wie die sekretorischen Proteine (Ceriotti \& Colman, 1988), wurde das Fehlen von ER residenten Proteinen in den Vesikeln durch einen selektiven Export der Proteine aus dem ER erklärt. 
Hierbei werden die Frachtmoleküle selektiv in die Vesikel verpackt, während ER residente Proteine vom Transport ausgeschlossen werden (Bednarek et al., 1995; Aridor et al., 1998). Somit könnte die Sortierung löslicher Proteine während des ER Exports durch die COPII Vesikel nach einem ähnlichen Mechanismus erfolgen wie der selektive Transport löslicher Proteine durch die CCVs (siehe 1.5.1 und Abbildung 1.5-2 sowie 1.3.1-1.3.3). Dies setzt jedoch die Existenz von Rezeptoren vorraus, durch die diese Selektivität erreicht wird.

Als mögliche Kandidaten für Rezeptoren zur Sortierung löslicher Proteine wurde die Gruppe der p24 Proteine beschrieben. Diese Transmembranproteine interagieren mit ihrer cytoplasmatischen Domäne sowohl mit dem Coatomer als auch mit dem Sec23p Proteinkomplex (Sohn et al., 1996; Dominguez et al., 1998; Bremser et al., 1999) und könnten durch ihre Oligomerisierung (Belden \& Barlowe, 1996; Dominguez et al., 1998; Gommel et al., 1999; Marzioch et al., 1999) variable luminale Bindungsttellen für lösliche Proteine kreieren. Die Interaktion löslicher Proteine mit den luminalen Domänen der p24 Proteine konnte jedoch nicht bewiesen werden (Klumperman, 2000). Darüber hinaus führt die Deletion aller acht p24 Proteine in Hefen zu keiner Inhibierung der Sekretion löslicher Proteine (Springer et al., 2000).

In Folge der Vermutung eines selektiven ER Exports wurde die Beobachtung, daß die Deletion des ER Retentionssignals von BiP nur zu einer schwachen Sekretion führt (Munro \& Pelham, 1987), dahingehend interpretiert, daß neben dem ER Retentionssignal weitere Mechanismen an der Retention der ER residenten Proteine beteiligt sind (Schekman \& Orci, 1996; Kuehn \& Schekman, 1997). Diese gegensätzlichen Beobachtungen können entweder durch Unterschiede in der Sortierung von Frachtmolekülen zwischen Hefen und Säugetieren bzw. Pflanzen oder durch einen COPII Vesikel unabhängigen „bulk-flow“ aus dem ER erklärt werden.

Die im Rahmen dieser Arbeit entwickelte Methode zur Inhibierung des COPII Vesikel vermittelten Transports durch die Überproduktion von AtSec12p in vivo ermöglichte bereits den Nachweis der Beteiligung von COPII Vesikeln am Transport der $\alpha$-Amylase. Mit Hilfe dieser Methode konnte nun untersucht werden, ob der Transport des „bulk-flow“ Markers PAT (Denecke et al., 1990) und ein sekretierbares Derivat des Calreticulin (Cal $\triangle \mathrm{HDEL}$ ) in Abhängigkeit des COPII Vesikel vermittelten Transports aus dem ER exportiert werden. Um auszuschließen, daß die Überproduktion des AtSec12p einen Einfluß auf die Retentionskapazität des ER ausübt, wurde der COPII Vesikel vermittelte Proteintransport ebenfalls durch die Überproduktion der hydrolysedefizienten AtSar1p H74L Mutante inhibiert. Die Ergebnisse zeigten eindeutig, daß sowohl die Sekretion der PAT als auch die des Cal $\triangle$ HDEL sowohl durch die Überproduktion des AtSec12p als auch durch die Überproduktion des Sar1p H74L drastisch inhibiert wurde (siehe Abbildung 3.7-1). Dieses läßt darauf schließen, daß der beobachtete „bulk-flow“ von löslichen Protei- 
nen (Wieland et al., 1987; Denecke et al., 1990) doch durch die COPII Vesikel und nicht durch einen alternativen Transport erfolgt.

Darüber hinaus führten die Experimente zu der wichtigen Beobachtung, daß durch die Inhibierung des COPII Vesikel vermittelten Transports die Anreicherung von PAT und Cal $\triangle$ HDEL in den Zellen deutlich stärker war als die Abnahme der Konzentration der sekretierten Proteine im Kulturmedium (siehe Abbildung 3.7-1). Dieses wurde besonders bei der Expression des Cal $\Delta$ HDEL deutlich. Hierbei war ohne die Expression der beiden Effektoren das Protein weder in den Zellen, noch in dem Kulturmedium detektierbar. Erst die Überexpression von Cal $\Delta$ HDEL ermöglichte die Detektion in den Zellen. Die Verteilung des Cal $\Delta$ HDEL in Zellen und Medium zeigte hierbei eine höhere Konzentration von Cal $\triangle$ HDEL in den Zellen als in dem Kulturmedium. Dieses deutete zunächst auf eine niedrige Sekretion des Cal $\Delta$ HDEL hin. Transgene Tabakpflanzen, die Cal $\Delta$ HDEL überproduzieren, enthalten ebenfalls nur geringe Konzentrationen des Proteins im Vergleich zu Calreticulin überproduzierenden Pflanzen und zeigen auch nur eine geringe Sekretion des Cal $\triangle$ HDEL (Crofts et al., 1999). Dieses stimmt mit den beobachteten geringen Sekretionsraten ER residenter Proteine ohne Retentionssignal in Säugetierzellen (Munro \& Pelham, 1987) überein. Auch in früheren Untersuchungen zur Sekretion von Proteinen wurde beschrieben, daß eine C-terminale H/KDEL Sequenz zur Stabilisierung von Fusionsproteinen im sekretorischen Transportweg beiträgt (Denecke et al., 1992; Wandelt et al., 1992), jedoch ist die Ursache dieser Beobachtung noch unklar.

Eine Erklärungsmöglichkeit hierfür könnte die kontinuierliche Degradation dieser Proteine nach deren Export aus dem ER sein. Dafür sprechen auch die Ergebnisse der in vivo Inhibierung des COPII Vesikel vermittelten Transports (siehe Abbildung 3.7-1). Die drastische Anreicherung von PAT und Cal $\triangle$ HDEL in den Zellen als Folge der Inhibierung des Proteintransports zwischen dem ER und dem Golgi-Apparat läßt auf die Degradation der Proteine nach dem Erreichen des Golgi-Apparates schließen. Vorausgesetzt, daß der Unterschied zwischen Calreticulin und Cal $\triangle$ HDEL nur in der Fähigkeit der Bindung des HDEL Rezeptors liegt, ist die Degradation von Cal $\Delta$ HDEL erst nach dem Durchlaufen des cis-Golgi anzunehmen, da dort der HDEL-Rezeptor lokalisiert ist. Ob die Degradation des Proteins bereits im medialen- bzw. trans-Golgi-Apparat, in den Transportvesikeln zur Plasmamembran oder aber direkt in der lytischen Vakuole erfolgt, ist noch völlig ungeklärt.

Diese Ergebnisse zeigen deutlich, daß der Vergleich der Konzentration des Cal $\triangle$ HDEL in den Zellen mit der Konzentration des sekretierten Cal $\triangle$ HDEL in dem Medium keine Beurteilung der tatsächlichen Menge des aus dem ER exportierten Proteins zuläßt. Um trotz der intrazellulären Degradation dennoch das Ausmaß des Exports löslicher Proteine aus dem ER in Abhängigkeit eines ER Re- 
tentionssignals charakterisieren zu können, wurde untersucht, ob Derivate des „bulk-flow“ Markers PAT mit verschiedenen C-terminalen Tetrapeptiden (Denecke et al., 1992) in der Lage sind, bei einer Koexpression mit Amylase-HDEL im cisGolgi-Apparat um die Bindung am HDEL-Rezeptor zu kompetitieren. Da die Sekretion der Amylase-HDEL auf der Sättigung des HDEL-Rezeptors beruht (siehe Abbildung 3.4-1 und Abbildung 3.4-2), würde die Kompetition zusätzlicher HDELLiganden mit der Amylase-HDEL um den Rezeptor eine Erhöhung der Sekretion der Amylase-HDEL verursachen. Wäre der ER Export dieser zusätzlichen HDELLiganden aus dem ER jedoch marginal, dann dürfte auch keine Beeinflussung der Sekretion der Amylase-HDEL erfolgen. Wie aus der Abbildung 3.7-2 deutlich hervorgeht, ist PAT-HDEL, PAT-KDEL und auch PAT-RDEL in der Lage, die Sekretion der Amylase-HDEL durch die Kompetition um den Rezeptor im Vergleich zu PAT zu erhöhen. Die Beurteilung der maximal möglichen Sekretion erfolgte anhand einer Kontrolle, bei der die Amylase-HDEL mit dem cytosolischen PAT (ohne das N-terminale Signalpeptid; PAT $\Delta$ SP) koexprimiert wurde. Der Vergleich der Beeinflussung der Sekretion der Amylase-HDEL durch PAT-HDEL mit dieser Kontrolle beweist, daß PAT-HDEL genauso effizient aus dem ER exportiert wird wie die Amylase-HDEL selbst. Weiterhin konnte gezeigt werden, daß nur die PAT Derivate einen Einfluß auf die Sekretion der Amylase-HDEL ausübten, die sich auch tatsächlich in den Zellen anreicherten. Trotz der intrazellulären Anreicherung von PAT-HDEL, PAT-KDEL und PAT-RDEL zeigen sich doch Unterschiede in der Beeinflussung der Sekretion der Amylase-HDEL. Dieses könnte entweder auf unterschiedliche Affinitäten der verschiedenen PAT Derivate zu dem HDELRezeptor hindeuten oder aber auf die Beteiligung mehrerer Rezeptoren mit überlappenden aber dennoch unterschiedlichen Bindungsaffinitäten hinweisen. In Anbetracht der Tatsache, daß in Pflanzen bereits drei Isoformen des ERD2 sowie eine Gruppe ERD2 ähnlicher Proteine identifiziert worden sind (Hadlington \& Denecke, 2000), während in Hefen ERD2 durch ein einziges Gen kodiert wird, erscheint die Beteiligung mehrerer Rezeptoren an der ER Retention in Pflanzen nicht unwahrscheinlich.

Im Fall des Calreticulin ist der Export aus dem ER und die Beteiligung der HDEL Sequenz an der ER Retention umstritten (Crofts et al., 1999; Pagny et al., 2000; Pimpl \& Denecke, 2000). Intrazelluläres Calreticulin weist im Gegensatz zu dem sekretierten Calreticulin keine komplexen Glycosylierungen auf (Crofts et al., 1999). Im Vergleich dazu sind diese jedoch an der intrazellulären Form eines Fusionsproteins aus der Invertase mit einer C-terminalen HDEL Sequenz vorhanden. Aufgrund dieses Vergleichs von Calreticulin mit der Invertase wurde postuliert, daß Calreticulin nicht aus dem ER exportiert wird, und daß somit dessen HDEL Sequenz im Zusammenhang mit seiner Retention im ER nur eine untergeordnete Rolle spielt (Pagny et al., 2000). Die Autoren zeigten jedoch nicht, daß die komplex 
glycosylierte Form der Invertase tatsächlich im ER lokalisiert ist (Pimpl \& Denekke, 2000).

Die Mannosidase II, durch die diese komplexe Glycosylierung des sekretorischen Calreticulin während des Transits durch den Golgi-Apparat katalysiert wird, ist jedoch im medialen-Golgi-Apparat lokalisiert (Rabouille et al., 1995), während die Sortierung durch den HDEL-Rezeptor hauptsächlich im cis-Golgi-Apparat erfolgt (Pedrazzini et al., 1997; Crofts et al., 1999; Frigerio et al., 1999). Falls Calreticulin aus dem ER exportiert und durch die Interaktion mit dem HDEL-Rezeptor im cisGolgi-Apparat effizient zum ER zurück transportiert wird, muß eine Modifikation der Glycosylierungen nicht zwangsläufig erfolgen (Crofts et al., 1999). Da in Pflanzenzellen COPI Vesikel hauptsächlich am cis-Golgi-Apparat gebildet werden (Pimpl et al., 2000), ist es deswegen nicht unwahrscheinlich, daß ein Großteil des Calreticulin in der Zelle trotz Export aus dem ER keine Modifikation der Glycosylierung durch Golgi-Enzyme erfahren hat.

Einen deutlichen Hinweis auf den Export des Calreticulin aus dem ER in Abhängigkeit von seinem Retentionssignal zeigte die Kompetition der Amylase-HDEL mit Calreticulin bzw. Cal $\triangle$ HDEL um die Bindung an dem HDEL-Rezeptor (siehe Abbildung 3.7-3). Im Vergleich zu der Kontrolle (Amylase-HDEL allein) sank bei der Koexpression mit Cal $\triangle$ HDEL die Sekretion der Amylase-HDEL aufgrund der fehlenden Kompetition drastisch ab. Die Koexpression des Calreticulin führte jedoch aufgrund der eingetretenen Kompetition um den HDEL-Rezeptor zu einer Erhöhung der Sekretion, die der maximalen Sekretion in der Kontrolle entsprach.

Diese Ergebnisse zeigen eindeutig, daß Calreticulin genauso effizient aus dem ER exportiert wird wie die Amylase-HDEL. Auch hierbei übt das ER Retentionssignal keinen Einfluß auf den COPII Vesikel vermittelten Export aus dem ER aus. Während das Calreticulin jedoch aufgrund der Interaktion mit dem HDEL-Rezeptor effizient zum ER zurück transportiert werden kann, erfolgt im Fall des Cal $\triangle$ HDEL dessen Sekretion (siehe Abbildung 3.7-3). Zusammenfassend läßt sich somit feststellen, daß zumindest in Pflanzen sekretorische Proteine, ER residente Proteine und der „bulk-flow“ Marker PAT durch einen COPII Vesikel vermittelten Proteintransport aus dem ER exportiert werden. Dieser Proteintransport erfolgt unabhängig von ER Retentionssignalen und scheint ebenso wie in Säugetieren (Klumperman, 2000) nicht selektiv zu sein. 


\subsection{Effizienz des „bulk-flow“ aus dem ER}

Die im Rahmen der vorliegenden Arbeit durchgeführten Untersuchungen zur Charakterisierung des ER Exports löslicher Proteine in vivo zeigten, daß der „bulkflow" Marker PAT und das ER residente Protein Calreticulin durch den COPII Vesikel vermittelten Transport ebenso effizient aus dem ER exportiert werden, wie das sekretorische Protein $\alpha$-Amylase. Dieses läßt darauf schließen, daß der Export von löslichen Proteinen nicht selektiv, sondern durch „bulk-flow“ erfolgt. Hierbei konnte erstmals die drastische Degradation gezeigt werden, der ein ER residentes Protein ohne Retentionssignal unterliegt (Abbildung 3.7-1). Dieses läßt darauf schließen, daß in den bisher erfolgten Untersuchungen zur Retention löslicher ER residenter Proteine in Abhängigkeit ihres Retentionssignals (Munro \& Pelham, 1987) das tatsächliche Ausmaß des „bulk-flow“ und somit auch die Bedeutung ihres Retentionssignals systematisch unterschätzt wurde. In Hefen wurde sogar die Bildung von „BiP Bodies“, eine Dilatation des ER, als strukturelle Auswirkung der Inhibierung des ER Exports durch die Überproduktion von Sec12p bzw. Sec23p oder durch eine sec18 Mutation beschrieben (Nishikawa et al., 1994). Durch die thermoreversible sec12 bzw. sec18 Mutante konnte ebenfalls die Reversibilität der „BiP Bodies“ gezeigt werden. Die Kolokalisation der vakuolären Proteinase A in den „BiP Bodies“ verdeutlichte, daß es sich hierbei nicht nur um die Auswirkung auf ein spezifisches Protein handelt, sondern vielmehr um die Folge der generellen Inhibierung des ER Exports. Diese Anreicherung von BiP in dem ER als Folge der Inhibierung des ER Exports und dessen Verschwinden nach dem Temperaturwechsel zeigt deutlich, daß auch in Hefen die ER residenten Proteine in hohen Raten aus dem ER exportiert und offensichtlich sehr effizient durch den HDELRezeptor zurück transportiert werden. Weiterhin ist bemerkenswert, daß die Bildung der „BiP Bodies“ aus der in vivo Manipulation des COPII Vesikel vermittelten ER Exports resultiert, wobei die Überproduktion von Sec12p und Sec23p die Bildung der Vesikel und ein Defekt in Sec18p, dem NSF der Säugetiere homologen Protein der Hefen, deren Fusion inhibiert.

Ebenso lassen auch die Untersuchungen zur Retention löslicher ER residenter Proteine durch die Analysen des HDEL- Rezeptors ERD2 auf die Bedeutung des „bulkflow" und den damit verbundenen retrograden Transport vom Golgi-Apparat zum ER schließen. Hierbei konnte am Beispiel von BiP gezeigt werden, daß bei der Reduktion der Retention entweder durch die Deletion seines Retentionssignals oder durch Mutationen des ERD2 der Verlust des sekretierten BiP durch eine Erhöhung der Synthese ausgeglichen wird (Semenza et al., 1990; Beh \& Rose, 1995). Die letalen Folgen von Mutationen des ERD2, die keine Bindung von HDEL-Liganden ermöglichen und somit zum vollständigen Verlust der ER Retention führen (Townsley et al., 1994), lassen auf das Ausmaß des „bulk-flow“ und die Bedeutung des Retentionsmechanismus schließen. Weiterhin wurde als Folge der Reduktion der Retentionseffizienz eine Inhibierung des Wachstums der Zellen beschrieben, 
die durch die Erhöhung der ER Retentionseffizienz durch die Überproduktion des ERD2 aufgehoben wird. Hierbei führte die Inhibierung der Retention ebenfalls zu einer intrazellulären Anreicherung von Membranen, die darauf hinweist, daß der retrograde Transport nicht nur der Retention ER residenter Proteine, sondern auch dem Ausgleich des anterograden Membranflusses dient (Semenza et al., 1990; Townsley et al., 1994).

Diese Ergebnisse stehen deutlich im Gegensatz zu den Analysen der Fracht von in vitro induzierten COPII Vesikeln der Hefe (Barlowe et al., 1994), da hier als vorwärts gerichtetes Frachtmolekül nur der in vitro translatierte $\alpha$-Faktor und keine ER residenten Proteine nachgewiesen werden konnten. Diese gegensätzlichen Beobachtungen könnten möglicherweise durch den Überschuß des in vitro translatierten $\alpha$-Faktors gegenüber den endogenen ER residenten Proteinen erklärt werden. Die Koexpression des $\alpha$-Faktor mit einem ER residenten Protein könnte hierbei zu einer „Chancengleichheit“ während des Transports führen.

In den in vitro induzierten pflanzlichen COPI Vesikeln konnte sowohl Calreticulin als auch die Amylase-HDEL nachgewiesen werden. Dies läßt darauf schließen, daß der postulierte „bulk-flow“ des COPII Vesikel vermittelten ER Exports durch einen selektiven retrograden COPI Vesikel vermittelten Transport vom cis-GolgiApparat, dem Bildungsort der COPI Vesikel (Pimpl et al., 2000), zum ER ausgeglichen wird.

\subsection{Ausblick}

Im Rahmen der vorliegenden Arbeit wurde eine Methode zur selektiven in vitro Induktion pflanzlicher COPI Vesikel entwickelt. Die Verwendung von ER- und Golgi-Membranen aus Amylase-HDEL überproduzierenden Tabakpflanzen lieferten hierbei Hinweise auf die Beteiligung dieser Vesikel an dem retrograden Proteintransport vom cis-Golgi-Apparat zum ER. Zur Untersuchung, ob COPI Vesikel auch an einem vorwärts gerichteten Transport beteiligt sind, könnten Membranen aus Tabakpflanzen eingesetzt werden, die zusätzlich zu der Amylase-HDEL ein vorwärts gerichtetes Frachtmolekül wie z.B. ein vakuoläres Protein überproduzieren. Diese Methode könnte außerdem als Grundlage für eine Charakterisierung der molekularen Mechanismen, die der Bildung der Vesikel zugrunde liegen, eingesetzt werden.

Da die in vitro Induktion von COPII Vesikeln bisher nicht möglich war, sollte basierend auf der Methode zur Induktion und Isolation der COPI Vesikel untersucht werden, ob die Verwendung von rekombinantem AtSar1p zur Bildung der COPII Vesikel führt. Um auch hierbei eine selektive Induktion zu erreichen, sollte das Coatomer dafür affinitätschromatographisch mit den Zme-COP Antikörpern aus 
der Fraktion der cytosolischen Proteine entfernt werden. Dieses würde zusätzlich die weitere Charakterisierung des pflanzlichen Coatomers ermöglichen.

Zur Quantifizierung des „bulk-flow“ wurde eine Methode entwickelt, die auf der Kompetition unterschiedlicher Liganden um den HDEL-Rezeptor beruht. Durch diese Methode kann weiterhin die wichtige Fragestellung untersucht werden, ob auch Faltungsintermediate von Proteinen und falsch gefaltete Proteine aus dem ER exportiert werden und nur aufgrund der Assoziation mit BiP oder Calreticulin durch einen effizienten Rücktransport vom cis-Golgi-Apparat im ER zu detektieren sind. Die Beantwortung dieser Frage könnte zu neuen Einsichten in die Bedeutung der ER Retention führen.

Durch die entwickelte Methode zur Inhibierung des COPII Vesikel vermittelten Transports in vivo konnte gezeigt werden, daß große Mengen von Cal $\Delta$ HDEL und PAT nach ihrem Export aus dem ER degradiert werden. In weiterführenden Experimenten könnte untersucht werden, ob diese Degradation in der Vakuole erfolgt. Als Folge der Sättigung des vakuolären Transports werden vakuoläre Proteine sekretiert (Frigerio et al., 1998b). Basierend auf der Beobachtung, daß sowohl Cal $\triangle$ HDEL als auch PAT in einem post-ER Kompartiment abgebaut werden, würde die Koexpression von Cal $\triangle$ HDEL bzw. PAT mit einem vakuolären Protein zu einer Kompetition um den vakuolären Sortierungsrezeptor führen und somit die Sekretion des vakuolären Proteins verstärken. Die Kompetition von verschiedenen Liganden um den vakuolären Sortierungsrezeptor in vivo wäre eine weitere wichtige Methode zur Untersuchung des vakuolären Transports. 


\section{Zusammenfassung}

Im Rahmen der vorliegenden Arbeit wurden Antiseren gegen die den Hefen und Säugetieren homologen GTPasen Sar1p und Arf1p aus Arabidopsis hergestellt. Die Detektion von AtSar1p und AtArf1p ermöglichte den Nachweis und die Charakterisierung der Rekrutierung der Hüllproteine der COPI und der COPII Vesikel in vitro. Hierbei konnte die unterschiedliche Membranassoziation von AtSar1p und AtArf1p aufgezeigt und die Spezifität der Rekrutierung der Hüllproteine der COPI Vesikel in Abhängigkeit von ATP und GTP $\mathrm{S}$ S nachgewiesen werden. Durch die Rekonstitution der Rekrutierungsreaktion in vitro konnte als Folge der kontinuierlich ablaufenden Rekrutierungsreaktion eine angereicherte Vesikel Fraktion isoliert werden. Mit Hilfe der Immunogold-Negativkontrastierung konnten in dieser Fraktion COPI Vesikel eindeutig identifiziert, und somit die Existenz pflanzlicher COPI Vesikel bewiesen werden.

Der Nachweis der Rekrutierung der COPI Hüllproteine aus Blumenkohl an isolierte Membranen aus Tabak ermöglichte die Einführung der Amylase-HDEL als Reporterprotein zur Untersuchung der Funktion der induzierten COPI Vesikel. Hierbei konnten in Abhängigkeit von ATP und GTP $\gamma$ S COPI Vesikel induziert werden, die sowohl Amylase-HDEL als auch Calreticulin als potentielle Frachtmoleküle enthielten. Dieses ließ auf eine Beteiligung der COPI Vesikel am retrograden Proteintransport vom Golgi-Apparat zum ER schließen und unterstützte die Theorie, daß die Retention von ER residenten Proteinen durch einen selektiven Rücktransport aus dem Golgi-Apparat erreicht wird.

Zur Überprüfung dieser Theorie wurde der Export löslicher Proteine aus dem ER untersucht. Hierzu wurde ein Versuchssystem entwickelt, in dem die $\alpha$-Amylase (Amylase) als Reporterprotein für die Sekretion und ein Fusionsprotein aus $\alpha$-Amylase mit einem C-terminalen ER Retentionssignal (Amylase-HDEL) als Reporterprotein für den retrograden Proteintransport eingesetzt wurde. Im Rahmen der Charakterisierung dieses Versuchssystems durch transiente Genexpressionsstudien in Tabakprotoplasten konnte gezeigt werden, daß es sich bei der Sekretion und der Retention von Proteinen um zwei unterschiedliche intrazelluläre Vorgänge handelt und daß sowohl die Sekretion als auch die Retention der $\alpha$-Amylase einer Sättigung unterliegen. Darüber hinaus führte die Charakterisierung des Versuchssystems zu dem Ergebnis, daß die Sekretion der Pflanzenzellen im Gegensatz zu den Säugetierzellen, mit sinkenden Temperaturen in einer feinen Stufung nur langsam abnimmt.

Zur Charakterisierung des ER Exports löslicher Proteine wurde ein Methode entwickelt, die eine Inhibierung des ER Exports in vivo ermöglicht. Hierbei konnte in transienten Genexpressionsstudien an Tabakprotoplasten gezeigt werden, daß die Überproduktion von AtSec12p in Abhängigkeit von AtSar1p sowie die Überproduk- 
tion einer GTP hydrolysedefizienten Mutante des AtSar1p zur Inhibierung der Sekretion führt.

Weiterhin konnte gezeigt werden, daß die AtSec12p induzierte Inhibierung der Sekretion durch die Titration des cytosolischen AtSar1p aufgrund einer verstärkten Rekrutierung an die Membranen hervorgerufen wird. Durch diese Ergebnisse konnte in Pflanzen erstmals die Beteiligung von COPII Vesikeln am Export löslicher Proteine aus dem ER nachgewiesen werden. Weiterhin führten diese Untersuchungen zu dem Ergebnis, daß sowohl ER residente Proteine wie das Calreticulin als auch der „bulk-flow“ Marker PAT und sekretorische Proteine wie die $\alpha$-Amylase durch einen COPII Vesikel vermittelten Transport aus dem ER exportiert werden.

Im Rahmen dieser Untersuchungen konnte erstmals gezeigt werden, daß sowohl Calreticulin ohne ein ER Retentionssignal als auch der „bulk-flow“ Marker PAT nach dem ER Export einer starken Degradation unterliegen. Dieser Abbau führte in früheren Untersuchungen zur Sekretion und Retention von Proteinen in Hefen und Säugetierzellen zu einer systematischen Unterschätzung des Ausmaßes und der Effizienz des „bulk-flow“. Zur Quantifizierung des „bulk-flow“ wurde deshalb eine Methode entwickelt, die auf der Kompetition verschiedener Liganden um den HDEL-Rezeptor basiert. Hierdurch konnte gezeigt werden, daß das ER residente Protein Calreticulin mit der gleichen Effizienz aus dem ER exportiert wird wie die Amylase-HDEL. Durch diese Ergebnisse konnte bewiesen werden, daß die Retention von ER residenten Proteinen nicht durch die Verhinderung ihres ER Exports, sondern durch einen effizienten Rücktransport aus dem cis-Golgi-Apparat erreicht wird. 


\section{Literaturverzeichnis}

Aridor, M., Weissman, J ., Bannykh, S., Nuoffer, C. \& Balch, W. E. (1998). Cargo selection by the COPII budding machinery during export from the ER. J . Cell Biol. 141, 61-70.

Balch, W. E., Dunphy, W. G., Braell, W. A. \& Rothman, J . E. (1984). Reconstitution of the transport of protein between successive compartments of the Golgi measured by the coupled incorporation of $\mathrm{N}$-acetylglucosamine. Cell 39, 405-416.

Bannykh, S. I., Rowe, T. \& Balch, W. E. (1996). The organization of endoplasmic reticulum export complexes. J . Cell Biol. 135, 19-35.

Barlowe, C., d'Enfert, C. \& Schekman, R. (1993). Purification and characterization of SAR1p, a small GTP-binding protein required for transport vesicle formation from the endoplasmic reticulum. J. Biol. Chem. 268, 873879.

Barlowe, C. \& Schekman, R. (1993). SEC12 encodes a guanine-nucleotideexchange factor essential for transport vesicle budding from the ER. Nature 365, 347-349.

Barlowe, C., Orci, L., Yeung, T., Hosobuchi, M., Hamamoto, S., Salama, N., Rexach, M. F., Ravazzola, M., Amherdt, M. \& Schekman, R. (1994). COPII: a membrane coat formed by Sec proteins that drive vesicle budding from the endoplasmic reticulum. Cell 77, 895-907.

Barlowe, C. (2000). Traffic COPs of the early secretory pathway. Traffic 1, 371377.

Bar-Peled, M. \& Raikhel, N. V. (1997). Characterization of AtSEC12 and AtSAR1. Proteins likely involved in endoplasmic reticulum and Golgi transport. Plant Physiol. 114, 315-324.

Bednarek, S. Y. \& Raikhel, N. V. (1991). The barley lectin carboxyl-terminal propeptide is a vacuolar protein sorting determinant in plants. Plant Cell 3, 1195-1206.

Bednarek, S. Y., Ravazzola, M., Hosobuchi, M., Amherdt, M., Perrelet, A., Schekman, R. \& Orci, L. (1995). COPI- and COPII-coated vesicles bud directly from the endoplasmic reticulum in yeast. Cell 83, 1183-1196. 
Beh, C. T. \& Rose, M. D. (1995). Two redundant systems maintain levels of resident proteins within the yeast endoplasmic reticulum. Proc. Natl. Acad. Sci. USA 92, 9820-9823.

Belden, W. J . \& Barlowe, C. (1996). Erv25p, a component of COPII-coated vesicles, forms a complex with Emp24p that is required for efficient endoplasmic reticulum to Golgi transport. J . Biol. Chem. 271, 26939-26946.

Block, M. R., Glick, B. S., Wilcox, C. A., Wieland, F. T. \& Rothman, J. E. (1988). Purification of an N-ethylmaleimide-sensitive protein catalyzing vesicular transport. Proc. Natl. Acad. Sci. USA 85, 7852-7856.

Boevink, P., Martin, B., Oparka, K., Cruz, S. S. \& Hawes, C. (1999). Transport of virally expressed green fluorescent protein through the secretory pathway in tobacco leaves is inhibited by cold-shock and Brefeldin A. Planta 208, 392-400.

Bradford, M. M. (1976). A rapid and sensitive method for the quantitation of microgram quantities of protein utilizing the principle of protein-dye binding. Anal. Biochem. 72, 248-254.

Braulke, T. (1996). Origin of lysosomal proteins. Subcell. Biochem. 27, 15-49.

Braun, M., Waheed, A. \& von Figura, K. (1989). Lysosomal acid phosphatase is transported to lysosomes via the cell surface. EMBO J . 8, 3633-3640.

Bremser, M., Nickel, W., Schweikert, M., Ravazzola, M., Amherdt, M., Hughes, C. A., Sollner, T. H., Rothman, J . E. \& Wieland, F. T. (1999). Coupling of coat assembly and vesicle budding to packaging of putative cargo receptors. Cell 96, 495-506.

Campbell, N. A. \& Garber, R. C. (1980). Vacuolar reorganization in the cells of Albizzia during leaf movement. Planta 148, 251-255.

Cantor, A. B., Baranski, T. J . \& Kornfeld, S. (1992). Lysosomal enzyme phosphorylation. II. Protein recognition determinants in either lobe of procathepsin D are sufficient for phosphorylation of both the amino and carboxyl lobe oligosaccharides. J . Biol. Chem. 267, 23349-23356.

Cao, X., Rogers, S. W., Butler, J ., Beevers, L. \& Rogers, J . C. (2000). Structural requirements for ligand binding by a probable plant vacuolar sorting receptor. Plant Cell 12, 493-506.

Casadaban, M. J . \& Cohen, S. N. (1980). Analysis of gene control signals by DNA fusion and cloning in Escherichia coli. J . Mol. Biol. 138, 179-207. 
Ceriotti, A. \& Colman, A. (1988). Binding to membrane proteins within the endoplasmic reticulum cannot explain the retention of the glucose-regulated protein GRP78 in Xenopus oocytes. EMBO J . 7, 633-638.

Chardin, P., Paris, S., Antonny, B., Robineau, S., Beraud-Dufour, S., J ackson, C. L. \& Chabre, M. (1996). A human exchange factor for ARF contains Sec7- and pleckstrin-homology domains. Nature 384, 481-484.

Chrispeels, M. J . (1991). Sorting of proteins in the secretory system. Annu. Rev. Plant Physiol. Plant Mol. Biol. 42, 21-53.

Clark, D. W., Tkacz, J . S. \& Lampen, J . O. (1982). Asparagine-linked carbohydrate does not determine the cellular location of yeast vacuolar nonspecific alkaline phosphatase. J . Bacteriol. 152, 865-873.

Conibear, E. \& Stevens, T. H. (1998). Multiple sorting pathways between the late Golgi and the vacuole in yeast. Biochim. Biophys. Acta 1404, 211-230.

Contreras, I., Ortiz-Zapater, E., Castilho, L. M. \& Aniento, F . (2000). Characterization of Cop I coat proteins in plant cells. Biochem. Biophys. Res. Commun. 273, 176-182.

Cooper, A. A. \& Stevens, T. H. (1996). Vps10p cycles between the late-Golgi and prevacuolar compartments in its function as the sorting receptor for multiple yeast vacuolar hydrolases. J . Cell Biol. 133, 529-541.

Cosson, P. \& Letourneur, F. (1994). Coatomer interaction with di-lysine endoplasmic reticulum retention motifs. Science 263, 1629-1631.

Cosson, P., Demolliere, C., Hennecke, S., Duden, R. \& Letourneur, F. (1996). Delta- and zeta-COP, two coatomer subunits homologous to clathrinassociated proteins, are involved in ER retrieval. EMBO J . 15, 1792-1798.

Coughlan, S. J ., Hastings, C. \& Winfrey, R., J r. (1997). Cloning and characterization of the calreticulin gene from Ricinus communis L. Plant Mol. Biol. 34, 897-911.

Cowles, C. R., Snyder, W. B., Burd, C. G. \& Emr, S. D. (1997). Novel Golgi to vacuole delivery pathway in yeast: identification of a sorting determinant and required transport component. EMBO J . 16, 2769-2782.

Crofts, A. J . \& Denecke, J . (1998). Calreticulin and calnexin in plants. Trends Plant Sci. 3, 396-399.

Crofts, A. J ., Leborgne-Castel, N., Hillmer, S., Robinson, D. G., Phillipson, B., Carlsson, L. E., Ashford, D. A. \& Denecke, J . (1999). Saturation of the endoplasmic reticulum retention machinery reveals anterograde bulk flow. Plant Cell 11, 2233-2248. 
Dascher, C. \& Balch, W. E. (1994). Dominant inhibitory mutants of ARF1 block endoplasmic reticulum to Golgi transport and trigger disassembly of the Golgi apparatus. J . Biol. Chem. 269, 1437-1448.

Dean, N. \& Pelham, H. R. (1990). Recycling of proteins from the Golgi compartment to the ER in yeast. J . Cell Biol. 111, 369-377.

Denecke, J ., Botterman, J . \& Deblaere, R. (1990). Protein secretion in plant cells can occur via a default pathway. Plant Cell 2, 51-59.

Denecke, J ., Goldman, M. H., Demolder, J ., Seurinck, J . \& Botterman, J . (1991). The tobacco luminal binding protein is encoded by a multigene family. Plant Cell 3, 1025-1035.

Denecke, J ., De Rycke, R. \& Botterman, J . (1992). Plant and mammalian sorting signals for protein retention in the endoplasmic reticulum contain a conserved epitope. EMBO J . 11, 2345-2355.

Denecke, J ., Carlsson, L. E., Vidal, S., Hoglund, A. S., Ek, B., van Zeijl, M. J ., Sinjorgo, K. M. \& Palva, E. T. (1995). The tobacco homolog of mammalian calreticulin is present in protein complexes in vivo. Plant Cell 7, 391406.

d'Enfert, C., Wuestehube, L. J ., Lila, T. \& Schekman, R. (1991a). Sec12pdependent membrane binding of the small GTP-binding protein Sar1p promotes formation of transport vesicles from the ER. J . Cell Biol. 114, 663670.

d'Enfert, C., Barlowe, C., Nishikawa, S., Nakano, A. \& Schekman, R. (1991b). Structural and functional dissection of a membrane glycoprotein required for vesicle budding from the endoplasmic reticulum. Mol. Cell Biol. $11,5727-5734$.

d'Enfert, C., Gensse, M. \& Gaillardin, C. (1992). Fission yeast and a plant have functional homologues of the Sar1 and Sec12 proteins involved in ER to Golgi traffic in budding yeast. EMBO J . 11, 4205-4211.

Dhugga, K. S., Tiwari, S. C. \& Ray, P. M. (1997). A reversibly glycosylated polypeptide (RGP1) possibly involved in plant cell wall synthesis: purification, gene cloning, and trans-Golgi localization. Proc. Natl. Acad. Sci. USA 94, 7679-7684.

Di Sansebastiano, G. P., Paris, N., Marc-Martin, S. \& Neuhaus, J . M. (1998). Specific accumulation of GFP in a non-acidic vacuolar compartment via a Cterminal propeptide-mediated sorting pathway. Plant J . 15, 449-457. 
Dominguez, M., Dejgaard, K., Fullekrug, J ., Dahan, S., Fazel, A., Paccaud, J. P., Thomas, D. Y., Bergeron, J. J. \& Nilsson, T. (1998). gp25L/emp24/p24 protein family members of the cis-Golgi network bind both COP I and II coatomer. J . Cell Biol. 140, 751-765.

Donaldson, J . G., Finazzi, D. \& Klausner, R. D. (1992). Brefeldin A inhibits Golgi membrane-catalysed exchange of guanine nucleotide onto ARF protein. Nature 360, 350-352.

Donaldson, J . G. \& J ackson, C. L. (2000). Regulators and effectors of the ARF GTPases. Curr. Opin. Cell Biol. 12, 475-482.

Donaldson, J . G. (2000). Filling in the GAPs in the ADP-ribosylation factor story. Proc. Natl. Acad. Sci. USA 97, 3792-3794.

Dozolme, P., Marty-Mazars, D., Clemencet, M. C. \& Marty, F . (1995). Monoclonal antibody TeM 106 reacts with a tonoplast intrinsic protein of $106 \mathrm{kDa}$ from Brassica oleracea L. J . Cell Sci. 108, 1509-1517.

Draper, R. K., Goda, Y., Brodsky, F. M. \& Pfeffer, S. R. (1990). Antibodies to clathrin inhibit endocytosis but not recycling to the trans Golgi network in vitro. Science 248, 1539-1541.

Drucker, M. (1995). ATP-hydrolysierende Enzyme in pflanzlichen "ClathrinCoated Vesicles". Dissertation, Cuvillier Verlag, Göttingen.

Duden, R., Griffiths, G., Frank, R., Argos, P. \& Kreis, T. E . (1991). Beta-COP, a $110 \mathrm{kd}$ protein associated with non-clathrin-coated vesicles and the Golgi complex, shows homology to beta-adaptin. Cell 64, 649-665.

Duden, R., Hosobuchi, M., Hamamoto, S., Winey, M., Byers, B. \& Schekman, R. (1994). Yeast beta- and beta'-coat proteins (COP). Two coatomer subunits essential for endoplasmic reticulum-to-Golgi protein traffic. J . Biol. Chem. 269, 24486-24495.

Duden, R. \& Schekman, R. (1997). Insights into Golgi function through mutants in yeast and animal cells. in Berger, E. G.; Roth, J . (Eds) The Golgi apparatus. Basel, Switzerland, Birkhäuser Verlag, pp. 219-246.

Duden, R., Kajikawa, L., Wuestehube, L. \& Schekman, R. (1998). epsilon$\mathrm{COP}$ is a structural component of coatomer that functions to stabilize alphaCOP. EMBO J . 17, 985-995.

Duncan, J . R. \& Kornfeld, S. (1988). Intracellular movement of two mannose 6phosphate receptors: return to the Golgi apparatus. J . Cell Biol. 106, 617628. 
Evans, E. A., Gilmore, R. \& Blobel, G. (1986). Purification of microsomal signal peptidase as a complex. Proc. Natl. Acad. Sci. USA 83, 581-585.

Farquhar, M. G. \& Palade, G. E. (1998). The Golgi apparatus: 100 years of progress and controversy. Trends Cell Biol. 8, 2-10.

Faulstich, D., Auerbach, S., Orci, L., Ravazzola, M., Wegchingel, S., Lottspeich, F., Stenbeck, G., Harter, C., Wieland, F. \& Tschochner, H. (1996). Architecture of coatomer: molecular characterization of deltaCOP and protein interactions within the complex. J . Cell Biol. 135, 53-61.

Ferro-Novick, S. \& J ahn, R. (1994). Vesicle fusion from yeast to man. Nature 370, 191-193.

Fitting, T.\& Kabat, D. (1982). Evidence for a glycoprotein "signal" involved in transport between subcellular organelles. Two membrane glycoproteins encoded by murine leukemia virus reach the cell surface at different rates. J . Biol. Chem. 257, 14011-14017.

Franco, M., Boretto, J ., Robineau, S., Monier, S., Goud, B., Chardin, P. \& Chavrier, P. (1998). ARNO3, a Sec7-domain guanine nucleotide exchange factor for $\mathrm{ADP}$ ribosylation factor 1 , is involved in the control of Golgi structure and function. Proc. Natl. Acad. Sci. USA 95, 9926-9931.

Freedman, R. B. (1989). Protein disulfide isomerase: multiple roles in the modification of nascent secretory proteins. Cell 57, 1069-1072.

Frigerio, L., Vitale, A., Lord, J . M., Ceriotti, A. \& Roberts, L. M. (1998a). Free ricin A chain, proricin, and native toxin have different cellular fates when expressed in tobacco protoplasts. J . Biol. Chem. 273, 14194-14199.

Frigerio, L., de Virgilio, M., Prada, A., Faoro, F. \& Vitale, A. (1998b). Sorting of phaseolin to the vacuole is saturable and requires a short $\mathrm{C}$ - terminal peptide. Plant Cell 10, 1031-1042.

Frigerio, L., Pastres, A., Prada, A. \& Vitale, A. (1999). KDEL acts before the Golgi-mediated formation of complex asparagine-linked glycans. Meeting abstract (The annual meeting of the American Society of Plant Physiologists, Baltimore, Maryland USA, July 24-28, 1999).

Fukunaga, T., Furuno, A., Hatsuzawa, K., Tani, K., Yamamoto, A. \& Tagaya, M. (1998). NSF is required for the brefeldin A-promoted disassembly of the Golgi apparatus. FEBS Lett. 435, 237-240.

Futter, C. E., Pearse, A., Hewlett, L. J . \& Hopkins, C. R. (1996). Multivesicular endosomes containing internalized EGF-EGF receptor complexes mature and then fuse directly with lysosomes. J . Cell Biol. 132, 1011-1023. 
Galili, G., Sengupta-Gopalan, C.\& Ceriotti, A. (1998). The endoplasmic reticulum of plant cells and its role in protein maturation and biogenesis of oil bodies. Plant Mol. Biol. 38, 1-29.

Gavel, Y. \& von Heijne, G. (1990). Sequence differences between glycosylated and non-glycosylated Asn-X- Thr/Ser acceptor sites: implications for protein engineering. Protein Eng. 3, 433-442.

Gething, M. J ., McCammon, K. \& Sambrook, J . (1986). Expression of wild-type and mutant forms of influenza hemagglutinin: the role of folding in intracellular transport. Cell 46, 939-50.

Gething, M. J . \& Sambrook, J . (1992). Protein folding in the cell. Nature 355, $33-45$.

Glick, B. S. \& Malhotra, V. (1998). The curious status of the Golgi apparatus. Cell 95, 883-889.

Goldberg, J . (1999). Structural and functional analysis of the ARF1-ARFGAP complex reveals a role for coatomer in GTP hydrolysis. Cell 96, 893-902.

Gommel, D., Orci, L., Emig, E. M., Hannah, M. J ., Ravazzola, M., Nickel, W., Helms, J. B., Wieland, F. T. \& Sohn, K. (1999). p24 and p23, the major transmembrane proteins of COPI-coated transport vesicles, form heterooligomeric complexes and cycle between the organelles of the early secretory pathway. FEBS Lett. 447, 179-185.

Gomord, V. \& Faye, L. (1996). Signals and mechanisms involved in intracellular transport of secreted proteins in plants. Plant Physiol. Biochem. 34, 165181.

Griff, I. C., Schekman, R., Rothman, J . E. \& Kaiser, C. A. (1992). The yeast SEC17 gene product is functionally equivalent to mammalian alpha-SNAP protein. J . Biol. Chem. 267, 12106-12115.

Griffiths, G. \& Simons, K. (1986). The trans Golgi network: sorting at the exit site of the Golgi complex. Science 234, 438-443.

Hadlington, J . L. \& Denecke, J . (2000). Sorting of soluble proteins in the Secretory Pathway of Plants. Curr. Opin. Plant Biol. 3, 461-468.

Hamman, B. D., Chen, J . C., J ohnson, E. E. \& J ohnson, A. E. (1997). The aqueous pore through the translocon has a diameter of 40-60 A during cotranslational protein translocation at the ER membrane. Cell 89, 535-544.

Hamman, B. D., Hendershot, L. M. \& J ohnson, A. E. (1998). BiP maintains the permeability barrier of the ER membrane by sealing the lumenal end of the translocon pore before and early in translocation. Cell 92, 747-758. 
Hammond, C. \& Helenius, A. (1995). Quality control in the secretory pathway. Curr. Opin. Cell Biol. 7, 523-529.

Hanahan, D. (1983). Studies on transformation of Escherichia coli with plasmids. J. Mol. Biol. 166, 557-580.

Hara-Kuge, S., Kuge, O., Orci, L., Amherdt, M., Ravazzola, M., Wieland, F . \& Rothman, J . (1994). En bloc incorporation of coatomer subunits during the assembly of COP- coated vesicles. J . Cell Biol. 124, 883-892.

Hardwick, K. G., Boothroyd, J . C., Rudner, A. D. \& Pelham, H. R. (1992). Genes that allow yeast cells to grow in the absence of the HDEL receptor. EMBO J . 11, 4187-4195.

Hartl, F. U. (1996). Molecular chaperones in cellular protein folding. Nature 381, 571-579.

Hartmann, E., Sommer, T., Prehn, S., Gorlich, D., J entsch, S. \& Rapoport, T. A. (1994). Evolutionary conservation of components of the protein translocation complex. Nature 367, 654-657.

Hebert, D. N., Foellmer, B. \& Helenius, A. (1995). Glucose trimming and reglucosylation determine glycoprotein association with calnexin in the endoplasmic reticulum. Cell 81, 425-433.

Hebert, D. N., Foellmer, B. \& Helenius, A. (1996). Calnexin and calreticulin promote folding, delay oligomerization and suppress degradation of influenza hemagglutinin in microsomes. EMBO J . 15, 2961-2968.

Heese-Peck, A. \& Raikhel, N. V. (1998). The nuclear pore complex. Plant Mol. Biol. 38, 145-162.

Helenius, A., Trombetta, E. S., Herbert, D. N. \& Simons, J . F. (1997). Calnexin, calreticulin and the folding of glycoproteins. Trends Cell Biol. 7, 193200.

Helms, J . B. \& Rothman, J . E. (1992). Inhibition by brefeldin A of a Golgi membrane enzyme that catalyses exchange of guanine nucleotide bound to ARF. Nature 360, 352-354.

Hendrick, J . P . \& Hartl, F. U. (1993). Molecular chaperone functions of heatshock proteins. Annu. Rev. Biochem. 62, 349-384.

Hicke, L. \& Schekman, R. (1989). Yeast Sec23p acts in the cytoplasm to promote protein transport from the endoplasmic reticulum to the Golgi complex in vivo and in vitro. EMBO J . 8, 1677-1684. 
Hicke, L., Yoshihisa, T. \& Schekman, R. (1992). Sec23p and a novel 105-kDa protein function as a multimeric complex to promote vesicle budding and protein transport from the endoplasmic reticulum. Mol. Biol. Cell 3, 667676.

Hillmer, S., Freund, H. \& Robinson, D. G. (1988). The partially coated reticulum and its relationship to the Golgi apparatus in higher plant cells. Eur. J . Cell Biol. 47, 206-212.

Hillmer, S., Movafeghi, A., Robinson, D. G. \& Hinz, G. (2001). Vacuolar storage proteins are sorted in the cis-cisternae of the pea cotyledon Golgi apparatus. J. Cell Biol. 152, 41-50.

Hinshaw, J . E. \& Schmid, S. L. (1995). Dynamin self-assembles into rings suggesting a mechanism for coated vesicle budding. Nature 374, 190-192.

Hinz, G., Menze, A., Hohl, I. \& Vaux, D. (1997). Isolation of prolegumin from developing pea seeds: Its binding to endomembranes and assembly into prolegumin hexamers in the protein storage vacuole. J . Exp. Botany 48, 139149.

Hinz, G., Hillmer, S., Baumer, M. \& Hohl, I. (1999). Vacuolar storage proteins and the putative vacuolar sorting receptor BP- 80 exit the golgi apparatus of developing pea cotyledons in different transport vesicles. Plant Cell 11, 1509-1524.

Hoh, B., Hinz, G., J eong, B. K. \& Robinson, D. G. (1995). Protein storage vacuoles form de novo during pea cotyledon development. J. Cell Sci. 108, 299-310.

Hohl, I., Robinson, D. G., Chrispeels, M. J . \& Hinz, G. (1996). Transport of storage proteins to the vacuole is mediated by vesicles without a clathrin coat. J . Cell Sci. 109, 2539-2550.

Holwerda, B. C., Padgett, H. S. \& Rogers, J . C. (1992). Proaleurain vacuolar targeting is mediated by short contiguous peptide interactions. Plant Cell 4 , 307-318.

Hosobuchi, M., Kreis, T. \& Schekman, R. (1992). SEC21 is a gene required for ER to Golgi protein transport that encodes a subunit of a yeast coatomer. Nature 360, 603-605.

Hunt, D. C. \& Chrispeels, M. J . (1991). The signal peptide of a vacuolar protein is necessary and sufficient for the efficient secretion of a cytosolic protein. Plant Physiol. 96, 18-25. 
Hurtley, S. M. \& Helenius, A. (1989). Protein oligomerization in the endoplasmic reticulum. Annu. Rev. Cell Biol. 5, 277-307.

Hwang, C., Sinskey, A. J . \& Lodish, H. F. (1992). Oxidized redox state of glutathione in the endoplasmic reticulum. Science 257, 1496-1502.

J ackson, M. R., Nilsson, T. \& Peterson, P. A. (1990). Identification of a consensus motif for retention of transmembrane proteins in the endoplasmic reticulum. EMBO J . 9, 3153-3162.

J ackson, M. R., Nilsson, T. \& Peterson, P. A. (1993). Retrieval of transmembrane proteins to the endoplasmic reticulum. J . Cell Biol. 121, 317-333.

J ahn, R. \& Hanson, P. I. (1998). Membrane fusion. SNAREs line up in new environment. Nature 393, 14-15.

J auh, G. Y., Phillips, T. E. \& Rogers, J . C. (1999). Tonoplast intrinsic protein isoforms as markers for vacuolar functions. Plant Cell 11, 1867-1882.

J ohnson, K. D., Herman, E. M. \& Chrispeels, M. J . (1989). An abundant, highly conserved tonoplast protein in seeds. Plant Physiol. 91, 1006-1013.

Kahn, R. A., Randazzo, P., Serafini, T., Weiss, O., Rulka, C., Clark, J ., Amherdt, M., Roller, P., Orci, L. \& Rothman, J . E. (1992). The amino terminus of ADP-ribosylation factor (ARF) is a critical determinant of ARF activities and is a potent and specific inhibitor of protein transport. J . Biol. Chem. 267, 13039-13046.

Kalies, K. U., Gorlich, D. \& Rapoport, T. A. (1994). Binding of ribosomes to the rough endoplasmic reticulum mediated by the Sec61p-complex. J . Cell Biol. 126, 925-934.

Kirchhausen, T. \& Harrison, S. C. (1981). Protein organization in clathrin trimers. Cell 23, 755-761.

Kirchhausen, T. (2000). Clathrin. Annu. Rev. Biochem. 69, 699-727.

Kirsch, T., Saalbach, G., Raikhel, N. V. \& Beevers, L. (1996). Interaction of a potential vacuolar targeting receptor with amino- and carboxyl-terminal targeting determinants. Plant Physiol. 111, 469-474.

Klionsky, D. J ., Banta, L. M. \& Emr, S. D. (1988). Intracellular sorting and processing of a yeast vacuolar hydrolase: proteinase A propeptide contains vacuolar targeting information. Mol. Cell Biol. 8, 2105-2116.

Klumperman, J . (2000). Transport between ER and golgi. Curr. Opin. Cell Biol. $12,445-449$. 
Koch, G. L. (1987). Reticuloplasmins: a novel group of proteins in the endoplasmic reticulum. J . Cell Sci. 87, 491-492.

Kornfeld, S. (1992). Structure and function of the mannose 6-phosphate/insulinlike growth factor II receptors. Annu. Rev. Biochem. 61, 307-330.

Kuehn, M. J . \& Schekman, R. (1997). COPII and secretory cargo capture into transport vesicles. Curr. Opin. Cell Biol. 9, 477-483.

Laemmli, U. K. (1970). Cleavage of structural proteins during the assembly of the head of bacteriophage T4. Nature227, 680-685.

Le Borgne, R. \& Hoflack, B. (1998). Protein transport from the secretory to the endocytic pathway in mammalian cells. Biochim. Biophys. Acta 1404, 195209.

Leidreiter, K., Kruse, A., Heinecke, D., Robinson, D. G. \& Heldt, H.-W. (1995). Subcellular volumes and metabolite concentrations in potato (Solanum tuberosum cv. Desiree) leaves. Botanica Acta 108, 439-444.

Lerouge, P., Cabanes-Macheteau, M., Rayon, C., Fischette-Laine, A. C., Gomord, V. \& Faye, L. (1998). N-glycoprotein biosynthesis in plants: recent developments and future trends. Plant Mol. Biol. 38, 31-48.

Letourneur, F., Gaynor, E. C., Hennecke, S., Demolliere, C., Duden, R., Emr, S. D., Riezman, H. \& Cosson, P. (1994). Coatomer is essential for retrieval of dilysine-tagged proteins to the endoplasmic reticulum. Cell 79, 1199-1207.

Lewis, M. J ., Sweet, D. J . \& Pelham, H. R. (1990). The ERD2 gene determines the specificity of the luminal ER protein retention system. Cell 61, 13591363.

Lewis, M. J . \& Pelham, H. R. (1990). A human homologue of the yeast HDEL receptor. Nature 348, 162-163.

Lewis, M. J . \& Pelham, H. R. (1992). Ligand-induced redistribution of a human KDEL receptor from the Golgi complex to the endoplasmic reticulum. Cell 68, 353-364.

Lewis, M. J . \& Pelham, H. R. (1996). SNARE-mediated retrograde traffic from the Golgi complex to the endoplasmic reticulum. Cell 85, 205-215.

Lodish, H. F., Kong, N., Snider, M. \& Strous, G. J . (1983). Hepatoma secretory proteins migrate from rough endoplasmic reticulum to Golgi at characteristic rates. Nature 304, 80-83. 
Lowe, M. \& Kreis, T. E . (1995). In vitro assembly and disassembly of coatomer. J . Biol. Chem. 270, 31364-31371.

Lowe, M.\& Kreis, T. E . (1996). In vivo assembly of coatomer, the COP-I coat precursor. J . Biol. Chem. 271, 30725-30730.

Lucas, W. J . \& Wolf, S. (1993). Plasmodesmata: the intercellular organelles of green plants. Trends Cell Biol. 3, 308-315.

Ludwig, T., Le Borgne, R. \& Hoflack, B. (1995). Roles for mannose-6-phosphate receptors in lysosomal enzyme sorting, IGF-II binding and clathrin-coat assembly. Trends Cell Biol. 5, 202-206.

Macer, D. R. J . \& Koch, G. L. (1988). Identification of a set of calcium binding proteins in reticuloplasm, the luminal content of the endoplasmic reticulum. J . Cell Sci. 92, 61-70.

Malhotra, V., Orci, L., Glick, B. S., Block, M. R. \& Rothman, J. E. (1988). Role of an $\mathrm{N}$-ethylmaleimide-sensitive transport component in promoting fusion of transport vesicles with cisternae of the Golgi stack. Cell 54, 221227.

Malhotra, V., Serafini, T., Orci, L., Shepherd, J . C. \& Rothman, J . E. (1989). Purification of a novel class of coated vesicles mediating biosynthetic protein transport through the Golgi stack. Cell 58, 329-336.

Marcusson, E. G., Horazdovsky, B. F., Cereghino, J . L., Gharakhanian, E. \& Emr, S. D. (1994). The sorting receptor for yeast vacuolar carboxypeptidase $\mathrm{Y}$ is encoded by the VPS10 gene. Cell 77, 579-586.

Marks, M. S., Ohno, H., Kirchhausen, T. \& Bonifacino, J . S. (1997). Protein sorting by tyrosine-based signals: Adapting to the Ys and wherefores. Trends Cell Biol. 7, 124-128.

Martinez-Menarguez, J. A., Geuze, H. J., Slot, J. W. \& Klumperman, J . (1999). Vesicular tubular clusters between the ER and Golgi mediate concentration of soluble secretory proteins by exclusion from COPI-coated vesicles. Cell 98, 81-90.

Marzioch, M., Henthorn, D. C., Herrmann, J . M., Wilson, R., Thomas, D. Y., Bergeron, J. J ., Solari, R. C. \& Rowley, A. (1999). Erp1p and Erp2p, partners for Emp24p and Erv25p in a yeast p24 complex. Mol. Biol. Cell 10, 1923-1938. 
Matsuoka, K., Matsumoto, S., Hattori, T., Machida, Y. \& Nakamura, K. (1990). Vacuolar targeting and posttranslational processing of the precursor to the sweet potato tuberous root storage protein in heterologous plant cells. J . Biol. Chem. 265, 19750-19757.

Matsuoka, K., Orci, L., Amherdt, M., Bednarek, S. Y., Hamamoto, S., Schekman, R. \& Yeung, T. (1998). COPII-coated vesicle formation reconstituted with purified coat proteins and chemically defined liposomes. Cell 93, 263-275.

Medford, J . I., Elmer, J . S. \& Klee, H. J . (1991). Molecular cloning and characterization of genes expressed in shoot apical meristems. Plant Cell 3, 359370.

Melançon, P., Glick, B. S., Malhotra, V., Weidman, P. J ., Serafini, T., Gleason, M. L., Orci, L. \& Rothman, J . E. (1987). Involvement of GTPbinding "G" proteins in transport through the Golgi stack. Cell 51, 10531062.

Melnick, J ., Aviel, S. \& Argon, Y. (1992). The endoplasmic reticulum stress protein GRP94, in addition to BiP, associates with unassembled immunoglobulin chains. J . Biol. Chem. 267, 21303-21306.

Meyer, D. I., Krause, E. \& Dobberstein, B. (1982). Secretory protein translocation across membranes-the role of the "docking protein". Nature 297, 647650.

Mollenhauer, H. H. \& Moreé, D. J . (1994). Structure of Golgi apparatus. Protoplasma 180, 14-28.

Movafeghi, A., Happel, N., Pimpl, P., Tai, G. H. \& Robinson, D. G. (1999). Arabidopsis Sec21p and Sec23p homologs. Probable coat proteins of plant COP-coated vesicles. Plant Physiol. 119, 1437-1445.

Munro, S. \& Pelham, H. R. (1986). An Hsp70-like protein in the ER: identity with the $78 \mathrm{kd}$ glucose- regulated protein and immunoglobulin heavy chain binding protein. Cell 46, 291-300.

Munro, S. \& Pelham, H. R. (1987). A C-terminal signal prevents secretion of luminal ER proteins. Cell 48, 899-907.

Nakano, A., Brada, D. \& Schekman, R. (1988). A membrane glycoprotein, Sec12p, is required for transport from the endoplasmic erticulum to the Golgi apparatus in yeast. J . Cell Biol. 107, 851-863. 
Nakano, A., Otsuka, H., Yamagishi, M., Yamamoto, E., Kimura, K., Nishikawa, S. \& Oka, T. (1994). Mutational analysis of the Sar1 protein, a small GTPase which is essential for vesicular transport from the endoplasmic reticulum. J . Biochem. 116, 243-247.

Napier, R. M., Fowke, L. C., Hawes, C., Lewis, M. \& Pelham, H. R. (1992). Immunological evidence that plants use both HDEL and KDEL for targeting proteins to the endoplasmic reticulum. J . Cell Sci. 102, 261-271.

Nauseef, W. M., McCormick, S. J . \& Clark, R. A. (1995). Calreticulin functions as a molecular chaperone in the biosynthesis of myeloperoxidase. J . Biol. Chem. 270, 4741-4747.

Neuhaus, J . M. \& Rogers, J . C. (1998). Sorting of proteins to vacuoles in plant cells. Plant Mol. Biol. 38, 127-144.

Neuhoff, V., Stamm, R. \& Eible, H. (1985). Clear background and highly sensitive protein staining with coomassie blue dyes in polyacrylamid gels: A systematic analysis. Electrophoresis 6, 427-448.

Nilsson, T., J ackson, M. \& Peterson, P. A. (1989). Short cytoplasmic sequences serve as retention signals for transmembrane proteins in the endoplasmic reticulum. Cell 58, 707-718.

Nishikawa, S., Hirata, A. \& Nakano, A. (1994). Inhibition of endoplasmic reticulum (ER)-to-Golgi transport induces relocalization of binding protein (BiP) within the ER to form the BiP bodies. Mol. Biol. Cell 5, 1129-1143.

Orci, L., Glick, B. S. \& Rothman, J . E. (1986). A new type of coated vesicular carrier that appears not to contain clathrin: its possible role in protein transport within the Golgi stack. Cell 46, 171-184.

Orci, L., Malhotra, V., Amherdt, M., Serafini, T. \& Rothman, J. E. (1989). Dissection of a single round of vesicular transport: sequential intermediates for intercisternal movement in the Golgi stack. Cell 56, 357-368.

Orci, L., Tagaya, M., Amherdt, M., Perrelet, A., Donaldson, J. G., Lippincott-Schwartz, J ., Klausner, R. D. \& Rothman, J . E. (1991). Brefeldin A, a drug that blocks secretion, prevents the assembly of non-clathrin-coated buds on Golgi cisternae. Cell 64, 1183-1195.

Orci, L., Palmer, D. J ., Amherdt, M. \& Rothman, J . E. (1993a). Coated vesicle assembly in the Golgi requires only coatomer and ARF proteins from the cytosol. Nature 364, 732-734. 
Orci, L., Palmer, D. J ., Ravazzola, M., Perrelet, A., Amherdt, M. \& Rothman, J . E. (1993b). Budding from Golgi membranes requires the coatomer complex of non-clathrin coat proteins. Nature 362, 648-652.

Orci, L., Stamnes, M., Ravazzola, M., Amherdt, M., Perrelet, A., Sollner, T. H. \& Rothman, J . E. (1997). Bidirectional transport by distinct populations of COPI-coated vesicles. Cell 90, 335-349.

Ostermann, J ., Orci, L., Tani, K., Amherdt, M., Ravazzola, M., Elazar, Z. \& Rothman, J . E. (1993). Stepwise assembly of functionally active transport vesicles. Cell 75, 1015-1025.

Paccaud, J. P., Reith, W., Carpentier, J . L., Ravazzola, M., Amherdt, M., Schekman, R. \& Orci, L. (1996). Cloning and functional characterization of mammalian homologues of the COPII component Sec23. Mol. Biol. Cell 7, 1535-1546.

Page, L.J . \& Robinson, M. S. (1995). Targeting signals and subunit interactions in coated vesicle adaptor complexes. J . Cell Biol. 131, 619-630.

Pagny, S., Cabanes-Macheteau, M., Gillikin, J. W., Leborgne-Castel, N., Lerouge, P., Boston, R. S., Faye, L. \& Gomord, V. (2000). Protein recycling from the Golgi apparatus to the endoplasmic reticulum in plants and its minor contribution to calreticulin retention. Plant Cell 12, 739-755.

Palade, G. (1975). Intracellular aspects of the process of protein synthesis. Science 189, 347-358.

Palevitz, B. A., O'Kane, D. J ., Kobres, R. E. \& Raikhel, N. V. (1981). The vacuole system in stomatal cells of Allium: Vacuole movements and changes in morphology in differentiating cells as revealed by epifluorescence, video and electron microscopy. Protoplasma 109, 23-55.

Palmer, D. J ., Helms, J . B., Beckers, C. J ., Orci, L.\& Rothman, J . E. (1993). Binding of coatomer to Golgi membranes requires ADP-ribosylation factor. J . Biol. Chem. 268, 12083-12089.

Paris, N., Stanley, C. M., J ones, R. L. \& Rogers, J . C. (1996). Plant cells contain two functionally distinct vacuolar compartments. Cell 85, 563-572.

Pearse, B. M. \& Robinson, M. S. (1990). Clathrin, adaptors, and sorting. Annu. Rev. Cell Biol. 6, 151-171.

Pedrazzini, E., Giovinazzo, G., Bielli, A., de Virgilio, M., Frigerio, L., P esca, M., Faoro, F., Bollini, R., Ceriotti, A. \& Vitale, A. (1997). Protein quality control along the route to the plant vacuole. Plant Cell 9, 1869-1880. 
Pelham, H. R. (1988). Evidence that luminal ER proteins are sorted from secreted proteins in a post-ER compartment. EMBO J . 7, 913-918.

Pelham, H. R., Hardwick, K. G. \& Lewis, M. J . (1988). Sorting of soluble ER proteins in yeast. EMBO J . 7, 1757-1762.

Pelham, H. R. (1989). Control of protein exit from the endoplasmic reticulum. Annu. Rev. Cell Biol. 5, 1-23.

Peterson, G. L. (1977). A simplification of the protein assay method of Lowry et al. which is more generally applicable. Anal. Biochem. 83, 346-356.

Peyroche, A., Paris, S. \& J ackson, C. L. (1996). Nucleotide exchange on ARF mediated by yeast Gea1 protein. Nature 384, 479-481.

Peyroche, A., Antonny, B., Robineau, S., Acker, J ., Cherfils, J . \& J ackson, C. L. (1999). Brefeldin A acts to stabilize an abortive ARF-GDP-Sec7 domain protein complex: involvement of specific residues of the Sec7 domain. Mol. Cell 3, 275-285.

Pfanner, N., Orci, L., Glick, B. S., Amherdt, M., Arden, S. R., Malhotra, V. \& Rothman, J. E. (1989). Fatty acyl-coenzyme A is required for budding of transport vesicles from Golgi cisternae. Cell 59, 95-102.

Pfeffer, S. R. \& Rothman, J . E. (1987). Biosynthetic protein transport and sorting by the endoplasmic reticulum and Golgi. Annu. Rev. Biochem. 56, 829852.

Pfeffer, S. R. (1999). Transport-vesicle targeting: tethers before SNAREs. Nat. Cell Biol. 1, 17-22.

Phillipson, B. A., Pimpl, P., Crofts, A. J ., Taylor, J. P., Movafeghi, A., Robinson, D. G. \& Denecke, J . (2001). Secretory bulk flow of soluble proteins is COPII dependent. Plant Cell in press.

Pimpl, P., Movafeghi, A., Coughlan, S., Denecke, J ., Hillmer, S. \& Robinson, D. G. (2000). In situ localization and in vitro induction of plant COPIcoated vesicles. Plant Cell 12, 2219-2236.

Pimpl, P. \& Denecke, J . (2000). ER retention of soluble proteins: retrieval, retention, or both? Plant Cell 12, 1517-1521.

Piper, R. C., Bryant, N. J . \& Stevens, T. H. (1997). The membrane protein alkaline phosphatase is delivered to the vacuole by a route that is distinct from the VPS-dependent pathway. J . Cell Biol. 138, 531-545. 
Pryer, N. K., Salama, N. R., Schekman, R. \& Kaiser, C. A. (1993). Cytosolic Sec13p complex is required for vesicle formation from the endoplasmic reticulum in vitro. J . Cell Biol. 120, 865-875.

Rabouille, C., Hui, N., Hunte, F., Kieckbusch, R., Berger, E. G., Warren, G. \& Nilsson, T. (1995). Mapping the distribution of Golgi enzymes involved in the construction of complex oligosaccharides. J . Cell Sci. 108, 1617-1627.

Rajagopalan, S., Xu, Y. \& Brenner, M. B. (1994). Retention of unassembled components of integral membrane proteins by calnexin. Science 263 , 387390.

Rambourg, A. \& Clermont, Y. (1990). Three-dimensional electron microscopy: structure of the Golgi apparatus. Eur. J . Cell Biol. 51, 189-200.

Regad, F., Bardet, C., Tremousaygue, D., Moisan, A., Lescure, B. \& Axelos, M. (1993). cDNA cloning and expression of an Arabidopsis GTP-binding protein of the ARF family. FEBS Lett. 316, 133-136.

Rexach, M. F . \& Schekman, R. W. (1991). Distinct biochemical requirements for the budding, targeting, and fusion of ER-derived transport vesicles. J . Cell Biol. 114, 219-229.

Rexach, M. F., Latterich, M. \& Schekman, R. W. (1994). Characteristics of endoplasmic reticulum-derived transport vesicles. J . Cell Biol. 126, 11331148 .

Robinson, D. G., Ehlers, U., Herken, R., Herrmann, B. \& Schürmann, F. W. (1985). Präparationstechnik in der Elektronenmikroskopie. Springer Verlag, Berlin, Heidelberg.

Robinson, D. G. (1996). Clathrin-mediated trafficking. Trends Plant Sci. 1, 349355.

Robinson, D. G. \& Hinz, G. (1997). Vacuole biogenesis and protein transport to the plant vacuole: a comparison with the yeast vacuole and the mammalian lysosome. Protoplasma 197, 1-25.

Robinson, D. G., Hinz, G. \& Holstein, S. E. H. (1998). The molecular characterization of transport vesicles. Plant Mol. Biol. 38, 49-76.

Robinson, D. G. \& Hinz, G. (1999). Golgi-mediated Transport of Seed Storage Proteins. Seed Sci. Res. 9, 267-283.

Rogers, J . (1985). Two barley $\alpha$-amylase gene families are regulated differently in barley aleurone cells. J . Biol. Chem. 260, 3731-3738. 
Rose, J. K. \& Doms, R. W. (1988). Regulation of protein export from the endoplasmic reticulum. Annu. Rev. Cell Biol. 4, 257-288.

Rothman, J . E . \& Orci, L. (1992). Molecular dissection of the secretory pathway. Nature 355, 409-415.

Rothman, J. E. (1994). Mechanisms of intracellular protein transport. Nature 372, 55-63.

Rothman, J . E. \& Wieland, F. T. (1996). Protein sorting by transport vesicles. Science 272, 227-234.

Saalbach, G., J ung, R., Kunze, G., Saalbach, I., Adler, K. \& Muntz, K. (1991). Different legumin protein domains act as vacuolar targeting signals. Plant Cell 3, 695-708.

Saito, Y., Kimura, K., Oka, T. \& Nakano, A. (1998). Activities of mutant Sar1 proteins in guanine nucleotide binding, GTP hydrolysis, and cell-free transport from the endoplasmic reticulum to the Golgi apparatus. J Biochem. $124,816-823$.

Salama, N. R., Yeung, T. \& Schekman, R. W. (1993). The Sec13p complex and reconstitution of vesicle budding from the ER with purified cytosolic proteins. EMBO J . 12, 4073-4082.

Salama, N. R., Chuang, J . S. \& Schekman, R. W. (1997). Sec31 encodes an essential component of the COPII coat required for transport vesicle budding from the endoplasmic reticulum. Mol. Biol. Cell. 8, 205-217.

Salinovich, O. \& Montelaro, R. C. (1986). Reversible staining and peptide mapping of proteins transferred to nitrocellulose after separation by sodium dodecylsulfate-polyacrylamide gel electrophoresis. Anal. Biochem. 156, 341347.

Sanderfoot, A. A. \& Raikhel, N. V. (1999). The specificity of vesicle trafficking: coat proteins and SNAREs. Plant Cell 11, 629-642.

Sandholzer, U., von Figura, K. \& Pohlmann, R. (2000). Function and properties of chimeric MPR 46-MPR 300 mannose 6-phosphate receptors. J. Biol. Chem. 275, 14132-14138.

Sanger, F., Nicklen, S. \& Coulsen, A. R. (1977). DNA sequencing with chaintermination inhibitors. Proc. Natl. Acad. Sci. USA 74, 5463-5467.

Saraste, J . \& Kuismanen, E. (1984). Pre- and post-Golgi vacuoles operate in the transport of Semliki Forest virus membrane glycoproteins to the cell surface. Cell 38, 535-549. 
Satiat-J eunemaitre, B., Cole, L., Bourett, T., Howard, R. \& Hawes, C. (1996). Brefeldin A effects in plant and fungal cells: something new about vesicle trafficking? J . Microscopy 181, 162-177.

Schekman, R. \& Orci, L. (1996). Coat proteins and vesicle budding. Science 271, 1526-1533.

Schröder, S. \& Ungewickell, E. (1991). Subunit interaction and function of clathrin-coated vesicle adaptors from the Golgi and the plasma membrane. J . Biol. Chem. 266, 7910-7918.

Schwaiger, H., Hasilik, A., von Figura, K., Wiemken, A. \& Tanner, W. (1982). Carbohydrate-free carboxypeptidase $\mathrm{Y}$ is transferred into the lysosome- like yeast vacuole. Biochem. Biophys. Res. Commun. 104, 950-956.

Schweizer, A., Fransen, J . A., Matter, K., Kreis, T. E., Ginsel, L. \& Hauri, H. $P$. (1990). Identification of an intermediate compartment involved in protein transport from endoplasmic reticulum to Golgi apparatus. Eur. J . Cell Biol. 53, 185-196.

Schweizer, A., Matter, K., Ketcham, C. M. \& Hauri, H. P. (1991). The isolated ER-Golgi intermediate compartment exhibits properties that are different from ER and cis-Golgi. J . Cell Biol. 113, 45-54.

Semenza, J . C., Hardwick, K. G., Dean, N. \& Pelham, H. R. (1990). ERD2, a yeast gene required for the receptor-mediated retrieval of luminal ER proteins from the secretory pathway. Cell 61, 1349-1357.

Serafini, T., Orci, L., Amherdt, M., Brunner, M., Kahn, R. A. \& Rothman, J . E. (1991). ADP-ribosylation factor is a subunit of the coat of Golgi-derived COP- coated vesicles: a novel role for a GTP-binding protein. Cell 67, 239253.

Shelness, G. S. \& Blobel, G. (1990). Two subunits of the canine signal peptidase complex are homologous to yeast SEC11 protein. J . Biol. Chem. 265, 95129519.

Shin, J ., Dunbrack, R. L., J r., Lee, S. \& Strominger, J . L. (1991). Signals for retention of transmembrane proteins in the endoplasmic reticulum studied with CD4 truncation mutants. Proc. Natl. Acad. Sci. USA 88, 1918-1922.

Silberstein, S. \& Gilmore, R. (1996). Biochemistry, molecular biology, and genetics of the oligosaccharyltransferase. FASEB J . 10, 849-858.

Sitia, R. \& Meldolesi, J . (1992). Endoplasmic reticulum: a dynamic patchwork of specialized subregions. Mol. Biol. Cell 3, 1067-1072. 
Sogaard, M., Tani, K., Ye, R. R., Geromanos, S., Tempst, P., Kirchhausen, T., Rothman, J . E. \& Sollner, T. (1994). A rab protein is required for the assembly of SNARE complexes in the docking of transport vesicles. Cell 78, 937-948.

Sohn, K., Orci, L., Ravazzola, M., Amherdt, M., Bremser, M., Lottspeich, F., Fiedler, K., Helms, J . B. \& Wieland, F. T. (1996). A major transmembrane protein of Golgi-derived COPI-coated vesicles involved in coatomer binding. J . Cell Biol. 135, 1239-1248.

Söllner, T., Whiteheart, S. W., Brunner, M., Erdjument-Bromage, H., Geromanos, S., Tempst, P . \& Rothman, J . E . (1993). SNAP receptors implicated in vesicle targeting and fusion. Nature 362, 318-324.

Sousa, M. \& Parodi, A. J . (1995). The molecular basis for the recognition of misfolded glycoproteins by the UDP-Glc:glycoprotein glucosyltransferase. EMBO J . 14, 4196-4203.

Sousa, M. C., Ferrero-Garcia, M. A. \& Parodi, A. J . (1992). Recognition of the oligosaccharide and protein moieties of glycoproteins by the UDPGlc:glycoprotein glucosyltransferase. Biochemistry 31, 97-105.

Spang, A., Matsuoka, K., Hamamoto, S., Schekman, R. \& Orci, L. (1998). Coatomer, Arf1p, and nucleotide are required to bud coat protein complex Icoated vesicles from large synthetic liposomes. Proc. Natl. Acad. Sci. USA 95, 11199-11204.

Spang, A. \& Schekman, R. (1998). Reconstitution of Retrograde Transport from the Golgi to the ER In Vitro. J . Cell Biol. 143, 589-599.

Spiess, M. (1995). Heads or tails - what determines the orientation of proteins in the membrane. FEBS Lett. 369, 76-79.

Springer, S., Chen, E., Duden, R., Marzioch, M., Rowley, A., Hamamoto, S., Merchant, S. \& Schekman, R. (2000). The p24 proteins are not essential for vesicular transport in Saccharomyces cerevisiae. Proc. Natl. Acad. Sci. USA 97, 4034-4039.

Staehelin, L. A. \& Moore, I. (1995). The Plant Golgi Apparatus: Structure, Functional Organization, and Trafficking Mechanisms. Annu. Rev. Plant Physiol. Plant Mol. Biol. 46, 261-288.

Staehelin, L. A. (1997). The plant ER: a dynamic organelle composed of a large number of discrete functional domains. Plant J . 11, 1151-1165. 
Sticher, L., Hinz, U., Meyer, A. D. \& Meins, F. J . (1992). Intracellular transport and processing of a tobacco vacuolar $\beta-1,3$-glucanase. Planta 188, 559565.

Sturm, A., J ohnson, K. D., Szumilo, T., Elbein, A. D. \& Chrispeels, M. J . (1987). Subcellular localization of glycosidases and glycosyltransferases involved in the processing of N-linked oligosaccharides. Plant Physiol . 85, 741745 .

Swanson, S. J ., Bethke, P. C. \& J ones, R. L. (1998). Barley aleurone cells contain two types of vacuoles. Characterization Of lytic organelles by use of fluorescent probes. Plant Cell 10, 685-698.

Takeuchi, M., Ueda, T., Sato, K., Abe, H., Nagata, T. \& Nakano, A. (2000). A dominant negative mutant of Sar1 GTPase inhibits protein transport from the endoplasmic reticulum to the Golgi apparatus in tobacco and Arabidopsis cultured cells. Plant J . 23, 517-525.

Tang, B. L., Wong, S. H., Qi, X. L., Low, S. H. \& Hong, W. (1993). Molecular cloning, characterization, subcellular localization and dynamics of $\mathrm{p} 23$, the mammalian KDEL receptor. J . Cell Biol. 120, 325-328.

Tanigawa, G., Orci, L., Amherdt, M., Ravazzola, M., Helms, J . \& Rothman, J. (1993). Hydrolysis of bound GTP by ARF protein triggers uncoating of Golgi- derived COP-coated vesicles. J . Cell Biol. 123, 1365-1371.

Tartakoff, A. M. (1986). Temperature and energy dependence of secretory protein transport in the exocrine pancreas. EMBO J . 5, 1477-1482.

Tatu, U. \& Helenius, A. (1997). Interactions between newly synthesized glycoproteins, calnexin and a network of resident chaperones in the endoplasmic reticulum. J . Cell Biol. 136, 555-565.

Teasdale, R. D. \& J ackson, M. R. (1996). Signal-mediated sorting of membrane proteins between the endoplasmic reticulum and the golgi apparatus. Annu. Rev. Cell Develop. Biol. 12, 27-54.

Torii, S., Banno, T., Watanabe, T., Ikehara, Y., Murakami, K. \& Nakayama, K. (1995). Cytotoxicity of brefeldin A correlates with its inhibitory effect on membrane binding of COP coat proteins. J . Biol. Chem. 270, 11574-11580.

Towbin, H., Staehelin, T.\& Gordon, J . (1979). Electrophoretic transfer of proteins from polyacrylamide gels to nitrocellulose sheets: procedure and some applications. Proc. Natl. Acad. Sci. USA 76, 4350-4354.

Townsley, F. M., Frigerio, G. \& Pelham, H. R. (1994). Retrieval of HDEL proteins is required for growth of yeast cells. J . Cell Biol. 127, 21-28. 
Trombetta, S. E . \& Parodi, A. J . (1992). Purification to apparent homogeneity and partial characterization of rat liver UDP-glucose:glycoprotein glucosyltransferase. J . Biol. Chem. 267, 9236-9240.

Ungewickell, E. \& Branton, D. (1981). Assembly units of clathrin coats. Nature 289, 420-422.

Ungewickell, E., Ungewickell, H., Holstein, S. E., Lindner, R., Prasad, K., Barouch, W., Martin, B., Greene, L. E. \& Eisenberg, E. (1995). Role of auxilin in uncoating clathrin-coated vesicles. Nature 378, 632-635.

Valls, L. A., Winther, J . R. \& Stevens, T. H. (1990). Yeast carboxypeptidase Y vacuolar targeting signal is defined by four propeptide amino acids. J . Cell Biol. 111, 361-368.

Varki, A. (1998). Factors controlling the glycosylation potential of the Golgi apparatus. Trends Cell Biol. 8, 34-40.

Vassilakos, A., Cohen-Doyle, M. F., Peterson, P. A., J ackson, M. R. \& Williams, D. B. (1996). The molecular chaperone calnexin facilitates folding and assembly of class I histocompatibility molecules. EMBO J . 15, 14951506.

Vida, T. A., Huyer, G. \& Emr, S. D. (1993). Yeast vacuolar proenzymes are sorted in the late Golgi complex and transported to the vacuole via a prevacuolar endosome-like compartment. J . Cell Biol. 121, 1245-1256.

Vierling, E. (1991). The Roles Of Heat Shock Proteins In Plants. Annu. Rev. Plant Physiol. Plant Mol. Biol. 42, 579-620.

Vitale, A. \& Denecke, J . (1999). The endoplasmic reticulum-gateway of the secretory pathway. Plant Cell 11, 615-628.

Vitale, A. \& Raikhel, N. V. (1999). What do proteins need to reach different vacuoles? Trends Plant Sci. 4, 149-155.

Voelker, T. A., Herman, E. M. \& Chrispeels, M. J . (1989). In vitro mutated phytohemagglutinin genes expressed in tobacco seeds: role of glycans in protein targeting and stability. Plant Cell 1, 95-104.

von Heijne, G. (1988). Transcending the impenetrable: how proteins come to terms with membranes. Biochim. Biophys. Acta 947, 307-333.

Walter, P. \& Blobel, G. (1981). Translocation of proteins across the endoplasmic reticulum. II. Signal recognition protein (SRP) mediates the selective binding to microsomal membranes of in-vitro-assembled polysomes synthesizing secretory protein. J . Cell Biol. 91, 551-556. 
Wandelt, C. I., Khan, M. R., Craig, S., Schroeder, H. E., Spencer, D. \& Higgins, T.J . (1992). Vicilin with carboxy-terminal KDEL is retained in the endoplasmic reticulum and accumulates to high levels in the leaves of transgenic plants. Plant J . 2, 181-192.

Wang, C. C. \& Tsou, C. L. (1993). Protein disulfide isomerase is both an enzyme and a chaperone. FASEB J . 7, 1515-1517.

Wanker, E. E., Sun, Y., Savitz, A. J . \& Meyer, D. I. (1995). Functional characterization of the 180-kD ribosome receptor in vivo. J . Cell Biol. 130, 29-39.

Waters, M. G., Serafini, T. \& Rothman, J . E . (1991). 'Coatomer': a cytosolic protein complex containing subunits of non- clathrin-coated Golgi transport vesicles. Nature 349, 248-251.

Weber, T., Zemelman, B. V., McNew, J . A., Westermann, B., Gmachl, M., Parlati, F., Sollner, T. H. \& Rothman, J . E . (1998). SNAREpins: minimal machinery for membrane fusion. Cell 92, 759-772.

Wessel, D. \& Flugge, U. I. (1984). A method for the quantitative recovery of protein in dilute solution in the presence of detergents and lipids. Anal. Biochem. 138, 141-143.

Wieland, F. T., Gleason, M. L., Serafini, T. A. \& Rothman, J . E. (1987). The rate of bulk flow from the endoplasmic reticulum to the cell surface. Cell 50, 289-300.

Wilson, D. W., Lewis, M. J . \& Pelham, H. R. (1993). pH-dependent binding of KDEL to its receptor in vitro. J . Biol. Chem. 268, 7465-7468.

Wink, M. (1993). The plant vacuole: A multifunctional compartment. J . Exp. Botany $44,231-246$.

Yoshihisa, T., Barlowe, C. \& Schekman, R. (1993). Requirement for a GTPaseactivating protein in vesicle budding from the endoplasmic reticulum. Science 259, 1466-1468.

Zhao, L., Helms, J. B., Brugger, B., Harter, C., Martoglio, B., Graf, R., Brunner, J . \& Wieland, F. T. (1997). Direct and GTP-dependent interaction of ADP ribosylation factor 1 with coatomer subunit beta. Proc. Natl. Acad. Sci. USA 94, 4418-4423. 


\section{Danksagung}

Ich möchte mich bei Herrn Prof. Dr. D. G. Robinson für die Überlassung des interessanten Themas sowie für die fortwährende Unterstützung und Diskussionsbereitschaft in allen Phasen der Arbeit bedanken.

Herrn Prof. Dr. H. W. Heldt danke ich für die Übernahme des Korreferats.

Bei Dr. S. Hillmer und Dr. G. Hinz möchte ich mich für die vielen anregenden Diskussionen, konstruktive Kritik und für zahlreiche Ratschläge zur Durchführung der experimentellen Arbeiten bedanken.

Ich danke Herrn Dr. J. Denecke nicht nur für die Überlassung der transgenen Pflanzen und der im Rahmen der experimentellen Arbeiten eingesetzten Plasmide, sondern auch für die Vermittlung vieler molekularbiologischer Arbeitsmethoden während meiner Arbeitsaufenthalte in seinem Labor. Weiterhin danke ich ihm auch für die Unterstützung bei der Zusammenarbeit mit Jan Leffe. Ebenfalls danke ich Jane Hadlington, Andy Crofts und Chris Snowden für die freundliche Unterstützung und die hilfreiche Zusammenarbeit während dieser Zeit.

Bei allen Mitarbeitern der Abteilung „Strukturelle Zellphysiologie“ des Albrecht von Haller Instituts für Pflanzenwissenschaften möchte ich mich für die freundschaftliche Zusammenarbeit und Hilfsbereitschaft während der experimentellen Arbeiten bedanken.

Bei der Abteilung „Allgemeine und Entwicklungsphysiologie der Pflanze“ des Albrecht von Haller Instituts für Pflanzenwissenschaften unter der Leitung von Frau Prof. Dr. C. Gatz möchte ich mich dafür bedanken, daß ich viele technische Geräte benutzen durfte. Weiterhin danke ich Wolfram Brenner und allen anderen Mitgliedern dieser Arbeitsgruppe für ihre freundliche Unterstützung und Hilfsbereitschaft.

Ich danke auch Herrn Wedemeyer für die sorgsame und mühevolle Anzucht der vielen Tabak- und Blumenkohlpflanzen, ohne die diese Arbeit nicht möglich gewesen wäre.

Weiterhin möchte ich mich auch bei Herrn Kramer, Herrn Unger und Herrn Sader für die schnelle Anfertigung der Elektrophoresekammern und einer Vielzahl weiterer Spezialanfertigungen und Reparaturen bedanken.

Nicht zuletzt möchte ich mich bei meinen Eltern, bei meiner Verlobten Claudia Schnick und bei meiner Schwester Stephanie für die Unterstützung und Aufmunterung in allen Phasen der Arbeit bedanken. 


\section{Lebenslauf}

Persönliche Daten: Peter Pimpl

02.05.1970 geboren in Helmarshausen

Staatsangehörigkeit: deutsch

1976-1980 Grundschule Oberweser

1980-1986 Integrierte Gesamtschule Bad Karlshafen

1986-1989 Gymnasiale Oberstufenschule:

Albert-Schweitzer-Schule Hofgeismar

18.05.1989 Erwerb der Allgemeinen Hochschulreife

1989-1990 Ableistung des Grundwehrdienstes

1991 Beginn des Studiums der Biologie an der

Georg-August-Universität zu Göttingen

22.10.1993 Diplomvorprüfung in den Fächern

Botanik, Mikrobiologie, Chemie und Physikalische Chemie

03.11.1995 Diplomprüfung in den Fächern

Botanik, Mikrobiologie und Chemie

Nov. 1995-Jun.1997 Diplomarbeit am Albrecht-von-Haller Institut für Pflanzenwissenschaften der Universität Göttingen mit dem Thema: Untersuchungen zur in vitro Induktion von COP Vesikeln in transgenem Tabak

Seit Jun. 1997 Experimentelle Arbeiten zur Promotion im

Albrecht-von-Haller Institut für Pflanzenwissenschaften der Universität Göttingen

Jun. 1997-Mai 1998 Befristete Tätigkeit als wissenschaftlicher Mitarbeiter am Albrecht-von-Haller Institut

Mai 1998-Juli 1999 Stipendiat des Graduiertenkollegs „Signalvermittelter Transport von Proteinen und Vesikeln“

Juni-Juli 1999 Forschungsaufenthalt im Labor von Dr. J. Denecke und (Leeds Institute for Plant Biotechnology and Agriculture, März-Juni $2000 \quad$ University of Leeds, UK)

Juli 1999-Dez.2000 Förderung durch den Sonderforschungsbereich SFB523 der Deutschen Forschungsgemeinschaft 